\title{
Pregnancy-related urinary incontinence, does it bother?
}

Citation for published version (APA):

Moossdorff - Steinhauser, H. (2021). Pregnancy-related urinary incontinence, does it bother? [Doctoral Thesis, Maastricht University]. Ridderprint. https://doi.org/10.26481/dis.20211105hm

Document status and date:

Published: 01/01/2021

DOI:

10.26481/dis.20211105hm

Document Version:

Publisher's PDF, also known as Version of record

\section{Please check the document version of this publication:}

- A submitted manuscript is the version of the article upon submission and before peer-review. There can be important differences between the submitted version and the official published version of record.

People interested in the research are advised to contact the author for the final version of the publication, or visit the DOI to the publisher's website.

- The final author version and the galley proof are versions of the publication after peer review.

- The final published version features the final layout of the paper including the volume, issue and page numbers.

Link to publication

\footnotetext{
General rights rights.

- You may freely distribute the URL identifying the publication in the public portal. please follow below link for the End User Agreement:

www.umlib.nl/taverne-license

Take down policy

If you believe that this document breaches copyright please contact us at:

repository@maastrichtuniversity.nl

providing details and we will investigate your claim.
}

Copyright and moral rights for the publications made accessible in the public portal are retained by the authors and/or other copyright owners and it is a condition of accessing publications that users recognise and abide by the legal requirements associated with these

- Users may download and print one copy of any publication from the public portal for the purpose of private study or research.

- You may not further distribute the material or use it for any profit-making activity or commercial gain

If the publication is distributed under the terms of Article $25 \mathrm{fa}$ of the Dutch Copyright Act, indicated by the "Taverne" license above, 


\section{PREGNANCY-RELATED URINARY INCONTINENCE, DOES IT BOTHER?}

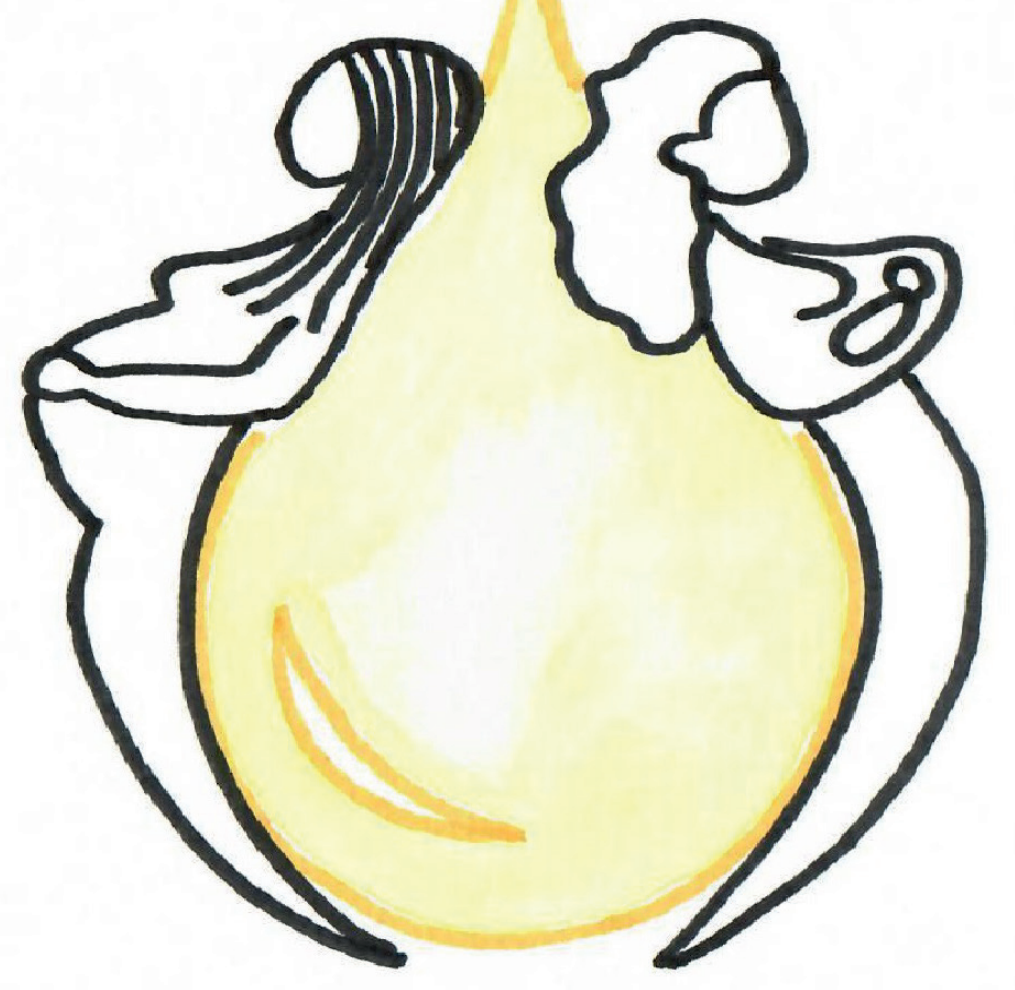

Heidi Moossdorff-Steinhauser 



\section{Pregnancy-related urinary incontinence, does it bother?}

Heidi Moossdorff-Steinhauser 
Pregnancy-related urinary incontinence, does it bother?

Heidi F.A. Moossdorff-Steinhauser

ISBN: 978-94-6416-706-1

Cover design: Inge van Engelenburg

Lay-out: $\quad$ Publiss | www.publiss.nl

Printed by: $\quad$ Ridderprint | www.ridderprint.nl

(c) Copyright Heidi F.A. Moossdorff-Steinhauser, Maastricht 2021

All rights reserved. No part of this thesis may be reproduced or transmitted in any form or by any means, electronic or mechanical, including photocopying, recording or any information storage or retrieval system, without permission in writing from the author, or, when appropriate, from the publishers of the publications. 


\title{
Pregnancy-related urinary incontinence, does it bother?
}

\author{
PROEFSCHRIFT
}

Ter verkrijging van de graad van doctor

aan de Universiteit Maastricht,

op gezag van de Rector Magnificus,

Prof.dr. Rianne M. Letschert

volgens het besluit van het College van Decanen,

in het openbaar te verdedigen

op vrijdag 5 november 2021 om 14.00

door

Heidi Franziska Angelina Moossdorff-Steinhauser 


\section{Promotores}

Prof. dr. M.E.A. Spaanderman

Dr. L.C.M. Berghmans

\section{Copromotor}

Dr. E.M.J. Bols

\section{Beoordelingscommissie}

Prof. dr. G.A. van Koeveringe (voorzitter)

Prof. dr. M.Y. Bongers

Prof. dr. R.F.P.M. Kruitwagen

Prof. dr. S. Mørkved (Norwegian University of Science and Technology, Trondheim, Norway)

Prof. dr. J.P.W.R. Roovers (AMC-UVA)

The research presented in this thesis was conducted at CAPHRI Care and Public Health Research Institute, Department of epidemiology, of Maastricht University. CAPHRI participates in the Netherlands School of Public Health and Care Research CaRe. The studies presented in this thesis were conducted with financial support from ZonMw.

The printing of this thesis was financially supported by Maastricht University, the Scientific College Physical Therapy (WCF) of the Royal Dutch Society for Physical Therapy (KNGF), the Dutch association for Pelvic Physical Therapy (NVFB); Avans+, Sylo-pen, and Pelvitec B.V. 


\section{Contents}

Chapter 1 General introduction and outline of the thesis 7

Chapter 2 Prevalence, incidence and bothersomeness of urinary incontinence in pregnancy: a systematic review and metaanalysis

Chapter 3 Prevalence, incidence and bothersomeness of urinary incontinence between 6 weeks and 1 year post-partum: a systematic review and meta-analysis

Chapter 4 Long-term effects of motherfit group therapy in pre(motherfit1) and post-partum women (motherfit2) with stress urinary incontinence compared to care-as-usual; study protocol of two multi-centred randomised controlled trials

Chapter 5 Pelvic floor muscle group therapy for the treatment of urinary incontinence during pregnancy and post-partum: a randomized controlled trial

Chapter 6 Urinary incontinence during pregnancy: prevalence, experience of bother, beliefs, and help-seeking behavior

Chapter 7 Urinary incontinence 6 weeks to 1 year post-partum: prevalence, experience of bother, beliefs, and help-seeking behavior

Chapter 8 Experiences of peri-partum urinary incontinence from a women's and health care perspective: a qualitative study

Chapter 9 General discussion

Chapter 10 Scientific and societal impact

Summary

Samenvatting

Dankwoord 


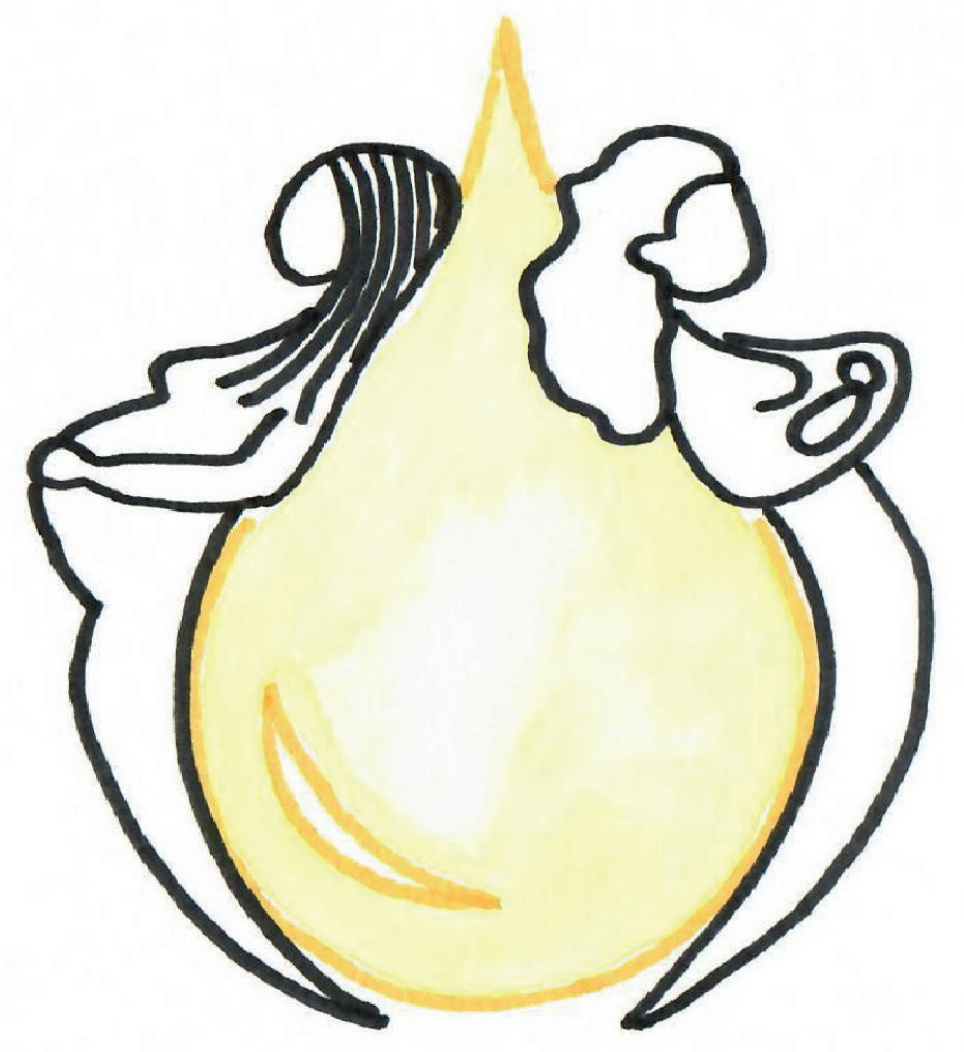


CHAPTER 1

\section{GENERAL INTRODUCTION AND OUTLINE OF THE THESIS}




\section{GENERAL INTRODUCTION}

'Every woman should be able to skip the first and start with the second pregnancy and delivery'.

Pregnancy and delivery are well known risk factors for developing urinary incontinence (UI). ${ }^{1}$ The first delivery has the largest effect with an additional increase in risk every subsequent delivery. ${ }^{1}$ Stress (S) and mixed (M)UI are the most common types of UI associated with pregnancy and delivery. ${ }^{1} \mathrm{SUI}$ is defined as any involuntary leakage of urine on effort or exertion, or on sneezing or coughing. ${ }^{2} \mathrm{MUI}$ has both a stress and urgency component. ${ }^{2}$ SUI may be due to the following causes: 1) a reduced urethral closure function; 2) damage to the urethrovaginal support system; and 3) high abdominal pressure compared to the ability of the support system. ${ }^{3}$ During a rise in abdominal pressure the urethral closure pressure is maintained by both the intrinsic urethral sphincter mechanism and the urethral support mechanism. ${ }^{4}$ The intrinsic urethral sphincter consists of the submucosa with the submucosal vascularization, the urethral smooth muscles, and the striated external urethral sphincter., 5 The urethral support system consists of the anterior vaginal wall, the levator ani muscle (LAM), the arcus tendineus fasciae pelvis, the endopelvic fascia, and the internal obturator muscle. ${ }^{7,8}$ The LAM is attached to the arcus tendineus fascia pelvis on both sides and provides a hammock under the urethra and bladder neck.

During a rise in intra-abdominal pressure, by for instance coughing, jumping or laughing, the urethra is compressed against the hammock, which prevents a downward movement. ${ }^{9}$ At the same time, the urethral sphincter closing mechanism is active as it moves the urethra in- and upward towards the pubic bone, with concurrent contraction of the compressor urethra (part of the external urethral sphincter), clamping the upward moving urethra, resulting in increase of the intra-urethral pressure. ${ }^{9}$ If the function of the LAM is compromised in any way, and/or the intrinsic sphincter urethra is damaged, the total closing mechanism may be malfunctioning and involuntary loss of urine can occur. ${ }^{6}$

The exact aetiology of $\mathrm{UI}$ in pregnancy is uncertain, but anatomical and hormonal changes are considered to contribute to UI. ${ }^{10}$ The growing foetus (and weight gain of the mother $)^{11}$ will increase the pressure on the bladder and hormonal changes will result in remodelling of fibres of all tissues to increase the visco-elasticity. As a 
result of the increased visco-elasticity, connective tissue is weaker, the resting tone of the LAM is reduced, and there is less strength in the endopelvic fascia and arcus tendineus fasciae pelvis, with the ultimate aim to prepare for delivery. ${ }^{6}$ During vaginal delivery the LAM stretches up to 3.3 times (pubococcygeal muscle) it's natural length ${ }^{12}$, which can damage the LAM and the nerves. ${ }^{13}$ Magnetic resonance imaging of the LAM at 9 to 12 months post-partum revealed that approximately $20 \%$ of all primiparous women have a defect in the LAM. Furthermore, postpartum women with SUI are twice as likely to have a defect in the LAM compared to continent primiparas. ${ }^{14}$

Pelvic floor muscle training (PFMT) is an accepted and effective treatment option for women with SUI. ${ }^{15-17}$ PFMT aims to improve the supportive system of the pelvic floor muscle (especially the LAM) in order to act with an appropriate precontraction in case of expected leakage, both with voluntary (the Knack manoeuvre) and involuntary contractions. ${ }^{18,19}$ PFMT may be provided individually or in a group. During group therapy, women can encourage each other to do their exercises and discuss experiences and coping strategies on how to implement PFMT in daily life. Recently, a meta-analysis on the effects of individual versus pelvic floor muscle group training (PFMGT) for women with UI, both provided by a specialized physical therapist, showed no significant difference in results between groups. ${ }^{20}$ The latter is of particular interest as group therapy is less expensive when compared to individual therapy, and might therefore be a cost-effective strategy. A Cochrane review reported that the effect of PFMT for the treatment of UI in the peri-partum period is uncertain; however the reported results are based on small studies with very low to low quality evidence. ${ }^{21-23}$

The reported mean prevalence of $\mathrm{UI}$ in pregnancy and between 6 weeks and 1 year post-partum varies greatly, between 9 to $63 \%{ }^{24,25}$ and 11 to $63 \%{ }^{26,27}$, respectively. In The Netherlands in 2018, 168.500 babies were born and 75.500 women had their first delivery. ${ }^{28}$ These numbers, although not stratified by delivery type, show the enormous number of potentially affected women with SUI or MUI. It is known that when SUI presents during pregnancy, the risk of having SUI 12 years after delivery is still significant ${ }^{29}$ and that $75 \%$ to $92 \%$ of women with SUI at 3 months post-partum, still have UI even after 12 years. ${ }^{30}$ Despite these high prevalence numbers, current Dutch guidelines for $1^{\text {st }}, 2^{\text {nd }}$ and $3^{\text {rd }}$ line care of pregnant and post-partum women hardly pay attention to UI. ${ }^{17,31}$ 
At present the societal and health care costs for pregnant and post-partum women with UI are unknown. However, it is known that the lifetime risk of surgery for SUI is $14 \%$ by the age of $80 .{ }^{32}$ The prevalence of SUI rises with age. ${ }^{33}$ This fact, together with the ageing population ${ }^{34}$ will result in increasing health care costs for SUI. ${ }^{35}$ The Dutch Ministry of Health, Welfare and Sports state that "it will be a challenge to provide good, accessible and affordable care for everyone in the future". ${ }^{36}$ Therefore, it is important to consider cost-effective strategies.

UI reduces physical quality of life and can be a barrier for exercise. ${ }^{37} \mathrm{UI}$ also has a negative impact on mental and social quality of life and reduces participation in work, sports and daily activities. ${ }^{38-40}$ Women change or adapt their activities to avoid $\mathrm{UI}$ and subsequent embarrassment. ${ }^{41}$ In the general population, an association exists between bothersome UI and help-seeking behavior. ${ }^{42,43}$ However, it is unclear which factors contribute to help-seeking behavior in pregnancy and the first year post-partum. Therefore, we aimed to investigate a wide range of factors regarding pregnancy-related UI.. The reported studies contribute to the body of knowledge of health care professionals concerning the beliefs of peripartum women regarding UI. This may support the development and divulgation of adequate information (strategies). Moreover, accurate prevalence numbers, knowledge about experienced bother in relation to peri-partum UI and helpseeking behavior, provides relevant information on the extent and impact of UI in this population, on which researchers and policy makers can base their future plans

\section{AIM AND OUTLINE OF THE THESIS}

The main objective of this thesis is to gain more knowledge on pregnancy related UI including prevalence, experienced bother, anticipated course, therapeutic effect of physical therapy and help-seeking behavior.

This thesis starts with the results of two systematic reviews and meta-analyses on the prevalence, incidence and bothersomeness of UI. Chapter $\mathbf{2}$ presents the results regarding pregnant women and in Chapter 3 the results for women between 6 weeks and 1 year post-partum are presented. Chapter $\mathbf{4}$ describes the design of two randomized controlled trials (RCTs), which aim to evaluate the long term effect of PFMGT compared to care-as-usual in pregnant and post-partum women. The 
protocols provide detailed information on the training protocol and assessment methods. Chapter 5 presents the results of the two RCTs, as presented in chapter 4. In addition, to gain more knowledge on bother in relation to $\mathrm{UI}$ and help-seeking behavior of both pregnant, and women between 6 weeks and 1 year post-partum, two surveys on self-reported UI, level of experienced bother and beliefs were conducted. Chapter 6 reveals the results of the survey among pregnant women. Chapter 7 shows the results of the survey among women between 6 weeks and 1 year post-partum. Chapter 8 reveals the results of a qualitative study. The objective was to gain more in depth knowledge regarding pregnant and up to 1 year postpartum women's beliefs, experiences and subsequent healthcare management as well as the views of health care professionals (HCPs). In Chapter 9 the main findings and conclusions are discussed, and, finally, Chapter 10 describes the scientific and societal impact of this thesis. 


\section{REFERENCES:}

1. Rortveit G, Hannestad YS, Daltveit AK, Hunskaar S. Age- and type-dependent effects of parity on urinary incontinence: the Norwegian EPINCONT study. Obstet Gynecol. 2001;98(6):1004-1010.

2. Haylen BT, de Ridder D, Freeman RM, et al. An International Urogynecological Association (IUGA)/International Continence Society (ICS) joint report on the terminology for female pelvic floor dysfunction. Int Urogynecol J. 2010;21(1):5-26.

3. Swenson CW, Kolenic GE, Trowbridge ER, et al. Obesity and stress urinary incontinence in women: compromised continence mechanism or excess bladder pressure during cough? Int Urogynecol J. 2017;28(9):1377-1385.

4. Delancey JO, Ashton-Miller JA. Pathophysiology of adult urinary incontinence. Gastroenterol. 2004;126(1 Suppl 1):S23-32.

5. Mistry MA, Klarskov N, DeLancey JO, Lose G. A structured review on the female urethral anatomy and innervation with an emphasis on the role of the urethral longitudinal smooth muscle. Int Urogynecol J. 2020;31(1):63-71.

6. Ashton-Miller JA, DeLancey JO. Functional anatomy of the female pelvic floor. Ann $N$ Y Acad Sci. 2007;1101:266-296.

7. Herschorn S. Female pelvic floor anatomy: the pelvic floor, supporting structures, and pelvic organs. Revi Urol. 2004;6 Suppl 5(Suppl 5):S2-s10.

8. Baba T, Homma Y, Takazawa N, et al. Is urinary incontinence the hidden secret complications after total hip arthroplasty? Eur J Orthop Surg Traumatol. 2014;24(8):1455-1460.

9. DeLancey JO. Structural support of the urethra as it relates to stress urinary incontinence: the hammock hypothesis. Am J Obstet Gynecol. 1994;170(6):1713-1720; discussion 1720-1713.

10. Hvidman L, Hvidman L, Foldspang A, Mommsen S, Bugge Nielsen J. Correlates of urinary incontinence in pregnancy. Int Urogynecol J Pelvic Floor Dysfunct. 2002;13(5):278-283.

11. Wesnes SL, Hunskaar S, Bo K, Rortveit G. Urinary incontinence and weight change during pregnancy and postpartum: A cohort study. Am J Epidemiol. 2010;172(9):1034-1044.

12. Lien KC, Mooney B, DeLancey JO, Ashton-Miller JA. Levator ani muscle stretch induced by simulated vaginal birth. Obstet Gynecol. 2004;103(1):31-40.

13. Dietz HP, Simpson JM. Does delayed child-bearing increase the risk of levator injury in labour? Aus N ZJ Obstet Gynaecol. 2007;47(6):491-495.

14. DeLancey JO, Kearney R, Chou Q, Speights S, Binno S. The appearance of levator ani muscle abnormalities in magnetic resonance images after vaginal delivery. Obstet Gynecol. 2003;101(1):46-53.

15. National Institute for Health and Care Excellence (NICE). Urinary incontinence and pelvic organ prolapse in women: management (NG123). 2019; https://www.nice.org.uk/guidance/ ng123/chapter/Recommendations\#physical-therapies. Accessed 8 February, 2021.

16. Kobashi. K, Albo. M, Dmochowski. R, Ginsberg. D, Goldman. H, Gomelski. A. Surgical Treatment of Female Stress Urinary Incontinence (SUI): AUA/SUFU Guideline (2017). American Urological Association. 2017. Accessed 17 January, 2021. 
17. Koninklijke Nederlandse Organisatie van Verloskundigen (KNOV). Multidisciplinaire richtlijn postnatale zorg 2018; https://www.knov.nl/serve/file/knov.nl/knov downloads/2882/file/Postnatale_zorg_opgemaakte_versie_door_IB_md_10_aug_2018. pdf. Accessed 8 February 2021.

18. Miller JM, Sampselle C, Ashton-Miller J, Hong GR, DeLancey JO. Clarification and confirmation of the Knack maneuver: the effect of volitional pelvic floor muscle contraction to preempt expected stress incontinence. Int Urogynecol J Pelvic Floor Dysfunct. 2008;19(6):773-782.

19. Miller JM, Perucchini D, Carchidi LT, DeLancey JO, Ashton-Miller J. Pelvic floor muscle contraction during a cough and decreased vesical neck mobility. Obstet Gynecol. 2001;97(2):255-260.

20. Paiva LL, Ferla L, Darski C, Catarino BM, Ramos JG. Pelvic floor muscle training in groups versus individual or home treatment of women with urinary incontinence: systematic review and meta-analysis. Int Urogynecol J. 2017;28(3):351-359.

21. Woodley SJ, Lawrenson P, Boyle R, et al. Pelvic floor muscle training for preventing and treating urinary and faecal incontinence in antenatal and postnatal women. Cochrane database Syst Rev. 2020;5(5):Cd007471.

22. Dinc A, Kizilkaya Beji N, Yalcin O. Effect of pelvic floor muscle exercises in the treatment of urinary incontinence during pregnancy and the postpartum period. Int Urogynecol J Pelvic Floor Dysfunct. 2009;20(10):1223-1231.

23. Woldringh $C$, van den Wijngaart $M$, Albers-Heitner $P$, Lycklama à Nijeholt AA, LagroJanssen T. Pelvic floor muscle training is not effective in women with UI in pregnancy: a randomised controlled trial. Int Urogynecol J Pelvic Floor Dysfunct. 2007;18(4):383-390.

24. Oliveira C, Seleme M, Cansi PF, et al. Urinary incontinence in pregnant women and its relation with socio-demographic variables and quality of life. Rev Assoc Med Bras (1992). 2013;59(5):460-466.

25. Dolan LM, Walsh D, Hamilton S, Marshall K, Thompson K, Ashe RG. A study of quality of life in primigravidae with urinary incontinence. Int Urogynecol J Pelvic Floor Dysfunct. 2004;15(3):160-164.

26. Durnea CM, Khashan AS, Kenny LC, Tabirca SS, O'Reilly BA. The role of prepregnancy pelvic floor dysfunction in postnatal pelvic morbidity in primiparous women. Int Urogynecol J. 2014;25(10):1363-1374.

27. Burgio KL, Zyczynski H, Locher JL, Richter HE, Redden DT, Wright KC. Urinary incontinence in the 12-month postpartum period. Obstet Gynecol. 2003;102(6):1291-1298.

28. (CBS). CBvdS. Leeftijd moeder bij eerste kind stijgt naar 29,9 jaar. 2019; https:// www.cbs.nl/nl-nl/nieuws/2019/19/leeftijd-moeder-bij-eerste-kind-stijgt-naar29-9-jaar\#: :text=Minder\%20jonge\%20vrouwen\%20voor\%20het\%20erst\%20 moeder\&text=In\%202018\%20werden\%2035\%20duizend,geboorten\%20van\%20 eerste\%20kinderen\%20gedaald.accessed. Accessed 15 January, 2021.

29. Viktrup L, Rortveit G, Lose G. Risk of stress urinary incontinence twelve years after the first pregnancy and delivery. Obstet Gynecol. 2006;108(2):248-254.

30. MacArthur $C$, Wilson $D$, Herbison $P$, et al. Urinary incontinence persisting after childbirth: extent, delivery history, and effects in a 12-year longitudinal cohort study. BJOG. 2016;123(6):1022-1029. 
31. Nederlandse Vereniging voor Obstetrie en Gynaecologie (NVOG). Samenvattingskaart Richtlijn Urine-incontinentie in de tweede- en derde lijnszorg 2.0. 2014; https://www. nvog.nl/wp-content/uploads/2018/02/Samenvattingskaart-richtlijn-update-urineincontinentie-definitief-versie-juni-2014-e.pdf. Accessed 8 February, 2021.

32. Wu JM, Matthews CA, Conover MM, Pate V, Jonsson Funk M. Lifetime risk of stress urinary incontinence or pelvic organ prolapse surgery. Obstet Gynecol. 2014;123(6):1201-1206.

33. Rortveit G, Daltveit AK, Hannestad YS, Hunskaar S. Urinary incontinence after vaginal delivery or cesarean section. N Eng/J Med. 2003;348(10):900-907.

34. Eurostat. Population structure and ageing. 2020; Bevolkingsopbouw https:// ec.europa.eu/eurostat/statistics-explained/index.php?title=Population_structure and_ageing\#Past_and_future_population_ageing_trends_in_the_EU-27. Accessed 19 February, 2021.

35. Rawlings T, Zimmern PE. Economic analyses of stress urinary incontinence surgical procedures in women. Neurourol Urodyn. 2016;35(8):1040-1045.

36. (RIVM) RvVeM. The Dutch healthcare system in an international perspective. RIVM official reports 2018; http://hdl.handle.net/10029/622021. Accessed 19 February, 2021.

37. Brown WJ, Miller YD. Too wet to exercise? Leaking urine as a barrier to physical activity in women. J Sci Med Sport. 2001;4(4):373-378.

38. Hermansen IL, O'Connell BO, Gaskin CJ. Women's explanations for urinary incontinence, their management strategies, and their quality of life during the postpartum period. $J$ Wound Ostomy Continence Nurs. 2010;37(2):187-192.

39. Handa VL, Zyczynski HM, Burgio KL, et al. The impact of fecal and urinary incontinence on quality of life 6 months after childbirth. Am J Obstet Gynecol. 2007;197(6):636.e631-636.

40. Van der Woude DA, Pijnenborg JM, de Vries J. Health status and quality of life in postpartum women: a systematic review of associated factors. Eur J Obstet Gynecol Reprod Biol. 2015;185:45-52.

41. Mannion CA, Vinturache AE, McDonald SW, Tough SC. The influence of back pain and urinary incontinence on daily tasks of mothers at 12 months postpartum. PLOS ONE. 2015;10 (6) (no pagination)(e0129615).

42. Hägglund D, Walker-Engström ML, Larsson G, Leppert J. Quality of life and seeking help in women with urinary incontinence. Acta Obstet Gynecol Scand. 2001;80(11):1051-1055.

43. Monz B, Chartier-Kastler E, Hampel C, et al. Patient characteristics associated with quality of life in European women seeking treatment for urinary incontinence: results from PURE. Eur Urol. 2007;51(4):1073-1081; discussion 1081-1072. 


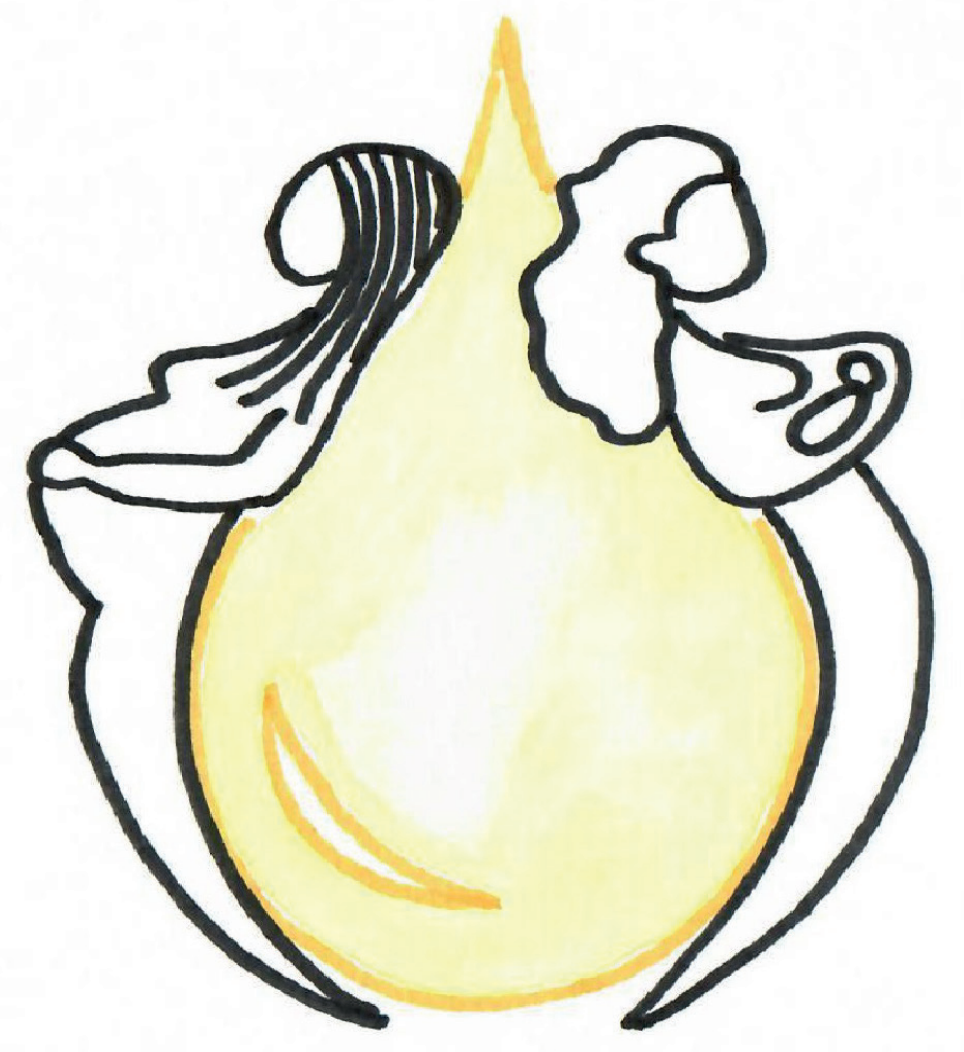




\title{
PREVALENCE, INCIDENCE AND BOTHERSOMENESS OF URINARY INCONTINENCE IN PREGNANCY: \\ A SYSTEMATIC REVIEW AND META-ANALYSIS
}

Heidi F.A. Moossdorff-Steinhauser ${ }^{1}$ Bary C.M. Berghmans ${ }^{2}$ Marc E.A. Spaanderman ${ }^{3}$ Esther M.J. Bols ${ }^{1}$

\begin{abstract}
${ }^{1}$ Maastricht University, Faculty of Health, Medicine and Life Sciences, Dept. Epidemiology, CAPHRI Care and Public Health Research Institute, P.O. Box 616, 6200 MD Maastricht, The Netherlands; ${ }^{2}$ Pelvic care Center Maastricht, CAPHRI, Maastricht University Medical Centre (MUMC+), Maastricht, The Netherlands; ${ }^{3}$ Department of Obstetrics and Gynecology, MUMC+, The Netherlands
\end{abstract}




\section{ABSTRACT}

Introduction and Hypothesis: Urinary incontinence (UI) is a common and embarrassing complaint for pregnant women. Reported prevalence and incidence figures show a large range, due to varying case definitions, recruited population and study methodology. Precise prevalence and incidence figures on (bothersome) $\mathrm{UI}$ are of relevance for health care providers, policy makers and researchers. Therefore, we conducted a systematic review and meta-analysis to investigate the prevalence and incidence of $\mathrm{UI}$ in pregnancy in the general population for relevant subgroups and assessed experienced bother.

Methods: All observational studies, published between January 1998 and October 2018 reporting on prevalence and/or incidence of UI during pregnancy were included. All women, regardless of weeks of gestation and type of UI presented in all settings were of interest. A random-effects model was used. Subgroup analyses were conducted by parity, trimester and subtype of UI.

Results: The mean (weighted) prevalence based on 44 included studies, containing a total of 88.305 women, was $41.0 \%$ (range of 9-75\%). Stress urinary incontinence $(63 \%)$ is the most prevalent type of UI. $26 \%$ of the women reported daily loss, whereas $40 \%$ reported loss on a monthly basis. Bother was experienced as mild to moderate.

Conclusions: UI is very prevalent and rising with the weeks of gestation in pregnancy. SUI is the most common type and in most cases it was a small amount. Bother for $\mathrm{UI}$ is heterogeneously assessed and experienced as mild to moderate by pregnant women. 


\section{INTRODUCTION}

Urinary incontinence (UI) is the complaint of involuntary loss of urine. ${ }^{1}$ It is a common and embarrassing problem, evoking substantial individual morbidity, loss in quality of life and socio-economic costs. ${ }^{2,3}$ In addition to the loss of bladder control, the need to wear incontinence pads often harms the individuality and selfconfidence of young pre-partum women. ${ }^{4}$ UI ranges from occasionally leaking urine when coughing or sneezing (stress UI (SUI)) to UI preceded by urgency (urgency $\mathrm{UI}(\mathrm{UUI})$ ), or a combination of both (mixed UI (MUI)). In the peri-partum period women often experience $\mathrm{UI}$ for the first time. In general, SUI is more related to the peri-partum period, whereas the prevalence of UUI and MUI increases with age. ${ }^{5}$ Pregnancy and (vaginal) delivery are important risk factors in the development of UI in life. 2,6 Moreover, when SUI presents during pregnancy, the risk of having SUI at 12 years post-partum is significant. ${ }^{7}$

The prevalence and incidence of UI in pregnancy is widely researched. However, these prevalence and/or incidence figures vary greatly throughout published reports, depending on local setting, case definitions applied, recruited population (trimester of pregnancy and parity), and study methodology. ${ }^{8-10}$ Former systematic reviews focused on the prevalence of pelvic floor disorders (PFDs) among community-dwelling women ${ }^{11}$, the prevalence of UI in nulliparous women ${ }^{12}$ or in female athletes. ${ }^{13}$ To our knowledge, no systematic review and meta-analysis on the prevalence and incidence of $\mathrm{UI}$ in pregnancy is available. Reliable prevalence and incidence rates on $\mathrm{UI}$ in pregnancy are not only needed to indicate the burden of the health problem, but also to better inform health professionals, policy makers and researchers in order to set priorities and to assist in planning management of UI. ${ }^{14}$

Furthermore, it is known that not all pregnant women are bothered by experiencing UI. It is reported that the crude $\mathrm{UI}$ prevalence rate is higher and probably overestimated compared to the prevalence rate of significant or bothersome UI. ${ }^{3}$ As bothersome UI is associated with help-seeking behaviour this discrepancy may have crucial consequences for research planning, health care providers and policy makers. ${ }^{15}$ However, a clear and widely accepted definition of bothersome UI still does not exist, which results in the use of heterogeneous terminology and measurement instruments. 
Therefore, the primary aim of this systematic review and meta-analysis was to examine the pooled overall prevalence and incidence of $\mathrm{UI}$ in pregnancy in the general population, specified for relevant subcategories (trimester of pregnancy, parity, type of UI, frequency and amount). A secondary aim was to provide an overview of the measurement instruments and their outcomes for bother in relation to UI as used in included studies.

\section{METHODS}

The MOOSE statement for reporting systematic reviews and meta-analyses was followed. ${ }^{16}$ The research protocol was published in the PROSPERO database (registration number CRD42018111991).

\section{Search strategy}

We performed a systematic review and meta-analysis of observational studies reporting on the prevalence and/or incidence of UI during pregnancy and experienced bother in relation to UI. We searched the electronic databases of PubMed, EMBASE and CINAHL.

We used the following search terms to search all databases: pregnancy, pregn*, prepartum, pre-partum, pre partum, peripartum, peri-partum, peri partum, nulliparous, primiparous, primigrav*, primipar*, multiparous, multigrav*, multipar*, urinary incontinence, urine loss, pelvic floor disorders, pelvic floor dysfunctions, leaking urine, incontinence, prevalence, incidence, epidemiology, bothersomeness, bother* and quality of life. In the Appendix the complete search strategy for PubMed is provided. This search string was adapted for use in the other databases.

\section{Eligibility criteria}

Observational studies published between January 1, 1998 and January 1, 2019 in Dutch, English, Portuguese, German and French were included. All studies examining prevalence and/or incidence of UI among adult primi- and multigravid women, regardless of weeks of gestation, type of UI, setting and country were of interest. Outcomes of interest were prevalence and/or incidence of (bothersome) UI. Exclusion criteria were: articles not available in full or not reporting an overall 
UI prevalence of any frequency, and studies examining only twin pregnancies. When articles did not report a prevalence or incidence figure or response rate, an attempt was made for estimation from the information provided. Throughout this article we use the term bother (in relation to UI) as umbrella term for related constructs (impact on daily life or quality of life (QOL)).

\section{Study selection}

Titles and/or abstracts of studies retrieved using the search strategy and those from additional sources were screened independently by two reviewers (HM and EB) to identify studies that potentially meet the inclusion criteria. The full text of these potentially eligible studies were retrieved and independently assessed for eligibility by two reviewers. Any disagreement on eligibility was resolved through discussion with a third reviewer (BB). All the included articles were reference checked.

\section{Data extraction and risk of bias}

Information on each study was extracted in a standardised data extraction form, based on the Cochrane Public Health Data Extraction and Assessment template. ${ }^{17}$ To assess the risk of bias, the Joanna Briggs critical appraisal tool for studies reporting prevalence data was used. ${ }^{18,19}$ The checklist consists of nine questions, with the response options yes, no, unclear or not applicable. Overall risk of study bias was rated as low (defined as 8-9 criteria answered as 'yes'), moderate (4-7 criteria answered as 'yes') or high risk ( $\leq 3$ criteria answered as 'yes'). The response option not applicable (occasionally scored in criteria 5) was considered to be a 'yes'. Two reviewers extracted data independently. Inconsistencies were identified and resolved through discussion including a third author if necessary.

Characteristics regarding measurement instruments for bother were extracted in a separate standardised extraction form. The form contains items like measurement instrument, related construct and measurement results.

\section{Summary measures, statistical analyses and heterogeneity}

We used a random effects model to pool the inverse variance (IV) weighted prevalence of $\mathrm{UI}$ in individuals to avoid undue influence on the summary estimate 
from smaller and less precise studies or studies with a very small prevalence. Pooled prevalence and incidence values were reported with 95\% confidence intervals $(\mathrm{Cl})$. The degree of heterogeneity was determined by the $\mathrm{I}^{2}$ statistic, with $1^{2}>75 \%$ labelled as considerable heterogeneity. ${ }^{20}$

We performed subgroup analyses based on trimester, parity, type and frequency of UI, as these factors may explain why studies show varying prevalence figures. Trimesters 1, 2 and 3 were defined as weeks 1-13, 14-26 and 27 to at term (42 weeks) respectively. STATA Statistical Software, release 15, was used for analysis.

In order to determine the overall experienced bother in relation to $\mathrm{UI}$ across included studies, the total scores of the different measurement instruments for bother were converted to a (standardized) 0 to 100 scale, with 0 indicating no bother and 100 indicating extremely bothered. We classified 1 to 20 as no to mild bother, 20 to 40 as mild to moderate bother, 40 to 60 as moderate to severe, 60 to 80 as severe to very severe, and 80 to 100 as extremely severe bother.

\section{RESULTS}

\section{Study selection}

Among the 1338 papers initially identified, 44 met the eligibility criteria (Figure 1), resulting in a total of 88,305 participants. All included studies were observational and published between 1998 and January 1, 2019.

\section{Risk of bias}

The risk of bias items for each study are shown in Table 1. High, moderate and low risk of bias were considered to be present in 3, 34 and 7 studies respectively. Risk of bias items with the lowest ratings were 8 and 9, and risk of bias items with the highest ratings were 1 and 4 .

\section{Study characteristics}

17 studies originated from Asia, 15 from Europe, 8 from the USA, 3 from Africa and 1 from Oceania. The majority of women were included from a (tertiary) hospital. Other studies included women from a civil registration system ${ }^{21}$, midwifery area ${ }^{22}$, hospital and maternity unit ${ }^{23}$ or obstetric/child health clinic. ${ }^{24,25}$ Table 1 summarizes the study characteristics of included studies. 


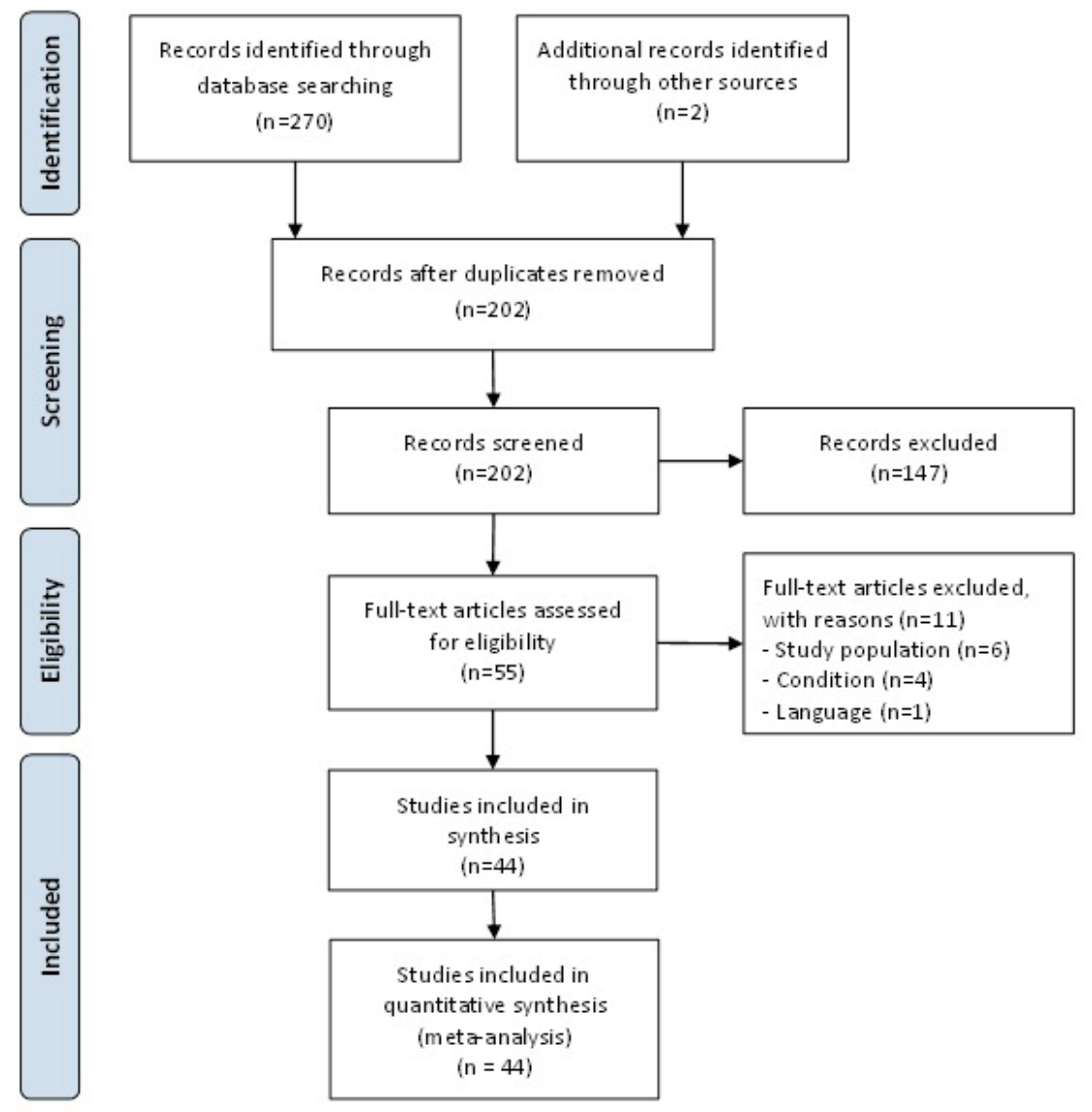

Figure 1 Study flow diagram

13 studies reported on (measurement instruments for) bother, whereas one study (73) reported on two measurement instruments. The result of only one measurement instrument was reported for this study, as the second one (SF-36) was incomplete. Table 2 provides an overview of the measurement instruments as used in included studies, with the original and the converted (0-100 scale) measurement results.

Six different measurement instruments for bother were used, of which the ICIQ-UI SF was most frequently used. Two studies reported the results of the ICIQ-UI SF as categories. ${ }^{26,27}$ One measurement instrument was self-constructed and nonvalidated. ${ }^{28}$ 


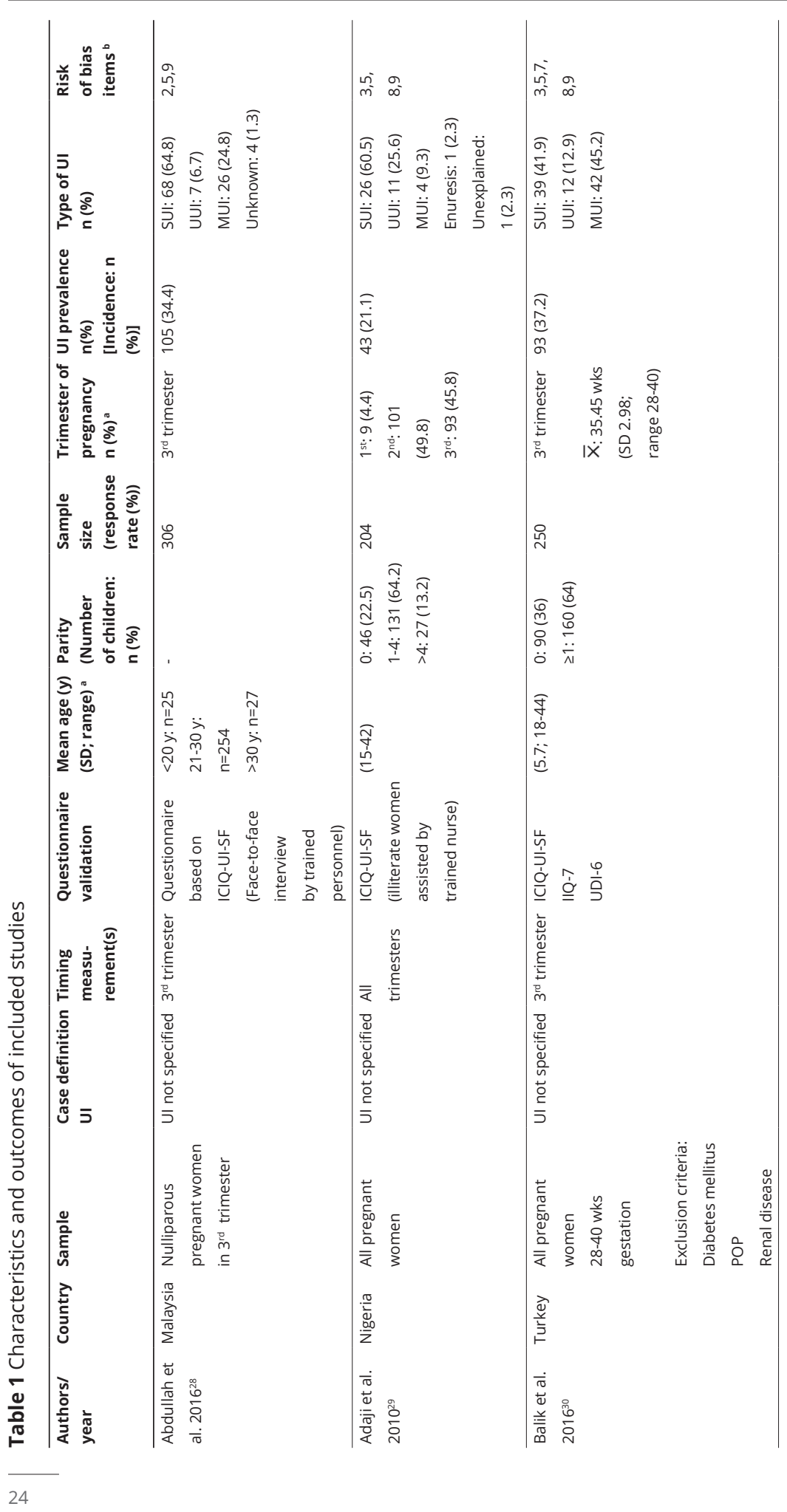




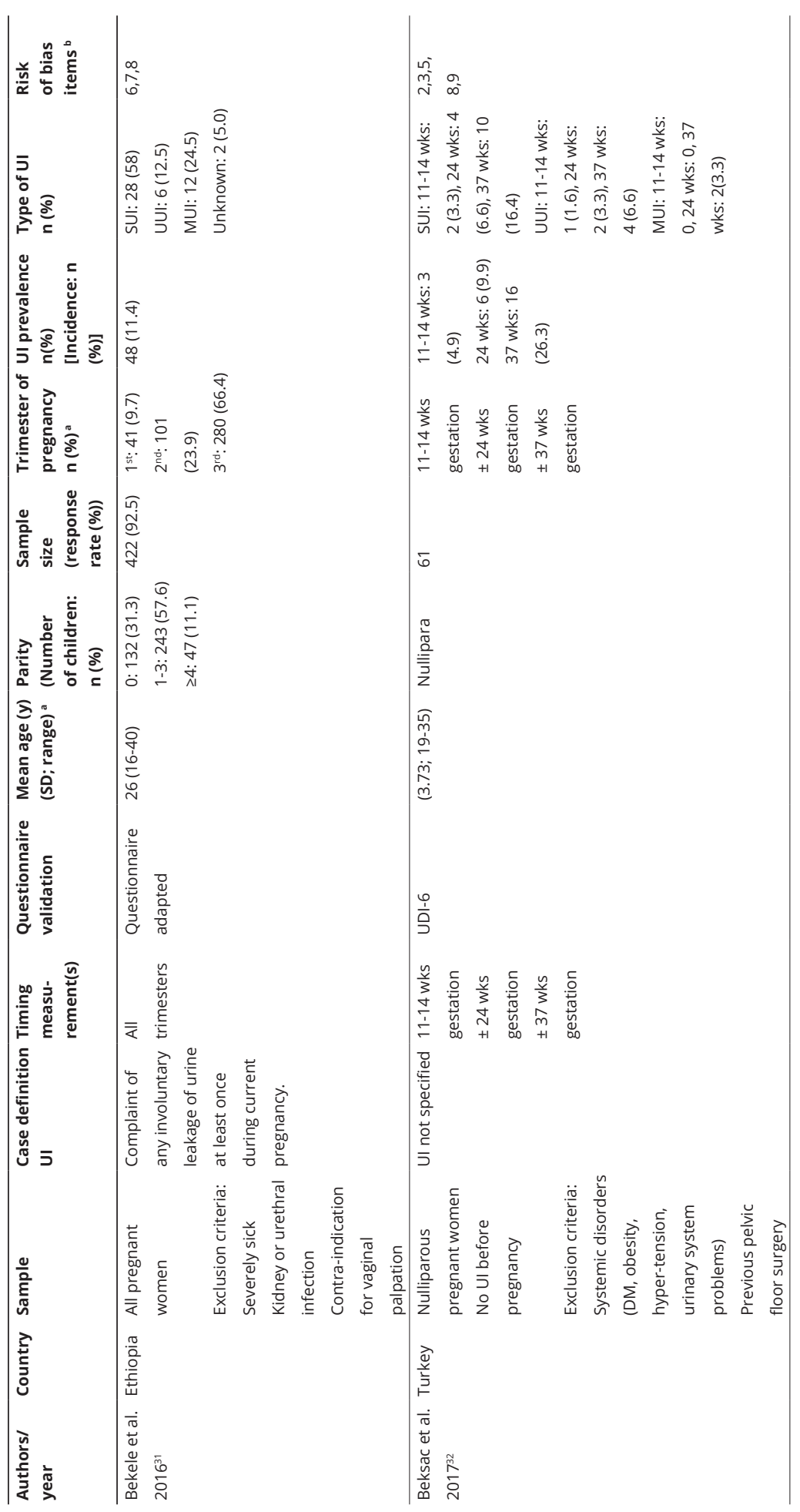




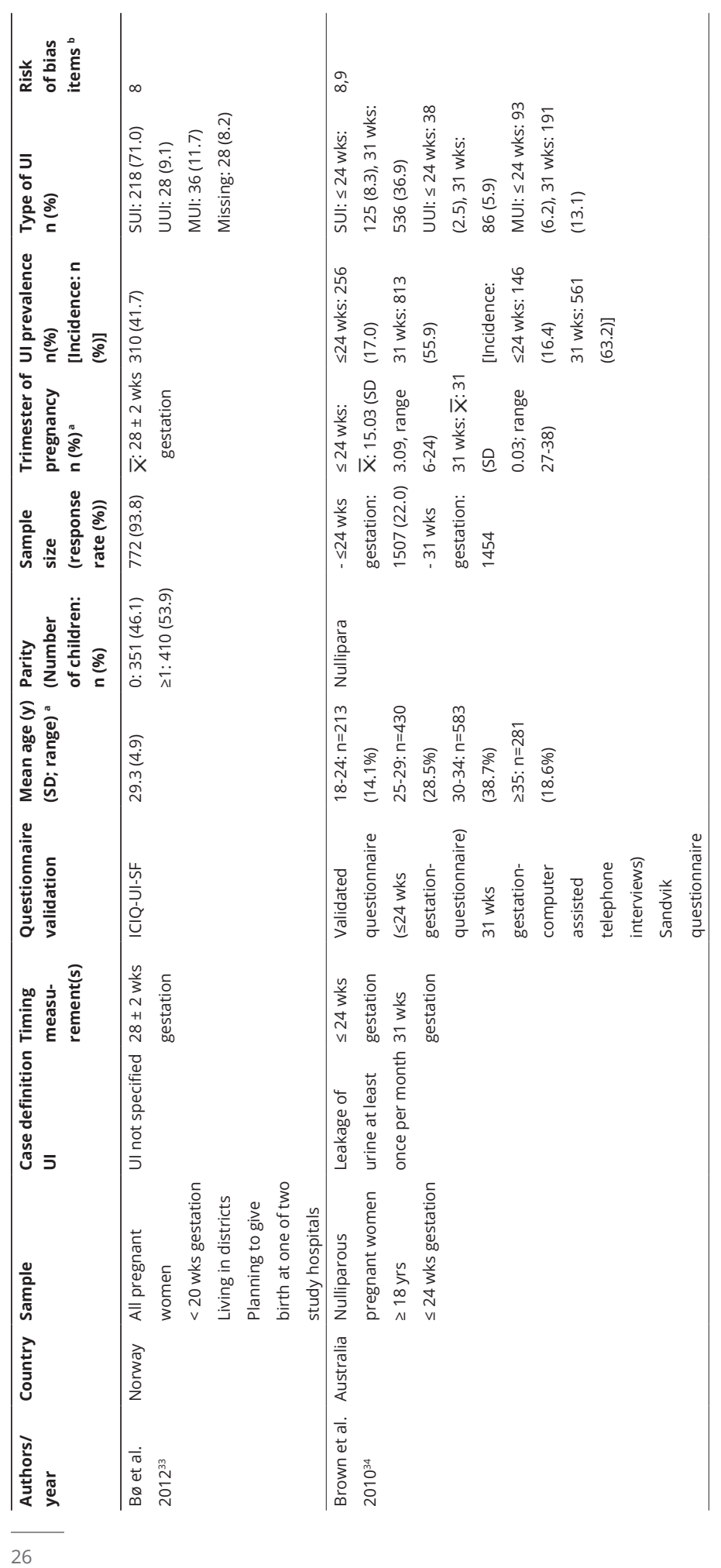




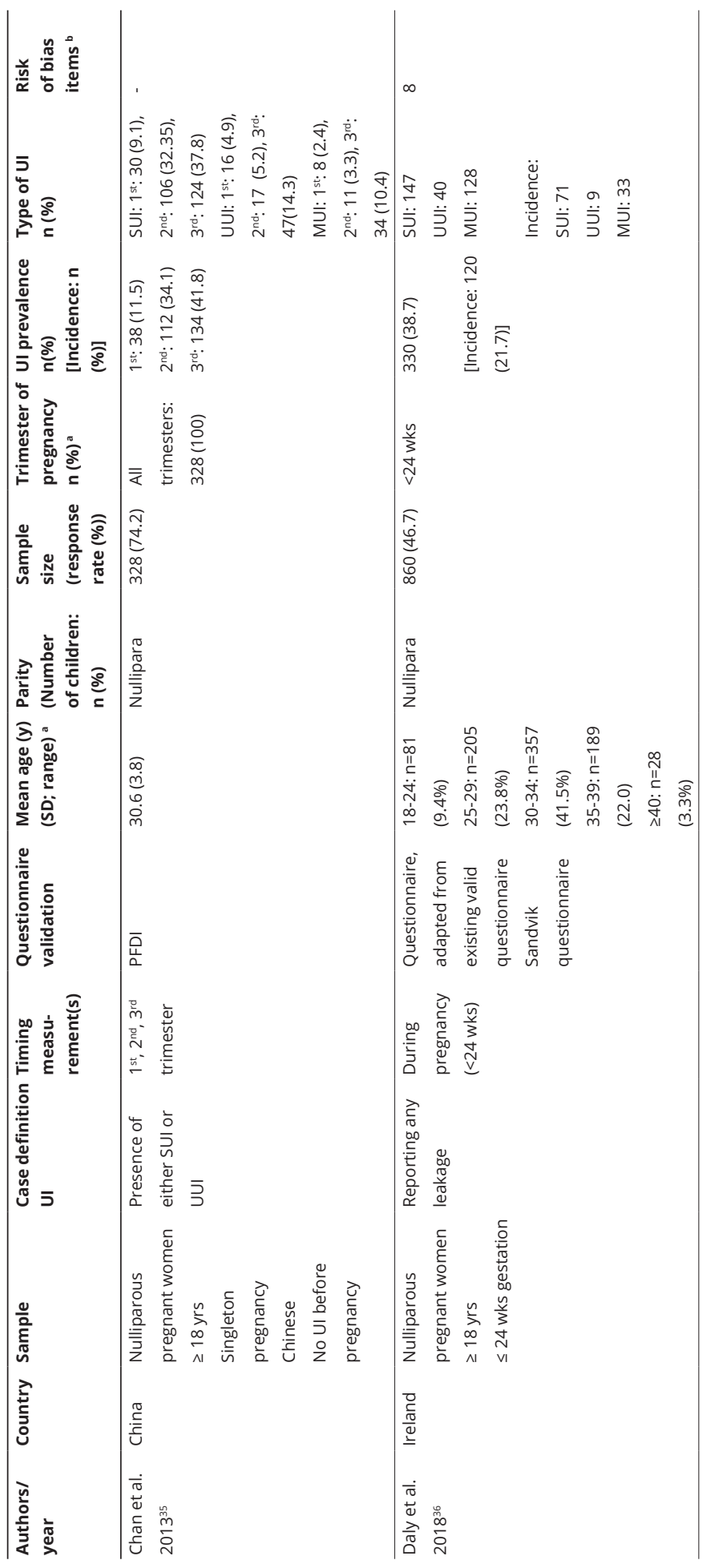




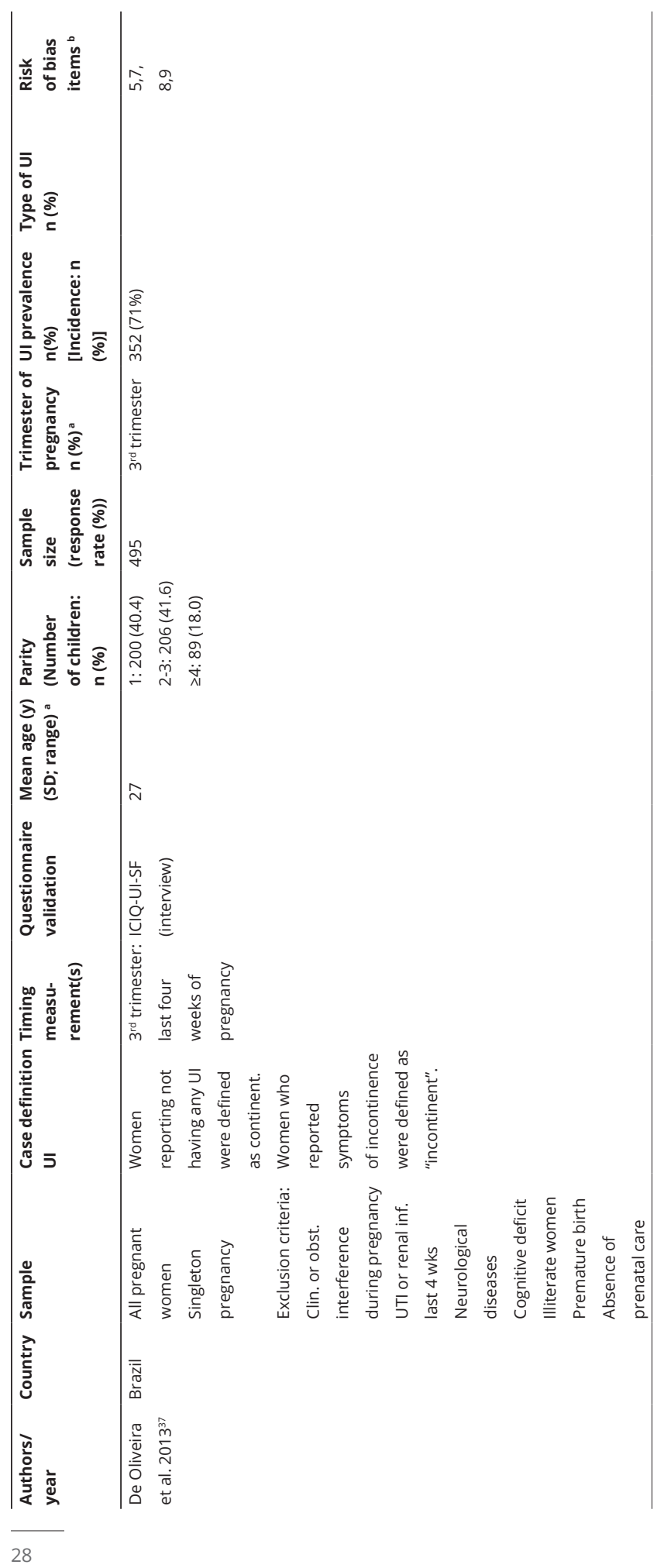




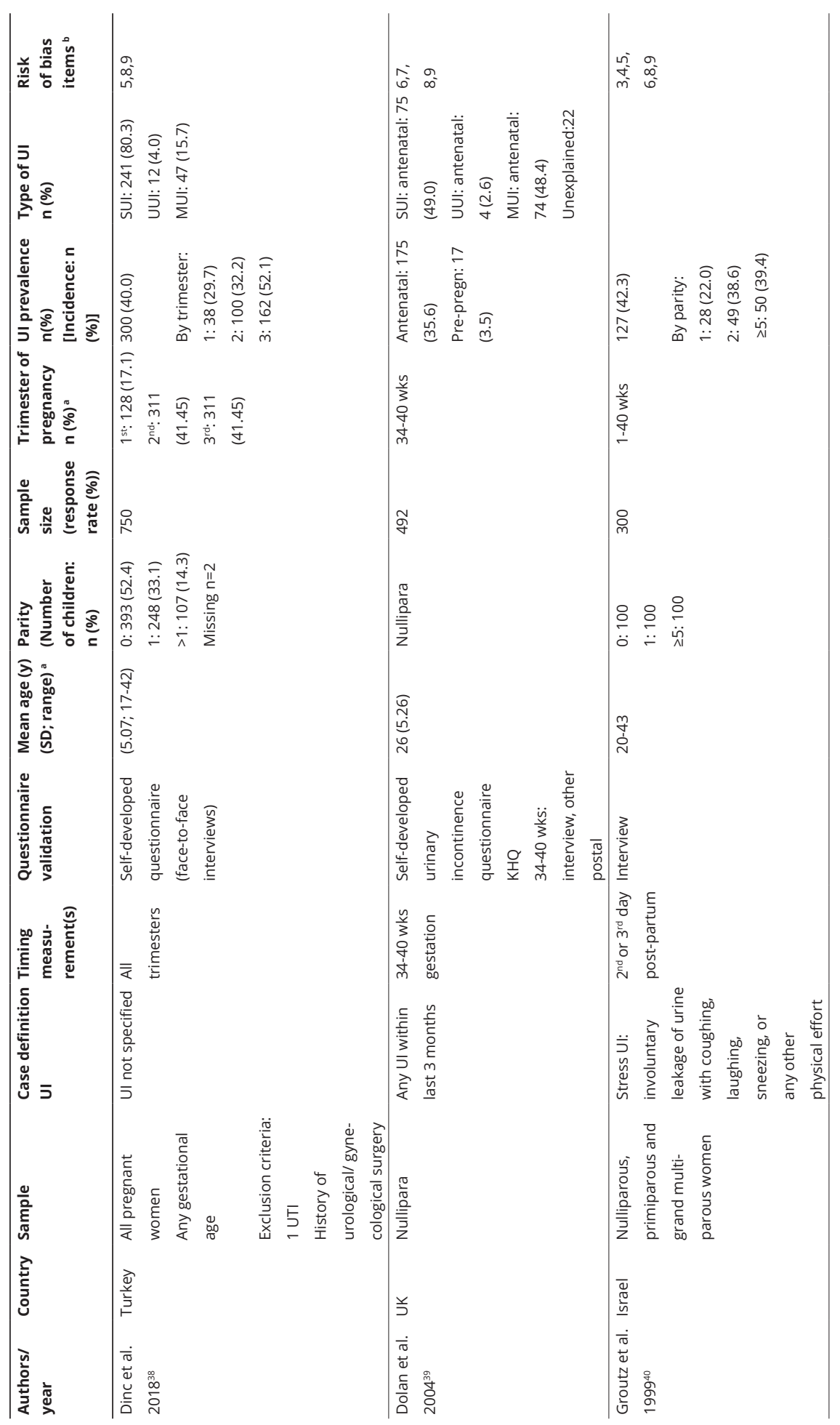




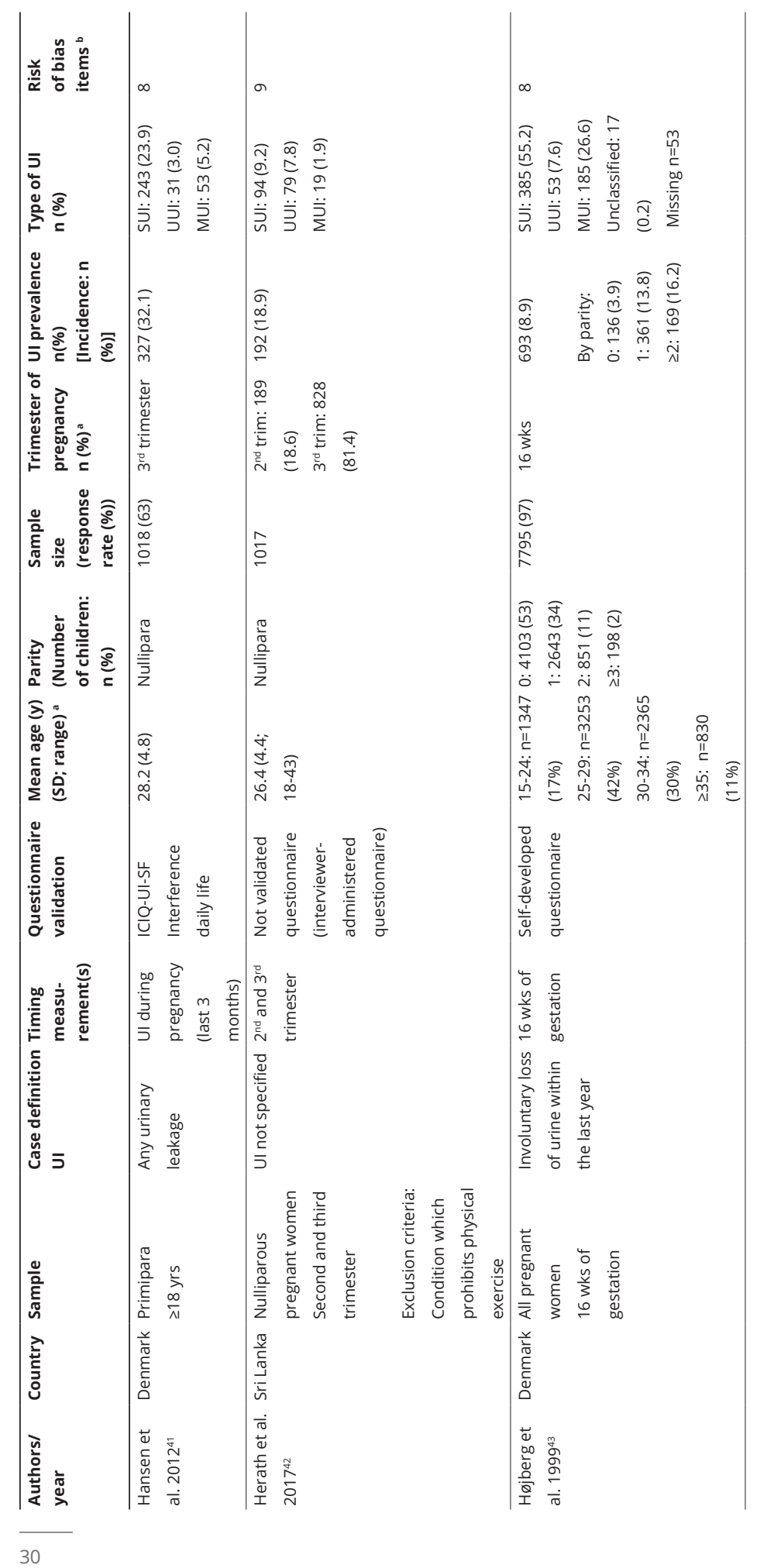




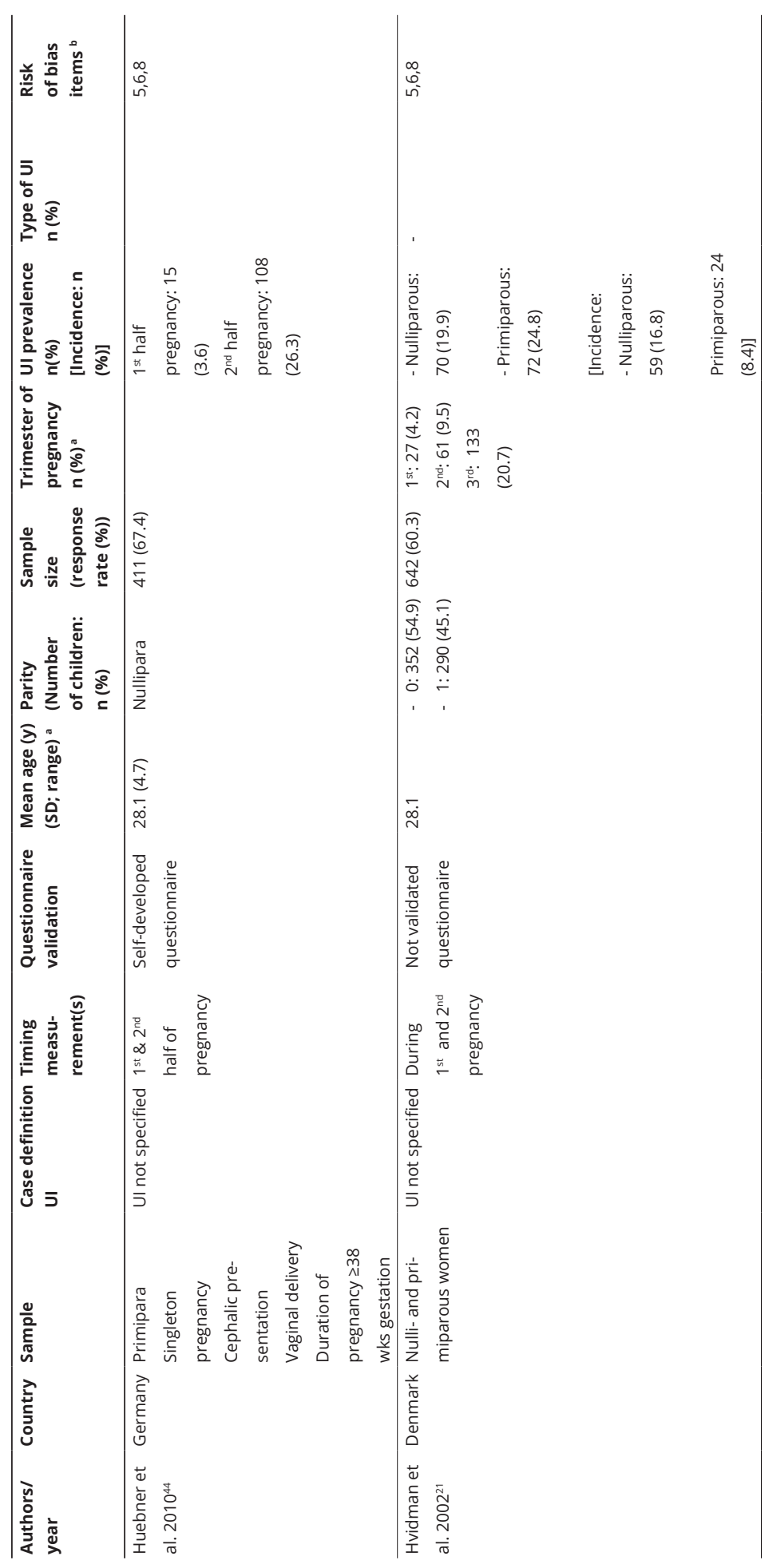




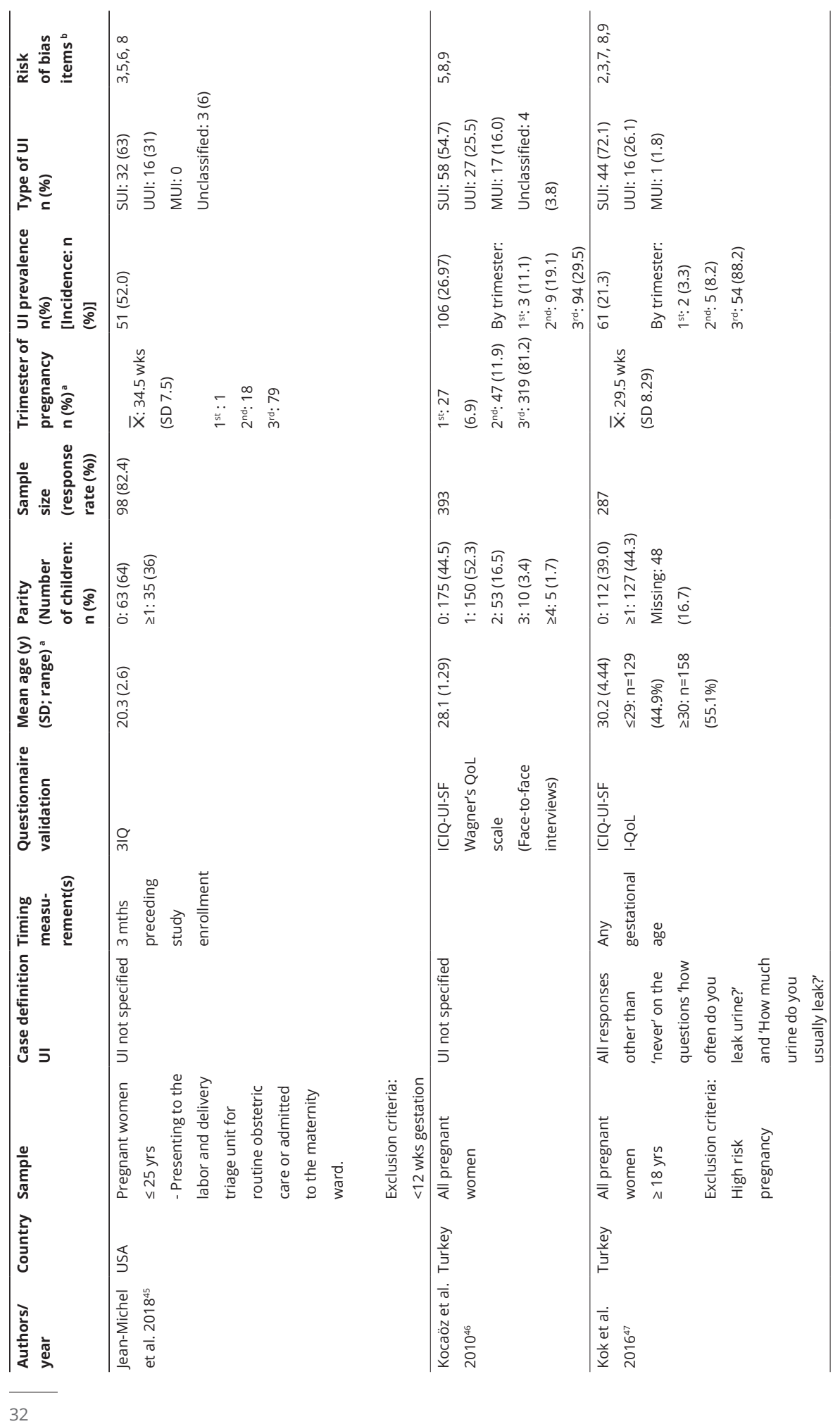




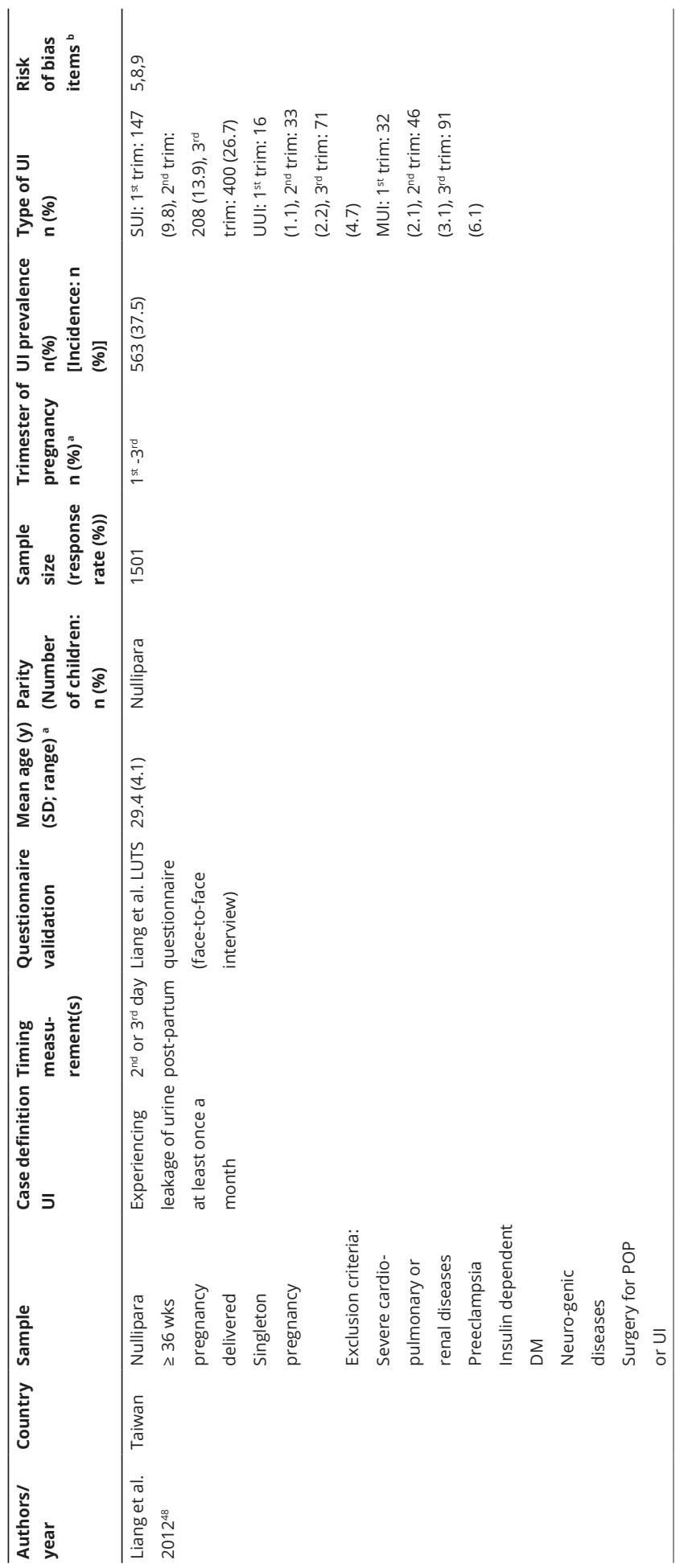




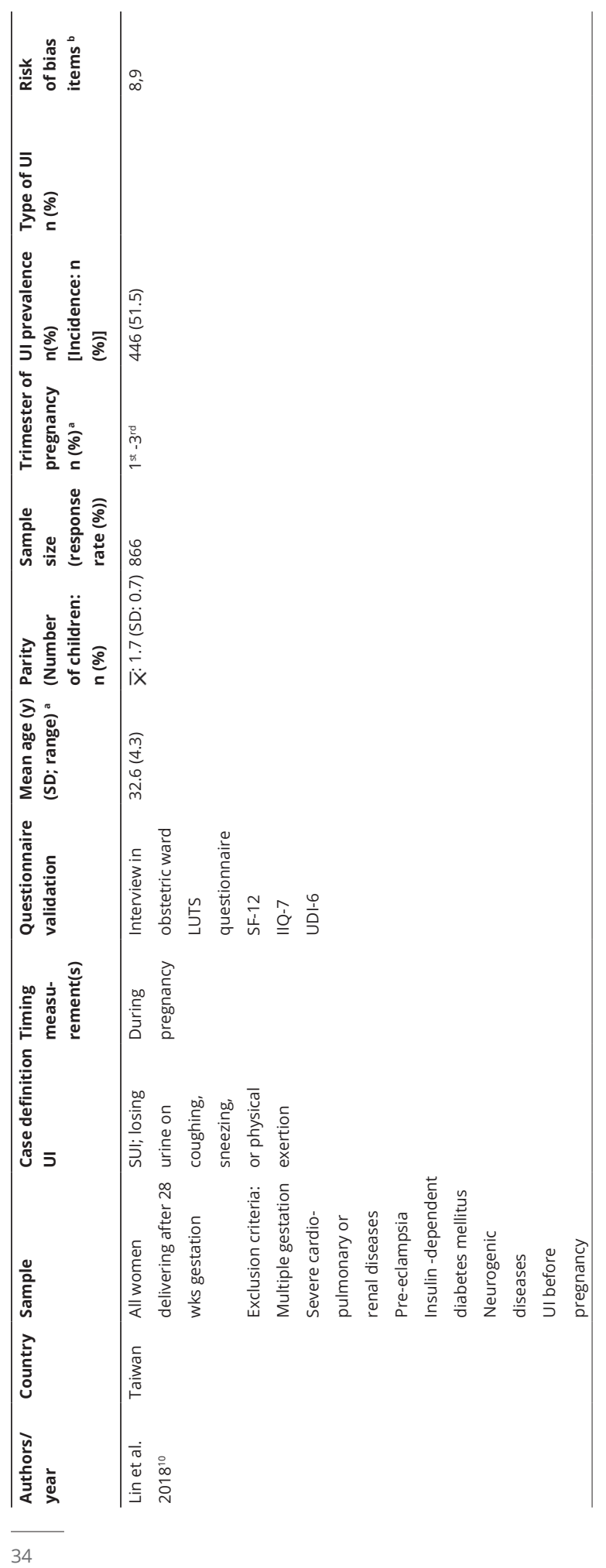




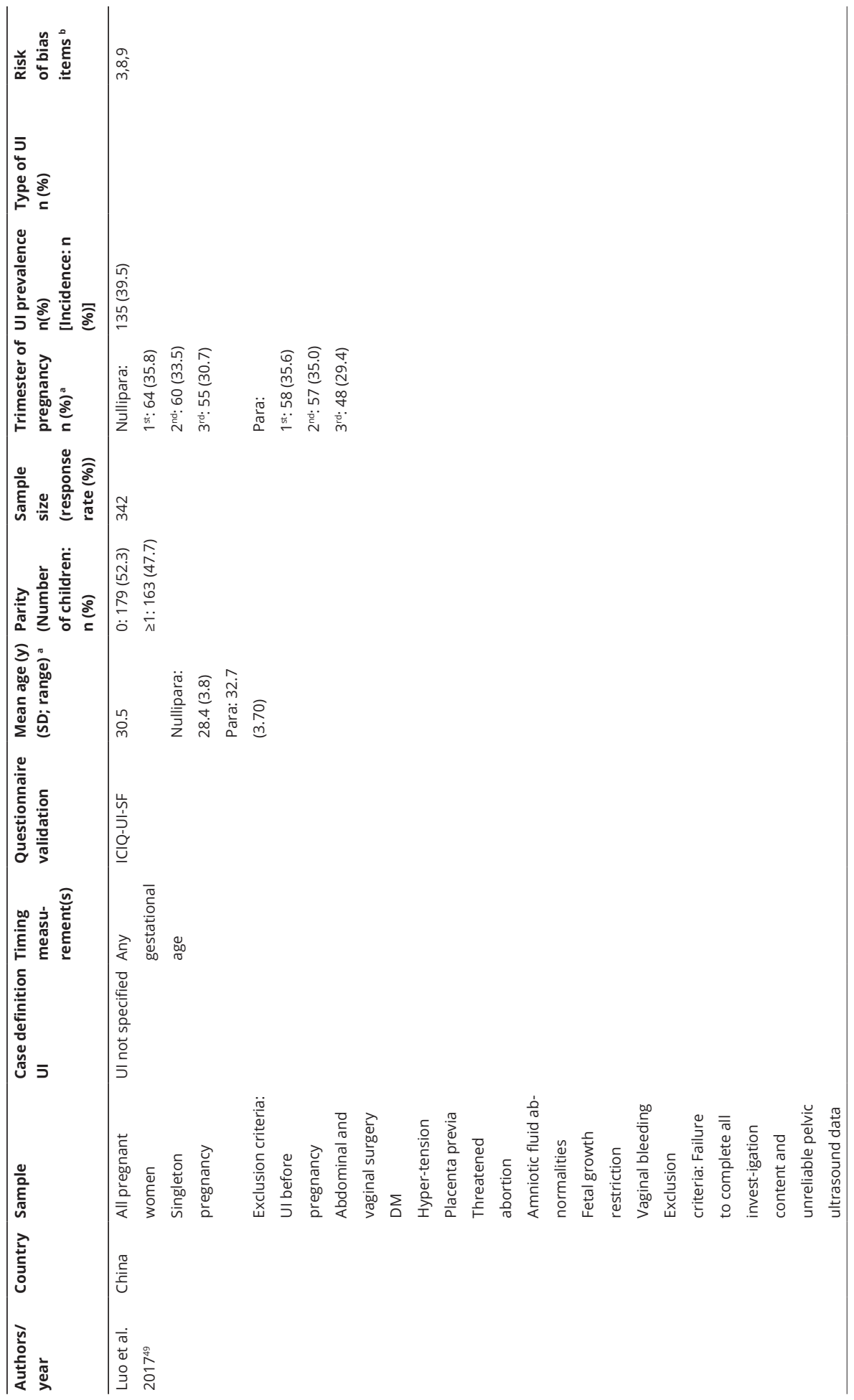




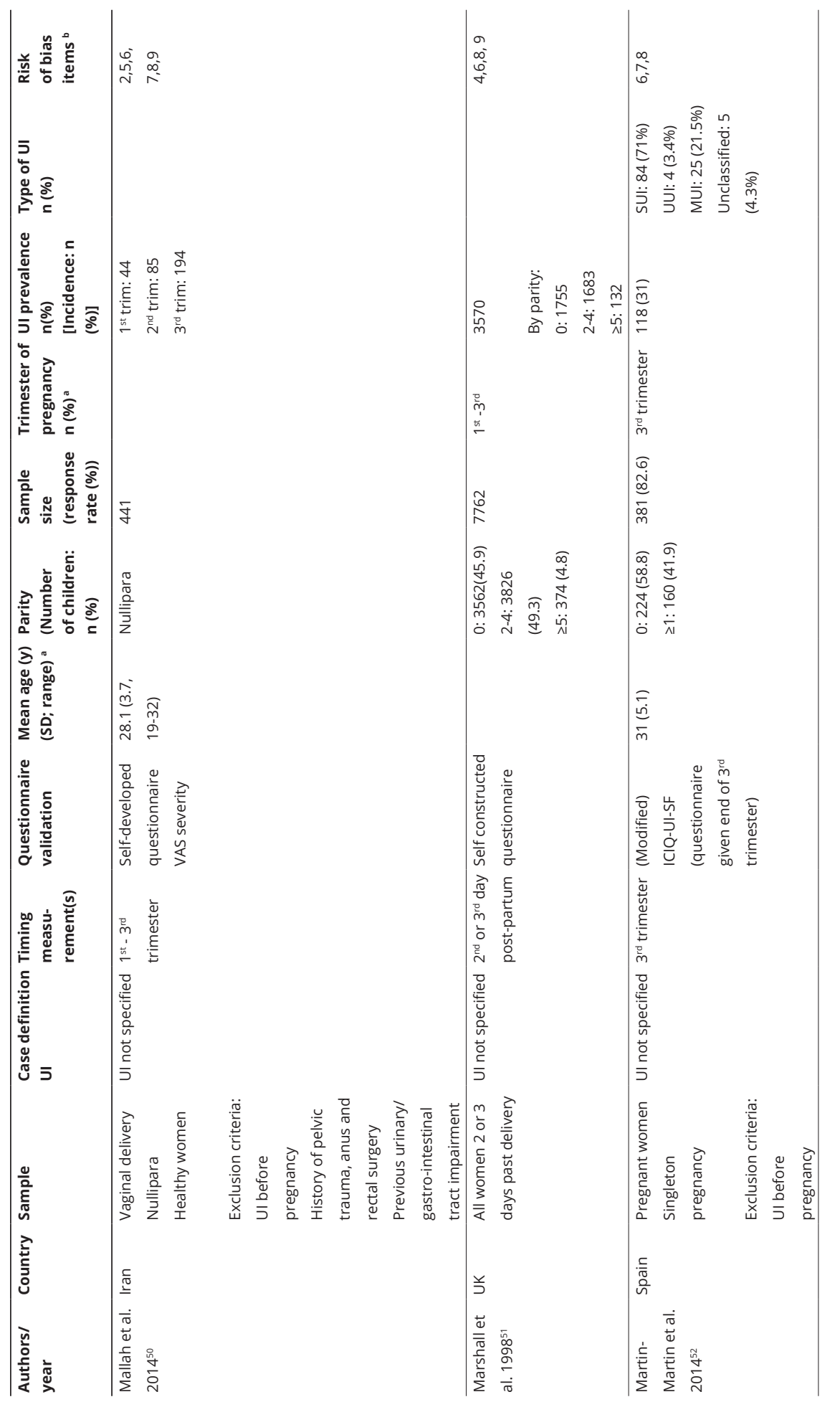




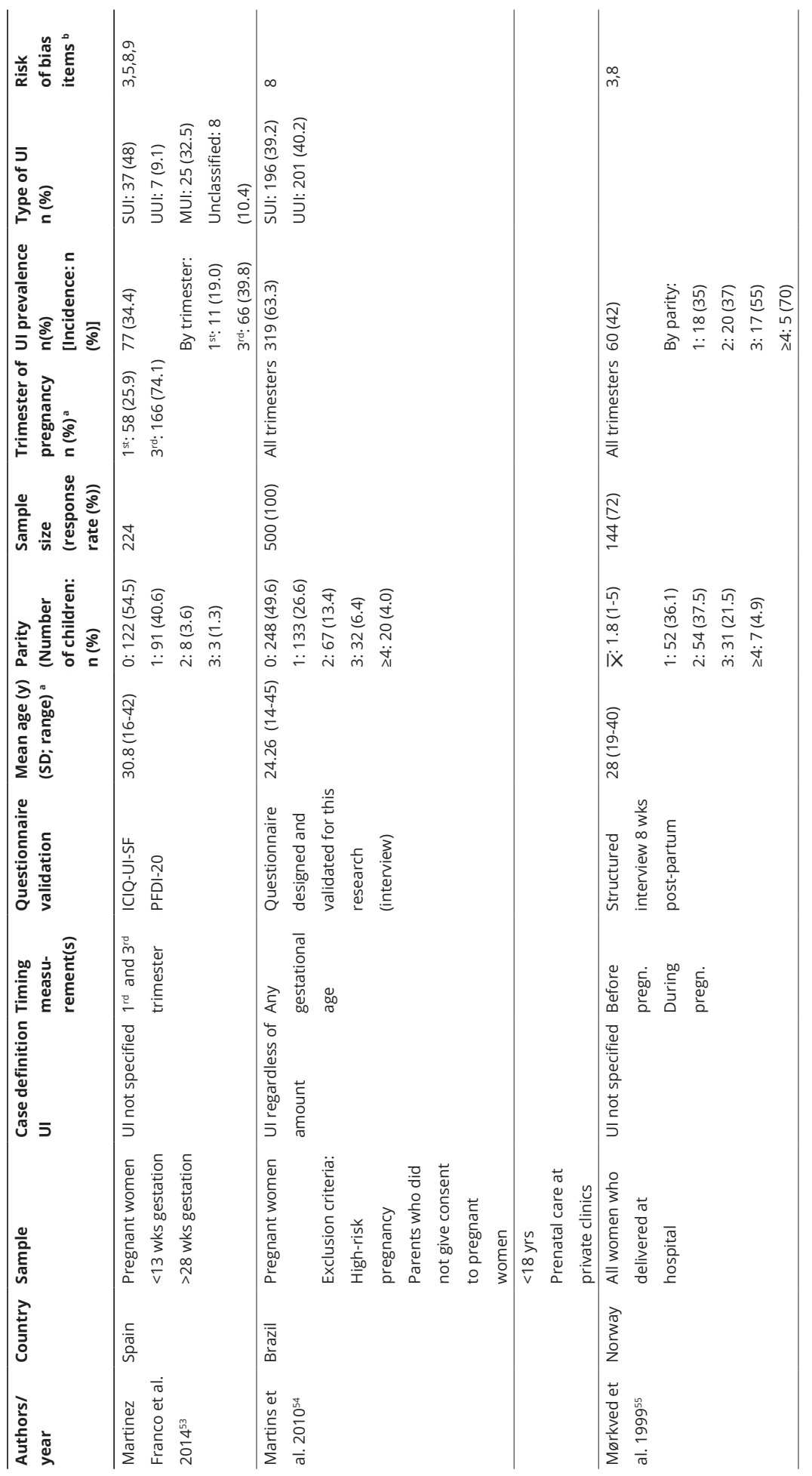




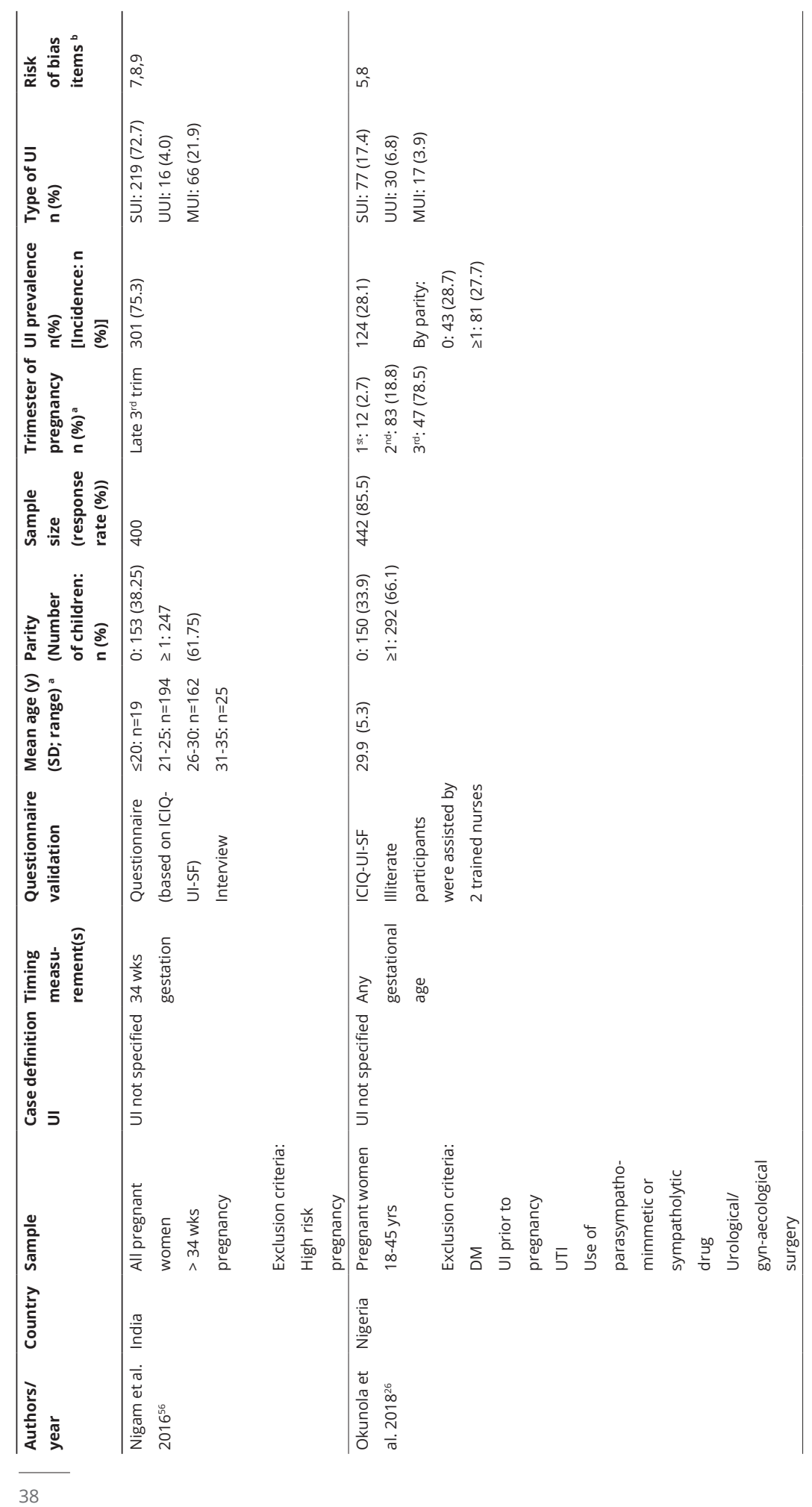




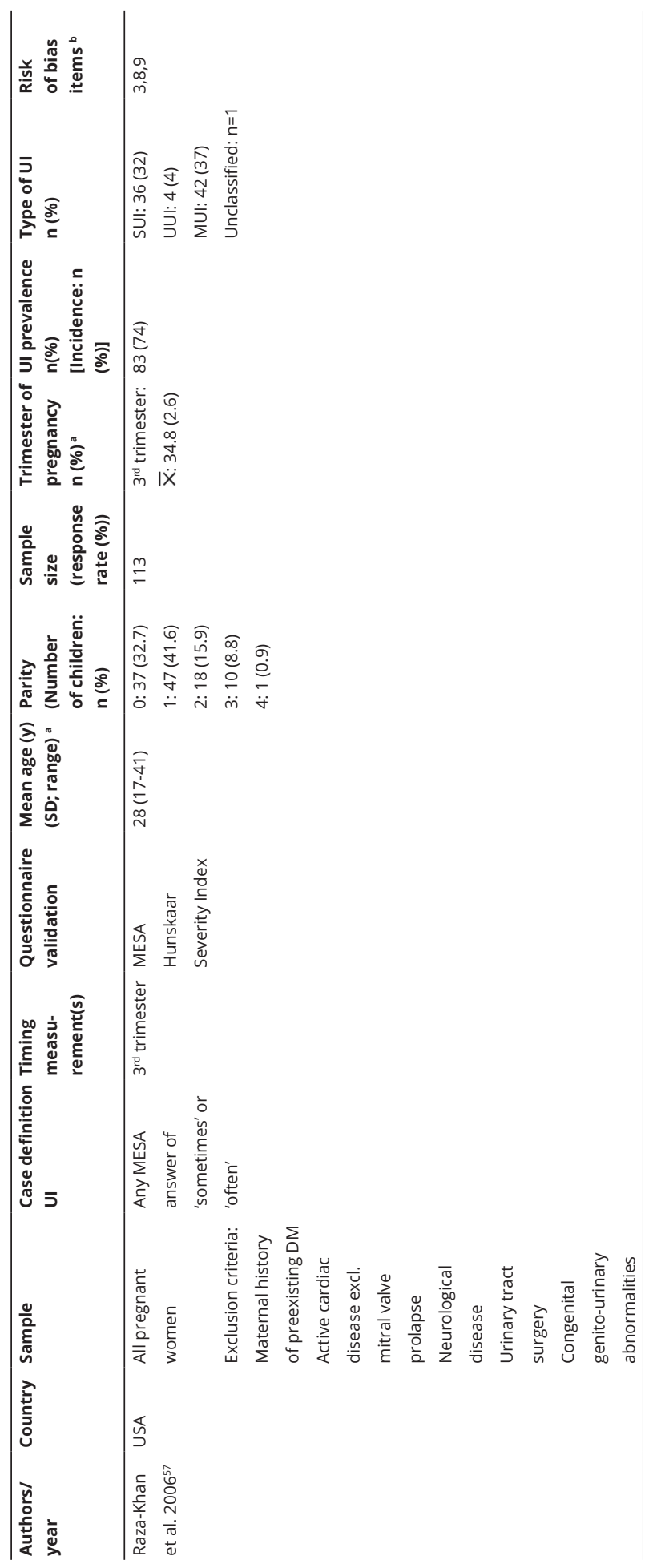




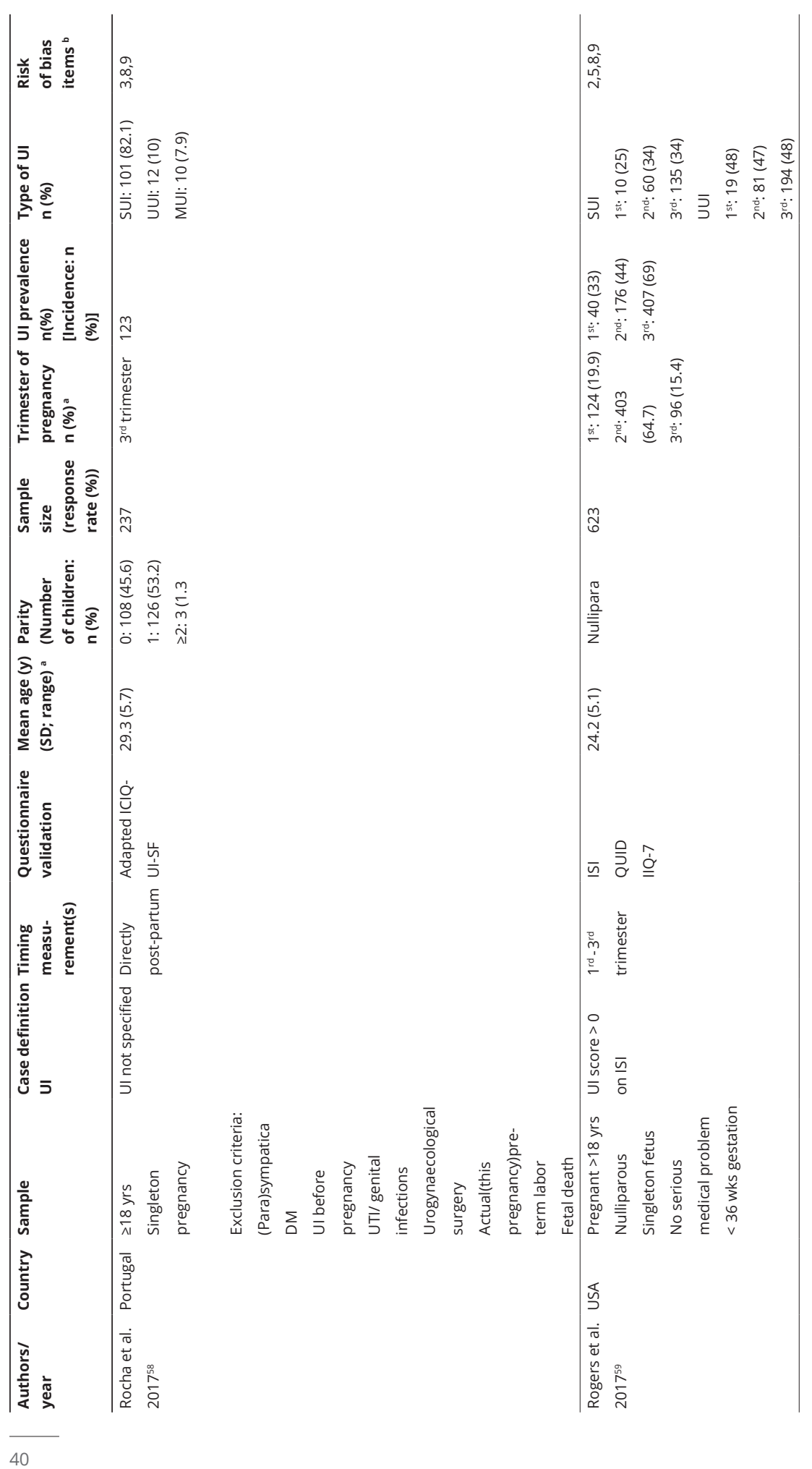




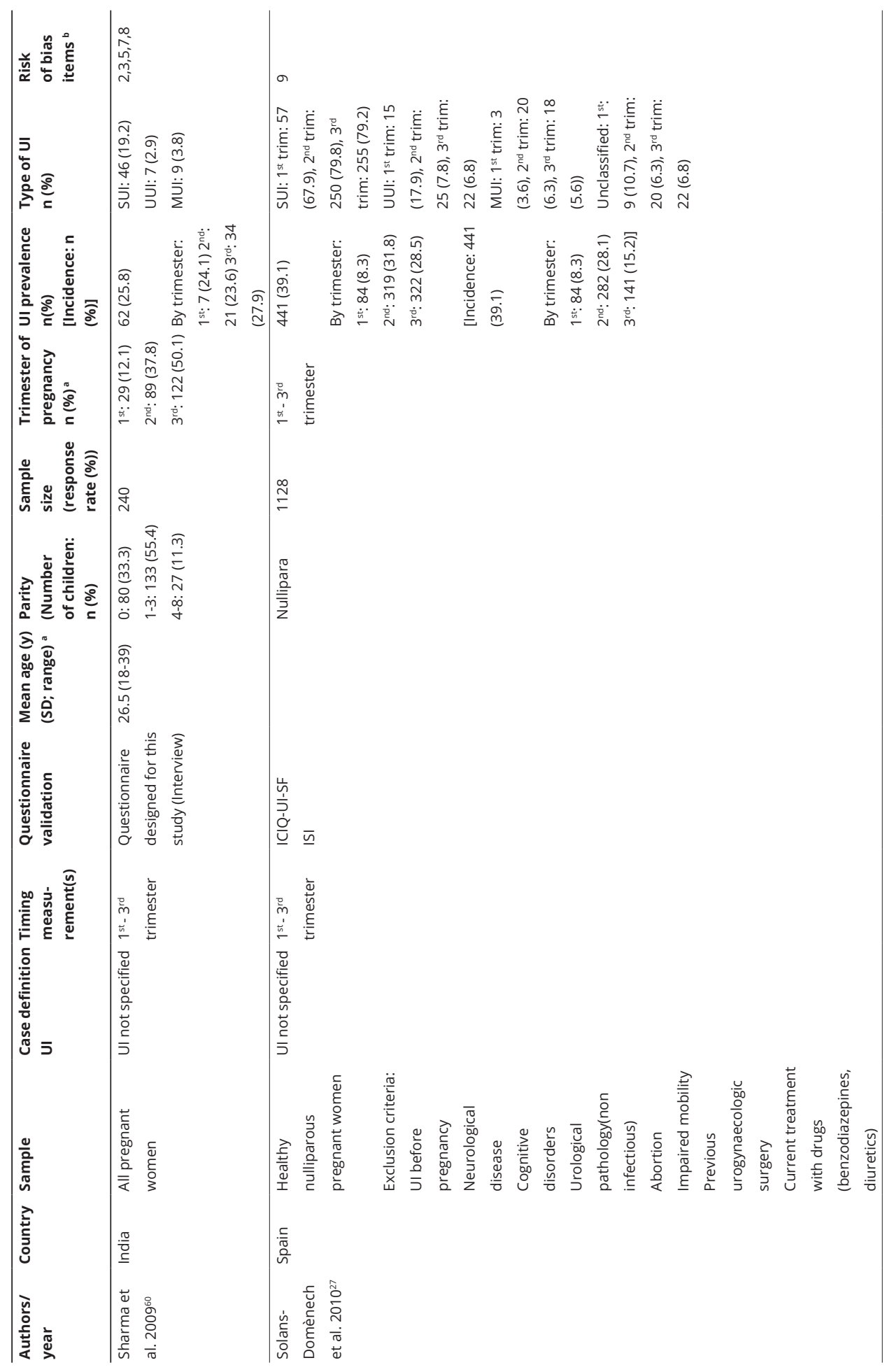




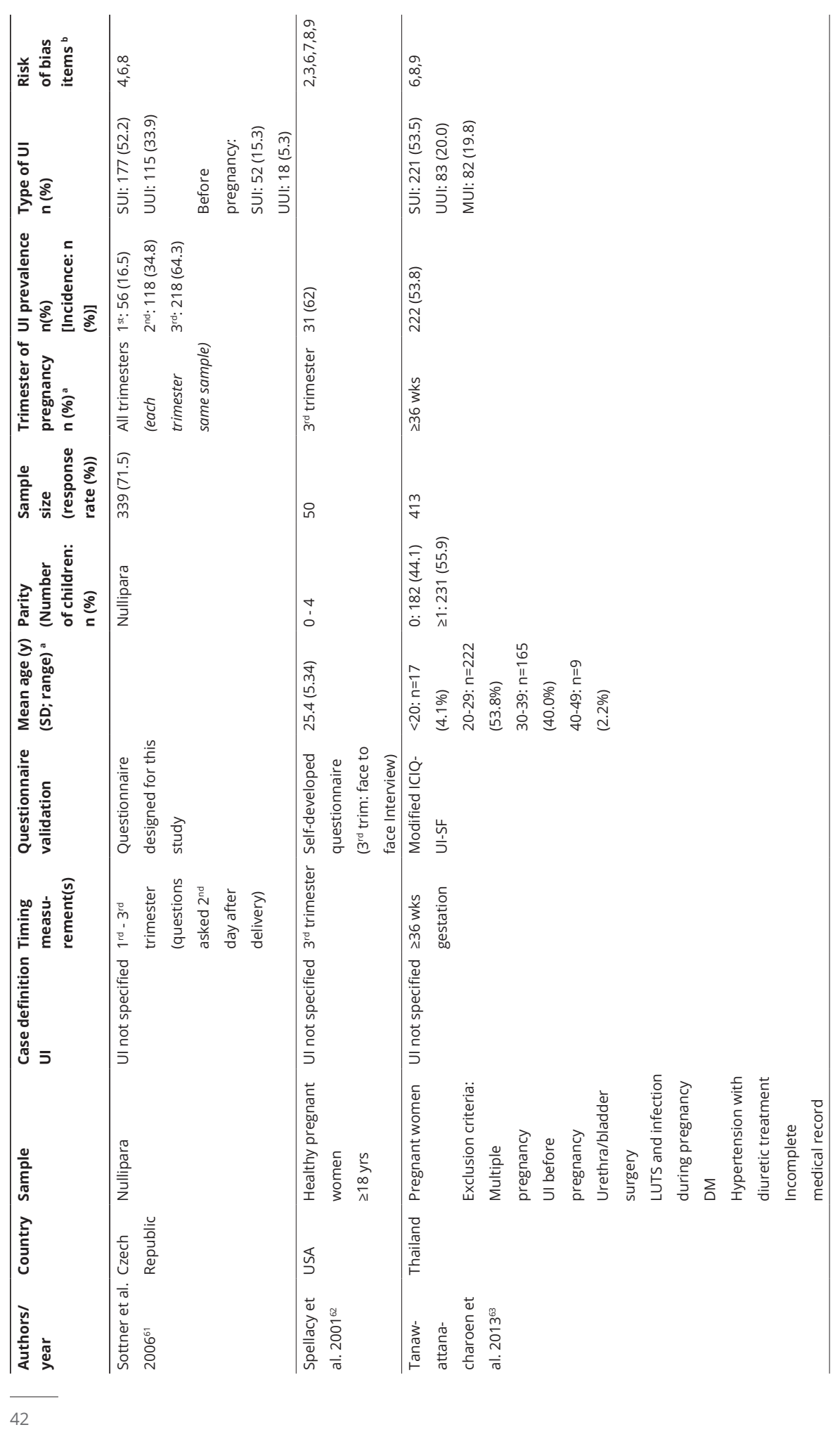




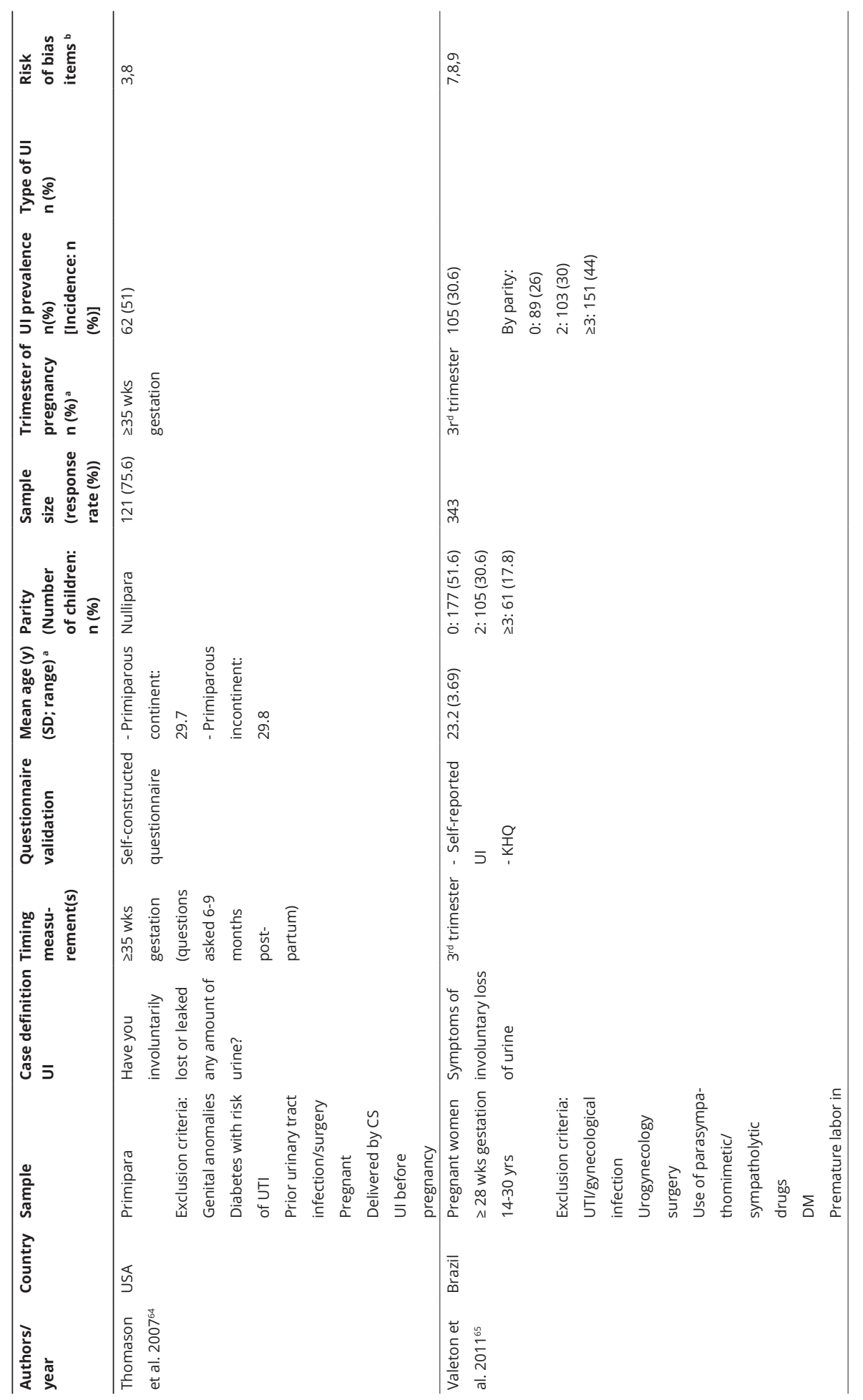




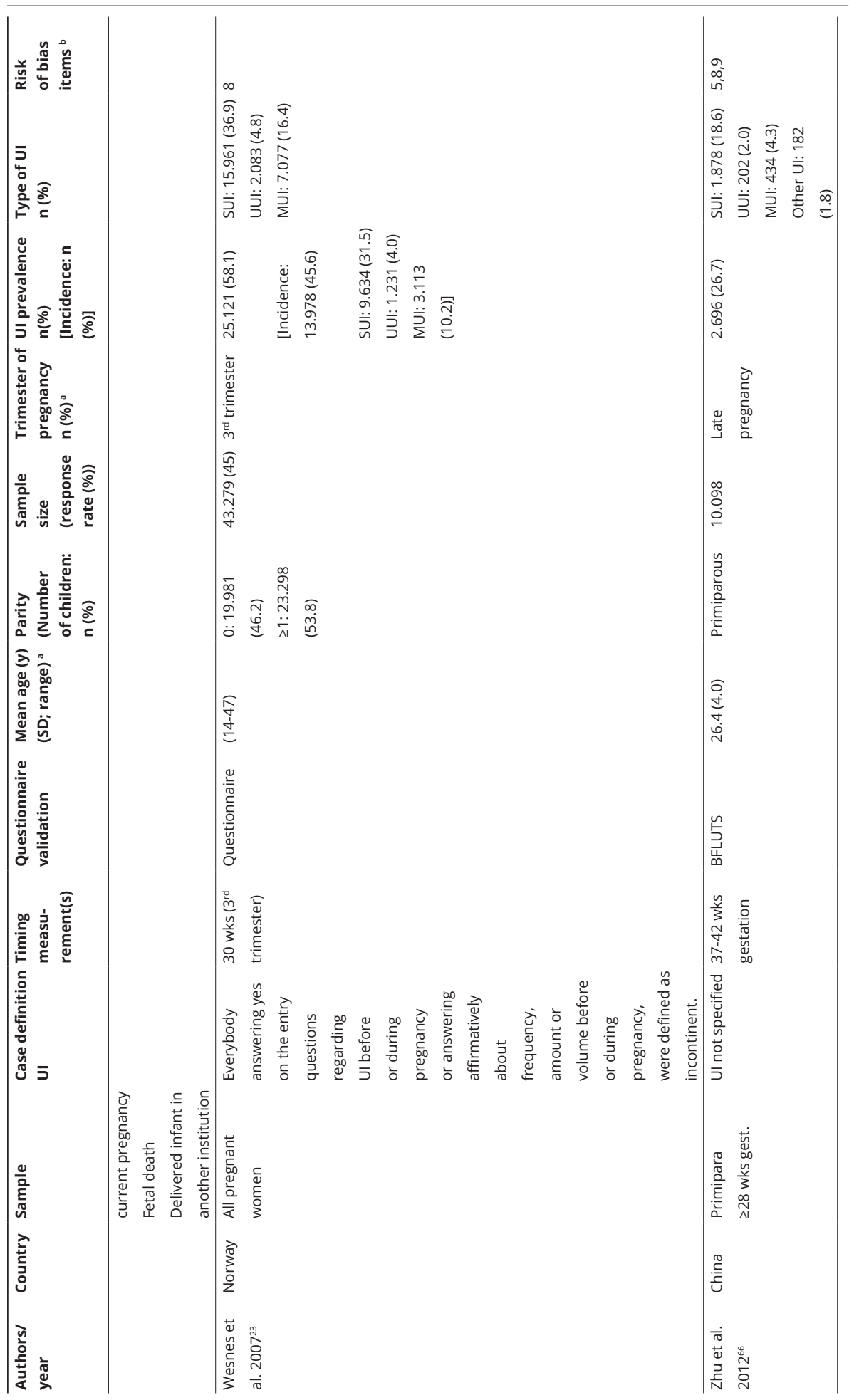




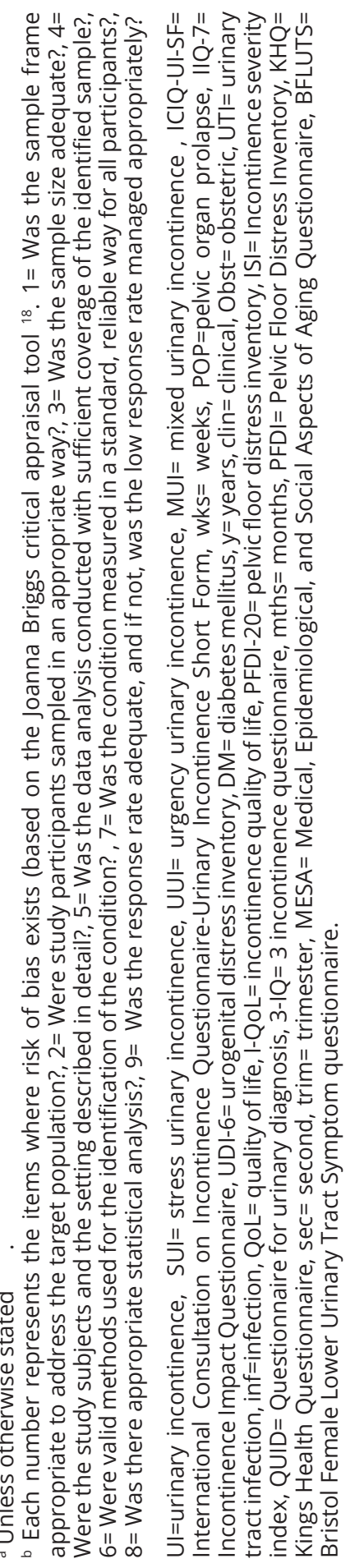


Table 2 Measurement of bother and results

\begin{tabular}{|c|c|c|c|c|c|}
\hline $\begin{array}{l}\text { Measurement } \\
\text { instrument }\end{array}$ & $\begin{array}{l}\text { Background } \\
\text { information on } \\
\text { measurement } \\
\text { instrument }\end{array}$ & Study & $\begin{array}{l}\text { Original } \\
\text { measurement } \\
\text { result (mean) }\end{array}$ & $\begin{array}{l}\text { Trimester/ } \\
\text { weeks }\end{array}$ & $\begin{array}{l}\text { (Converted) } \\
\text { measurement } \\
\text { results } \\
(0-100) \\
\end{array}$ \\
\hline \multirow{6}{*}{$\begin{array}{l}\text { ICIQ-UI SF } \\
(0-21)\end{array}$} & \multirow{6}{*}{$\begin{array}{l}\text { To assess symptoms } \\
\text { of UI and impact on } \\
\text { QoL. ( } 4 \text { questions, } \\
\text { question } 4 \text { is on } \\
\text { moment of UI and } \\
\text { is not within the } \\
\text { calculation of the } \\
\text { total). }\end{array}$} & 54 & 4.1 & AT & 19.3 \\
\hline & & 58 & 6.3 & $\begin{array}{l}\text { (28 wks +/- } 2 \\
\text { wks) T3 }\end{array}$ & 30.0 \\
\hline & & 44 & 12.1 & $\begin{array}{l}\text { (last } 4 \text { wks } \\
\text { pregn) } \\
\text { T3 }\end{array}$ & 57.6 \\
\hline & & 63 & 6.2 & T3 & 29.5 \\
\hline & & 73 & 6.6 & $\begin{array}{l}\text { (T1 and T3) } \\
\text { AT }\end{array}$ & 31.4 \\
\hline & & 26,27 & $\begin{array}{l}\text { Results } \\
\text { reported in } \\
\text { categories. No } \\
\text { total score. }\end{array}$ & & \\
\hline \multirow{4}{*}{$\begin{array}{l}\text { ICIQ-UI SF } \\
\text { Question } 3 \\
\text { (QoL) } \\
(0-10)\end{array}$} & \multirow{4}{*}{$\begin{array}{l}\text { Question } 3 \text { of the } \\
\text { ICIQ-UI SF is on the } \\
\text { interference in daily } \\
\text { life of UI. }\end{array}$} & 69 & Nulliparous 2.7 & AT & 26.7 \\
\hline & & & $\begin{array}{l}\text { Multiparous } \\
3.6\end{array}$ & AT & 35.8 \\
\hline & & & 3.1 & AT & 31.3 \\
\hline & & 72 & 3.5 & T3 & 34.8 \\
\hline $\mathrm{I-QOL}$ & $\begin{array}{l}\text { Quality of life } \\
\text { in persons with } \\
\text { UI. } 3 \text { subscales: } \\
\text { 1. Avoidance and } \\
\text { limiting behaviour, } \\
\text { 2. Psychosocial } \\
\text { impact, 3. Social } \\
\text { embarrassment. (22 } \\
\text { questions) }\end{array}$ & 67 & 82.4 & AT & 17.7 \\
\hline 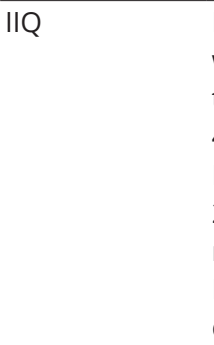 & $\begin{array}{l}\text { Interference of UI of } \\
\text { women's daily life and } \\
\text { the bothersomeness. } \\
4 \text { subscales: } 1 . \\
\text { Physical activity, } \\
\text { 2. Travel, } 3 \text {. Social } \\
\text { relationships, } 4 \text {. } \\
\text { Emotional health. (31 } \\
\text { questions) }\end{array}$ & 77 & $\begin{array}{l}9.5 \\
(\mathrm{~T} 1: 8.2, \mathrm{~T} 2: \\
\text { 7.1, T3: 13.3) }\end{array}$ & $\begin{array}{l}\text { AT (T1, T2, } \\
\text { T3) }\end{array}$ & 9.5 \\
\hline
\end{tabular}




\begin{tabular}{|c|c|c|c|c|c|}
\hline $\begin{array}{l}\text { Measurement } \\
\text { instrument }\end{array}$ & $\begin{array}{l}\text { Background } \\
\text { information on } \\
\text { measurement } \\
\text { instrument }\end{array}$ & Study & $\begin{array}{l}\text { Original } \\
\text { measurement } \\
\text { result (mean) }\end{array}$ & $\begin{array}{l}\text { Trimester/ } \\
\text { weeks }\end{array}$ & $\begin{array}{l}\text { (Converted) } \\
\text { measurement } \\
\text { results } \\
(0-100)\end{array}$ \\
\hline $\begin{array}{l}\text { Wagner's } \\
\text { quality of life } \\
\text { scale }\end{array}$ & $\begin{array}{l}\text { Questions on daily } \\
\text { lives and psychosocial } \\
\text { characteristics. ( } 28 \\
\text { questions) }\end{array}$ & 66 & 9.9 & AT & 11.8 \\
\hline $\begin{array}{l}\text { Self- } \\
\text { constructed } \\
\text { non-validated } \\
\text { questionnaire }\end{array}$ & & 28 & & & \\
\hline
\end{tabular}

ICIQ-UI SF= International Consultation on Incontinence Questionnaire -Urinary Incontinence Short Form, I-OOL= Incontinence Quality of Life, IIQ-7= Incontinence Impact Questionnaire, $\mathrm{N}=$ number, $\mathrm{AT}=\mathrm{All}$ trimesters, $\mathrm{T} 1=$ Trimester 1, T2= Trimester 2, T3= Trimester 3.

\section{Synthesis of results}

\section{Overall prevalence}

44 studies involving a total of 88.305 women were used to calculate the overall prevalence of UI. The weighted average of UI prevalence among pregnant women was 41.0\% (Cl 95\% 34.0-48.0\%; I2: 99.77\%), regardless of trimester, parity or type of UI (Figure 2). The lowest prevalence of UI found in the included studies was $9 \%$ and the highest prevalence $75 \%{ }^{56}$. Prevalence figures for low, moderate and high risk of bias studies were 38\% (95\% 18.0-58.0), $41 \%$ (95\% 36.0-46.0), 47\% (95\% 39.054.0) respectively.

\section{Subcategories trimester of pregnancy, type of $U I$ and parity}

Five out of the 44 studies included women from trimester one or two, or two out of three pregnancy trimesters. 15 studies recruited women from the third trimester, with an overall UI prevalence of 47\% (95\%-CI: 37.0-58.0\%). 24 studies recruited women from trimester 1-3, with an overall UI prevalence of 40\% (95\%-Cl: $34.0-$ $45.0 \%)$. Based on 24 studies, SUI accounts for $63 \%$ of UI cases, whereas UUI, MUI and unexplained UI, were $12 \%, 22 \%$ and $3 \%$ respectively.

When parity is taken into account, $42 \%$ of nulliparous women experience UI (based on 12 studies; 95\% Cl 33.0-51.0\%; ${ }^{2}=98.6 \%$ ), whereas 4 studies reporting only on primiparous women, found an overall UI prevalence of 31\% (95\% Cl 26.0$36.0 \%$; $I^{2}$ 90.6\%). 27 studies included women with any parity, resulting in a pooled prevalence of $42 \%$ (95\% Cl 32.0-53.0\%; I $^{2}$ 99.8\%). 
Based on 12 out of 44 studies, the overall prevalence for $\mathrm{UI}$ in trimesters 1, 2 and 3 is $9 \%\left(95 \% \mathrm{Cl} 6.0-12.0 \% ; \mathrm{I}^{2} 97.7 \%\right), 19 \%\left(95 \% \mathrm{Cl} 12.0-25.0 \% ; \mathrm{I}^{2} 98.7 \%\right)$ and $34 \%$ (95\% Cl 23.0-46.0\%; I $^{2}$ 99.0\%) respectively.

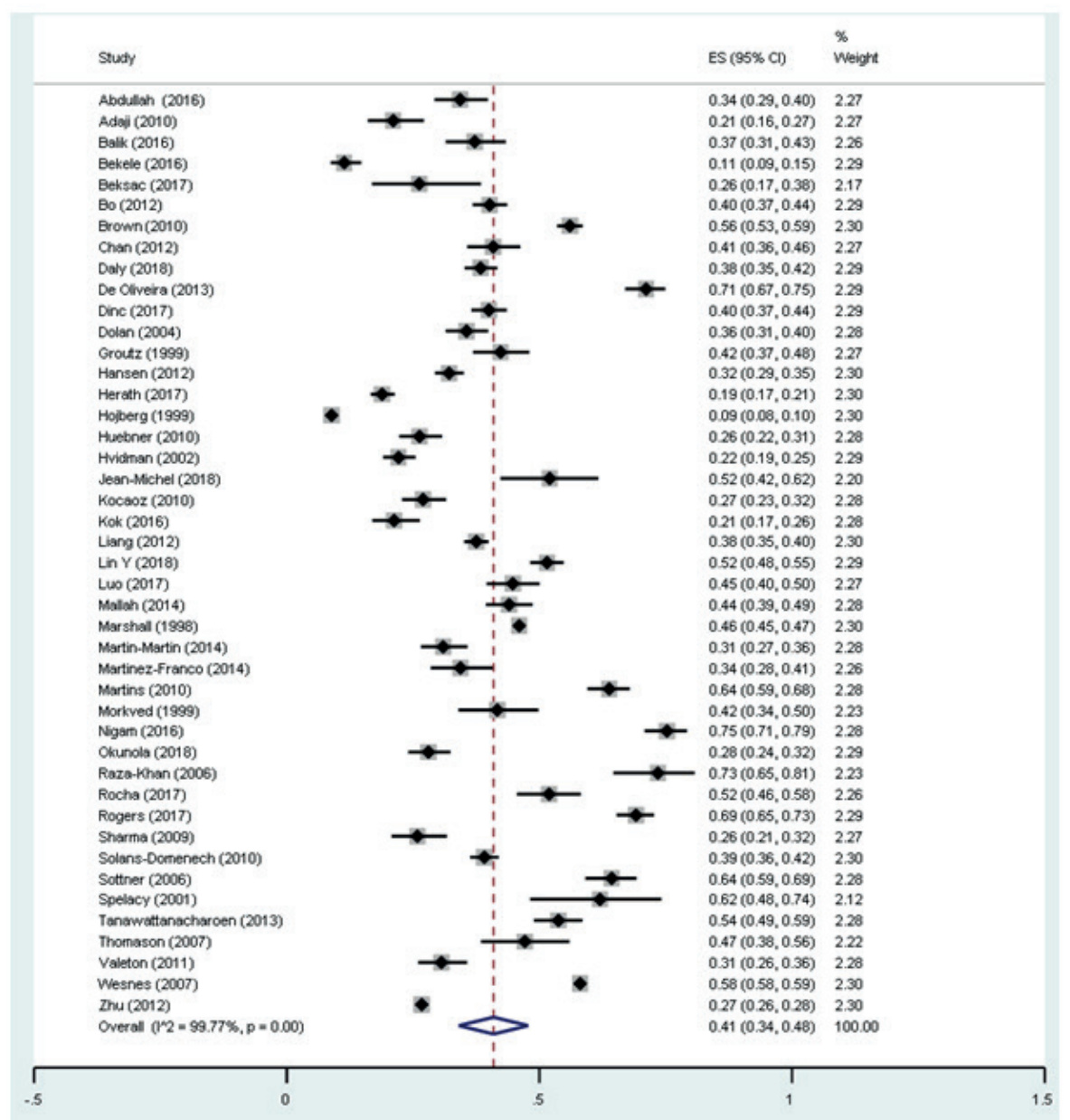

Figure 2 Pooled prevalence of UI during pregnancy

\section{Subcategories frequency and amount of $\mathrm{UI}$}

Based on 10 studies, monthly UI accounts for $40 \%$ of UI cases (95\% Cl 23.0-57.0\%; I2 99.0\%), weekly UI for 33\% (95\% CI 23.0-43.0\%; I2 94.8\%) and daily UI for 26\% (95\% Cl 20.0-32.0\%; $\left.\left.\right|^{2} 86.9 \%\right)$. 
The majority of studies ( $n=9)$, reporting on the amount of urine loss $(n=14)$, used the International Consultation on Incontinence Questionnaire - Urinary Incontinence Short Form (ICIQ-UI SF) to assess this parameter (none, small, moderate, large amount). ${ }^{67}$ Three studies reported separately the ICIQ-UI SF amount item, showing that the majority (79.2-86.9\%) of UI cases lose a small amount. Other descriptions of amount of urine lost were: drops or just a little, more like a trickle, more than a trickle ${ }^{34,36}$, a few droplets, a stream ${ }^{60}$ and drops, small splashes, more..$^{27,57}$

\section{Bother}

13 studies reported on impact on daily life, quality of life or bother. It was heterogeneously assessed, however the ICIQ-UI SF was used in the majority of studies ( $n=7$ ). In two studies question 3 of the ICIQ-UI SF on interference on daily life was reported as a measurement instrument for bother. Other measurement instruments that were used only once were the Incontinence Quality of Life (I-QOL), Incontinence Impact Questionnaire (IIQ-7), Wagner's quality of life questionnaire, and a self-constructed non-validated questionnaire. The overall bother of $\mathrm{UI}$ during pregnancy, on a 0 to 100 scale, ranges between 9.5 and 34.1, consistent with mild to moderate bother, whereas the experienced bother is higher in the $3^{\text {rd }}$ trimester (between 13.3 and 57.6) (Table 3).

\section{Case definition}

The majority of studies $(n=30)$ did not specify a case definition for UI. Four studies used as a case definition 'any leakage', or used a frequency ( $n=5)$, amount/ volume $(n=1)$, timeframe $(n=2)$ or UI type $(n=3)$ criteria in their case definition, or a combination of those $(n=3)$.

Table 3 Converted results $0-100$ by measurement instrument

\begin{tabular}{|c|c|c|c|c|}
\hline & $\begin{array}{l}\text { Total } \\
\text { (all instruments) }\end{array}$ & $\begin{array}{l}\text { ICIQ-UI SF } \\
\text { (total score) }\end{array}$ & $\begin{array}{l}\text { ICIQ-question } \\
3 \text { (QoL) }\end{array}$ & $\begin{array}{l}\text { Other measurement } \\
\text { instruments (I-Qol, IIQ-7, } \\
\text { Wagner's QoL) }\end{array}$ \\
\hline $\begin{array}{l}\text { All } \\
\text { trimesters }\end{array}$ & $\begin{array}{l}9.5 \text { - } 34.1 \text { (7 } \\
\text { studies) }\end{array}$ & $\begin{array}{l}19.3 \text { - } 31.4 \text { (2 } \\
\text { studies) }\end{array}$ & 31.3 (1 study) & 9.5 - 34.1 (3 studies) \\
\hline $\begin{array}{l}3^{\text {rd }} \\
\text { trimester }\end{array}$ & $\begin{array}{l}13.3-57.6 \text { (5 } \\
\text { studies) }\end{array}$ & $\begin{array}{l}29.5 \text { - } 57.6 \text { (3 } \\
\text { studies) }\end{array}$ & 34.8 (1 study) & 13.3 (1 study) \\
\hline
\end{tabular}

ICIQ-UI SF= International Consultation on Incontinence Questionnaire -Urinary Incontinence Short Form, I-QOL=Incontinence Quality of Life, IIQ-7= Incontinence Impact Questionnaire, wks $=$ weeks 


\section{Incidence}

Few studies have examined incidence of UI during pregnancy, using different trimesters of pregnancy and case definitions. Therefore no pooling was done for this outcome. Five studies reported on new-onset UI during pregnancy among women who were continent 12 months before the index pregnancy ${ }^{34,36}$ or who had no UI previous to pregnancy ${ }^{21,23,27}$. Daly et al. reported that $21.7 \%$ of nulliparous women experienced any new-onset urinary leakage in early pregnancy. ${ }^{36}$ The frequency of leakage among new-onset UI was less than once per month in 55\% of cases, on a monthly, weekly and daily basis in $26.7 \%, 13.3 \%$ and $5.0 \%$ of cases respectively. The majority (83.1\%) experienced drops or just a little amount of leakage. Brown et al. ${ }^{34}$ reported 146 incident cases for any $\mathrm{UI}$ in early pregnancy ( $\leq 24$ weeks of gestation; 16.4\%) compared to 561 cases in late pregnancy (31 weeks; 63.2\%). It appeared that new cases of SUI accounted for more than two thirds of prevalent cases in early and late pregnancy, $70.4 \%$ and $73.9 \%$, respectively. Hvidman et al. concluded that $\mathrm{UI}$ incidence during pregnancy was $16.8 \%$ among nulliparous and $8.4 \%$ among primiparous women. ${ }^{21}$ Overall, incidence rates in early pregnancy among nulliparous women range between $16.4 \%$ and $21.7 \% .{ }^{34,36}$ When considering late pregnancy, the incidence rate increases to $45.6-63.2 \% .23,34$ The incidence rate of UI during first pregnancy, regardless of trimester, is $16.8-39.1 \% .21,27$

\section{DISCUSSION}

The aim of this systematic review was to examine the pooled prevalence and incidence of $\mathrm{UI}$ during pregnancy and to provide an overview of measurement instruments, including the measurement results, to assess bother in relation to UI. The results show an overall mean prevalence of UI during pregnancy of $41 \%$, with a range of $9-75 \%$. The prevalence numbers rise with gestational period from $9 \%$ in the first trimester to $34 \%$ in the third. SUI is the most prevalent type of UI, accounting for $63 \%$ of cases. $26 \%$ of the women reported daily loss, whereas $40 \%$ reported loss on a monthly basis. Most of the cases reported a small amount of urine loss.

Incidence/new onset $\mathrm{UI}$ in nulliparous women in early pregnancy varied between $16.4 \%$ and $21.7 \%$. $^{34,36}$ This variation might be explained by the different case definition used for $\mathrm{UI}$ (e.g. any $\mathrm{UI}^{36}$ in contrast to $\mathrm{UI}$ at least once a month ${ }^{34}$ ). Incidence in late pregnancy increased to $63.2 \% .^{34}$ Over $70 \%$ of new onset UI was 
SUI. The high prevalence and rising incidence numbers of SUI during pregnancy might be due to several factors like physiological weight gain which results in increased intra-abdominal pressure on the bladder and pelvic floor muscles. ${ }^{68}$ Additionally, it is known that pregnant women with SUI have significant less pelvic floor muscle strength and thickness ${ }^{69}$ and/or a larger hiatal area at rest and during pelvic floor muscle contraction. ${ }^{70}$ But also previous childbirth and high body mass index are risk factors for developing SUI.71,72

Most included studies showed a moderate risk of bias. Although several factors influence reported prevalence rates, e.g. case definition, studies with moderate or high risk of bias may distort prevalence and/or incidence rates. The prevalence rate among three studies with high risk of bias is $47 \%$ compared to $38 \%$ among studies with low risk of bias (in studies with a moderate risk of bias the prevalence is $41 \%)$. As studies with a low risk of bias tend to have a slightly lower prevalence, it is likely that the real prevalence of UI in pregnant women is in the range of $38-41 \%$.

Only 13 out of 44 studies reported bother in relation to UI, these studies used a variety of measurement instruments. In an attempt to provide an overall assessment of experienced bother in relation to UI, we (arbitrarily) chose to standardize the measurement results of different bother scales to a 0 to 100 scale. Bother of UI during pregnancy ranges between 9.5 and 34.1 on a (standardized) 0 to 100 scale. The 0 to 100 scale can be regarded as a visual analogue scale (VAS). The VAS is a valid and reproducible method to measure the impact of UI on QOL. ${ }^{73}$ No studies are known that report on cut-off points for QOL in pregnant women with UI. Therefore, cut-off points must be interpreted cautiously. One study comparing the VAS with a measure that assesses the impact on functioning in patients with pain identified three classes. Class 1, mild interference (score 1 - 34), class 2, moderate interference (score 35 - 64), and class 3, severe interference with daily life (score 65 - 100). ${ }^{74}$ Based on these classes the overall bother of UI during pregnancy is mild, and in the third trimester mild to moderate. One study reporting on bother of $\mathrm{UI}$ in the last four weeks of pregnancy reported the highest bother of 57.45 This might be due to the rising prevalence over time in pregnancy. ${ }^{37,45,56,57,62-64}$

The ICI provides an overview of (recommended) grade A (high quality) measurement instruments for bother in relation to $\mathrm{UI}^{3}$ and advises to report prevalence figures 
in combination with the experienced bother. The ICIQ-UI SF, IIQ and I-QOL, for example, are rated as grade A measurement instruments. Wagner's QOL and the VAS are not incorporated in the ICI overview, nor is the separate use of question 3 of the ICIQ-UI SF as a bother measure. A closer look at the measurement instruments shows that there are differences with regard to assessed constructs and domains. The ICIQ-UI SF is a quick way to assess frequency, severity and bother of UI. The IIQ, I-QOL, and Wagner's QOL scale assess bother of UI with a variety of subscales like: psychosocial impact, social embarrassment, relations, and physical activity and provide therefore more in depth information.

This systematic review revealed that the reporting of prevalence with a measure of bother is not common practice yet. To improve the reporting of UI prevalence, it is recommended that in research projects both prevalence and bother are measured with high quality measurement instruments in line with the recommendations of $\mathrm{ICl}$. In clinical practice, measurement results of bother support healthcare professionals in the clinical reasoning process as it may provide information on diagnosis, prognosis or may evaluate one's own actions. At the same time, it standardizes communication with colleagues. Moreover, measurement results can be used to better inform patients about their situation and to involve them more easily in joint therapy decisions (shared decision making).

The construct bother in relation to UI seems difficult to grasp, as included studies used different definitions. The following terms were used: effect on daily activities/ everyday life, interference on daily life, health-related quality of life, severity, lifestyle changes, (perceived) impact on quality of life, distress, experienced discomfort and amount of bother. As the degree of bother is related to help-seeking behaviour for $\mathrm{UI}^{75,76}$ it is of importance to define the construct bother (what does bother in relation to UI mean for pregnant women) and quantify bother. When bother is well defined and quantified, this will support researchers in selecting the appropriate measurement instrument and interpretation of the results.

Based on the prevalence figures, it would appear that UI in pregnancy is an enormous healthcare problem. However, not everyone seeks (medical) help for UI immediately. Several factors determine help-seeking behaviour of pregnant women, such as awareness of treatment possibilities and the experienced burden of UI. ${ }^{76,77}$ Also the belief that UI will resolve by itself after delivery and the lack of knowledge that UI during pregnancy raises the odds for post-partum UI 
substantially obstructs help-seeking. ${ }^{78,79}$

Management of UI should be directed to women who seek help for UI, but may also be directed towards women who experience bother or have risk factors for developing UI (prevention). Such uncertainties require further evaluation and data on duration of treatment effects of PFM(G)T. ${ }^{80}$ Maternity care workers need to assess women for the presence, severity and bother of UI and, in consultation with them, develop a specially tailored plan of care to meet the women's needs.

The strength of this systematic review is the large number of included studies, which resulted in the availability of prevalence and incidence numbers for different subpopulation (countries, parity, trimester of pregnancy) and for different purposes (research planning, health care providers and policy makers). This review is the first one that focused on assessment methods for bother in relation to $\mathrm{UI}$ and degree of adherence to the recommendations of $\mathrm{ICI}$ with regard to this topic.

The limitations of this systematic review are, firstly, the presence of substantial clinical heterogeneity of the studies. Clinical heterogeneity is due to differences in: case definition (any UI or different frequencies of UI in a certain period of time), population (primigravida- multigravida) or periods researched (first, second, third trimester or any specific trimester). Secondly, the considerable statistical heterogeneity of the studies resulting in large Cl's. Thirdly, as the Joanna Briggs critical appraisal tool does not recommend cut-off points for high, moderate or low risk of bias, we arbitrarily chose the cut-off points reported in this systematic review to explore possible differences in prevalence numbers if stratified for risk of bias. However, we did not include or exclude studies based on risk of bias.

\section{CONCLUSION}

$\mathrm{UI}$ is a very common symptom in pregnancy and the prevalence rises as weeks of gestation progress. SUI is the most common type and in most of the cases a small amount of urine was lost. The level of bother for UI is heterogeneously assessed and is experienced as mild to moderate by pregnant women. 


\section{APPENDIX:}

\section{Search strategy for PubMed:}

(()(()(()(()(()((pregnancy[MeSH $\quad$ Terms]) $\quad$ OR $\quad$ pregnancy[Title/Abstract]) OR pregn*) OR prepartum[Title/Abstract]) OR 'pre-partum'[Title/Abstract]) OR ‘pre partum'[Title/Abstract]) OR peripartum[Title/Abstract]) OR 'peri-partum'[Title/ Abstract]) OR 'peri partum'[Title/Abstract]) OR nulliparous[Title/Abstract]) OR primiparous[Title/Abstract]) OR primigrav*[Title/Abstract]) OR primipar*[Title/ Abstract]) OR multiparous[Title/Abstract]) OR multigrav*[Title/Abstract]) OR multipar*[Title/Abstract])) AND (((c((()(('urinary incontinence'[MeSH Terms]) OR urinary incontinence title/abstract) OR 'urine loss'[Title/Abstract]) OR 'pelvic floor disorders'[MeSH Terms]) OR 'pelvic floor disorders'[Title/Abstract]) OR 'pelvic floor dysfunctions'[Title/Abstract])) OR incontinence[Title/Abstract])) OR 'leaking urine'[Title/Abstract]))) AND ((((()(((((prevalence[MeSH Terms]) OR prevalence[Title/ Abstract]) OR epidemiology[MeSH Terms]) OR epidemiology[Title/Abstract]) OR quality of life[MeSH Terms]) OR 'quality of life'[Title/Abstract]) OR bother*[Title/ Abstract]) OR bothersomeness[Title/Abstract])))))) 


\section{REFERENCES}

1. Haylen BT, de Ridder D, Freeman RM, et al. An International Urogynecological Association (IUGA)/International Continence Society (ICS) joint report on the terminology for female pelvic floor dysfunction. Int Urogynecol J. 2010;21(1):5-26.

2. Morkved S, Bo K, Schei B, Salvesen KA. Pelvic floor muscle training during pregnancy to prevent urinary incontinence: a single-blind randomized controlled trial. Obstet Gynecol. 2003;101(2):313-319.

3. Abrams A, Cardozo L, Wagg A, Wein A, eds. Incontinence 6th edition. Bristol, UK: ICI-ICS. International Continence Society; 2017.

4. Stafne SN, Salvesen K, Romundstad PR, Torjusen IH, Mørkved S. Does regular exercise including pelvic floor muscle training prevent urinary and anal incontinence during pregnancy? A randomised controlled trial. BJOG. 2012;119(10):1270-1280.

5. Botlero R, Davis SR, Urquhart DM, Shortreed S, Bell RJ. Age-specific prevalence of, and factors associated with, different types of urinary incontinence in community-dwelling Australian women assessed with a validated questionnaire. Maturitas. 2009;62(2):134139.

6. Boyle R, Hay-Smith EJ, Cody JD, Morkved S. Pelvic floor muscle training for prevention and treatment of urinary and faecal incontinence in antenatal and postnatal women. Cochrane Database Syst Rev. 2012;10:Cd007471.

7. Viktrup L, Rortveit G, Lose G. Risk of stress urinary incontinence twelve years after the first pregnancy and delivery. Obstet Gynecol. 2006;108(2):248-254.

8. Lin $\mathrm{YH}$, Chang SD, Hsieh WC, et al. Persistent stress urinary incontinence during pregnancy and one year after delivery; its prevalence, risk factors and impact on quality of life in Taiwanese women: An observational cohort study. Taiwan J Obstet Gynecol. 2018;57(3):340-345.

9. Bedretdinova D, Fritel X, Panjo H, Ringa V. Prevalence of Female Urinary Incontinence in the General Population According to Different Definitions and Study Designs. Eur Urol. 2016;69(2):256-264.

10. Lin $\mathrm{YH}$, Chang SD, Hsieh WC, et al. Persistent stress urinary incontinence during pregnancy and one year after delivery; its prevalence, risk factors and impact on quality of life in Taiwanese women: An observational cohort study. Taiwan J Obstet Gynecol. 2018;57(3):340-345.

11. Islam RM, Oldroyd J, Rana J, Romero L, Karim MN. Prevalence of symptomatic pelvic floor disorders in community-dwelling women in low and middle-income countries: a systematic review and meta-analysis. Int Urogynecol J. 2019.

12. Almousa $\mathrm{S}$, Bandin van Loon A. The prevalence of urinary incontinence in nulliparous adolescent and middle-aged women and the associated risk factors: A systematic review. Maturitas. 2018;107:78-83.

13. Teixeira RV, Colla C, Sbruzzi G, Mallmann A, Paiva LL. Prevalence of urinary incontinence in female athletes: a systematic review with meta-analysis. Int Urogynecol J. 2018;29(12):1717-1725.

14. Cetinel B, Demirkesen $O$, Tarcan $T$, et al. Hidden female urinary incontinence in urology and obstetrics and gynecology outpatient clinics in Turkey: what are the determinants 
of bothersome urinary incontinence and help-seeking behavior? Int Urogynecol J Pelvic Floor Dysfunct. 2007;18(6):659-664.

15. Hägglund D, Walker-Engström ML, Larsson G, Leppert J. Quality of life and seeking help in women with urinary incontinence. Acta Obstet Gynecol Scand. 2001;80(11):1051-1055.

16. Stroup DF, Berlin JA, Morton SC, et al. Meta-analysis of observational studies in epidemiology: a proposal for reporting. Meta-analysis Of Observational Studies in Epidemiology (MOOSE) group. JAMA. 2000;283(15):2008-2012.

17. (CPH) CPH. Data Extraction and Assessment Template. 2020; https://ph.cochrane.org/ review-authors.

18. Munn Z, Moola S, Riitano D, Lisy K. The development of a critical appraisal tool for use in systematic reviews addressing questions of prevalence. Int J Health Policy Manag. 2014;3(3):123-128.

19. Munn Z, Moola S, Lisy K, Riitano D, Tufanaru C. Methodological guidance for systematic reviews of observational epidemiological studies reporting prevalence and cumulative incidence data. Int J Evid Based Healthc. 2015;13(3):147-153.

20. J HJT, J C, Cumpston M LT, MJ P, (editors) WV. Cochrane Handbook for Systematic Reviews of Interventions version 6.0 (updated July 2019). 2019; www.training.cochrane.org/ handbook.

21. Hvidman L, Hvidman L, Foldspang A, Mommsen S, Bugge Nielsen J. Correlates of urinary incontinence in pregnancy. Int Urogynecol J Pelvic Floor Dysfunct. 2002;13(5):278-283.

22. Herath INS, Balasuriya A, Sivayogan S. Physical and psychological morbidities among selected antenatal females in Kegalle district of Sri Lanka: A cross sectional study. J Obstet Gynaecol. 2017;37(7):849-854.

23. Wesnes SL, Rortveit G, Bø K, Hunskaar S. Urinary incontinence during pregnancy. Obstet Gynecol. 2007;109(4):922-928.

24. Balik G, Guven ES, Tekin YB, et al. Lower Urinary Tract Symptoms and Urinary Incontinence During Pregnancy. Low Urin Tract Symptoms. 2016;8(2):120-124.

25. Bø K, Pauck øglund G, Sletner L, Mørkrid K, Jenum A. The prevalence of urinary incontinence in pregnancy among a multi-ethnic population resident in Norway. BJOG: 2012;119(11):1354-1360.

26. Okunola TO, Olubiyi OA, Omoya S, Rosiji B, Ajenifuja KO. Prevalence and risk factors for urinary incontinence in pregnancy in Ikere-Ekiti, Nigeria. Neurourol Urodyn. 2018;37(8):2710-2716.

27. Solans-Domènech $M$, Sánchez $E$, Espuña-Pons $M$. Urinary and anal incontinence during pregnancy and postpartum: incidence, severity, and risk factors. Obstet Gynecol. 2010;115(3):618-628.

28. Abdullah B, Ayub SH, Mohd Zahid AZ, Noorneza AR, Isa MR, Ng PY. Urinary incontinence in primigravida: the neglected pregnancy predicament. Eur J Obstet Gynecol Reprod Biol. 2016;198:110-115.

29. Adaji SE, Shittu OS, Bature SB, Nasir S, Olatunji O. Suffering in silence: pregnant women's experience of urinary incontinence in Zaria, Nigeria. Eur J Obstet Gynecol Reprod Biol. 2010;150(1):19-23.

30. Balik G, Güven ES, Tekin YB, et al. Lower Urinary Tract Symptoms and Urinary Incontinence During Pregnancy. Low Urin Tract Symptoms. 2016;8(2):120-124. 
31. Bekele A, Adefris M, Demeke S. Urinary incontinence among pregnant women, following antenatal care at University of Gondar Hospital, North West Ethiopia. BMC Pregnancy Childbirth. 2016;16(1):333.

32. Beksac AT, Aydin E, Orhan C, Karaagaoglu E, Akbayrak T. Gestational Urinary Incontinence in Nulliparous Pregnancy- A Pilot Study.J Clin Diagn Res. 2017;11(8):Qc01-qc03.

33. Bo K, Oglund G, Sletner L, Morkrid K, Jenum A. The prevalence of urinary incontinence among a multi-ethnic population resident in Norway. BJOG. 2012(119):1354-1360.

34. Brown SJ, Donath S, MacArthur C, McDonald EA, Krastev AH. Urinary incontinence in nulliparous women before and during pregnancy: prevalence, incidence, and associated risk factors. Int Urogynecol J. 2010;21(2):193-202.

35. Chan SS, Cheung RY, Yiu KW, Lee LL, Chung TK. Prevalence of urinary and fecal incontinence in Chinese women during and after their first pregnancy. Int Urogynecol J. 2013;24(9):1473-1479.

36. Daly D, Clarke M, Begley C. Urinary incontinence in nulliparous women before and during pregnancy: prevalence, incidence, type, and risk factors. Int Urogynecol J. 2018;29(3):353362.

37. Oliveira C, Seleme M, Cansi PF, et al. Urinary incontinence in pregnant women and its relation with socio-demographic variables and quality of life. Rev Assoc Med Bras (1992). 2013;59(5):460-466.

38. Dinç A. Prevalence of Urinary Incontinence During Pregnancy and Associated Risk Factors. Low Urin Tract Symptoms. 2018;10(3):303-307.

39. Dolan LM, Walsh D, Hamilton S, Marshall K, Thompson K, Ashe RG. A study of quality of life in primigravidae with urinary incontinence. Int Urogynecol J Pelvic Floor Dysfunct. 2004;15(3):160-164.

40. Groutz A, Gordon D, Keidar R, et al. Stress urinary incontinence: prevalence among nulliparous compared with primiparous and grand multiparous premenopausal women. Neurourol Urodyn. 1999;18(5):419-425.

41. Hansen BB, Svare J, Viktrup L, Jorgensen T, Lose G. Urinary incontinence during pregnancy and 1 year after delivery in primiparous women compared with a control group of nulliparous women. Neurourol Urodyn. 2012;31(4):475-480.

42. Herath INS, Balasuriya A, Sivayogan S. Physical and psychological morbidities among selected antenatal females in Kegalle district of Sri Lanka: A cross sectional study. J Obstet Gynaecol. 2017;37(7):849-854.

43. Hojberg KE, Salvig JD, Winslow NA, Lose G, Secher NJ. Urinary incontinence: prevalence and risk factors at 16 weeks of gestation. Br J Obstet Gynaecol. 1999;106(8):842-850.

44. Huebner M, Antolic A, Tunn R. The impact of pregnancy and vaginal delivery on urinary incontinence. Int J Gynaecol Obstet. 2010;110(3):249-251.

45. Jean-Michel M, Kroes J, Marroquin GA, Chau EM, Salafia CM, Mikhail M. Urinary Incontinence in Pregnant Young Women and Adolescents: An Unrecognized At-Risk Group. Female Pelvic Med Reconstr Surg. 2018;24(3):232-236.

46. Kocaoz S, Talas MS, Atabekoglu CS. Urinary incontinence in pregnant women and their quality of life. J Clin Nurs. 2010;19(23-24):3314-3323. 
47. Kok G, Seven M, Guvenc G, Akyuz A. Urinary Incontinence in Pregnant Women: Prevalence, Associated Factors, and Its Effects on Health-Related Quality of Life.J Wound Ostomy Continence Nurs. 2016;43(5):511-516.

48. Liang CC, Chang SD, Lin SJ, Lin YJ. Lower urinary tract symptoms in primiparous women before and during pregnancy. Arch Gynecol Obstet. 2012;285(5):1205-1210.

49. Luo $D, C h e n ~ L, Y u X$, et al. Differences in urinary incontinence symptoms and pelvic floor structure changes during pregnancy between nulliparous and multiparous women. PeerJ. 2017;5:e3615.

50. Mallah F, Tasbihi P, Navali N, Azadi A. Urinary Incontinence During Pregnance and Postpartum Incidence, Severity and Risk Factors in Alzahra and Taleqani Hospitals in Tabriz, Iran 2011-2012. IJWHR. 2014;2(3):178-185.

51. Marshall K, Thompson KA, Walsh DM, Baxter GD. Incidence of urinary incontinence and constipation during pregnancy and postpartum: survey of current findings at the Rotunda Lying-In Hospital. Br J Obstet Gynaecol. 1998;105(4):400-402.

52. Martin-Martin S, Pascual-Fernandez A, Alvarez-Colomo C, Calvo-Gonzalez R, MuñozMoreno M, Cortiñas-Gonzalez JR. Urinary incontinence during pregnancy and postpartum. Associated risk factors and influence of pelvic floor exercises. Arch Esp Urol. 2014;67(4):323-330.

53. Martínez Franco E, Parés D, Lorente Colomé N, Méndez Paredes JR, Amat Tardiu L. Urinary incontinence during pregnancy. Is there a difference between first and third trimester? Eur J Obstet Gynecol Reprod Biol. 2014;182:86-90.

54. Martins G, Soler ZA, Cordeiro JA, Amaro JL, Moore KN. Prevalence and risk factors for urinary incontinence in healthy pregnant Brazilian women. Int Urogynecol J. 2010;21(10):1271-1277.

55. Morkved S, Bo K. Prevalence of Urinary Incontinence During Pregnancy and Postpartum. Int Urogynecol J. 1999(10):394-398.

56. Nigam A, Ahmad A, Gaur D, Elahi A, Batra S. Prevalence and risk factors for urinary incontinence in pregnant women in late third trimester. IJRCOG. 2016;5(7):2187-2191.

57. Raza-Khan F, Graziano S, Kenton K, Shott S, Brubaker L. Peripartum urinary incontinence in a racially diverse obstetrical population. Int Urogynecol J Pelvic Floor Dysfunct. 2006;17(5):525-530.

58. RochaJ, Brandão P, Melo A, Torres S, Mota L, Costa F. [Assessment of Urinary Incontinence in Pregnancy and Postpartum: Observational Study]. Acta Med Port. 2017;30(7-8):568572.

59. Rogers RG, Ninivaggio C, Gallagher K, Borders AN, Qualls C, Leeman LM. Pelvic floor symptoms and quality of life changes during first pregnancy: a prospective cohort study. Int Urogynecol J. 2017;28(11):1701-1707.

60. Sharma JB, Aggarwal S, Singhal S, Kumar S, Roy KK. Prevalence of urinary incontinence and other urological problems during pregnancy: a questionnaire based study. Arch Gynecol Obstet. 2009;279(6):845-851.

61. Sottner O, Zahumenski J, Krcmar M, et al. Urinary Incontinence in a Group of Primiparous Women in the Czech Republic. Gynecol Obstet Invest. 2006; (62):33-47.

62. Spellacy C. Urinary Incontinence in Pregnancy and Puerperium. JOGNN. 2001;30(6):634641. 
63. Tanawattanacharoen S, Thongtawee S. Prevalence of urinary incontinence during the late third trimester and three months postpartum period in King Chulalongkorn Memorial Hospital. J Med Assoc Thai. 2013;96(2):144-149.

64. Thomason AD, Miller JM, Delancey JO. Urinary incontinence symptoms during and after pregnancy in continent and incontinent primiparas. Int Urogynecol J Pelvic Floor Dysfunct. 2007;18(2):147-151.

65. Valeton $\mathrm{CT}$, do Amaral VF. Evaluation of urinary incontinence in pregnancy and postpartum in Curitiba Mothers Program: a prospective study. Int Urogynecol J. 2011;22(7):813-818

66. Zhu L, Li L, Lang JH, Xu T. Prevalence and risk factors for peri- and postpartum urinary incontinence in primiparous women in China: a prospective longitudinal study. Int Urogynecol J. 2012;23(5):563-572.

67. Avery K, Donovan J, Peters TJ, Shaw C, Gotoh M, Abrams P. ICIQ: a brief and robust measure for evaluating the symptoms and impact of urinary incontinence. Neurourol Urodyn. 2004;23(4):322-330.

68. Lambert DM, Marceau S, Forse RA. Intra-abdominal pressure in the morbidly obese. Obes Surg. 2005;15(9):1225-1232.

69. Mørkved S, Salvesen KA, Bø K, Eik-Nes S. Pelvic floor muscle strength and thickness in continent and incontinent nulliparous pregnant women. Int Urogynecol J Pelvic Floor Dysfunct. 2004;15(6):384-389; discussion 390.

70. van Veelen A, Schweitzer K, van der Vaart H. Ultrasound assessment of urethral support in women with stress urinary incontinence during and after first pregnancy. Obstet Gynecol. 2014;124(2 Pt 1):249-256.

71. Swenson CW, Kolenic GE, Trowbridge ER, et al. Obesity and stress urinary incontinence in women: compromised continence mechanism or excess bladder pressure during cough? Int Urogynecol J. 2017;28(9):1377-1385.

72. MacLennan AH, Taylor AW, Wilson DH, Wilson D. The prevalence of pelvic floor disorders and their relationship to gender, age, parity and mode of delivery. BJOG. 2000;107(12):1460-1470.

73. Stach-Lempinen B, Kujansuu E, Laippala P, Metsänoja R. Visual analogue scale, urinary incontinence severity score and $15 \mathrm{D}$--psychometric testing of three different healthrelated quality-of-life instruments for urinary incontinent women. Scand J Urol Nephrol. 2001;35(6):476-483.

74. Boonstra AM, Schiphorst Preuper HR, Balk GA, Stewart RE. Cut-off points for mild, moderate, and severe pain on the visual analogue scale for pain in patients with chronic musculoskeletal pain. Pain. 2014;155(12):2545-2550.

75. Papanicolaou S, Hunskaar S, Lose G, Sykes D. Assessment of bothersomeness and impact on quality of life of urinary incontinence in women in France, Germany, Spain and the UK. BJU Int. 2005;96(6):831-838.

76. Kinchen KS, Burgio K, Diokno AC, Fultz NH, Bump R, Obenchain R. Factors associated with women's decisions to seek treatment for urinary incontinence. J Womens Health (2002). 2003;12(7):687-698.

77. Mason L, Glenn S, Walton I, Hughes C. Women's reluctance to seek help for stress incontinence during pregnancy and following childbirth. Midwifery. 2001;17(3):212-221. 
78. Burgio KL, Zyczynski H, Locher JL, Richter HE, Redden DT, Wright KC. Urinary incontinence in the 12-month postpartum period. Obstet Gynecol. 2003;102(6):1291-1298.

79. Gartland D, MacArthur C, Woolhouse H, McDonald E, Brown SJ. Frequency, severity and risk factors for urinary and faecal incontinence at 4 years postpartum: a prospective cohort. BJOG. 2016;123(7):1203-1211.

80. Woodley SJ, Lawrenson P, Boyle R, et al. Pelvic floor muscle training for preventing and treating urinary and faecal incontinence in antenatal and postnatal women. Cochrane Database Syst Rev. 2020;5:Cd007471. 


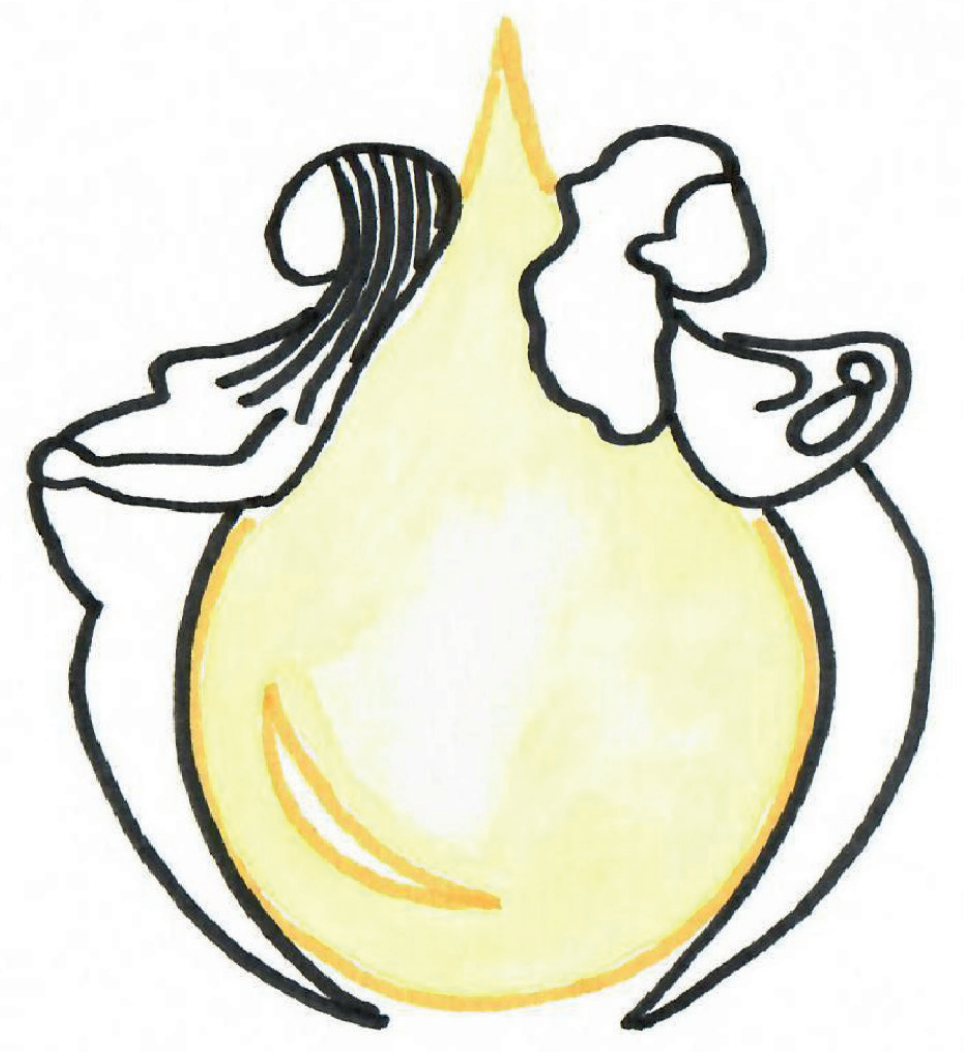




\title{
PREVALENCE, INCIDENCE AND BOTHERSOMENESS OF URINARY INCONTINENCE BETWEEN 6 WEEKS AND 1 YEAR POST-PARTUM: A SYSTEMATIC REVIEW AND META-ANALYSIS
}

Heidi F.A. Moossdorff-Steinhauser ${ }^{1}$ Bary C.M. Berghmans ${ }^{2}$ Marc E.A. Spaanderman ${ }^{3}$ Esther M.J. Bols ${ }^{1}$

\begin{abstract}
${ }^{1}$ Maastricht University, Faculty of Health, Medicine and Life Sciences, Dept. Epidemiology, CAPHRI Care and Public Health Research Institute, P.O. Box 616, 6200 MD Maastricht, The Netherlands; ${ }^{2}$ Pelvic care Center Maastricht, CAPHRI, Maastricht University Medical Centre (MUMC+), Maastricht, The Netherlands ${ }^{3}$ Department of Obstetrics and Gynecology, MUMC+, The Netherlands
\end{abstract}




\section{ABSTRACT}

Introduction: Urinary incontinence (UI) is a common complaint for post-partum women. Reported prevalence and incidence figures show a large range, due to varying study methodology. The crude prevalence of post-partum UI may differ when accounting for bother. Precise prevalence and incidence figures on (bothersome) UI are of relevance for health care providers, research planning, and policy makers. Therefore, we conducted a systematic review and metaanalysis to investigate the prevalence and incidence of $\mathrm{UI}$ in post-partum women in the Western world, for relevant subgroups and assessed experienced bother in relation to UI.

Methods: Observational studies, published between January 1998 and March 2020, and reporting on prevalence and incidence between 6 weeks and 1 year post-partum were included, regardless of type of UI or setting. We used a random effects model with subgroup analyses for post-partum period, parity, and subtype of UI.

Results: The mean (weighted) prevalence based on 24 included studies, containing a total of 35.064 women, was 31.0\%. After an initial drop in prevalence at 3 months post-partum, prevalence rises up to nearly the same level as in the third trimester of pregnancy at 1 year post-partum (32\%). Stress UI (54\%) is the most prevalent type. UI prevalence is equal amongst primi- and multiparous women. Experienced bother of $\mathrm{UI}$ is heterogeneously assessed and reported to be mild to moderate.

Conclusions: UI post-partum is highly prevalent in women in the Western world. After an initial drop it rises again at 1 year post-partum. Experienced bother is mild to moderate. 


\section{INTRODUCTION}

Urinary incontinence (UI) is the complaint of involuntary loss of urine. ${ }^{1}$ The main subtypes of UI are stress (S)UI, urgency (U)UI, and mixed (M)UI. SUI is leaking urine when coughing or sneezing. ${ }^{1} \mathrm{SUI}$ is more common in younger women. ${ }^{2}$ Pregnancy and vaginal delivery are well-documented risk factors for developing UI. ${ }^{3-5} 73 \%$ of women with UI 3 months post-partum still report UI at 6 years post-partum. ${ }^{6}$ In general, UI prevalence and incidence rise with ageing. ${ }^{7}$ Women often experience $\mathrm{UI}$ as embarrassing and humiliating, resulting in loss in quality of life. ${ }^{8} \mathrm{UI}$ also causes considerable socio-economic costs. ${ }^{9,10}$

The prevalence and incidence of UI in the post-partum period are widely studied. However, these prevalence and/or incidence figures vary greatly throughout published reports, depending on local setting, case definitions applied, recruited population (period post-partum and parity), and study methodology. ${ }^{11,12} \mathrm{~A}$ systematic review on the prevalence of post-partum UI and the relation to the mode of delivery was published in $2010 .{ }^{13}$ At that time, studies hardly reported on bother. In 2017 the International Consultation on Incontinence (ICI) recommended that prevalence numbers should be accompanied by the experienced bother ${ }^{14}$, as there are indications that the prevalence of bothersome $\mathrm{UI}$ is lower than the crude UI prevalence. ${ }^{14}$ As women with bothersome UI tend to seek more help ${ }^{15}$, health professionals, policy makers and researchers need reliable prevalence numbers to specify the health problem UI causes and to help set priorities and assist in planning the management of UI.

Therefore, the primary aim of this systematic review and meta-analysis was to examine the pooled overall prevalence and incidence of UI between 6 weeks and 1 year post-partum in the general population of the Western world, specified for relevant subcategories (period post-partum, parity, type of UI, frequency and amount). A secondary aim was to provide an overview of the assessment methods and outcomes for bother in relation to UI as used in included studies.

\section{METHODS}

The MOOSE statement for reporting systematic reviews and meta-analyses was followed. ${ }^{16}$ The research protocol was published in the PROSPERO database (registration number CRD42018111991). 


\section{Search strategy}

We performed a systematic review and meta-analysis of observational studies (cross-sectional and cohort studies) reporting on the prevalence and incidence of UI after delivery and experienced bother. We searched the electronic databases of PubMed, EMBASE and CINAHL. All included articles were reference checked. Titles and/or abstracts of studies retrieved using the search strategy and those from additional sources were screened independently by two reviewers. Full text of potentially eligible studies were retrieved and independently assessed for eligibility by two review team members. Any disagreement on eligibility was resolved through discussion with a third reviewer.

We used the following search terms to search all databases: postpartum, postpartum, post partum, peripartum, peri-partum, peri partum, primiparous, multiparous, multigrav*, multipar*, urinary incontinence, urine loss, leaking urine, incontinence, prevalence, incidence, epidemiology, frequency, bothersomeness, bother*, quality of life, hindrance. In the Appendix the complete search strategy for PubMed is provided. This search string was adapted for use in the other databases.

\section{Eligibility criteria}

Observational studies published between January 1, 1998 and March 1, 2020 in Dutch, English, German and French were included. All studies examining prevalence and/or incidence of UI from 6 weeks to 12 months post-partum among adult primiand multiparous women in the Western world, regardless of type of UI and setting were of interest. Six weeks post-partum was chosen to ensure a large proportion of the sample to have recovered physiologically from the delivery. Outcomes of interest were prevalence and/or incidence of (bothersome) UI. Exclusion criteria were: articles not available in full or not reporting an overall UI prevalence and/or incidence of any frequency, studies examining only twin pregnancies and studies originating from non-Western countries. The latter criteria were chosen for the purpose of homogeneity in population characteristics. When articles did not report a prevalence figure or response rate, an attempt was made for estimation from the information provided. Throughout this article we use the term bother (in relation to $\mathrm{UI}$ ) as umbrella term for related constructs (impact on daily life or quality of life (QOL)). 


\section{Study selection}

Titles and/or abstracts of studies retrieved using the search strategy and those from additional sources were screened independently by two reviewers (HM and EB) to identify studies that potentially meet the inclusion criteria outlined above. The full text of these potentially eligible studies were retrieved and independently assessed for eligibility by these two reviewers. Any disagreement on eligibility was resolved through discussion with a third reviewer (BB). All the included articles were reference checked.

\section{Data extraction and risk of bias}

Information on each study was extracted in a standardised data extraction form, based on the Cochrane Public Health Data Extraction and Assessment template. ${ }^{17}$ To assess the risk of bias, the Joanna Briggs critical appraisal tool for studies reporting prevalence data was used. ${ }^{18,19}$ The checklist consists of nine questions, with the response options yes, no, unclear or not applicable. Overall risk of study bias was rated as low (defined as 8-9 criteria answered as 'yes'), moderate (4-7 criteria answered as 'yes') or high risk ( $\leq 3$ criteria answered as 'yes'). The response option not applicable (occasionally scored in criteria 5 ) was considered to be a 'yes'. Two reviewers (HM, EB) extracted data independently. Inconsistencies were identified and resolved through discussion including a third author (BB) if necessary.

Characteristics regarding measurement instruments for bother were extracted in a separate standardised extraction form. The form contains items like measurement instrument, related construct and measurement results.

\section{Summary measures, statistical analyses and heterogeneity}

We used a random effects model to pool the inverse variance (IV) weighted prevalence of $\mathrm{UI}$ in individuals to avoid undue influence on the summary estimate from smaller and less precise studies or studies with a very small prevalence. Pooled prevalence and incidence values were reported with $95 \%$ confidence intervals $(\mathrm{Cl})$. The degree of heterogeneity was determined by the $\mathrm{I}^{2}$ statistic, with $\mathrm{I}^{2}>75 \%$ labelled as high heterogeneity. ${ }^{20}$ 
Prevalence was studied by subgroup [post-partum period ( 6 weeks, 3, 6, 9 and 12 months), type and frequency of $\mathrm{UI}$, and parity (primi- and multiparous)] as this might explain why studies show varying prevalence figures. ,. Studies reporting on a post-partum period other than the five established periods are classified in the closest post-partum period. Moreover, studies reporting a period prevalence (e.g. 9-12 months post-partum) are classified in the upper range of the period prevalence (i.e. 12 months), as most women will most likely report on their current status, which is less prone to recall bias. Incidence is reported in two periods: from delivery up to and including 3 months post-partum and from 3 to 12 months post-partum and for primi- and multiparous women. STATA Statistical Software, release 15 , was used for analysis.

In order to determine the overall experienced bother in relation to $\mathrm{UI}$ across included studies, the measurement results of the different measurement instruments for bother were converted -where possible- to a (standardized) 0 to 100 scale, with 0 indicating no bother and 100 indicating extremely bothered. We classified 1 to 20 as no to mild bother, 20 to 40 as mild to moderate bother, 40 to 60 as moderate to severe, 60 to 80 as severe to very severe, and 80 to 100 as extremely severe bother. We used the following conversion method for the ICIQUI SF (range 0-21): Converted score=observed original score * 4.76 (the value 4.76 is derived from 100 (upper limit converted score) / 21 (upper limit original score). Likewise, question 3 from the ICIQ-UI SF (range 0-10) is calculated as follows: converted score=observed original score * 10 .

\section{RESULTS}

\section{Study selection}

Among the 1063 papers initially identified, 31 met the eligibility criteria (Figure 1), resulting in a total of 38.209 participants. All included studies were observational and published between 1998 and March 1, 2020. Studies were excluded based on inadequate study design, study population, non-Western countries, outcome, follow-up or language. 29 studies reported on prevalence and/or incidence figures and two studies only reported on incidence figures. 


\section{Risk of bias}

The risk of bias for each study is shown in Table 1. High, moderate and low risk of bias was considered to be present in 1, 26 and 4 studies respectively. Risk-of-bias items with the lowest ratings were 8 and 9, and risk-of-bias items with the highest ratings were 1 and 3 .

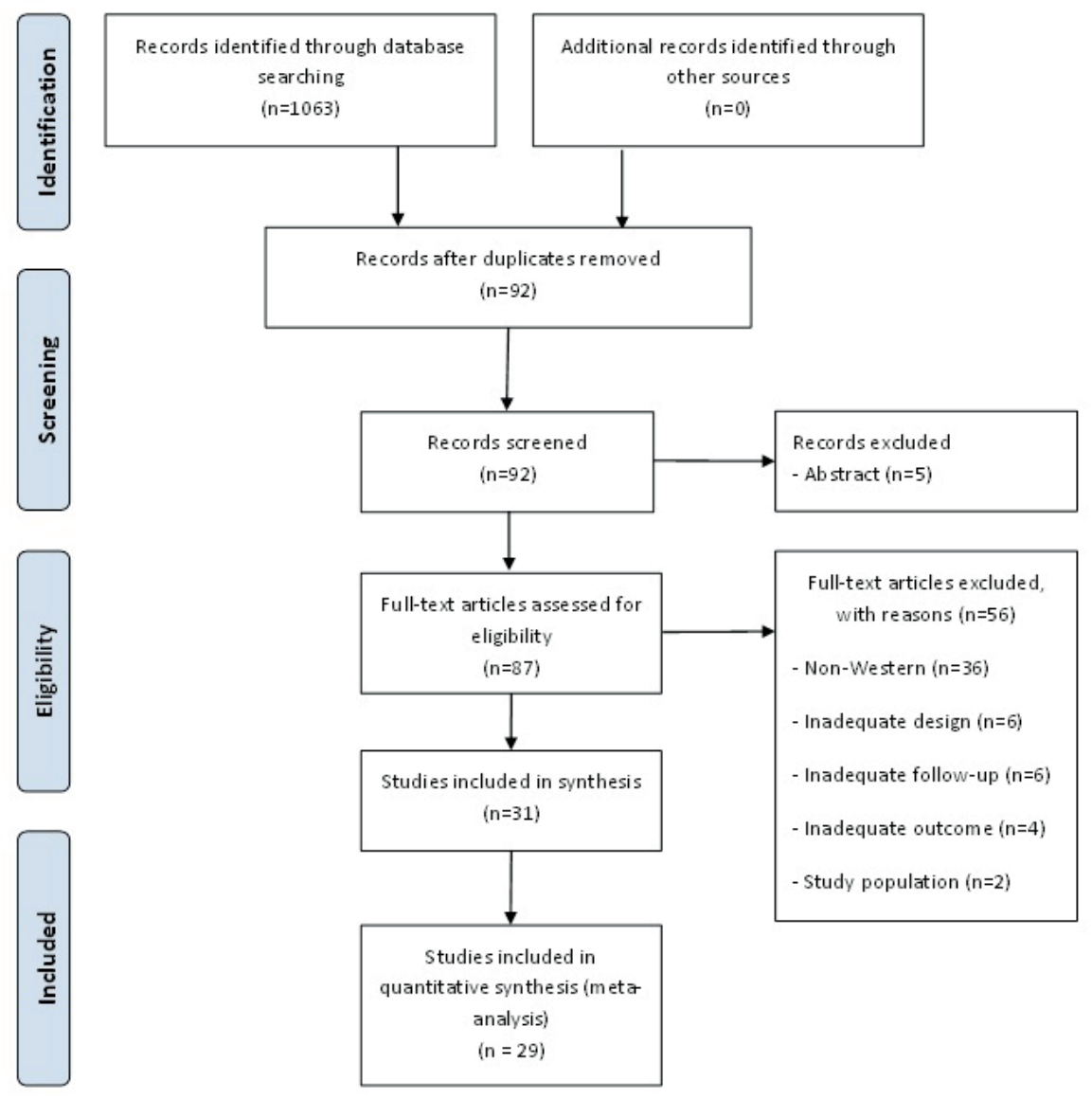

Figure 1 Study flow diagram 


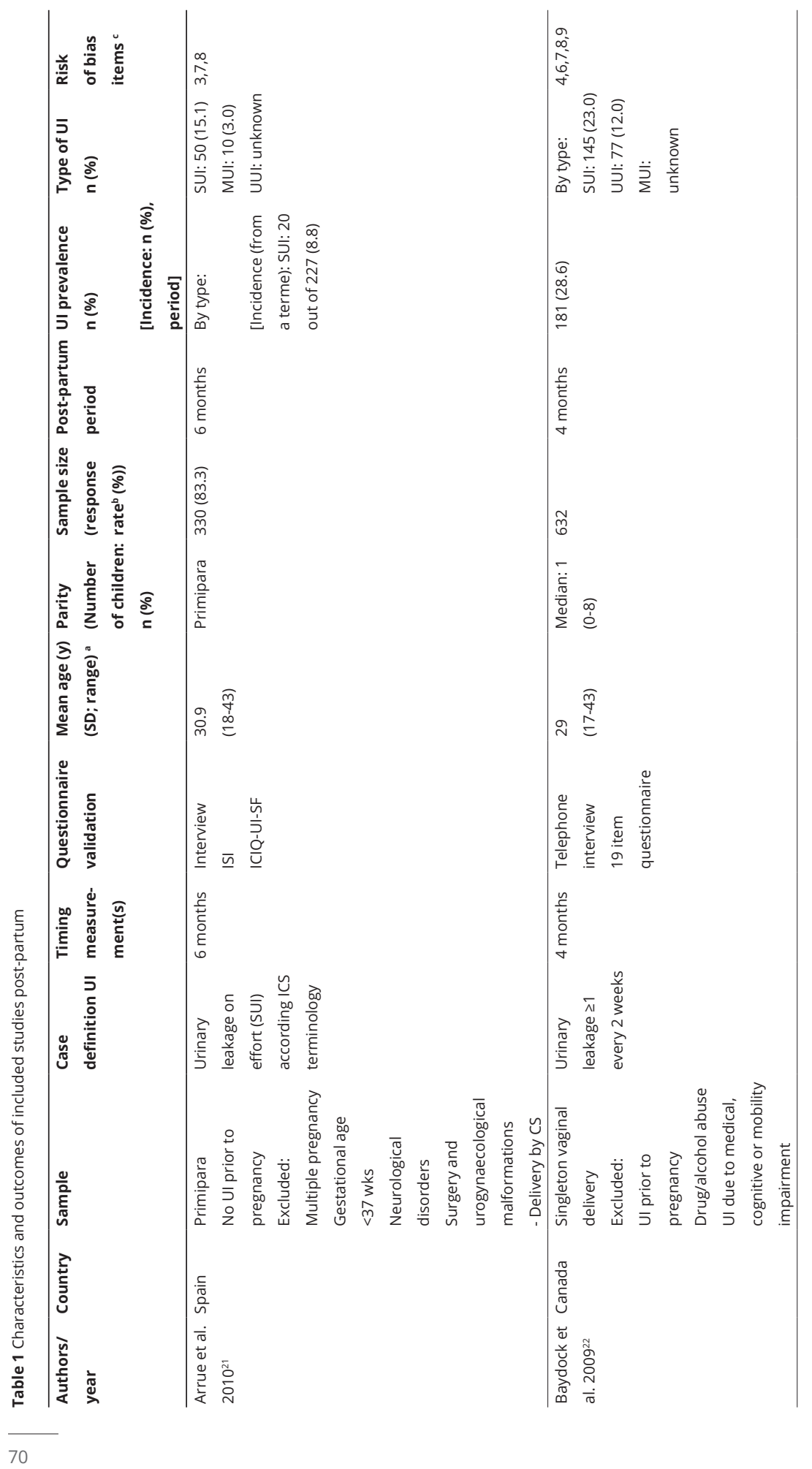




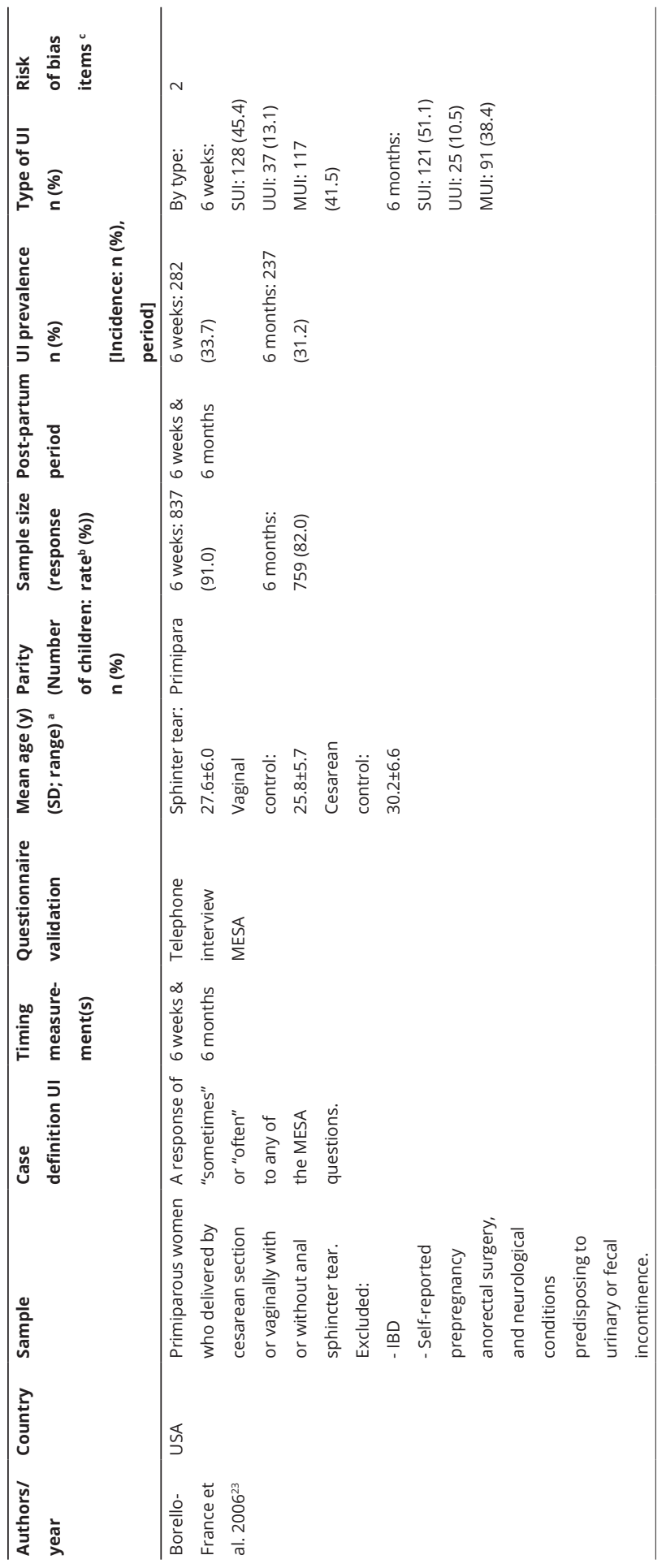




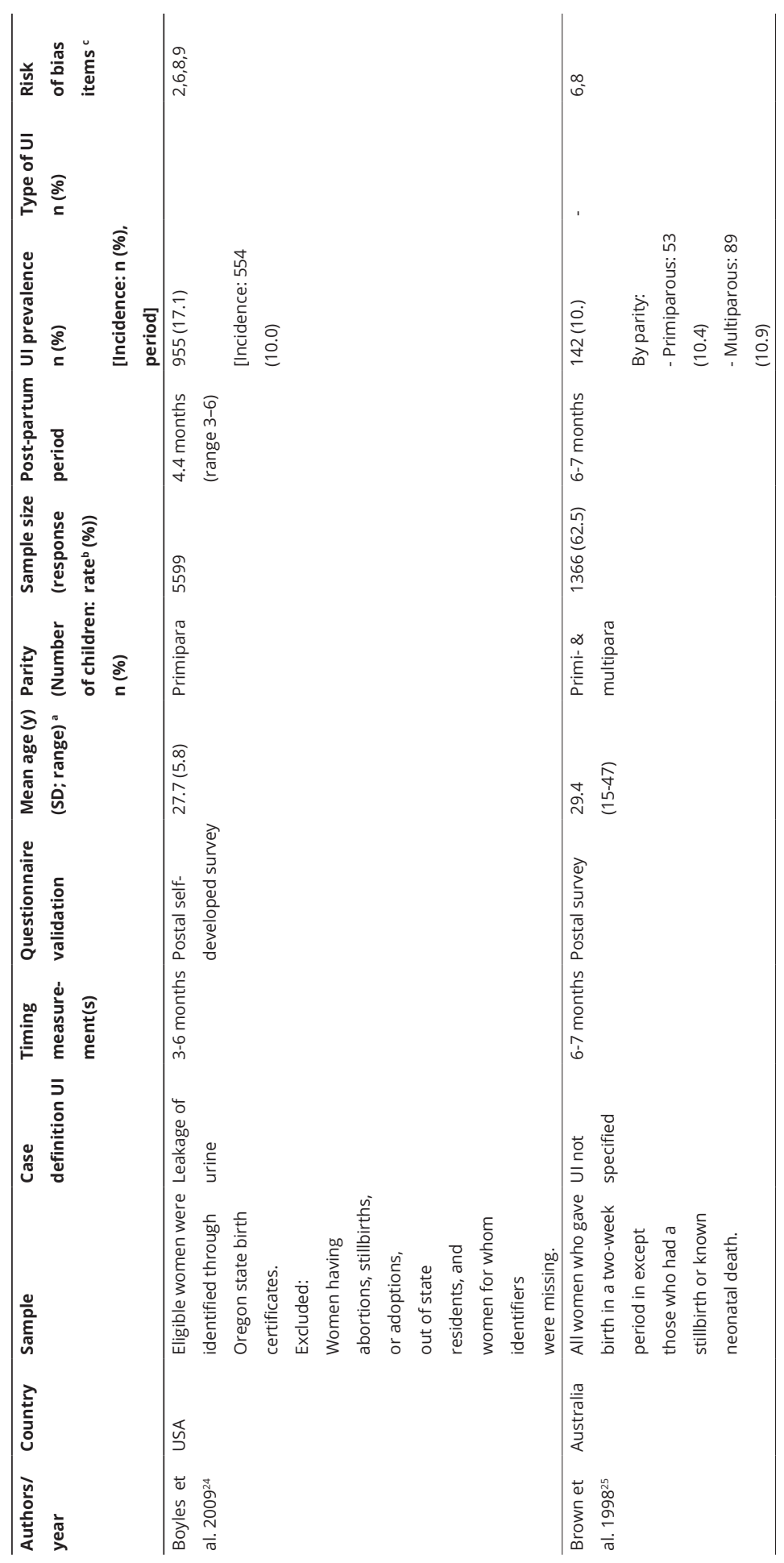




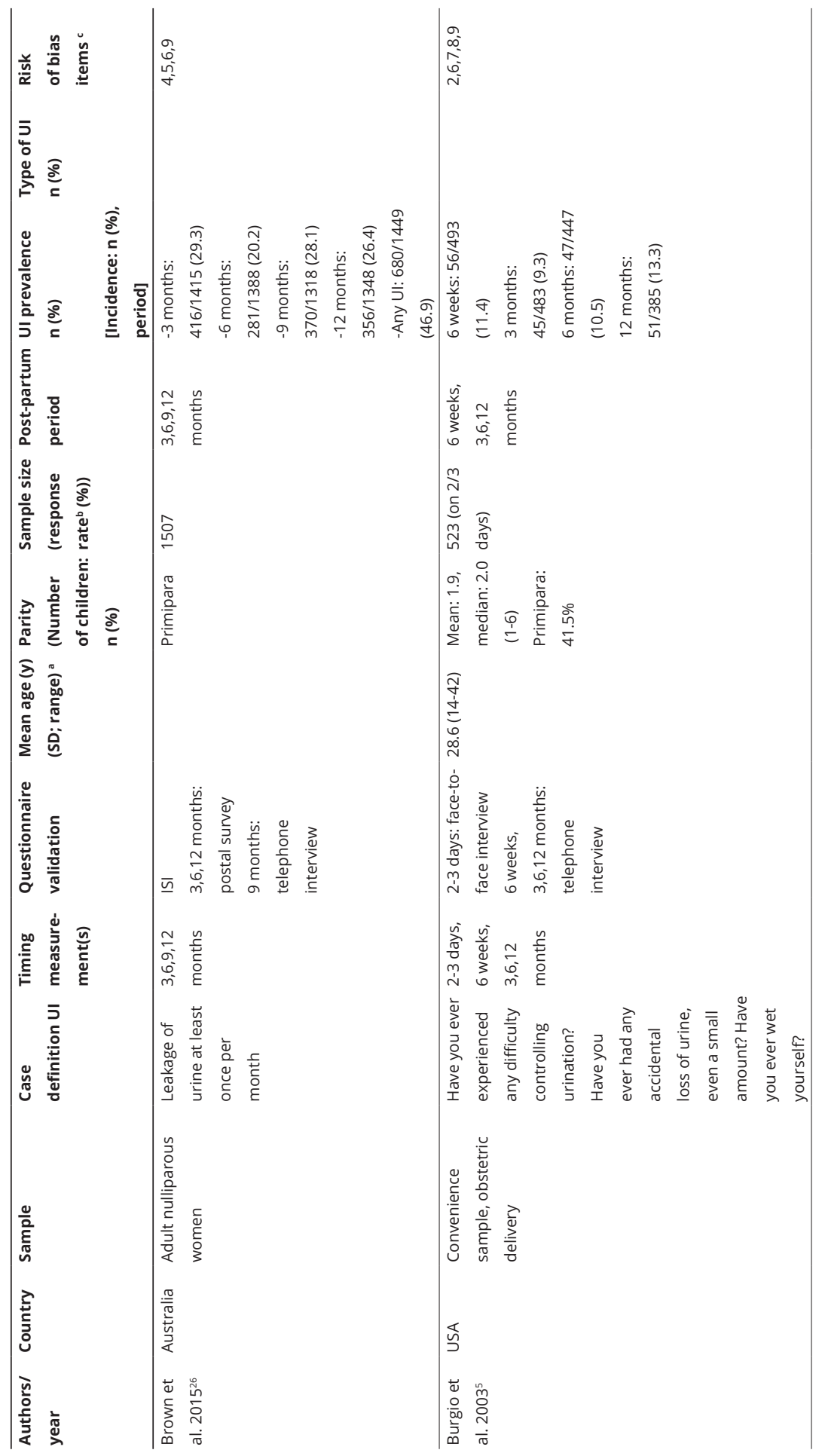




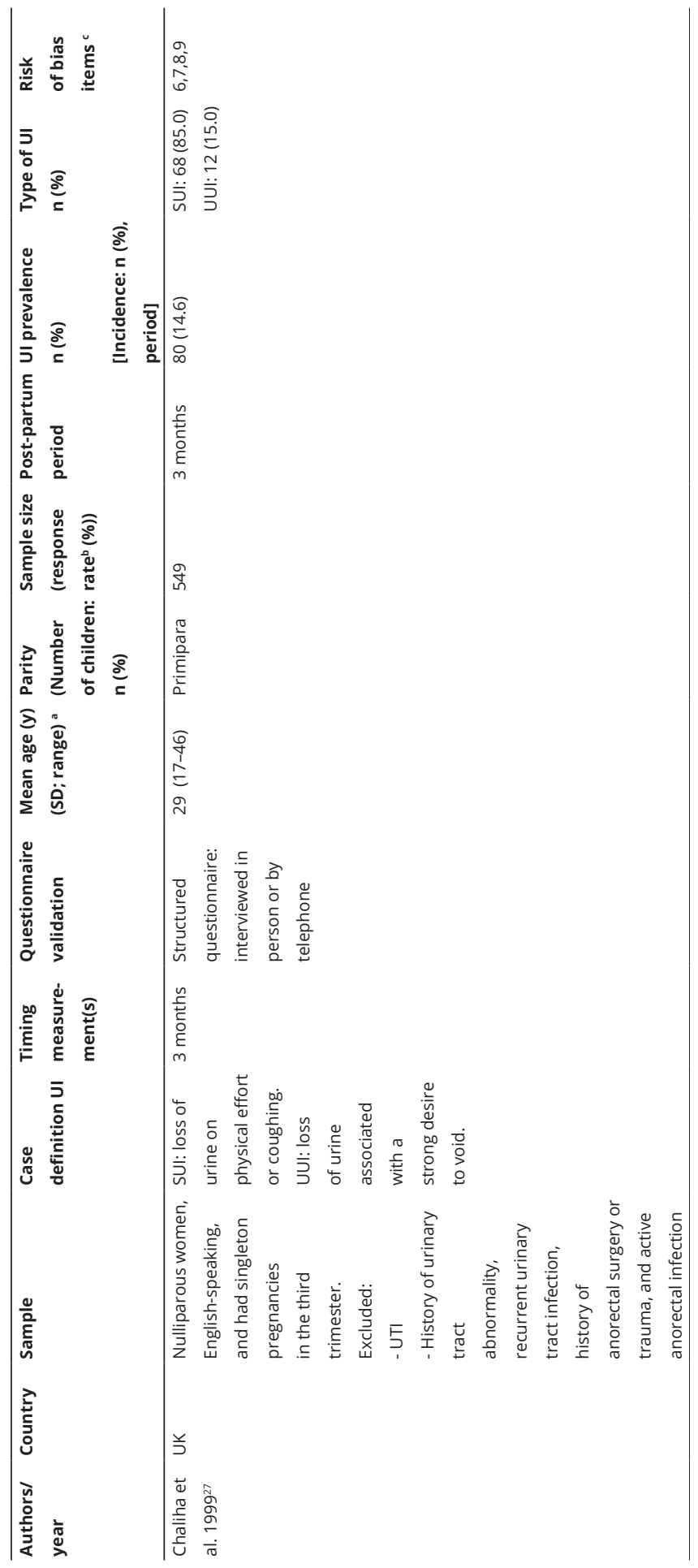




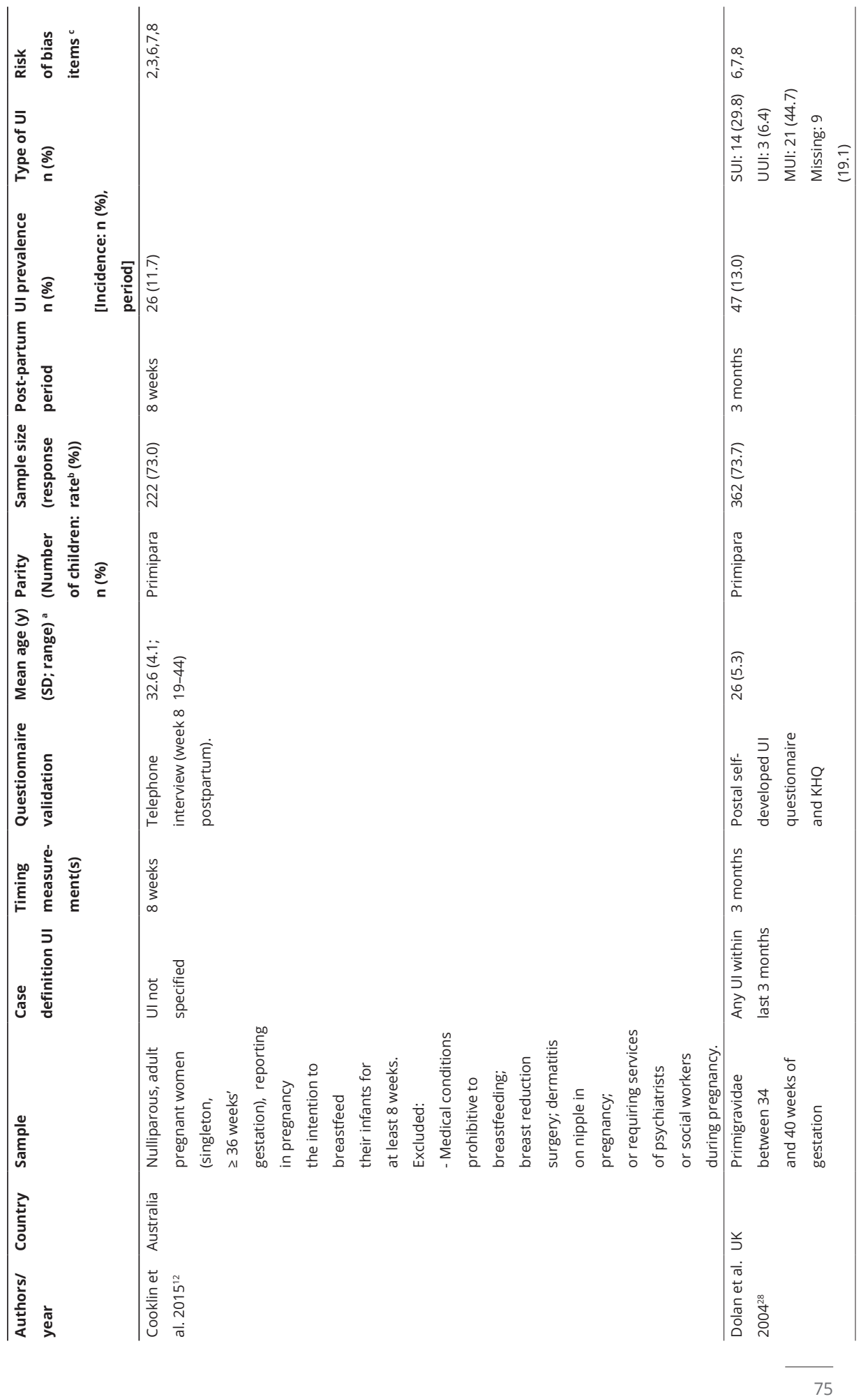




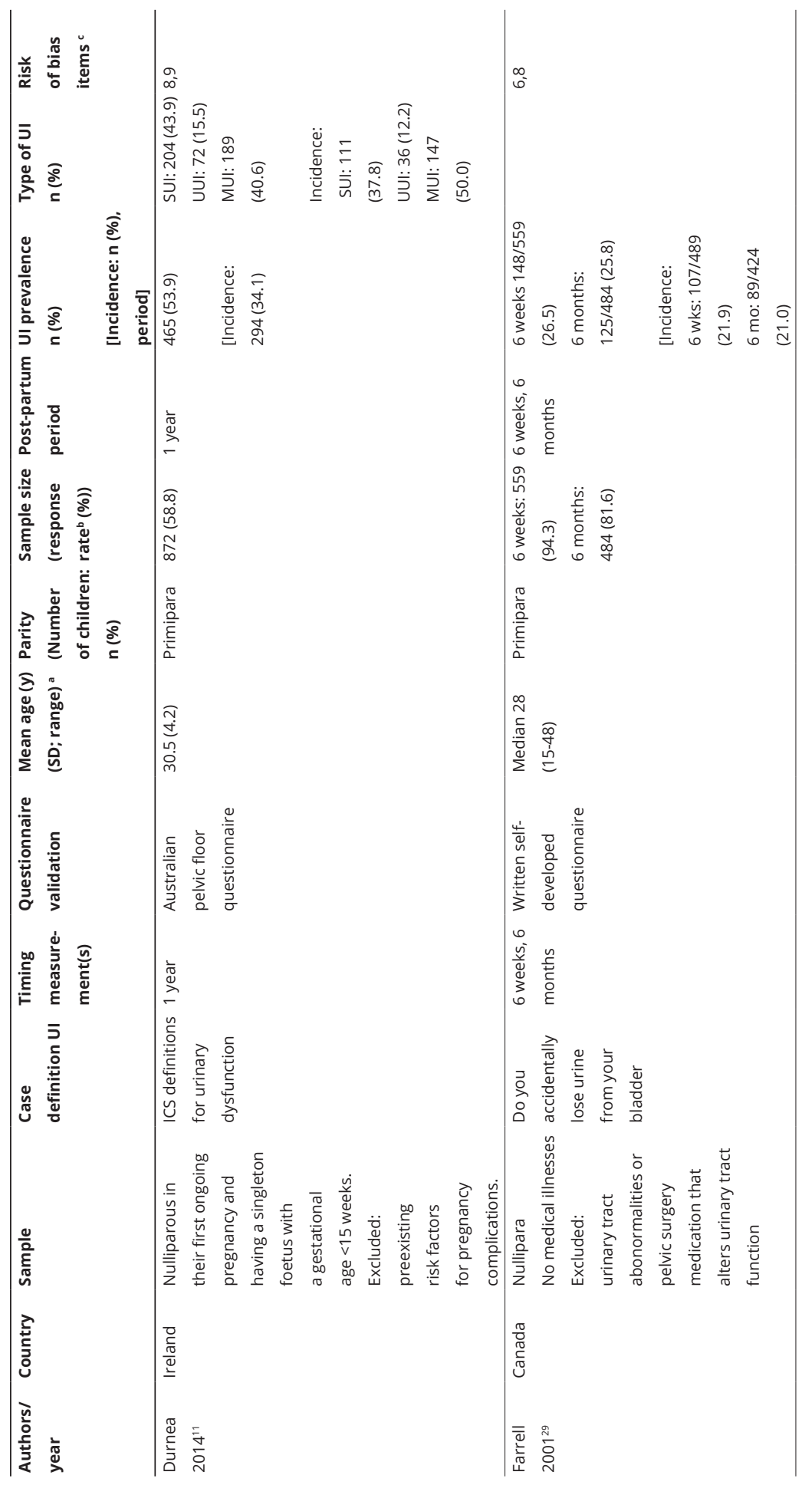




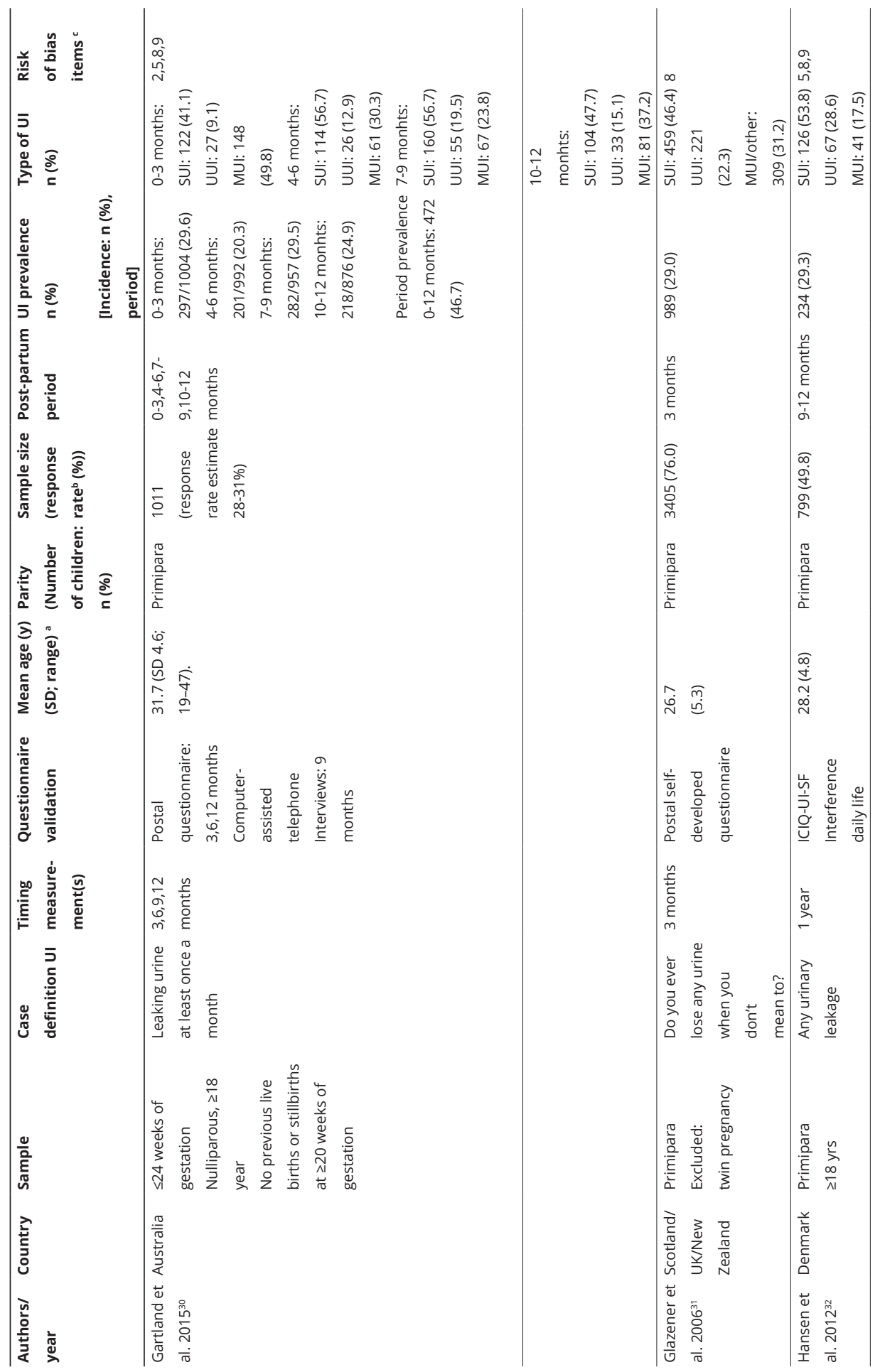




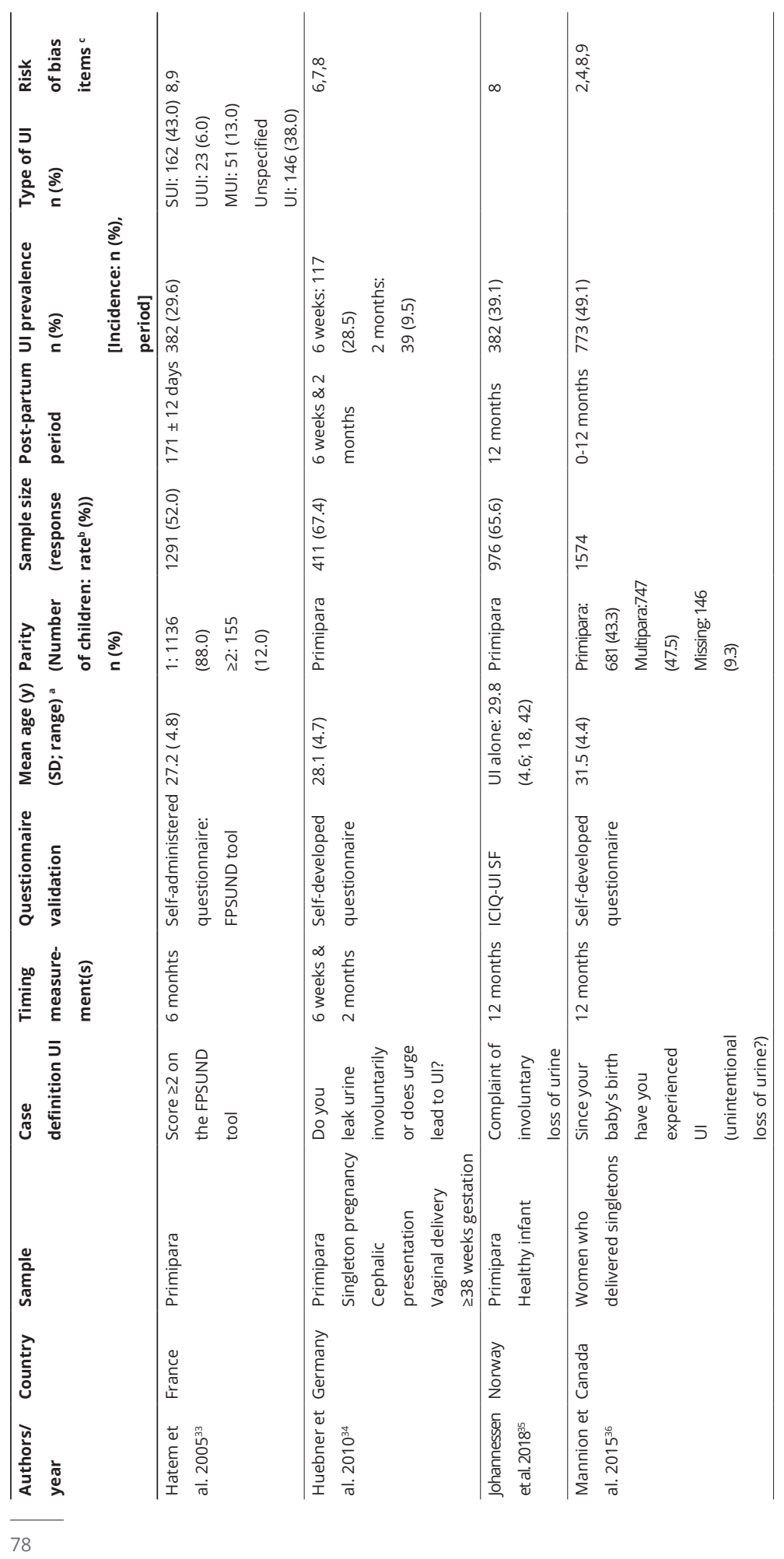




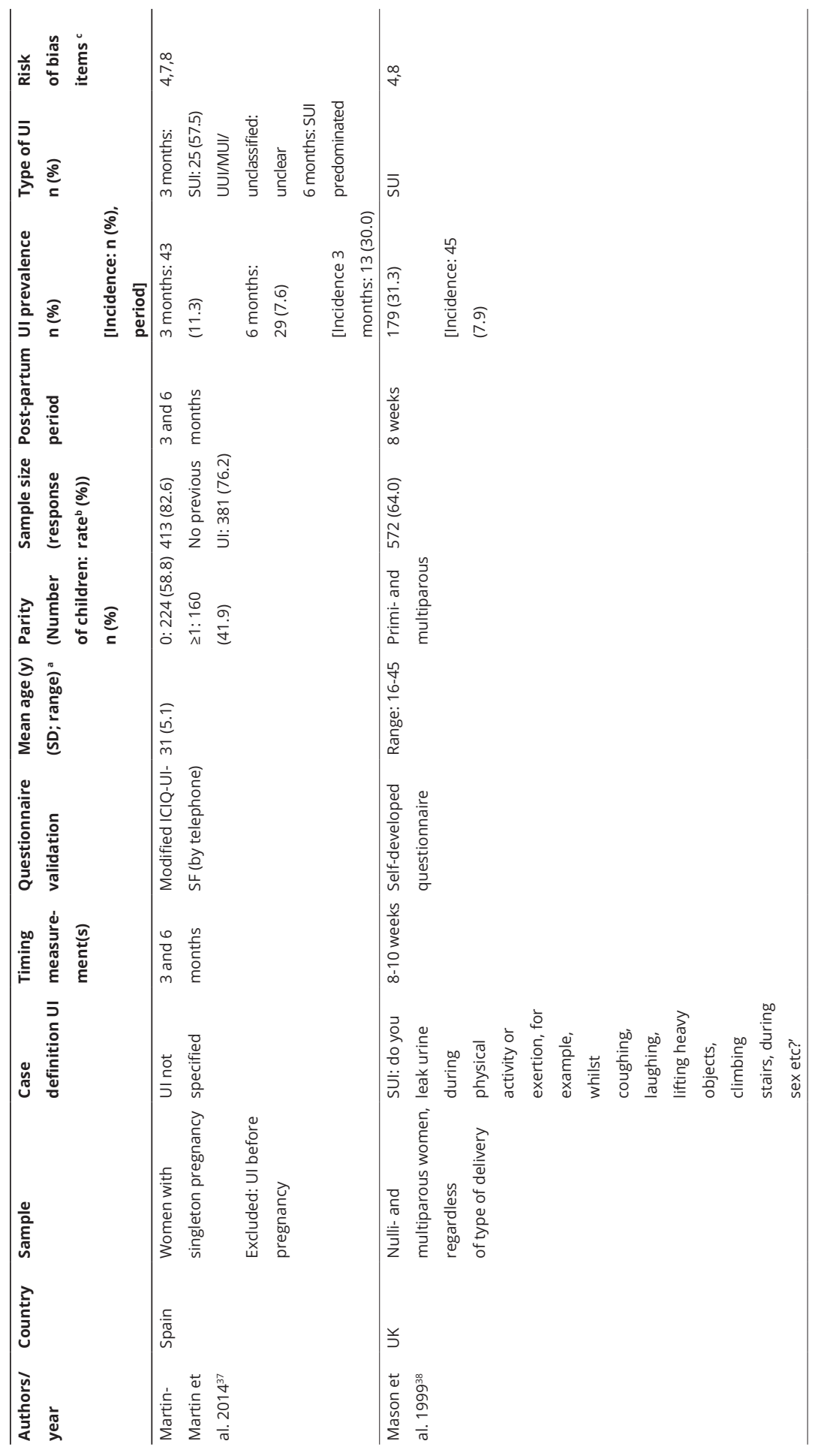




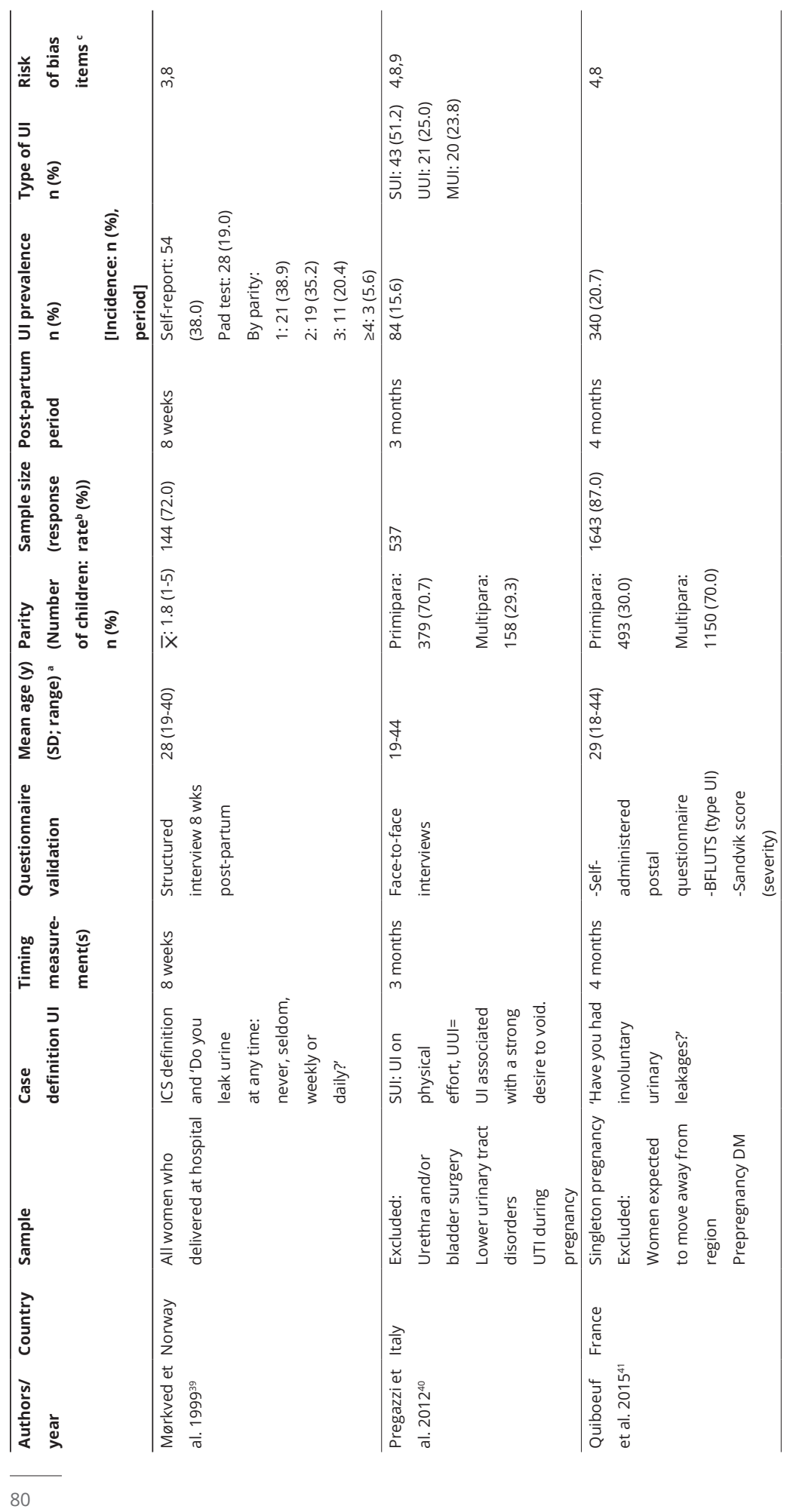




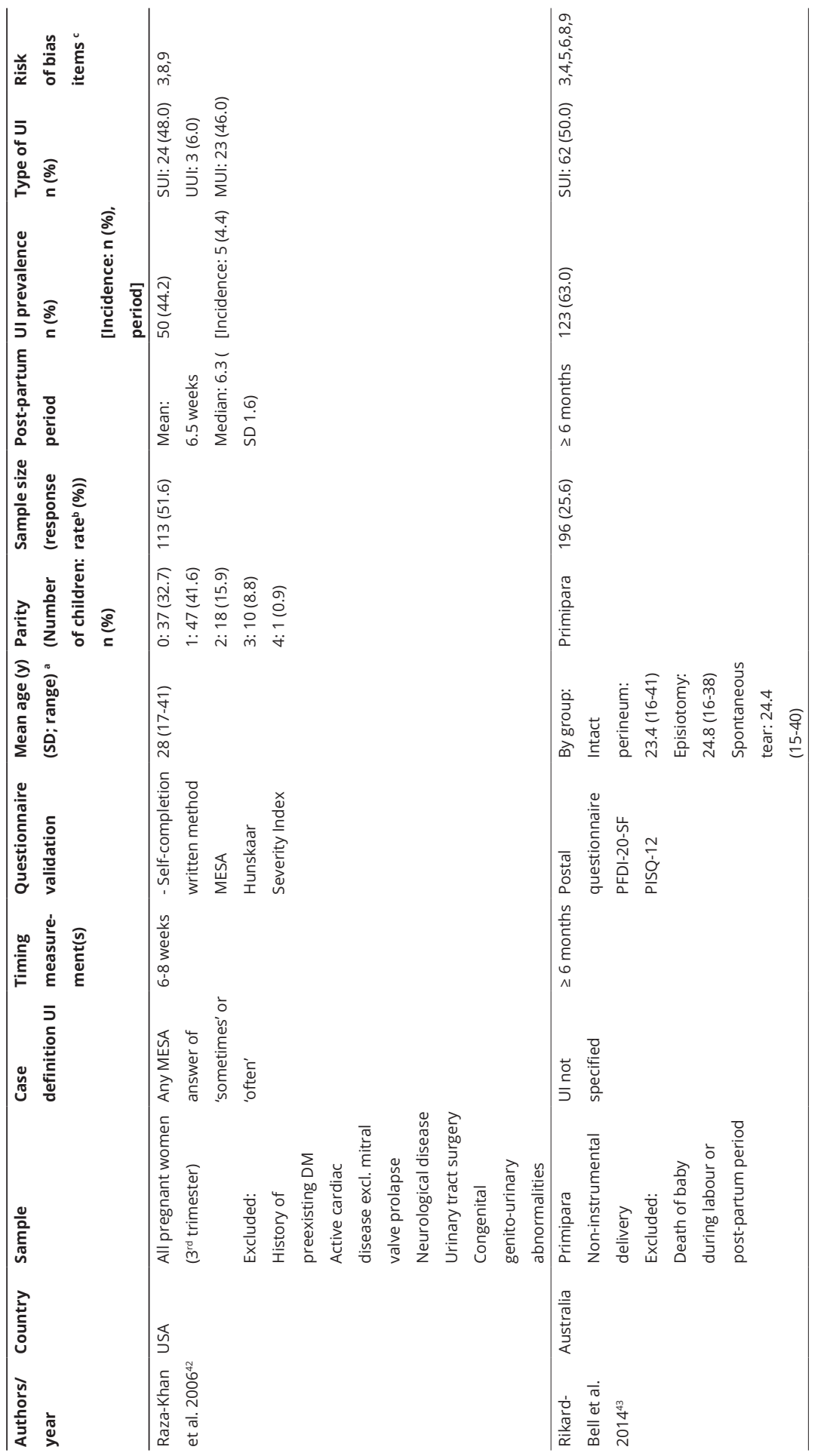




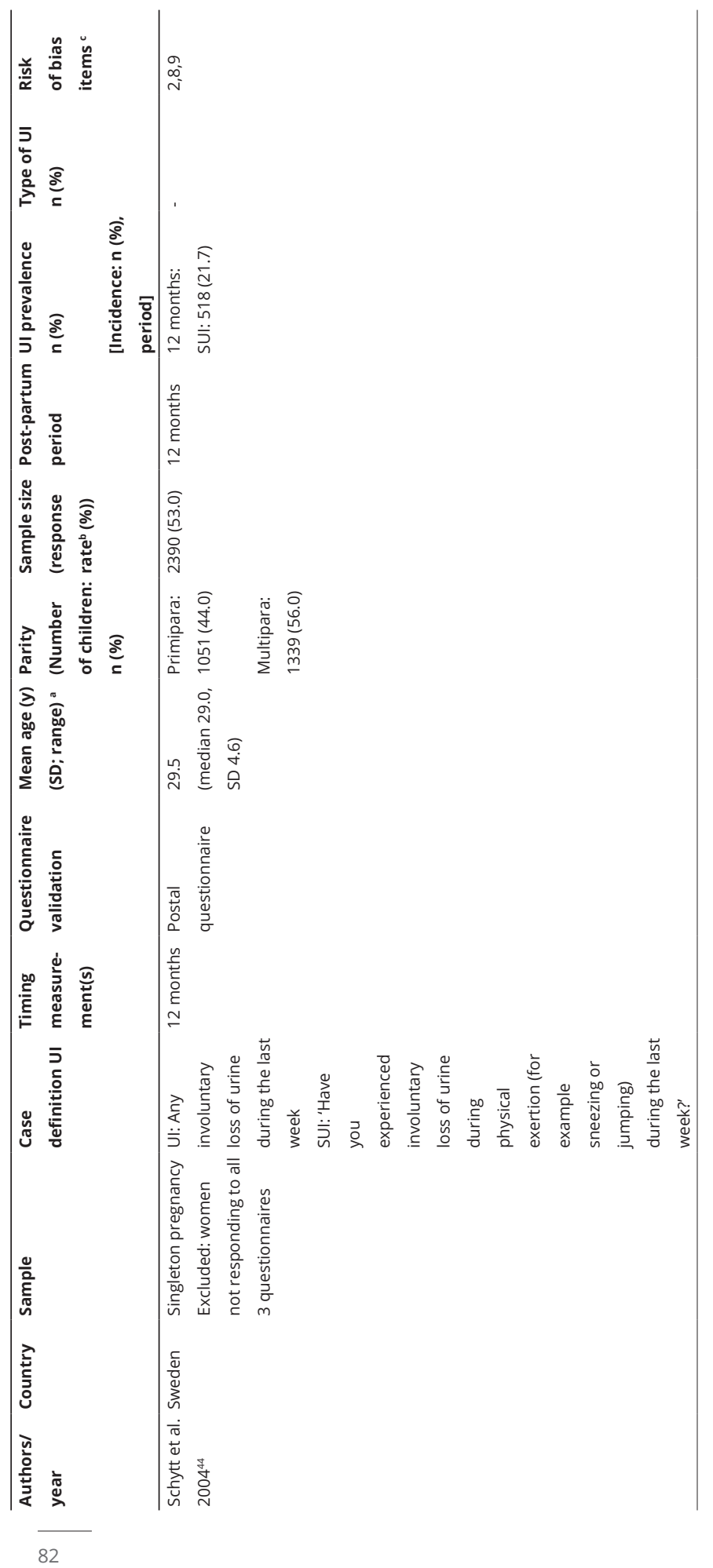




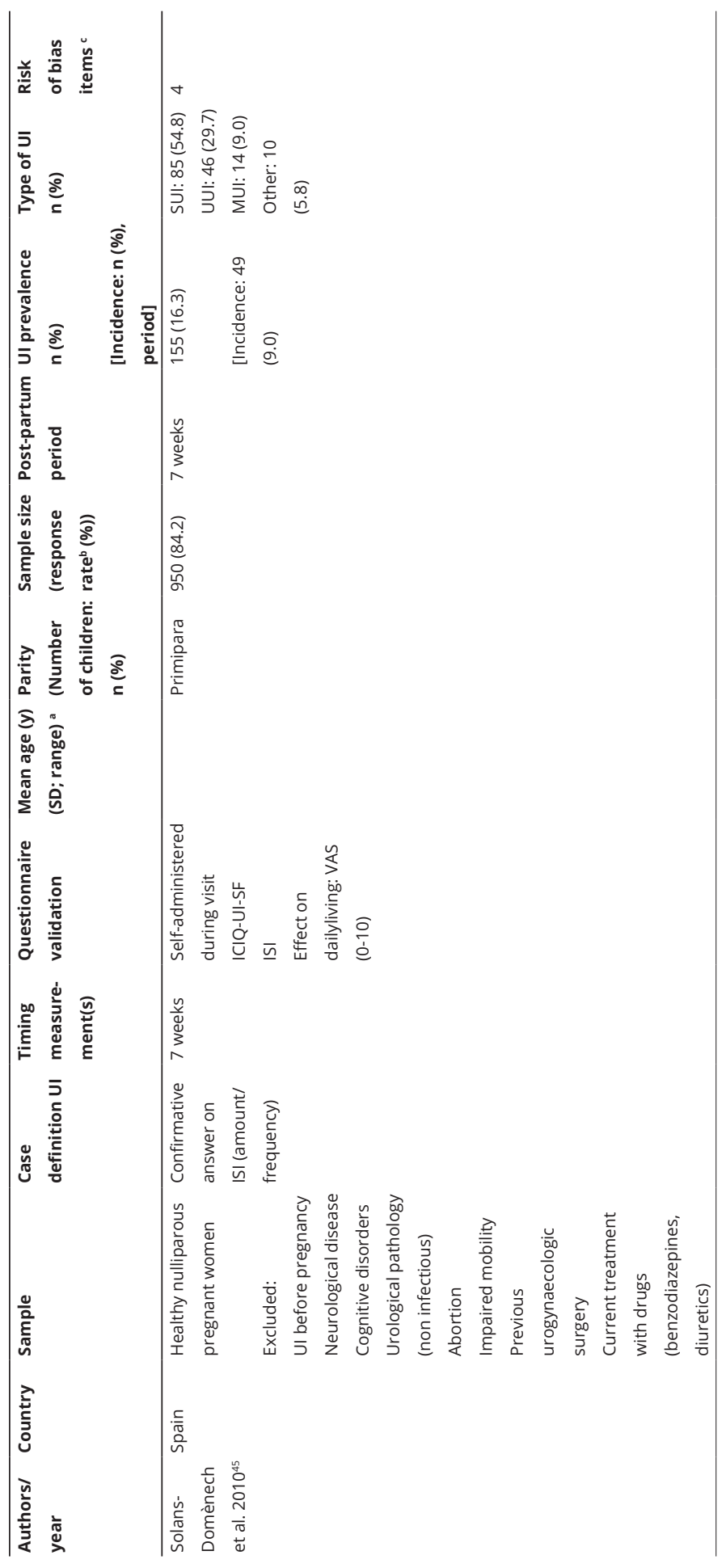




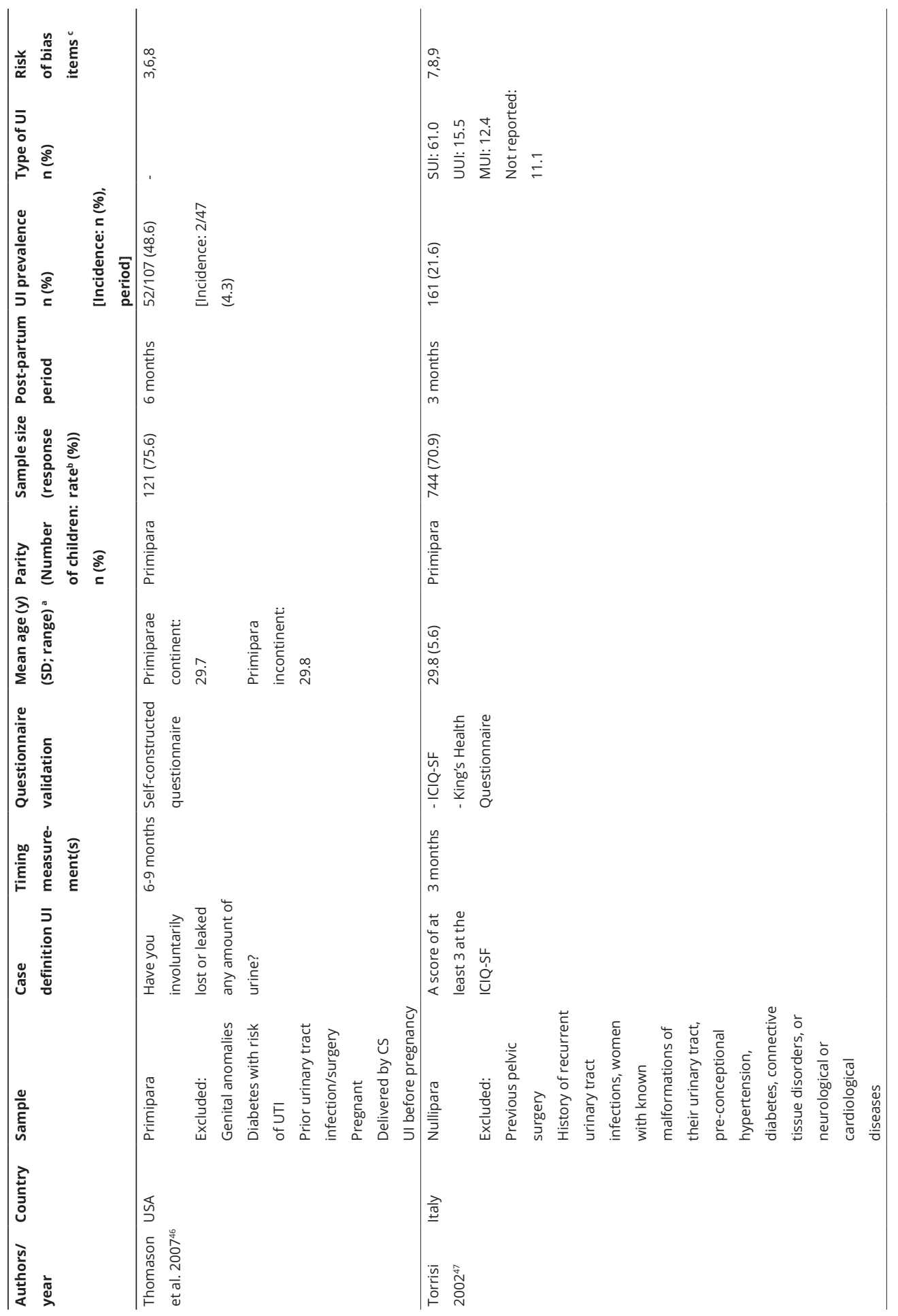




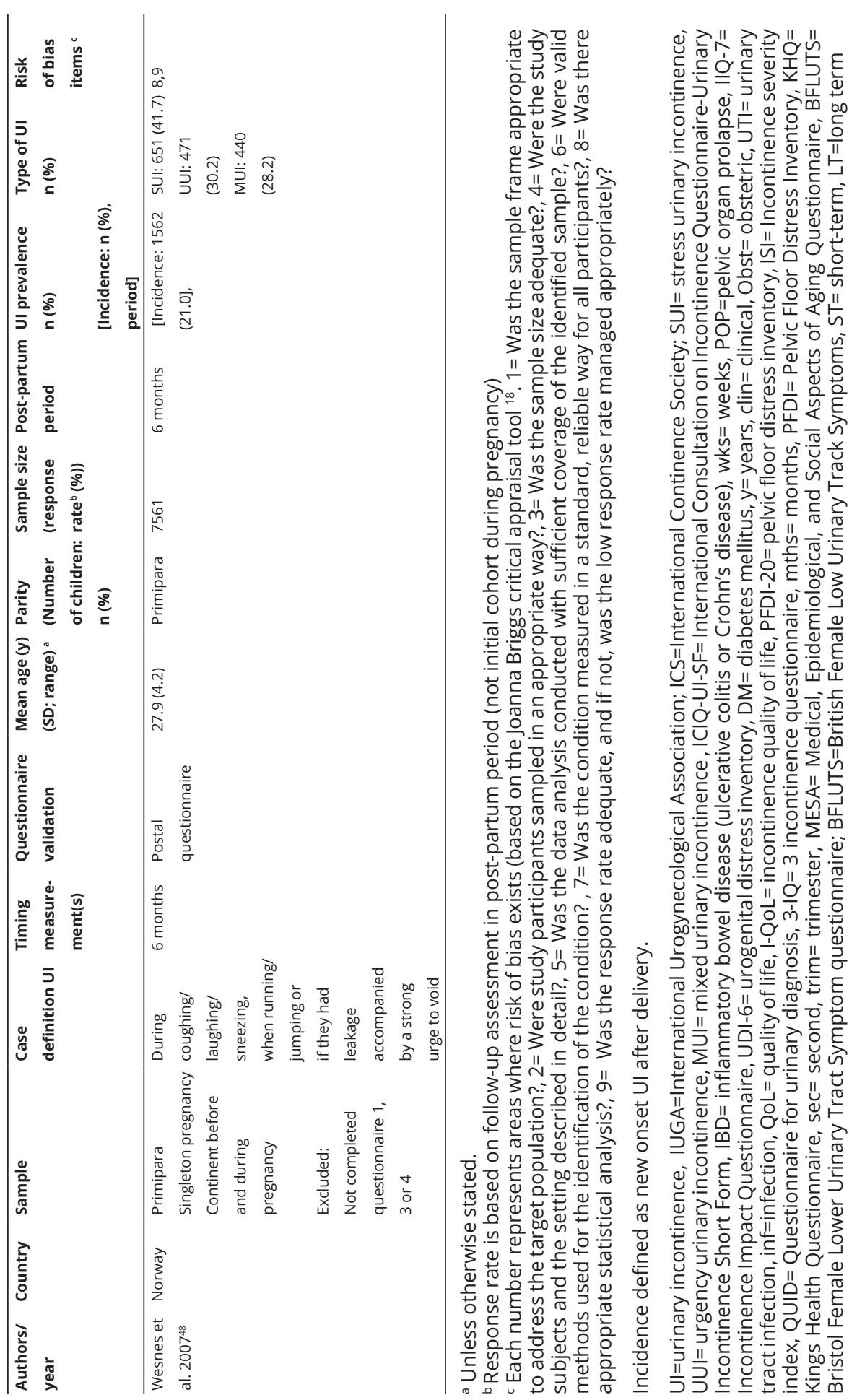




\section{Study characteristics}

The studies originated from Europe $(n=17)$, North-America $(n=8)$, and Australia $(n=5)$. One study was mixed Europe/Australia. The majority of women were included from a (tertiary) hospital $(n=26)$. The remaining studies included women from the community, primary health care service or health care insurance service. 19 studies only reported on primiparous women. Twelve studies used validated questionnaires to determine the presence of $\mathrm{UI}$ and 19 studies used self-constructed, non-validated questionnaires. Table 1 summarizes the study characteristics of included studies.

Nine studies reported on (measurement instruments for) bother. Table 2 provides an overview of the measurement instruments as used in the included studies, with the original and the converted (0-100 scale) measurement results. Five different measurement instruments for bother were used, of which the ICIQ-UI SF was most frequently used. . $1,32,47,49$ One study only reported the results of the ICIQ-UI SF as categories $^{50}$ and two studies did not report total scores. ${ }^{51,52}$ One measurement instrument was self-constructed and non-validated. ${ }^{53}$

\section{Synthesis of results}

\section{Overall prevalence}

24 out of 31 studies contributed to the calculation of the overall prevalence of post-partum UI, involving a total of 35.064 women. The weighted mean of UI prevalence among post-partum women (6 weeks to 12 months) was $31.0 \%$ (CI 95\% 26.0-36.0\%; I2: 99.0\%), regardless of parity or type of UI (Figure 2). The lowest prevalence of $\mathrm{UI}$ found in the included studies was $10 \% .^{54}$ and the highest prevalence $63 \% .{ }^{55}$ Prevalence figures for studies with low $(n=3)$, moderate $(n=20$ studies) and high risk of bias ( $n=1)$, were $28 \%$ (95\% Cl 17.0-39.0), 29\% (95\% Cl 24.035.0) and 63\%, respectively (Table 1 ).

\section{Subcategories post-partum period, type of UI and parity}

Figure 3 summarizes the mean UI prevalence at 6 weeks, 3, 6, 9, and 12 months post-partum. From an initial drop in prevalence between 6 weeks (24.0\%, 95\%-Cl: 17.0-32.0\%) and 3 months post-partum (21.0\%, 95\%-Cl: 17.0-25.0\%), prevalence numbers gradually rise to $32.0 \%$ at 12 months post-partum (95\%-Cl: $23.0-41.0 \%)$. 
Table 2 Measurement of bother and result

\begin{tabular}{|c|c|c|c|c|c|}
\hline $\begin{array}{l}\text { Measurement } \\
\text { instrument }\end{array}$ & $\begin{array}{l}\text { Background } \\
\text { information on } \\
\text { measurement } \\
\text { instrument }\end{array}$ & Study & $\begin{array}{l}\text { Original } \\
\text { measurement } \\
\text { result (mean) }\end{array}$ & $\begin{array}{l}\text { Period post } \\
\text { partum }\end{array}$ & $\begin{array}{l}\text { (Converted) } \\
\text { measurement } \\
\text { results } \\
(0-100)\end{array}$ \\
\hline \multirow{6}{*}{$\begin{array}{l}\text { ICIQ-UI SF } \\
(0-21)\end{array}$} & \multirow{6}{*}{$\begin{array}{l}\text { To assess } \\
\text { symptoms of } \\
\text { Ul and impact } \\
\text { on QoL. (4 } \\
\text { questions, } \\
\text { question } 4 \text { is on } \\
\text { moment of UI } \\
\text { and is not within } \\
\text { the calculation of } \\
\text { the total). }\end{array}$} & 21 & 8.2 for SUI & 6 months & 39.0 \\
\hline & & & 10.0 for $\mathrm{MUI}$ & 6 months & 47.6 \\
\hline & & 32 & 5.9 & 1 year & 28.1 \\
\hline & & 35 & 5.1 & 1 year & 24.3 \\
\hline & & 47 & 6.0 & 3 months & 28.6 \\
\hline & & 50 & $\begin{array}{l}\text { Results } \\
\text { reported in } \\
\text { categories. No } \\
\text { total score. }\end{array}$ & & \\
\hline \multirow{2}{*}{$\begin{array}{l}\text { ICIQ-UI SF } \\
\text { Question } 3 \\
\text { (QoL) } \\
(0-10)\end{array}$} & \multirow{2}{*}{$\begin{array}{l}\text { Question } 3 \text { of the } \\
\text { ICIQ-UI SF is on } \\
\text { the interference } \\
\text { in daily life of UI. }\end{array}$} & 70 & 4.1 & 3 months & 41.0 \\
\hline & & & 4.5 & 6 months & 45.0 \\
\hline I-QOL & $\begin{array}{l}\text { Quality of life } \\
\text { in persons with } \\
\text { UI. } 3 \text { subscales: } \\
\text { 1. Avoidance } \\
\text { and limiting } \\
\text { behaviour, } \\
\text { 2. Psychosocial } \\
\text { impact, 3. Social } \\
\text { embarrassment } \\
\text { (22 questions) }\end{array}$ & 51 & $\begin{array}{l}\text { No exact scores } \\
\text { reported }\end{array}$ & & \\
\hline KHQ & & 52 & $\begin{array}{l}\text { No total score } \\
\text { reported }\end{array}$ & & \\
\hline $\begin{array}{l}\text { Self- } \\
\text { constructed } \\
\text { questionnaire }\end{array}$ & & 53 & $\begin{array}{l}\text { No total score } \\
\text { reported }\end{array}$ & & \\
\hline
\end{tabular}

ICIQ-UI SF= International Consultation on Incontinence Questionnaire-Urinary Incontinence Short Form, QoL= quality of life, I-QoL= incontinence quality of life, KHQ= Kings Health Questionnaire, $\mathrm{SUI}=$ stress urinary incontinence, $\mathrm{MUI}=$ mixed urinary incontinence

The prevalence of UI post-partum is equal amongst primi- and multiparous women, $31 \% .^{11,12,32,35,46,47,52,56-62}$ and 30\% 25,42,51,53,63-68, respectively. Based on 9 studies, SUI accounts for $54 \%$, UUI and MUI for $26 \%$ and $16 \%$ of cases respectively, whereas $4 \%$ was unexplained UI. 32,42,47,52,58,60-62,66 


\section{Subcategories frequency and amount of $\mathrm{UI}$}

Seven out of 31 studies reported on frequency of UI. The most used frequency categories $(n=3)$, were: less than once a week, less than daily, more than or equal once per week, more than or equal daily leakage. A frequency of less than once a week was most frequently reported (50\%-66.3\%). 31,58,65 Two studies reported frequency of UI as: less than once per month, a few times a month, a few times a week, every day and/or night.42,50 One study reported as: occasionally, once per week, several times per week, daily ${ }^{38}$ and one study reported the ICIQ-UI SF question on frequency. ${ }^{32}$

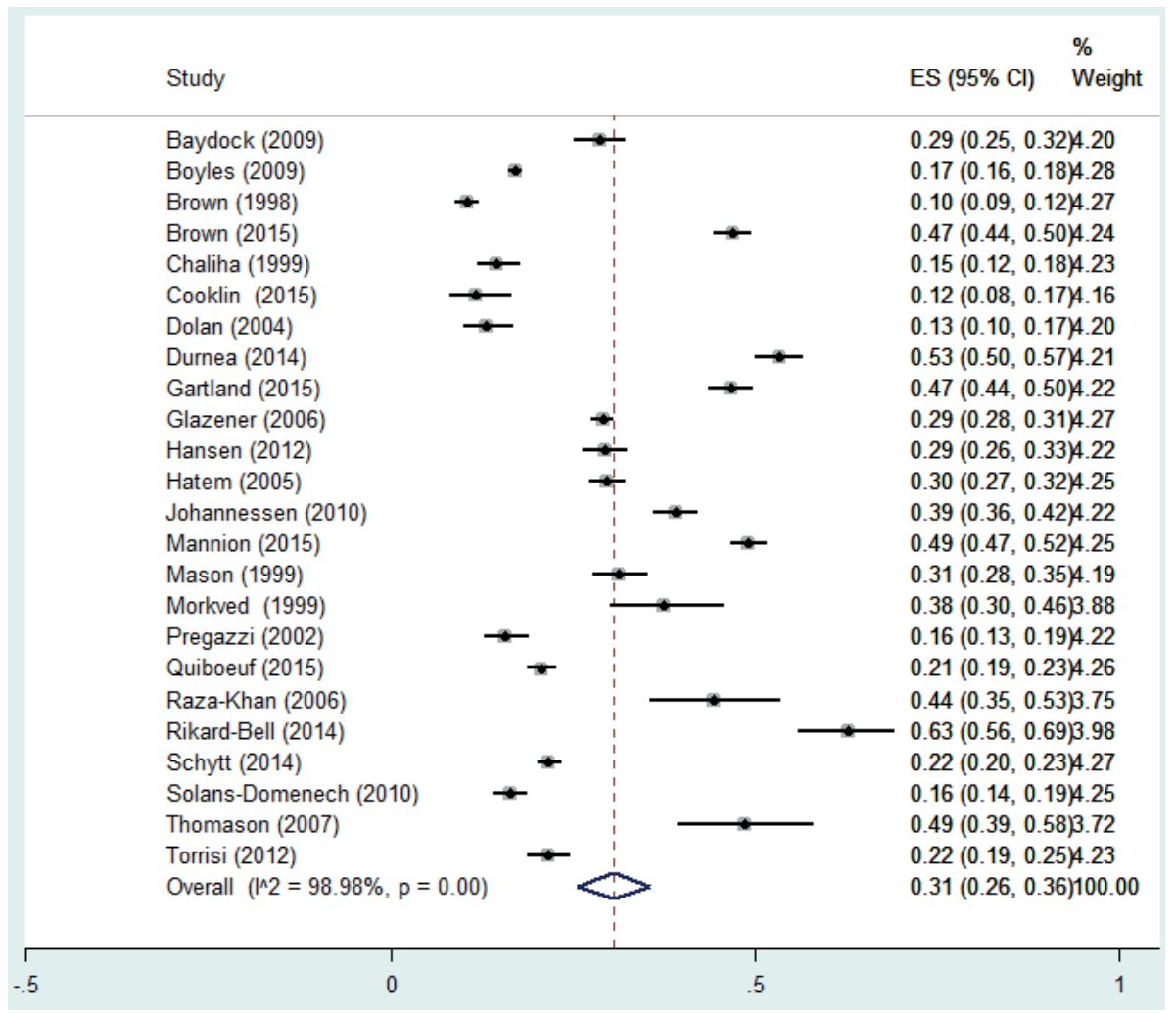

Figure 2 Pooled prevalence of UI post-partum stratified according to trimester wherever possible 

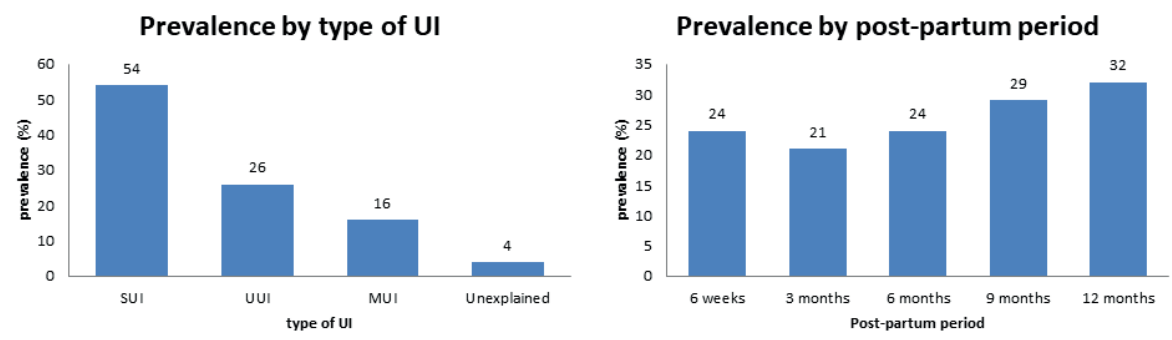

Figure 3 Prevalence of UI by type and period

Four studies reported on the amount of urine loss. ${ }^{32,42,50,69}$ One study used the ICIQ-UI SF to assess this parameter (none, small, moderate, large amount). ${ }^{32}$ One study reported separately the ICIQ-UI SF items 'amount', showing that the majority of UI cases lose a small amount (85.3\%). ${ }^{32}$ Other descriptions of amount of urine lost used were: drops, small splashes, and more. ${ }^{42,50}$ Drops were most frequently reported in $71.6 \%$ of cases. ${ }^{50}$ The remaining study reported amount as drop or two, pad or clothing damp, pad or clothing soaked. ${ }^{69}$

\section{Bother}

Nine studies reported on impact on daily life or quality of life 21,32,35,47,50-53,70, which was heterogeneously assessed. The ICIQ-UI SF total score was used most frequently (n-5). Martin-Martin et al. reported the impact on daily life (0-10) based on the ICIQ-UI SF. ${ }^{70}$ Other questionnaires used once to assess impact on daily life were: Incontinence Quality of life (I-QOL) ${ }^{51}$, King's Health Questionnaire $(\mathrm{KHQ})^{52}$ and a self-constructed non validated questionnaire. ${ }^{53}$ The overall bother of UI post-partum, on a 0 to 100 scale, ranges between 24.3 and 47.6, consistent with mild to moderate bother. At 3 months post-partum, degree of bother ranged between 28.6 and 41.0, at 6 months post-partum between 39.0 and 45.0 and at 12 months post-partum between 24.3 and 28.1 (Table 2).

\section{Case definition}

Themajorityofstudies(n=11) used'anyleakage' as a case definition. 31,32,35,46,52,53,67,69,71-73 Eight studies used the ICS definition which was not mentioned as such in some cases. ${ }^{11,21,38,58,65,66,68,74}$ Six studies did not specify a case definition for UI ${ }^{12,25,47,61,70,75}$, five used a frequency ${ }^{42,50,57,59,63}$, and one study used the Clinical classification of urinary incontinence (FPSUND)..$^{51}$ 


\section{Incidence}

Ten studies have examined incidence of UI post-partum (Table 1). 11,21,42,46,64,70-72,74 Five studies reported incidence up to and including three months $s^{42,50,64,70,72}$ and six reported from three until 12 months. $11,21,46,71,72,74$ One study reported for both periods. ${ }^{72}$ The incidence of $\mathrm{UI}$ in primiparous and multiparous women up and until three months was $9.0-21.9 \%$ and $4.4-30.0 \%$, respectively. Incidence up to 1 year was $4.3-34.1 \%$ in primiparous women.

\section{DISCUSSION}

The aim of this systematic review and meta-analysis was to summarize the pooled prevalence and incidence of UI between 6 weeks and 12 months post-partum, to provide an overview of assessment methods for bother in relation to UI, and to assess the degree of bother post-partum. The results show an overall mean prevalence rate of UI up to 1 year post-partum of $31 \%$, with a range of $10 \%$ to $63 \%$. The prevalence of $10 \%$ was reported in a study on maternal health using a generic questionnaire including only one question on $\mathrm{UI}^{25}$ in contrast to the other studies using health problem specific questionnaire. This might have influenced the tendency for women to report UI. ${ }^{76}$

The prevalence numbers in the first year post-partum rise from $24 \%$ at 6 weeks to $32 \%$ at 12 months post-partum after an initial drop between 6 weeks and 3 months. A recently published systematic review and meta-analysis on the prevalence of UI during pregnancy reported a prevalence of UI of 34\% in the third trimester. ${ }^{77}$ The drop in UI prevalence early post-partum compared to the $3^{\text {rd }}$ trimester of pregnancy might be explained by the natural recovery of the levator ani muscle which occurs mainly up to 4 to 6 months post-partum. ${ }^{78,79}$ The rise in prevalence from 3 to 12 months post-partum might be due to return to daily activities, such as return to work and starting with sports, with an associated increase in physical activity level and as a consequence loading of the continence system..$^{80,81}$ The prevalence of UI between primi- and multiparous women was nearly equal (31\% and 30\%). This is in line with the EPINCONT study on 27.900 women, which reported that the first delivery is the largest risk factor for UI, more specifically SUI and MUI, post-partum. ${ }^{82}$

Thom et al. ${ }^{83}$ published a systematic review with 33 studies on the prevalence of post-partum urinary incontinence. The overall prevalence reported by Thom et 
al. between 2 and 13 weeks post-partum was 33.3\%. As only one included study covered the period of 14 to 52 weeks post-partum, an overall prevalence number could not be calculated. ${ }^{13} 33.3 \%$ is a higher prevalence than the $24 \%$ at 6 weeks and $21 \%$ at 3 months reported in this study. This might be due to the fact that Thom et al. did not report a weighted prevalence.

When interpreting the prevalence numbers at different time points post-partum it is important to keep in mind that UI might be a dynamic phenomenon. This means that a woman's continence status can change both ways over a period of time. ${ }^{67}$

The incidence numbers between 6 weeks up to 3 months and 3 months up to 12 months and amongst primi- and multiparous women varied. The low incidence number of $4.3 \%$ in the short term might be explained by the fact that this study reported on SUI or MUI incidence only. ${ }^{46}$ Although the study of Thomason et al. claim to report the incidence of total UI, only women who reported UI with a positive (cough) stress test were included. Women who were able to contract their pelvic floor muscles properly and timely during an in advance known rise in abdominal pressure might therefore be considered continent. However, these women might be incontinent during an unexpected rise in abdominal pressure. Also the small sample $(n=121)$ in this study may explain the low incidence number. If the overall incidence of the up to 3 months post-partum is compared with the up to 12 months post-partum group the incidence numbers show a small rise in the latter, $4.3-30.0 \%$ and $4.4-34.1 \%$, respectively. The rise in incidence is following the pattern of the rise in prevalence of UI between 3 and 12 months post-partum.

Most included studies showed a moderate risk of bias, which influences the possibility to differentiate on prevalence between groups regarding risk of methodological quality. The mean prevalence of UI reported by studies with low and moderate risk of bias did not differ. However, the one high risk study reported the highest prevalence of $63 \% .{ }^{61}$ Because a weighted prevalence number was calculated, this high risk study with only 196 participants and low response rate of $25.6 \%$ hardly influences the overall prevalence of UI.

The $\mathrm{ICl}$ recommends reporting prevalence numbers along with a measure of experienced bother. ${ }^{14}$ Only nine out of 31 studies (approximately $30 \%$ ) reported bother in relation to UI with a variety of measurement instruments which shows that combined assessment is not yet common practice. . $^{1,32,35,47,51-53,62,70}$ Eight studies used high quality measurement instruments of which the ICIQ-UI SF 21,32,35,47,62 was 
used most frequently. In an attempt to provide an overall assessment of degree of experienced bother in relation to UI, we (arbitrarily) chose to standardize the measurement results of different bother scales to a 0 to a 100 scale. The 0 to 100 scale can be regarded as a visual analogue scale (VAS). The VAS is a valid and reproducible method to quantify the impact of $\mathrm{UI}$ on QoL ${ }^{84}$, although no studies are known that report on cut-off scores for QoL specifically in post-partum women with UI. Boonstra et al. compared the VAS with a measure that assesses the impact on functioning in patients with pain and identified three classes: class 1, mild interference (score 1-34), class 2, moderate interference (score 35 - 64), and class 3 , severe interference with daily life (score 65 - 100). ${ }^{85}$ Based on these classes, this systematic review revealed that women experience their post-partum UI as mild to moderate (range 24.3-47.6). Based on two studies, the results show a trend that bother of UI reduces at 12 months post-partum. ${ }^{32,35}$ Women report for instance that $\mathrm{UI}$ becomes less of a problem because they get used to it and that they find practical ways to cope, by using party-liners and avoiding certain activities. ${ }^{64}$

Nevertheless, over half of the women with UI post-partum think that it will improve by itself in time and only $25 \%$ of women with post-partum UI actually seek help. ${ }^{86}$ However, 73\% of women with UI 3 months post-partum still report UI at 6 years post-partum. ${ }^{6}$ Reliable information on UI prevalence is thus essential to estimate healthcare burden, allocation of health care resources and research planning.

\section{Strengths and limitations}

The strength of this systematic review and meta-analysis is the large number of included studies, which resulted in the availability of prevalence and incidence numbers for different subpopulations (parity, post-partum period, type of UI) and for different purposes (health care providers, research planning, and policy makers). This is the first review to report the prevalence and incidence over the first 12 months post-partum and bother in relation to post-partum UI.

The limitations of this study are, firstly, the presence of substantial clinical heterogeneity of the studies. Clinical heterogeneity may be due to differences in: case definition (any UI or different frequencies of UI in a certain period of time), population (primiparous and -multiparous) or periods researched. Secondly, the considerable statistical heterogeneity of the studies resulting in large Cl's. Thirdly, as the Joanna Briggs critical appraisal tool does not recommend cut-off points for 
high, moderate of low risk of bias, we arbitrarily chose the cut-off points reported in this systematic review to explore possible differences in prevalence numbers if stratified for risk of bias. However, we did not include or exclude studies based on risk of bias.

\section{CONCLUSION}

After an initial drop in prevalence of UI at 3 months post-partum (21\%), at 1 year post-partum, prevalence rises again to $31 \%$. UI prevalence does not differ between primi- and multiparous women. Bother of $\mathrm{UI}$ is heterogeneously assessed and is reported as mild to moderate. 


\section{Search strategy for PubMed}

\section{Appendix:}

((()((()(('urinary incontinence'[MeSH Terms]) OR urinary incontinence title/ abstract) OR ‘urine loss'[Title/Abstract]) OR 'pelvic floor disorders'[MeSH Terms]) OR 'pelvic floor disorders'[Title/Abstract]) OR 'pelvic floor dysfunctions'[Title/ Abstract])) OR incontinence[Title/Abstract])) OR ‘leaking urine'[Title/Abstract])) AND (((()((pregnancy[MeSH Terms]) OR pregnancy[Title/Abstract]) OR pregn[Title/ Abstract])) OR ((((()((postpartum[Title/Abstract]) OR post-partum[Title/Abstract]) OR post partum[Title/Abstract]) OR postpartum[Title/Abstract]) OR postpartum[Title/Abstract])) OR peripartum[Title/Abstract]) OR peri-partum[Title/ Abstract]) OR peri partum[Title/Abstract])) AND ((((nulliparous[Title/Abstract]) OR primiparous[Title/Abstract]) OR primigrav*[Title/Abstract]) OR primipara[Title/ Abstract]))))) AND ((()((()((()((()((()(((prevalence[MeSH Terms]) OR prevalence[Title/ Abstract]))) OR epidemiology[MeSH Terms])) OR epidemiology[Title/Abstract]) OR quality of life[MeSH Terms]) OR 'quality of life'[Title/Abstract]) OR bother*[Title/ Abstract]) OR bothersomeness[Title/Abstract])) 


\section{REFERENCES:}

1. Haylen BT, de Ridder D, Freeman RM, et al. An International Urogynecological Association (IUGA)/International Continence Society (ICS) joint report on the terminology for female pelvic floor dysfunction. Int Urogynecol J. 2010;21(1):5-26.

2. Botlero R, Davis SR, Urquhart DM, Shortreed S, Bell RJ. Age-specific prevalence of, and factors associated with, different types of urinary incontinence in community-dwelling Australian women assessed with a validated questionnaire. Maturitas. 2009;62(2):134139.

3. Viktrup L, Rortveit G, Lose G. Risk of stress urinary incontinence twelve years after the first pregnancy and delivery. Obstet Gynecol. 2006;108(2):248-254.

4. Linde JM, Nijman RJM, Trzpis M, Broens PMA. Urinary incontinence in the Netherlands: Prevalence and associated risk factors in adults. Neurourol Urodyn. 2017;36(6):15191528.

5. Burgio KL, Zyczynski H, Locher JL, Richter HE, Redden DT, Wright KC. Urinary incontinence in the 12-month postpartum period. Obstet Gynecol. 2003;102(6):1291-1298.

6. MacArthur $C$, Wilson $D$, Herbison $P$, et al. Urinary incontinence persisting after childbirth: extent, delivery history, and effects in a 12-year longitudinal cohort study. BJOG. 2016;123(6):1022-1029.

7. Ebbesen MH, Hunskaar S, Rortveit G, Hannestad YS. Prevalence, incidence and remission of urinary incontinence in women: longitudinal data from the Norwegian HUNT study (EPINCONT). BMC Urol. 2013;13:27.

8. Handa VL, Zyczynski HM, Burgio KL, et al. The impact of fecal and urinary incontinence on quality of life 6 months after childbirth. Am J Obstet Gynecol. 2007;197(6):636.e631636.

9. Coyne KS, Wein A, Nicholson S, Kvasz M, Chen Cl, Milsom I. Economic burden of urgency urinary incontinence in the United States: a systematic review. J Manag Care Pharm. 2014;20(2):130-140.

10. Mendes A, Hoga L, Gonçalves B, Silva P, Pereira P. Adult women's experiences of urinary incontinence: a systematic review of qualitative evidence. JBI Database System Rev Implement Rep. 2017;15(5):1350-1408.

11. Durnea CM, Khashan AS, Kenny LC, Tabirca SS, O'Reilly BA. The role of prepregnancy pelvic floor dysfunction in postnatal pelvic morbidity in primiparous women. Int Urogynecol J. 2014;25(10):1363-1374.

12. Cooklin AR, Amir LH, Jarman J, Cullinane M, Donath SM. Maternal Physical Health Symptoms in the First 8 Weeks Postpartum Among Primiparous Australian Women. Birth. 2015;42(3):254-260.

13. Thom $\mathrm{DH}$, Rortveit $\mathrm{G}$. Prevalence of postpartum urinary incontinence: a systematic review. Acta Obstet Gynecol Scand. 2010;89(12):1511-1522.

14. Abrams A, Cardozo L, Wagg A, Wein A, eds. Incontinence 6th edition. Bristol, UK: ICI-ICS. International Continence Society; 2017.

15. Hägglund D, Walker-Engström ML, Larsson G, Leppert J. Quality of life and seeking help in women with urinary incontinence. Acta Obstet Gynecol Scand. 2001;80(11):1051-1055. 
16. Stroup DF, Berlin JA, Morton SC, et al. Meta-analysis of observational studies in epidemiology: a proposal for reporting. Meta-analysis Of Observational Studies in Epidemiology (MOOSE) group. JAMA. 2000;283(15):2008-2012.

17. (CPH) CPH. Data Extraction and Assessment Template. 2020; https://ph.cochrane.org/ review-authors.

18. Munn Z, Moola S, Riitano D, Lisy K. The development of a critical appraisal tool for use in systematic reviews addressing questions of prevalence. Int J Health Policy Manag. 2014;3(3):123-128.

19. Munn Z, Moola S, Lisy K, Riitano D, Tufanaru C. Methodological guidance for systematic reviews of observational epidemiological studies reporting prevalence and cumulative incidence data. Int J Evid Based Healthc. 2015;13(3):147-153.

20. Cochrane Handbook for Systematic Reviews of Interventions version 6.0. 2019.

21. Arrue $M$, Ibañez $L$, Paredes J, et al. Stress urinary incontinence six months after first vaginal delivery. Eur J Obstet Gynecol Reprod Biol. 2010;150(2):210-214.

22. Baydock SA, Flood C, Schulz JA, et al. Prevalence and risk factors for urinary and fecal incontinence four months after vaginal delivery. J Obstet Gynaecol Can. 2009;31(1):36-41.

23. Borello-France $\mathrm{D}$, Burgio $\mathrm{KL}$, Richter $\mathrm{HE}$, et al. Fecal and urinary incontinence in primiparous women. Obstet Gynecol. 2006;108(4):863-872.

24. Boyles SH, Li H, Mori T, Osterweil P, Guise JM. Effect of mode of delivery on the incidence of urinary incontinence in primiparous women. Obstet Gynecol. 2009;113(1):134-141.

25. Brown S, Lumley J. Maternal health after childbirth: results of an Australian population based survey. Br J Obstet Gynaecol. 1998;105(2):156-161.

26. Brown S, Gartland D, Perlen S, McDonald E, MacArthur C. Consultation about urinary and faecal incontinence in the year after childbirth: a cohort study. BJOG. 2015;122(7):954962.

27. Chaliha C, Kalia V, Stanton SL, Monga A, Sultan AH. Antenatal Prediction of Postpartum Urinary andFecal Incontinence. Obstet Gynecol. 1999;94(5):689-694.

28. Dolan LM, Walsh D, Hamilton S, Marshall K, Thompson K, Ashe RG. A study of quality of life in primigravidae with urinary incontinence. Int Urogynecol J Pelvic Floor Dysfunct. 2004;15(3):160-164.

29. Farrell SA, Allen VM, Baskett TF. Parturition and urinary incontinence in primiparas. Obstet Gynecol. 2001;97(3):350-356.

30. Gartland D, MacArthur C, Woolhouse H, McDonald E, Brown SJ. Frequency, severity and risk factors for urinary and faecal incontinence at 4 years postpartum: a prospective cohort. BJOG. 2016;123(7):1203-1211.

31. Glazener CM, Herbison GP, MacArthur $C$, et al. New postnatal urinary incontinence: obstetric and other risk factors in primiparae. BJOG. 2006;113(2):208-217.

32. Hansen BB, Svare J, Viktrup L, Jorgensen T, Lose G. Urinary incontinence during pregnancy and 1 year after delivery in primiparous women compared with a control group of nulliparous women. Neurourol Urodyn. 2012;31(4):475-480.

33. Hatem M, Fraser W, Lepire E. Postpartum urinary and anal incontinence: a populationbased study of quality of life of primiparous women in Quebec. J Obstet Gynaecol Can. 2005;27(7):682-688. 
34. Huebner M, Antolic A, Tunn R. The impact of pregnancy and vaginal delivery on urinary incontinence. Int J Gynaecol Obstet. 2010;110(3):249-251.

35. Johannessen HH, Stafne SN, Falk RS, Stordahl A, Wibe A, Mørkved S. Prevalence and predictors of double incontinence 1 year after first delivery. Int Urogynecol J. 2018;29(10):1529-1535.

36. Mannion CA, Vinturache AE, McDonald SW, Tough SC. The Influence of Back Pain and Urinary Incontinence on Daily Tasks of Mothers at 12 Months Postpartum. PLoS One. 2015;10(6):e0129615.

37. Martin-Martin S, Pascual-Fernandez A, Alvarez-Colomo C, Calvo-Gonzalez R, MuñozMoreno M, Cortiñas-Gonzalez JR. Urinary incontinence during pregnancy and postpartum. Associated risk factors and influence of pelvic floor exercises. Arch Esp Urol. 2014;67(4):323-330.

38. Mason L, Glenn S, Walton I, Appleton C. The prevalence of stress incontinence during pregnancy and following delivery. Midwifery. 1999;15(2):120-128.

39. Morkved S, Bo K. Prevalence of Urinary Incontinence During Pregnancy and Postpartum. Int Urogynecol J. 1999(10):394-398.

40. Pregazzi R, Sartore A, Troiano L, et al. Postpartum urinary symptoms: prevalence and risk factors. EurJ Obstet Gynecol Reprod Biol. 2002;103(2):179-182.

41. Quiboeuf E, Saurel-Cubizolles MJ, Fritel X. Trends in urinary incontinence in women between 4 and 24 months postpartum in the EDEN cohort. BJOG. 2016;123(7):12221228.

42. Raza-Khan F, Graziano S, Kenton K, Shott S, Brubaker L. Peripartum urinary incontinence in a racially diverse obstetrical population. Int Urogynecol J Pelvic Floor Dysfunct. 2006;17(5):525-530.

43. Rikard-Bell J, lyer J, Rane A. Perineal outcome and the risk of pelvic floor dysfunction: a cohort study of primiparous women. Aust N Z J Obstet Gynaecol. 2014;54(4):371-376.

44. Schytt E, Lindmark G, Waldenström U. Symptoms of stress incontinence 1 year after childbirth: prevalence and predictors in a national Swedish sample. Acta Obstet Gynecol Scand. 2004;83(10):928-936.

45. Solans-Domènech $M$, Sánchez $E$, Espuña-Pons $M$. Urinary and anal incontinence during pregnancy and postpartum: incidence, severity, and risk factors. Obstet Gynecol. 2010;115(3):618-628.

46. Thomason AD, Miller JM, Delancey JO. Urinary incontinence symptoms during and after pregnancy in continent and incontinent primiparas. Int Urogynecol J Pelvic Floor Dysfunct. 2007;18(2):147-151.

47. Torrisi G, Minini G, Bernasconi F, et al. A prospective study of pelvic floor dysfunctions related to delivery. Eur J Obstet Gynecol Reprod Biol. 2012;160(1):110-115.

48. Wesnes SL, Hannestad Y, Rortveit G. Delivery parameters, neonatal parameters and incidence of urinary incontinence six months postpartum: a cohort study. Acta Obstet Gynecol Scand. 2017;96(10):1214-1222.

49. Johannessen HH, Wibe A, Stordahl A, Morkved S. Prevalence of anal and urinary incontinence in primiparas and impact on health related quality of life. Neurourol Urodyn. 2012;31 (6):1089-1091. 
50. Solans-Domenech M, Sanchez E, Espuna-Pons M. Urinary and anal incontinence during pregnancy and postpartum: Incidence, severity, and risk factors. Obstet Gynecol. 2010;115(3):618-628.

51. Hatem M, Fraser W, Lepire E. Postpartum Urinary and Anal Incontinence: A PopulationBased Study of Quality of Life of Primiparous Women in Quebec. J Obstet Gynaecol Can. 2005;27(7):682-688.

52. Dolan LM, Walsh D, Hamilton S, Marshall K, Thompson K, Ashe RG. A study of quality of life in primigravidae with urinary incontinence. Int Urogyn J. 2004;15(3):160-164.

53. Mannion CA, Vinturache AE, McDonald SW, Tough SC. The influence of back pain and urinary incontinence on daily tasks of mothers at 12 months postpartum. PLOS ONE. 2015;10 (6) (no pagination)(e0129615).

54. Hojberg KE, Salvig JD, Winslow NA, Lose G, Secher NJ. Urinary incontinence: prevalence and risk factors at 16 weeks of gestation. Br J Obstet Gynaecol. 1999;106(8):842-850.

55. Nigam A, Ahmad A, Gaur D, Elahi AA, Batra S. Prevalence and risk factors for urinary incontinence in pregnant women during late third trimester. IJRCOG. 2016;5(7):21872191.

56. Boyles $\mathrm{SH}$, $\mathrm{Li} \mathrm{H}$, Mori T, et al. Effect of mode of delivery on the incidence of urinary incontinence in primiparous women. Obstet Gynecol. 2009;113(1):134-141.

57. Brown S, Gartland D, Perlen S, McDonald E, MacArthur C. Consultation about urinary and faecal incontinence in the year after childbirth: A cohort study. BJOG. 2015;122(7):954962.

58. Chaliha C, Kalia V, Stanton S, Monga A, Sultan A. Antenatal Prediction of postpartum Urinary and Fecal Incontinence. Obstet Gynecol. 1999;94(5):689-694.

59. Gartland D, MacArthur C, Woolhouse H, McDonald E, Brown SJ. Frequency, severity and risk factors for urinary and faecal incontinence at 4 years postpartum: a prospective cohort. BJOG. 2016;123(7):1203-1211.

60. Glazener CMA, Herbison GP, MacArthur C, et al. New postnatal urinary incontinence: obstetric and other risk factors in primiparae. BJOG. 2006;113(2):208-217.

61. Rikard-Bell J, lyer J, Rane A. Perineal outcome and the risk of pelvic floor dysfunction: A cohort study of primiparous women. Aust N Z J Obstet Gynaecol. 2014;54(4):371-376.

62. Solans-Domènech $M$, Sánchez $E$, Espuña-Pons $M$. Urinary and anal incontinence during pregnancy and postpartum: incidence, severity, and risk factors. Obstet Gynecol. 2010;115(3):618-628.

63. Baydock SA, Flood C, Schulz JA, et al. Prevalence and Risk Factors for Urinary and Fecal Incontinence Four Months After Vaginal Delivery. J Obstet Gynaecol Can. 2009;31(1):3641.

64. Mason L, Glenn S, Walton I, Appleton C. The experience of stress incontinence after childbirth. Birth. 1999;26(3):164-171.

65. Morkved S, Bo K. Prevalence of urinary incontinence during pregnancy and postpartum. Int Urogynecol J. 1999;10(6):394-398.

66. Pregazzi R, Sartore A, Troiano L, et al. Postpartum urinary symptoms: Prevalence and risk factors. Eur J Obstet Gynecol Reprod Biol. 2002;103(2):179-182. 
67. Quiboeuf E, Saurel-Cubizolles MJ, Fritel X. Trends in urinary incontinence in women between 4 and 24 months postpartum in the EDEN cohort. BJOG. 2016;123(7):12221228.

68. Schytt E, Lindmark G, Waldenstrom U. Symptoms of stress incontinence 1 year after childbirth: Prevalence and predictors in a national Swedish sample. Acta Obstet Gynecol Scand. 2004;83(10):928-936.

69. Burgio KL, Zyczynski H, Locher JL, Richter HE, Redden DT, Wright KC. Urinary incontinence in the 12-month postpartum period. Obstet Gynecol. 2003;102(6):1291-1298.

70. Martin-Martin S, Pascual-Fernandez A, Alvarez-Colomo C, Calvo-Gonzalez R, MunozMoreno M, Cortinas-Gonzalez JR. Urinary incontinence during pregnancy and postpartum. Associated risk factors and influence of pelvic floor exercises. Arch Espanol Urol. 2014;67(4):323-330.

71. Boyles SH, Li H, Mori T, Osterweil P, Guise JM. Effect of mode of delivery on the incidence of urinary incontinence in primiparous women. Obstet Gynecol. 2009;113(1):134-141.

72. Farrell SA, Allen VM, Baskett TF. Parturition and urinary incontinence in primiparas. Obstet Gynecol. 2001;97(3):350-356.

73. Huebner M, Antolic A, Tunn R. The impact of pregnancy and vaginal delivery on urinary incontinence. Int J Gynecol Obstet. 2010;110(3):249-251.

74. Wesnes SL, Hunskaar S, Bo K, Rortveit G. Urinary incontinence and weight change during pregnancy and postpartum: A cohort study. Am J Epidemiol. 2010;172(9):10341044.

75. Borello-France $\mathrm{D}$, Burgio $\mathrm{KL}$, Richter $\mathrm{HE}$, et al. Fecal and urinary incontinence in primiparous women. Obstet Gynecol. 2006;108(4):863-872.

76. Streiner D, Norman G. Health measurement scales. Fourth Edition ed. Oxford, UK Oxford University Press; 1989.

77. Moossdorff-Steinhauser HFA, Berghmans BCM, Spaanderman MEA, Bols EMJ. Prevalence, incidence and bothersomeness of urinary incontinence in pregnancy: a systematic review and meta-analysis. Int Urogynecol J. 2021.Jan 13. Online ahead of print.

78. Stær-Jensen J, Siafarikas F, Hilde G, Benth J, Bø K, Engh ME. Postpartum recovery of levator hiatus and bladder neck mobility in relation to pregnancy. Obstet Gynecol. 2015;125(3):531-539.

79. Shek KL, Chantarasorn V, Langer S, Dietz HP. Does levator trauma 'heal'? Ultrasound Obstet Gynecol. 2012;40(5):570-575.

80. Hesketh KR, Evenson KR, Stroo M, Clancy SM, Østbye T, Benjamin-Neelon SE. Physical activity and sedentary behavior during pregnancy and postpartum, measured using hip and wrist-worn accelerometers. Prev Med Rep. 2018;10:337-345.

81. Evenson KR, Herring AH, Wen F. Self-Reported and objectively measured physical activity among a cohort of postpartum women: the PIN Postpartum Study. J Phys Act Health. 2012;9(1):5-20.

82. Rortveit G, Hannestad YS, Daltveit AK, Hunskaar S. Age- and type-dependent effects of parity on urinary incontinence: the Norwegian EPINCONT study. Obstet Gynecol. 2001;98(6):1004-1010. 
83. Thom DH, Rortveit G. Prevalence of Postpartum Urinary Incontinence: A Systematic Review. J Wound Ostomy Continence Nurs. 2011;38:S25-26.

84. Stach-Lempinen B, Kujansuu E, Laippala P, Metsänoja R. Visual analogue scale, urinary incontinence severity score and $15 \mathrm{D}$--psychometric testing of three different healthrelated quality-of-life instruments for urinary incontinent women. Scand J Urol Nephrol. 2001;35(6):476-483.

85. Boonstra AM, Schiphorst Preuper HR, Balk GA, Stewart RE. Cut-off points for mild, moderate, and severe pain on the visual analogue scale for pain in patients with chronic musculoskeletal pain. Pain. 2014;155(12):2545-2550.

86. Moossdorff-Steinhauser HFA, Berghmans BCM, Spaanderman MEA, Bols EMJ. Urinary incontinence 6 weeks to 1 year post-partum: prevalence, experience of bother, beliefs, and help-seeking behavior. Int Urogynecol J. 2021. 


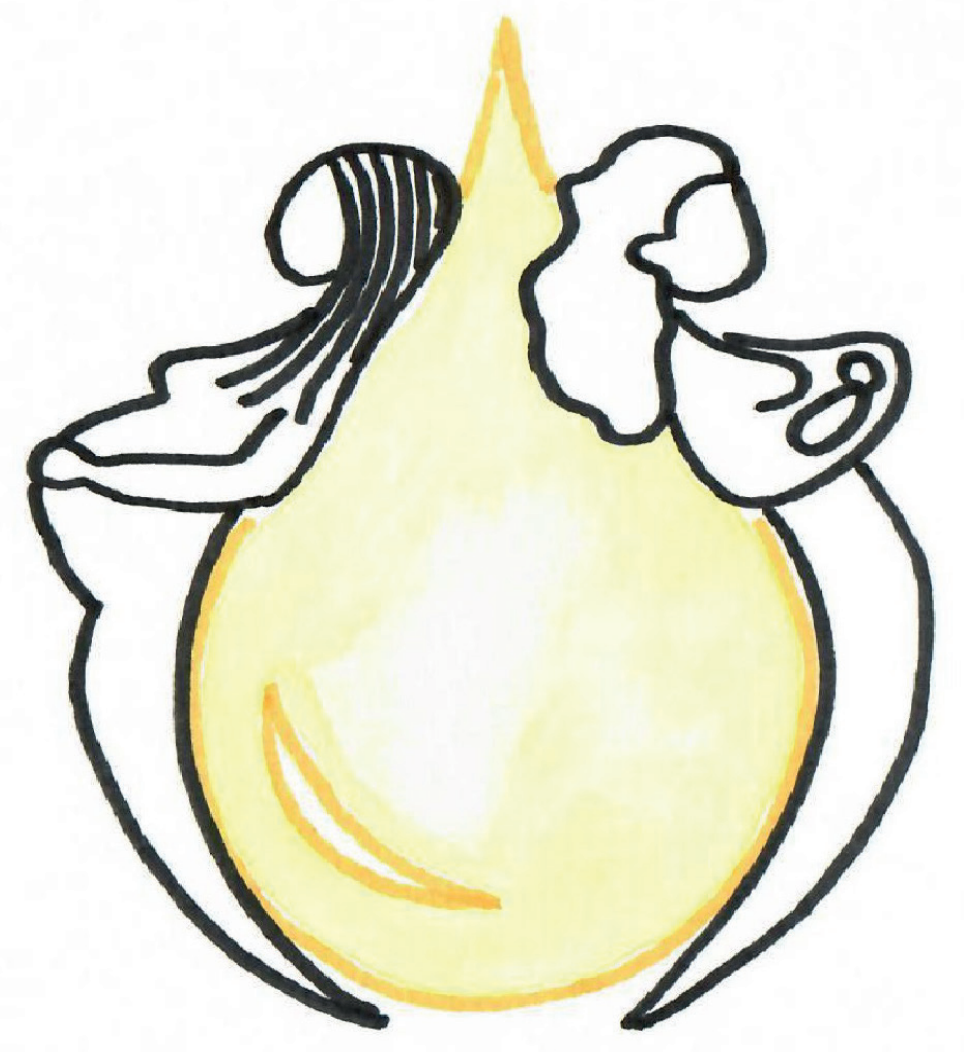




\section{LONG-TERM EFFECTS OF MOTHERFIT} GROUP THERAPY IN PRE-

\section{(MOTHERFIT1) AND POST-PARTUM WOMEN (MOTHERFIT2) WITH STRESS URINARY INCONTINENCE COMPARED TO CARE-AS-USUAL; STUDY PROTOCOL OF TWO MULTI-CENTRED RANDOMISED CONTROLLED TRIALS}

Heidi F.A. Moossdorff-Steinhauser ${ }^{1}$ Esther M.J. Bols ${ }^{1}$ Marc E.A. Spaanderman ${ }^{2,3}$ Carmen D. Dirksen ${ }^{2,5}$ Mirjam Weemhoff' Fred H.M. Nieman² Bary C.M. Berghmans ${ }^{2,4}$

${ }^{1}$ Maastricht University, Faculty of Health, Medicine and Life Sciences, Dept. Epidemiology, CAPHRI Care and Public Health Research Institute, P.O. Box 616, 6200 MD Maastricht, The Netherlands; ${ }^{2}$ Maastricht University Medical Centre (MUMC+), Maastricht, The Netherlands; ${ }^{3}$ Department of Obstetrics and Gynecology; ${ }^{4}$ Pelvic care Center Maastricht; ${ }^{5}$ Department of Clinical Epidemiology and Medical Technology Assessment; ${ }^{6}$ Zuyderland Medisch Centrum, Department of Obstetrics and Gynecology, Sittard-Geleen, The Netherlands 


\section{ABSTRACT}

Background: Stress urinary incontinence (SUI) is highly prevalent during pregnancy and after delivery. It is often associated with a failing pelvic floor, sphincteric and/ or supportive system. Pelvic floor muscle training (PFMT) peri-partum has been proven effective for up to one year post-partum, however long-term effects are unknown. Group PFMT given by a physiotherapist is proven equally effective as individual therapy. Motherfit is a group PFMT therapy with an emphasis on pelvic floor exercises, adherence and general fitness. Care-as-usual (CAU), if guideline driven, should as first treatment option consist of PFMT. Cost-effective strategies are of relevance, given the rise of health care costs. Motherfit group therapy has the potential to be cost-effective in women with urinary incontinence. Therefore, the objectives of the two current studies are: (1) to investigate whether intensive, supervised pre-partum (MOTHERFIT1) or post-partum (MOTHERFIT2) pelvic floor muscle group therapy reduces 18 months post-partum severity of SUI compared to CAU and (2) whether MOTHERFIT1 OR MOTHERFIT 2 is more (cost-)effective compared to CAU.

Methods: Two multi-centred randomised controlled trials (MOTHERFIT1, n=150, MOTHERFIT2, $n=90$ ) will be performed. Participants will be recruited by their midwife or gynaecologist during their routine check. Participants with SUI will receive either motherfit group therapy or CAU. Motherfit group therapy consists of eight group sessions of 60 minutes each, instructed and supervised by a registered pelvic physiotherapist. Motherfit group therapy includes instructions on pelvic floor anatomy and how to contract, relax and train the pelvic floor muscles correctly and is combined with general physical exercises. Adherence during and after motherfit will be stimulated by reinforcement techniques and a m(obile)App. The primary outcome measure is the absence of self-reported SUI based on the severity sum score of the International Consultation on Incontinence Questionnaire Short Form (ICIQ-UI SF) at 18 months post-partum. Secondary outcomes evaluate quality of life, subjective improvement and health care costs.

Discussion: The motherfit studies are, to our knowledge, the first studies that evaluate both long-term results and health care costs compared to CAU in pregnant and post-partum women with SUI. In case motherfit shows to be (cost-) effective, implementation in peri-partum care should be considered. 


\section{BACKGROUND}

Urinary incontinence (UI) affects $13-40 \%$ of women during their life. ${ }^{1-4}$ Pregnancy and childbirth are the most important provocative factors for UI during lifetime. ${ }^{5}$

Stress urinary incontinence (SUI), defined as any involuntary leakage of urine on effort or exertion, or on sneezing or coughing, is the most prevalent type of UI during pregnancy. ${ }^{6} \mathrm{SUI}$ can be the result of a failing pelvic floor, sphincteric and/ or supportive system. ${ }^{7}$ The prevalence of SUI rises from approximately $9 \%$ in the first trimester of pregnancy to 32\% in the second and 38\% in the third trimester. ${ }^{8-10}$ Eight weeks after delivery the prevalence of SUI is $19 \%$, rising to respectively $22 \%$ and $26 \%$ at six and 12 months post-partum. ${ }^{8,11}$ Mørkved et al. ${ }^{10}$ even reported a prevalence of $40 \%$ eight weeks post-partum. Many women believe that their UI will resolve by itself. ${ }^{12}$ However, it is known that 75 to $92 \%$ of the women with SUI at three months post-partum, still have UI even after five or 12 years. ${ }^{13,14}$ Often, UI reduces quality of life because of its negative impact on sexual relationships and daily life activities. ${ }^{15,16}$ Despite this, 75\% of women never seek help for UI because they feel embarrassed or feel that loosing urine is normal after giving birth. ${ }^{12,17,18}$

Pelvic floor muscle training (PFMT) aims to improve the supportive system and to achieve a timely contraction in case of expected leakage, both with voluntary (the Knack manoeuvre) and involuntary contractions. ${ }^{19}$ Positive effects of PFMT peri-partum are proven up to one year post-partum. ${ }^{20}$ However, it is still unknown whether long-term effects are lasting as well as whether pre- or post-partum PFMT is more effective in treating SUI compared to care-as-usual (CAU). Currently there are no guidelines on UI peri-partum for midwives and gynaecologists. ${ }^{21}$ Therefore, CAU is known to be applied differently among health care providers and sometimes only includes prescription of incontinence materials. ${ }^{22}$ PFMT may be provided individually or in a group. Recently, a meta-analysis on the effects of individual versus group PFMT for women with UI, both provided by a physiotherapist, showed no significant difference in results between the groups. ${ }^{23}$ The latter is of particular interest as group therapy is less expensive when compared to individual therapy, and might therefore be a cost-effective strategy. It is known that healthcare costs are rising due to an increasing level of unhealthy lifestyle and number of people with one or more chronic diseases. For that reason, it is of relevance to focus on the evaluation of potentially cost-effective therapies. ${ }^{24,25}$ Given the promising effects of PFMT on the short term and the potential of group therapy being a cost-effective 
strategy, the Pelvic care Center Maastricht (PcCM), embedded in the Maastricht University Medical Centre (MUMC+), developed motherfit group therapy. Motherfit group therapy includes pelvic floor muscle group therapy (PFMGT) combined with general fitness exercises, provided by pelvic physiotherapists, to treat peri-partum women with SUI. Moreover, motherfit group therapy has a strong focus on self-management, as it is reported that this will promote adherence and thereby sustain longer-term effects. ${ }^{26}$.

The primary objective of this study is to investigate whether a structured assessment and treatment program (motherfit group therapy) of intensive, supervised PFMGT, including a home maintenance program, reduces 18 months post-partum UI severity (frequency, amount, and impact) compared to CAU in adult pregnant women (MOTHERFIT1) and post-partum women with SUI (MOTHERFIT2). The secondary objective is to investigate whether motherfit group therapy is costeffective compared to CAU in pregnant (MOTHERFIT1) and post-partum women with SUI (MOTHERFIT2) 18 months post-partum.

It is hypothesized that intensive, supervised pre-partum (study 1: MOTHERFIT1) or post-partum (study 2: MOTHERFIT2) PFMGT is more (cost-)effective compared to CAU in adult pregnant (MOTHERFIT1) or post-partum women with SUI (MOTHERFIT2).

\section{METHODS}

\section{Study design}

The study consists of two multi-centred randomised controlled trials (RCTs), namely MOTHERFIT1 and MOTHERFIT2. MOTHERFIT1 focuses on investigating PFMGT pre-partum and MOTHERFIT2 on PFMGT post-partum. Participants will be recruited in the southern part of The Netherlands from the Maastricht University Medical Center (MUMC+), Zuyderland MC (Heerlen/Sittard), Laurentius hospital (Roermond), Maxima MC (Eindhoven) and surrounding midwifery practices. Except for Maxima MC all obstetric centres are part of the Obstetric Consortium Limburg, a first, second and third line obstetric midwifery maternity care collaboration. In every region, a registered pelvic physiotherapist will provide motherfit group therapy. 


\section{Participants}

Women will be included if they meet all of the following criteria: (1) $\geq 18$ years, (2) UI (stress or mixed with predominant stress UI factor, according to Haylen et al. ${ }^{6}$, (3) a score of $>3$ on the International Consultation on Incontinence modular questionnaire- urinary incontinence- short form (ICIQ-UI SF) questionnaire ${ }^{27}$, (4) motivated for participation in the motherfit program, (5) competent to speak and understand the Dutch language and to read and fill in forms independently, (6) mobile app (mApp) on tablet (Apple or Android) available.

Exclusion criteria are: (1) UI prior to first pregnancy, still existing during pregnancy, (2) high-risk pregnancy, resulting in a contra-indication for performing intensive pelvic floor muscle (PFM) exercises (f.i. placenta praevia, vaginal blood loss, preterm uterine contractions), (3) suffering from significant exercise limitations or co-morbidities (physical or psychological) that would restrain a woman from participation in motherfit group therapy, (4) history of chronic neurological disorders or diseases related to UI (e.g., multiple sclerosis, cerebrovascular accident, diabetes mellitus (during $\geq 1$ year with $\mathrm{HbA} 1 \mathrm{c}>10 \mathrm{mmol} / \mathrm{l}$ )), (5) urinary tract infection (urine-sediment, urine culture), (6) history of anti-incontinence or urogynaecological surgery, (7) women who are expected to be lost to follow-up (e.g., because of a planned change of residency), (8) recent pelvic physiotherapy (< six months), (9) refusal to use a mApp.

\section{Detailed study Plan}

\section{Patient recruitment/consent procedure}

The obstetrician/gynaecologist or midwife (case manager) at each centre will be responsible for identifying eligible participants. All women will receive written and digital (www.motherfit.net) general information about the motherfit study at:

The first visit to the case manager and may be recruited from the second visit at 12 weeks or later until 27 weeks gestation (MOTHERFIT1)

Routine control at six weeks post-partum (MOTHERFIT2)

In case a woman is interested to participate, a short vaginal examination is performed to check the ability to contract the pelvic floor muscles (Table 1 and 2). The woman will receive an envelope containing: patient information, two 
informed consent forms with return envelope and an information booklet on medical scientific research of the Dutch government. ${ }^{28}$ The case manager fills in the name, telephone number and email address of the woman at a secure site (digital database), which can only be accessed by the researcher. After one week, the researcher will contact the woman by telephone and asks whether the woman has any questions regarding the study after reading the patient information. If the woman is willing to participate, she will be asked to fill in the two informed consent forms and return them to the researcher. The researcher will sign the two informed consent forms and returns one to the participant.

Table 1 Schedule of enrolment, allocation, interventions and assessments for MOTHERFIT1

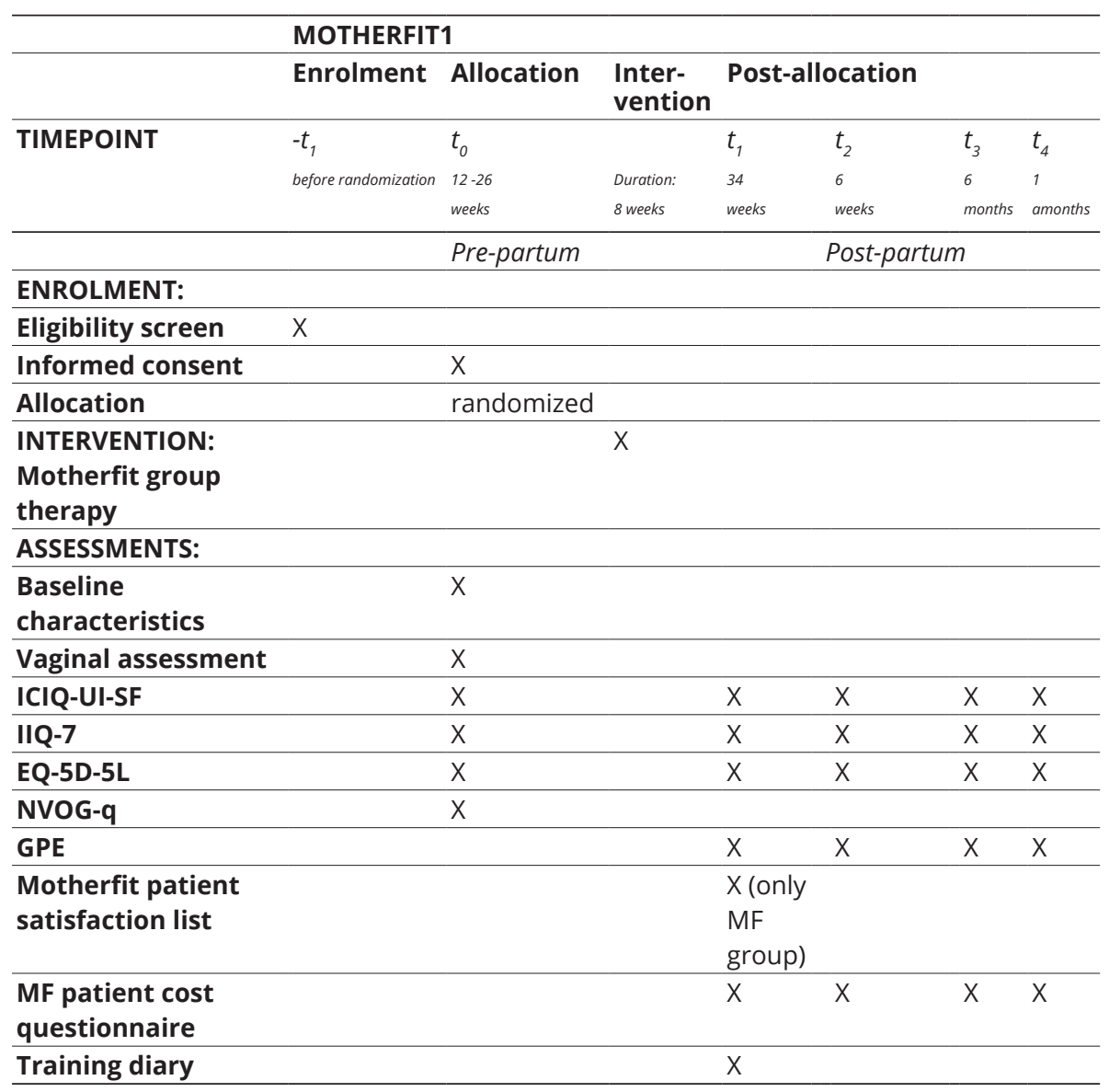

t=timepoint, ICIQ-UI-SF=International Consultation on Incontinence Questionnaire Short Form, IIQ-7=Incontinence Impact Questionnaire, EQ-5D-5L=EuroQol quality of life questionnaire, NVOG-q=Nederlandse Vereniging voor Obstetrie en Gynaecologie questionnaire, GPE=Patient Global Impression of Severity 
Table 2 Schedule of enrolment, allocation, interventions and assessments for MOTHERFIT2

\begin{tabular}{|c|c|c|c|c|c|c|}
\hline \multirow{4}{*}{ TIMEPOINT } & \multicolumn{6}{|l|}{ MOTHERFIT2 } \\
\hline & \multirow{3}{*}{$\begin{array}{l}\text { Enrolment } \\
-t_{1} \\
\text { before randomization }\end{array}$} & \multirow{2}{*}{$\begin{array}{l}\text { Allocation } \\
t_{0}\end{array}$} & \multirow{3}{*}{$\begin{array}{l}\text { Inter- } \\
\text { vention } \\
\text { Duration: } \\
8 \text { weeks }\end{array}$} & \multicolumn{3}{|c|}{ Post-allocation } \\
\hline & & & & $t_{1}$ & $t_{2}$ & $t_{4}$ \\
\hline & & 6 weeks & & 4 months & 9 months & 18 months \\
\hline & Post-partum & & & & & \\
\hline \multicolumn{7}{|l|}{ ENROLMENT: } \\
\hline Eligibility screen & $x$ & & & & & \\
\hline Informed consent & & $x$ & & & & \\
\hline Allocation & & randomized & & & & \\
\hline $\begin{array}{l}\text { INTERVENTION: } \\
\text { Motherfit group } \\
\text { therapy }\end{array}$ & & & $x$ & & & \\
\hline \multicolumn{7}{|l|}{ ASSESSMENTS: } \\
\hline $\begin{array}{l}\text { Baseline } \\
\text { characteristics }\end{array}$ & & $x$ & & & & \\
\hline $\begin{array}{l}\text { Vaginal } \\
\text { assessment }\end{array}$ & & $x$ & & & & \\
\hline ICIQ-UI-SF & & $x$ & & $x$ & $x$ & $x$ \\
\hline IIQ-7 & & $x$ & & $x$ & $x$ & $x$ \\
\hline$E Q-5 D-5 L$ & & $x$ & & $x$ & $x$ & $x$ \\
\hline NVOG-q & & $x$ & & & & \\
\hline GPE & & & & $\mathrm{X}$ & $x$ & $x$ \\
\hline $\begin{array}{l}\text { Motherfit patient } \\
\text { satisfaction list }\end{array}$ & & & & $\begin{array}{l}X \text { (only } \\
\text { group) }\end{array}$ & & \\
\hline $\begin{array}{l}\text { MF patient cost } \\
\text { questionnaire }\end{array}$ & & & & $x$ & $x$ & $x$ \\
\hline Training diary & & & & $x$ & & \\
\hline
\end{tabular}

t=timepoint, ICIQ-UI-SF=International Consultation on Incontinence Questionnaire Short Form, IIQ-7=Incontinence Impact Questionnaire, EQ-5D-5L=EuroQol quality of life questionnaire, NVOG-q=Nederlandse Vereniging voor Obstetrie en Gynaecologie questionnaire, GPE=Patient Global Impression of Severity

\section{Allocation of participants}

After signing informed consent, the participant will receive an email with a link to the electronic baseline questionnaires. Once the questionnaires are completed, block randomisation (block size is four) will be done by a computer-generated sequence in a 1:1 ratio on the individual patient and location level. Allocation in blocks of four is concealed and done using a central computer. Participants are either allocated to the motherfit program (intervention) or CAU (control group). 


\section{Blinding}

Due to the nature of the interventions, the participants and pelvic physiotherapists cannot be blinded. During the trial the coordinating researcher is not blinded. However, once the participant has completed the questionnaires, it is not possible to make changes in the data due to locking of the questionnaires. Moreover, before the statistical analyses all participants will be appointed a new study number for which the coordinating researcher is blinded. Therefore, analyses will be done blinded for treatment allocation.

\section{Protocol training}

\section{Case managers}

Preceding the inclusion period, on site information, instruction on the standardized assessment and inclusion procedures will be provided to case managers by the researcher for one hour. Assessment follows standard procedures of the Dutch Consortium Urogynecology to assess pelvic floor signs and symptoms. Special attention will be paid to the short assessment of a correct contraction of PFMs by observation and vaginal palpation of closing and lifting of the PFMs. ${ }^{29}$.

\section{Pelvic physiotherapists}

In The Netherlands, pelvic physiotherapy is a specialisation within the field of physiotherapy and has its own registration in order to guarantee quality. ${ }^{30}$ Preceding the inclusion period, information, instruction and training on the standardised assessment and group therapy protocol will be provided to involved pelvic physiotherapists (PPTs) during a two-hour workshop. The PPTs receive a set of laminated A4 papers with a detailed description for each therapy session, containing: topics to discuss, PFM and homework exercises.

\section{Interventions}

\section{Care-as-usual}

In case participants with SUI are allocated to the CAU group, participating case managers give their normal advices and women make their own choices whether they want to participate in any kind of pregnancy-related course, visit to a physician or therapist. 


\section{Motherfit group therapy}

All women allocated to motherfit group therapy, and unaware or unable to contract their PFMs correctly, will be referred to the PPT for individual instruction before joining the motherfit group therapy (Figure 1). Every participating region has a PPT who provides individual or group therapy. Motherfit consists of eight group therapy sessions of 60 minutes each, instructed and supervised by a registered PPT. In each group a maximum of four women are allowed to participate. Women of both studies can start when they have been randomised to motherfit group therapy. Therefore the participant's group composition may change over time. Motherfit includes instructions on pelvic floor anatomy and how to contract, relax and train the PFMs correctly and is combined with general physical exercises with a strong focus on self-management.

The PFMT protocol has been published previously by $\mathrm{B} \varnothing$ et $a l .^{31}$, and is based on the Norwegian Aerobic Fitness Model. It follows the general training principles and the recommendations concerning physical activity practice during and after pregnancy according to the American College of Obstetricians and Gynecologists and the World Health Organization (WHO) ${ }^{31,32}$ (Table 3).

Moreover, all women receive a mApp (iPelvis) ${ }^{33}$, an application with individualized pelvic physiotherapy exercises, and supportive video content and images. Performance and adherence to PFMT will be recorded in the participants personal training diary and is reinforced by regularly sending push notifications on the mApp. The training diary will be available for the motherfit group therapists and may be used to discuss the participants motivation to incorporate adequate PFMT and use of PFM in their daily activities. Although adverse events due to PFMT are very rare ${ }^{20}$, adverse event forms are used to register their occurrence during the motherfit group therapy. 


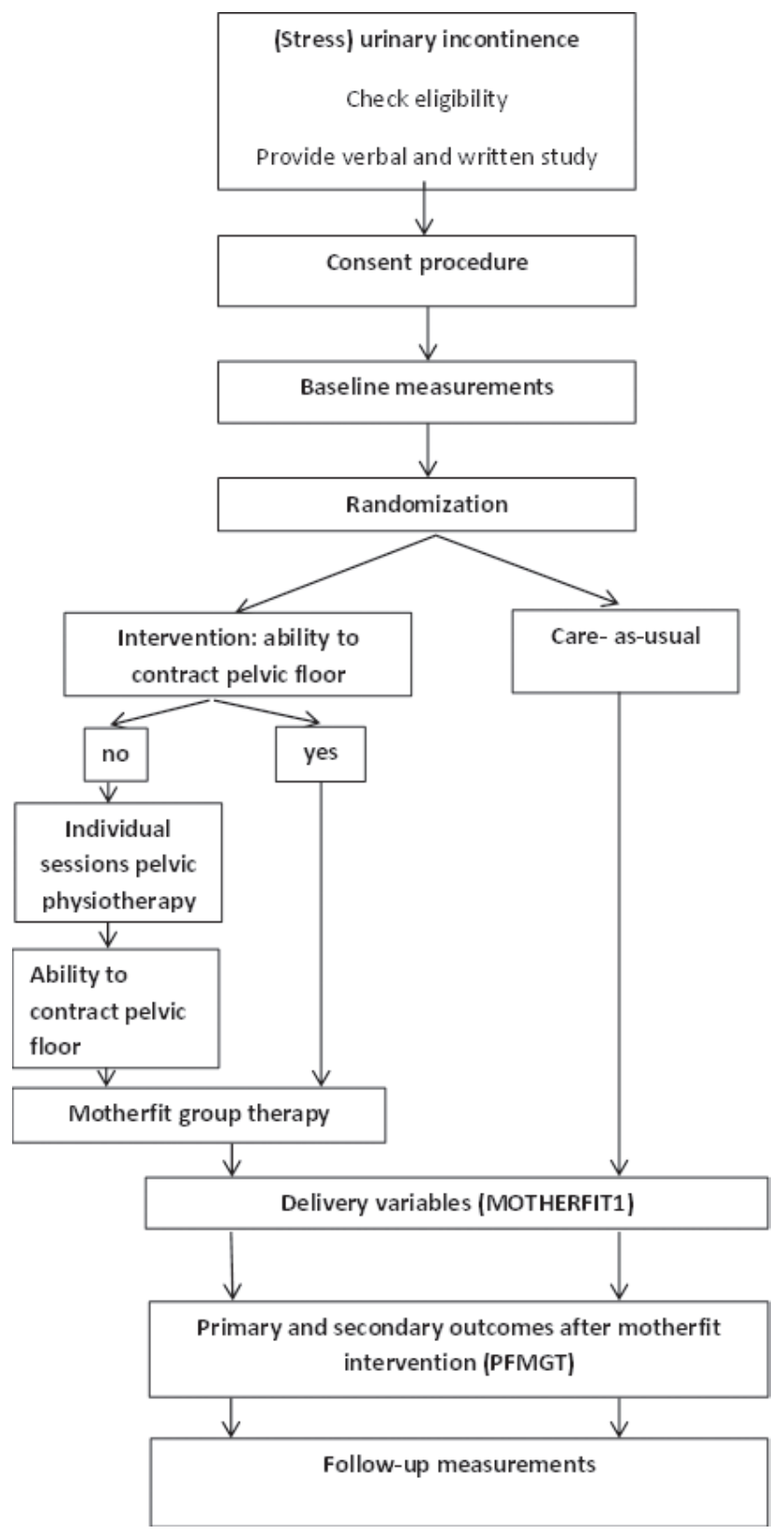

Figure 1 Study design 
Table 3 Types of training provided during MOTHERFIT1 and MOTHERFIT2 with accompanying aim and exercises

\begin{tabular}{|c|c|c|}
\hline $\begin{array}{l}\text { Type of } \\
\text { training }\end{array}$ & Aim & Exercise(s) \\
\hline Awareness & $\begin{array}{l}\text { Continue breathing during PFM } \\
\text { contraction }\end{array}$ & Breathing and PFM exercises \\
\hline Skills & $\begin{array}{l}\text { Consciously timed voluntary pre- } \\
\text { contraction }\end{array}$ & $\begin{array}{l}\text { The 'Knack'- closing of vaginal hiatus } \\
\text { and in-, up- and forward movement of } \\
\text { the PFMs before and during increased } \\
\text { abdominal pressure }\end{array}$ \\
\hline Functional & $\begin{array}{l}\text { Increase awareness to avoid } \\
\text { unnecessary abdominal pressure } \\
\text { and to prevent unnecessary or } \\
\text { extreme perineal descent during } \\
\text { daily activities }\end{array}$ & $\begin{array}{l}\text { Correct pushing technique during } \\
\text { defecation, or a PFM contraction in } \\
\text { situations associated with a rise in } \\
\text { abdominal pressure }\end{array}$ \\
\hline $\begin{array}{l}\text { Muscle } \\
\text { strength \& } \\
\text { endurance }\end{array}$ & $\begin{array}{l}\text { Build up long-lasting muscle } \\
\text { volume, providing structural } \\
\text { support/'stiffness', resulting in } \\
\text { reduced perineal descent }\end{array}$ & $\begin{array}{l}\text { Slow velocity } \\
\text { Build up to } 8 \text { - } 12 \text { contractions, of } 6 \text { - } 8 \\
\text { seconds (if possible), add } 3 \text { - } 4 \text { fast } \\
\text { contractions on top at the end to recruit } \\
\text { more slow twitch fibers. Start with } \\
\text { double time rest (complete relaxation) } \\
\text { between contractions. } \\
\text { Three sets of exercises during the day in } \\
\text { varying positions: lying, sitting, kneeling, } \\
\text { standing position. } \\
\text { Preferably daily training, but minimally } \\
3 \text { - } 4 \text { days a week, during at least } 5 \text { - } 6 \\
\text { months. } \\
\text { Maintenance muscle strength after } 6 \\
\text { months training; } 2 \text { days a week where } \\
\text { intensity is more important than } \\
\text { frequency. }\end{array}$ \\
\hline $\begin{array}{l}\text { Muscle } \\
\text { contraction: } \\
\text { speed }\end{array}$ & Build up explosive strength & $\begin{array}{l}\text { Fast repetitions } \\
\text {-Build up from } 10 \text { sets of } 3 \text { quick } \\
\text { contractions to } 10 \text { sets of } 5 \text { quick } \\
\text { contractions, } 3 \text { times a day }\end{array}$ \\
\hline
\end{tabular}

PFM= pelvic floor muscle training

\section{Data collection and outcome measures}

All data (electronic case report forms and questionnaires at baseline and followup) of the participants and case managers will be collected in a (web-based) digital central database. Demographic variables and personal characteristics will be registered by the Nederlandse Vereniging voor Obstetrie \& Gynaecologie vragenlijst (NVOG-q) at baseline for MOTHERFIT1 and MOTHERFIT2. 
MOTHERFIT1: data will be collected at baseline, 34 weeks of gestation, six weeks and six and 18 months post-partum.

MOTHERFIT2: data will be collected at baseline and four, nine and 18 months postpartum.

The case manager fills in a first survey after inclusion of a participant. For MOTHERFIT1 these questions include among others expected delivery date and current medication use. Two weeks after delivery, case managers receive a second survey regarding delivery variables. For MOTHERFIT2 the case manager fills in identical surveys, except the question on expected delivery date.

Participants in the intervention group fill in a training diary and three questions regarding their general physical activity level, weekly. The pelvic physiotherapists will register attendance of the participant during the intervention period and send it by postal mail to the researcher.

\section{Primary outcome measure}

Tables 1 and 2 show the schedule of assessments for MOTHERFIT1 and MOTHERFIT2. The primary outcome measure is self-reported UI based on the severity sum score of the International Consultation on Incontinence Questionnaire Short Form (ICIQUI SF). The ICIQ-UI SF is a brief (four questions) and robust measure for evaluating the frequency of symptoms and impact of UI. ${ }^{34}$ The total score ranges from 0 (not affected) to 21 (severely affected). The ICIQ-UI SF is divided into the following four severity categories: slight (1-5), moderate (6-12), severe (13-18) and very severe $(19-21) .{ }^{35}$ The questionnaire is translated in Dutch. ${ }^{36}$ Therapy success is defined as absence of UI or change from baseline of at least three points on the ICIQ-UI SF at 18 months post-partum. ${ }^{37}$

\section{Secondary outcome measures}

Patient-reported improvement: the Patient Global Impression of Severity (GPE) questionnaire assesses patients' self-reported improvement. ${ }^{38}$ it is an accepted and reliable scale for incontinence, consisting of one question and seven response options. ${ }^{39,40}$

Quality of life outcomes: the Incontinence Impact Questionnaire-7 (IIQ-7) contains seven items that reliably assess the impact of UI on health-related quality of life 
(QoL). ${ }^{41,42}$ It determines UI impact on four domains: mobility, physical functioning, emotional health and embarrassment and ranges from 0 to 100.

General activity level: the trainings diary has to be filled in weekly. Next to a question regarding the number of days PFM exercises have been executed, it contains three questions regarding general activity level. The questions on general activity level are modified from the Dutch healthy exercise norm (Nederlandse Norm Gezond Bewegen). This norm is based on publications of the American College of Sports Medicine. ${ }^{43}$

\section{Adherence to home training program}

Only participants in the intervention group register their performance of requested pelvic floor muscle exercises, including their general physical activity, weekly, at home in the training diary. The training diary is a data entry form and if scanned, an excel file will be computer generated.

\section{Cost-effectiveness}

For the purpose of the economic evaluation, a study specific cost questionnaire has been developed. Participants' resource use ((in)direct costs related to SUI) is collected from the societal and health care perspective. Furthermore, the EuroQol instrument (EQ-5D-5L) will be administered, a validated generic health state measure $[43,44]$ widely used in economic evaluations. The five-level version (EQ-5D-5L) is proposed by the recently updated Dutch guideline for economic evaluations in health care [47] and consists of the EQ Visual Analogue scale and a descriptive system. The descriptive system comprises five dimensions: mobility, self-care, usual activities, pain/discomfort and anxiety/depression. Each dimension can be rated at 5 levels: no problems, slight problems, moderate problems, severe problems and extreme problems.

\section{Process evaluation}

A study specific questionnaire has been developed to evaluate patient satisfaction of motherfit group therapy (part 1, ten items) and satisfaction with the use of the mApp (part 2, seven items). Questions on motherfit group therapy were f.i. on whether the participant liked training in a group and if there were enough opportunities to ask the motherfit group therapist questions. Questions regarding 
satisfaction of the mApp were f.i. on ease of use and whether participants would continue using the mApp after the intervention period. Each item ranges from 1 (strongly disagree) to 5 (strongly agree).

\section{STATISTICAL METHODS}

\section{Sample size calculation}

Assuming that the average score of the primary outcome measure (ICIQ-UI SF; range $0-21$ ) of MOTHERFIT1 will lie at 8 and for MOTHERFIT2 at 9 (which is also the expected mean ICIQ-UI SF score at 18 months post-partum in the CAU group; in contrast, the expected mean ICIQ-UI SF score at 18 months post-partum in the experimental group is 5 (for MOTHERFIT1 and MOTHERFIT2) together with a relatively high standard deviation of 5 at baseline (because of the non-normality of the measure), participants will - with $97.5 \%$ probability - vary at baseline within the ranges of 0 to 19. The minimum acceptable score of participants to be treated is set at 3, so the range lies approximately between 3 and 19. From earlier studies ${ }^{44}$, it became clear that the success of the PFMT exercises will be considerable and will be clinically relevant, if the gain will be higher than half the standard deviation of the baseline, presumably 3 with a somewhat smaller standard deviation of 3 , because of the homogenizing effects in the experimental arm. In contrast to MOTHERFIT1 (women remain stable), in MOTHERFIT2 it is assumed that the condition of CAU participants at 18 months will worsen with an average ICIQ-UI SF score going from 9 in the baseline to 10 (SD 5).

Assuming two-sided testing, a power of 90\% (beta $=0.10$ ) and a significance level of 0.95 (alpha=0.05) in each arm of the trial in MOTHERFIT1 minimally 60 and in MOTHERFIT2 minimally 35 participants will have to be included without taking into account that participants may drop out of the study during the 18 months of observations. Using a 20\% drop-out, in MOTHERFIT1 each arm will need 75 participants, 150 in total, and in MOTHERFIT2 each arm will need 45 participants, 90 in total.

\section{Statistical analysis}

Analysis of the participants will be reported in accordance with the Consolidated Standards of Reporting Trials (CONSORT) statement. ${ }^{44}$ Data will be analyzed according to the intention-to-treat principle. By preference, multiple imputation 
techniques are used for missing values.

\section{Descriptive analysis}

Firstly, descriptive, univariate statistics will be reported. In case of metric, normally distributed variables, mean and standard deviations are presented. If not normally distributed, medians and percentiles are presented. The Shapiro-Wilk test will be used to assess normality.

Process and structure indicators will be analyzed with descriptive statistics and presented as absolute and proportion data (\%) whenever the variable is categorical, or as mean (+/- standard deviation; 95\% confidence intervals) or quartiles for continuous variables. A p-value $<0.05$ will be considered to be statistically significant. Data analysis will be carried out using SPSS version 25 (IBM. Corporation, Somers. NY, USA).

\section{Analysis of main hypotheses}

In both studies, the main hypothesis concerns differential changes in ICIQUI SF within time between two randomised groups of participants. (Repeated measurements) ANCOVA will be performed with baseline measurements (T0) as covariate. Transformations of original scores will be attempted, if the ICIQ-UI SF shows a non-normal distribution at T0. Randomisation groups (motherfit group therapy versus (AU) are regarded as a between factor. Next, the within-participants linear trend in time of the outcome will be calculated with the weights from the first orthogonal polynomial contrast and this is used as a dependent variable in a multiple (dummy-) regression analysis. It concerns repeated measurements from T0 to T4 (MOTHERFIT1) and T0 to T3 (MOTHERFIT2). Next to the baseline covariate measurement and the randomisation groups dummy variable, other possible confounding variables will be used in this multiple linear regression analysis of the linear trend in time of the ICIQ-UI SF.

The following potential confounding variables are considered to be used in the multiple linear regression analysis: BMI before pregnancy (>25), parity, maternal age $(>35)$ and ability to perform a PFM contraction at baseline.

Forward selection and backward elimination techniques will be used to determine the best fit of the data to a final regression model. Testing of interactive relationships 
between statistically significant effects of predictors in the final model will be done, especially if it concerns the experimental between randomisation groups factor. List wise deletion of missing cases will be used in all linear regression modelling. This may be in case of lost-to-follow-up because of a succeeding pregnancy during the follow-up period of 18 months. For the final best-fitting regression model, a residual analysis will be done on the standardized Studentized z-scores and a screening will be performed on outliers to ensure the legitimacy and validity of the use of parametric statistics in analysis by testing the normality of distribution of the linear trend in ICIQ-UI SF.

Statistical analysis on the secondary outcomes of the study, such as the IIQ7, the GPE, and the EQ-5D-5L will be handled in the same way as the primary outcome measure ICIQ-UI SF. Process and structure indicators will be analyzed with descriptive statistics and presented quantitatively as numbers and absolute and proportion data.

\section{ECONOMIC EVALUATION}

\section{General considerations}

For both subgroups in MOTHERFIT1 and MOTHERFIT2, separate trial-based economic evaluations (EE) will be performed, but both EEs will have the same characteristics, except for the time horizon. The EE will take a societal and health care perspective, comparing motherfit group therapy with CAU. The time horizon for MOTHERFIT1 will be (about) 24 months starting from 12 weeks gestation (study inclusion) up to 18 months post-partum and for MOTHERFIT2 from approximately six weeks to 18 months post-partum. Cost-effectiveness ratios will be expressed as the societal cost per quality-adjusted life-year (QALY) (societal perspective), and the (healthcare) cost per woman in who $\mathrm{UI}$ is clinically relevant reduced (primary outcome; healthcare perspective). Bootstrap analysis and cost-effectiveness acceptability curves will be constructed; showing for a range of threshold values the probability that motherfit group therapy is cost-effective. Sensitivity analyses and subgroup analyses (e.g. on age categories, adherent versus non-adherent women) will be performed to test for the robustness of the results. 


\section{Cost- analysis}

The cost-analysis will be performed from both a societal and health care perspective. Resource use will be measured in natural units and will be valued in monetary terms by multiplying these units by the costs per unit. If available, standardized, national cost-prices (e.g. specified by the recently updated Dutch guideline for cost research in healthcare will be used..$^{45}$ Costs are distinguished into motherfit program costs including the group sessions and home-based part and costs of the mApp (initial and replacement costs for ICT hardware and software), healthcare costs (e.g. use of incontinence materials, visits to general practitioner, gynaecologist, midwife costs, visits to pelvic physiotherapist, surgery etc.), nonhealthcare costs (e.g. travel costs and productivity losses) and patient and family costs (time spent on the program, informal care costs). Data on (healthcare) resource utilization associated with SUI will be prospectively recorded during the study by the participants. Other healthcare, non-healthcare and patient and family costs will be collected by means of a standardized cost questionnaire to be filled out by patients. Costs occurring 12 months after study inclusion will be discounted at $4 \%$ according to the Dutch guidelines for economic evaluations health care. ${ }^{46}$

\section{Patient outcome analysis}

The outcome for the cost-utility analysis (societal perspective) is defined in terms of quality-adjusted life years (QALYs) from inclusion up to 18 months postpartum. The number of QALYs is derived by the adjustment of survival data with healthrelated quality of life (HRQL) HRQL will be measured with the EuroQol-5D (EQ5D) instrument, which provides a descriptive health profile and a Dutch valuation set for obtaining utility scores EQ-5D. ${ }^{47}$ The outcome for the cost-effectiveness analysis (healthcare perspective) is based on the proportion of women with clinically relevant reduction in UI at 18 months postpartum. Outcomes occurring 12 months following study inclusion will be discounted at $1.5 \%$ according to the Dutch guidelines for economic evaluations health care. ${ }^{46}$

\section{Long-term decision analytical modelling}

Next to the trial-based EE, a model-based EE will be performed, as it is expected that the economic impact of motherfit is best investigated by means of a long-term decision analytical model. First a structure and working model will be created that 
will facilitate the necessary analysis to be performed throughout the project. This model will be able to incorporate the values of all input parameters (both point estimates and uncertainty). Once the structure of the model is established, four essential types of data will be required: probabilities, costs, survival and health utilities (QALYs). Short term costs and effectiveness data are readily available from the trial-based EE, whereas longer term data may require synthesis of available evidence in the literature. Estimates of the economic impact will first be made using fixed estimates of probabilities, costs, and health outcomes. Subsequently a probabilistic sensitivity analysis will be performed which will address the joint uncertainty of the model inputs. As for the trial-based cost-effectiveness analysis, cost-effectiveness acceptability curves will be constructed. As with the trial-based $\mathrm{EE}$, the model-based EE will address the cost per QALY (societal perspective) and cost per UI prevented (healthcare perspective). We will express uncertainty by means of confidence intervals and by creating cost-effectiveness acceptability curves. The appropriate time horizon will be agreed upon during the study but is expected to be lifetime.

\section{Budget Impact Analysis (BIA)}

A BIA will be performed according to the International Society for Pharmacoeconomics and Outcomes Research (ISPOR) guidelines. ${ }^{48}$ The BIA addresses the financial stream of consequences related to the implementation of motherfit group therapy and thus its affordability. The budget impact will depend e.g. on patient acceptability of the program, the uptake of the program by healthcare professional and the target group, the cost-increase due to increased implementation of motherfit group therapy, and the cost-savings due to preventing or reducing UI, i.e. reduced cost-of-illness. The structure and some data input of the decision analytical model developed for the EE will be adapted for the BIA. Input parameters will be based on results of the trial, national prevalence data, unit prices and tariffs obtained in the trial-based EE, and available literature when necessary. The analyses will be performed from different perspectives, including a health care budgetary perspective and a health insurers' perspective. The model will take changes in the adoption / implementation of the program, and patient acceptability/uptake into account and will compare different scenarios as regards to the swiftness and extensiveness of the uptake. In order to test the robustness of the results, sensitivity analyses will be performed. The time horizon will be 
varied from one year up to five years. No discounting will be applied.

\section{Withdrawal of individual subjects}

Subjects can leave the study at any time for any reason if they wish to do so without any consequences. The investigator can decide to withdraw a subject from the study for urgent medical reasons.

All women enrolled in the study will be followed and accounted for. Women who are unwilling or unable to commit themselves to the study plan and followup schedule (i.e., serious illness, during pregnancy, f.i. premature rupture of membranes, blood loss, severe high blood pressure, pre-eclampsia, movement out of the local area, etc.) may be withdrawn from the study. Women who will become pregnant again during the follow-up period of 18 months will be handled as drop-out. Upon withdrawal of a subject, immediately all documentation is available for the investigators through the electronic case report file.

\section{DISCUSSION}

The two motherfit studies are studies aim to evaluate whether motherfit group therapy is (cost)-effective 18 months post-partum for pregnant (MOTHERFIT1) and post-partum women (MOTHERFIT2) with SUI. As health care costs are rising in general, there is a need for cost-effective strategies, which is oe of the main reasons for initiating the motherfit studies. The motherfit studies are, to our knowledge, the first studies that evaluate both longer term results and healthcare costs compared to CAU in pregnant and post-partum women with SUI. The endpoint of 18 months post-partum is chosen because of the increasing possibility of a subsequent pregnancy and consequently loss to follow-up. In order to sustain long-term results, it is known that adherence is a strong predictive factor. ${ }^{33}$ Therefore, motherfit group therapy not only focuses on PFMT, general fitness exercises and education, but also has a strong emphasis on adherence and self-management. Adherence to PFMT will be supported by a mApp.

Currently, no guidelines on urinary incontinence exist specifically for pregnant and post-partum women. In case motherfit demonstrates to be (cost-)effective, implementation of motherfit group therapy should be considered in peri-partum care and future guidelines. 


\section{REFERENCES}

1. Altaweel W, Alharbi M. Urinary incontinence: prevalence, risk factors, and impact on health related quality of life in Saudi women. Neurourol Urodyn. 2012;31(5):642-645.

2. Cooper J, Annappa M, Quigley A, Dracocardos D, Bondili A, Mallen C. Prevalence of female urinary incontinence and its impact on quality of life in a cluster population in the United Kingdom (UK): a community survey. Prim Health Care Res Dev. 2015;16(4):377382.

3. Irwin DE, Milsom I, Hunskaar S, et al. Population-based survey of urinary incontinence, overactive bladder, and other lower urinary tract symptoms in five countries: results of the EPIC study. Eur Urol. 2006;50(6):1306-1314; discussion 1314-1305.

4. Andersson G, Johansson JE, Garpenholt O, Nilsson K. Urinary incontinence--prevalence, impact on daily living and desire for treatment: a population-based study. Scand J Urol Nephrol. 2004;38(2):125-130.

5. Delancey JO. Why do women have stress urinary incontinence? Neurourol Urodyn. 2010;29 Suppl 1:S13-17.

6. Haylen BT, de Ridder D, Freeman RM, et al. An International Urogynecological Association (IUGA)/International Continence Society (ICS) joint report on the terminology for female pelvic floor dysfunction. Int Urogynecol J. 2010;21(1):5-26.

7. Delancey JO, Ashton-Miller JA. Pathophysiology of adult urinary incontinence. Gastroenterology. 2004;126(1 Suppl 1):S23-32.

8. Chan SS, Cheung RY, Yiu KW, Lee LL, Chung TK. Prevalence of urinary and fecal incontinence in Chinese women during and after their first pregnancy. Int Urogynecol J. 2013;24(9):1473-1479.

9. Solans-Domenech $M$, Sanchez $E$, Espuna-Pons $M$. Urinary and anal incontinence during pregnancy and postpartum: incidence, severity, and risk factors. Obstet Gynecol. 2010;115(3):618-628.

10. Morkved S, Bo K. Prevalence of urinary incontinence during pregnancy and postpartum. Int UrogynecolJ Pelvic Floor Dysfunct. 1999;10(6):394-398.

11. Brown S, Gartland D, Perlen S, McDonald E, MacArthur C. Consultation about urinary and faecal incontinence in the year after childbirth: a cohort study. BJOG. 2015;122(7):954962.

12. Buurman MB, Lagro-Janssen AL. Women's perception of postpartum pelvic floor dysfunction and their help-seeking behaviour: a qualitative interview study. Scand J Caring Sci. 2013;27(2):406-413.

13. MacArthur $C$, Wilson $D$, Herbison $P$, et al. Urinary incontinence persisting after childbirth: extent, delivery history, and effects in a 12-year longitudinal cohort study. BJOG. 2016;123(6):1022-1029.

14. Viktrup L, Lose G. The risk of stress incontinence 5 years after first delivery. Am J Obstet Gynecol. 2001;185(1):82-87.

15. Hermansen IL, O'Connell BO, Gaskin CJ. Women's explanations for urinary incontinence, their management strategies, and their quality of life during the postpartum period. $J$ Wound Ostomy Continence Nurs. 2010;37(2):187-192. 
16. Handa VL, Zyczynski HM, Burgio KL, et al. The impact of fecal and urinary incontinence on quality of life 6 months after childbirth. Am J Obstet Gynecol. 2007;197(6):636.e631636.

17. Hagglund D, Walker-Engstrom ML, Larsson G, Leppert J. Reasons why women with longterm urinary incontinence do not seek professional help: a cross-sectional populationbased cohort study. Int Urogynecol J Pelvic Floor Dysfunct. 2003;14(5):296-304.

18. Hagglund $D$, Wadensten $B$. Fear of humiliation inhibits women's care-seeking behaviour for long-term urinary incontinence. Scand J Caring Sci. 2007;21(3):305-312.

19. Miller JM, Sampselle C, Ashton-Miller J, Hong GR, DeLancey JO. Clarification and confirmation of the Knack maneuver: the effect of volitional pelvic floor muscle contraction to preempt expected stress incontinence. Int Urogynecol J Pelvic Floor Dysfunct. 2008;19(6):773-782.

20. Boyle R, Hay-Smith EJ, Cody JD, Morkved S. Pelvic floor muscle training for prevention and treatment of urinary and faecal incontinence in antenatal and postnatal women. Cochrane Database Syst Rev. 2012;10:Cd007471.

21. Albers-Heitner P, Berghmans B, Nieman F, Lagro-Janssen T, Winkens R. Adherence to professional guidelines for patients with urinary incontinence by general practitioners: a cross-sectional study. J Eval Clin Pract. 2008;14(5):807-811.

22. van Gerwen MA, Schellevis FG, Lagro-Janssen AL. Management of urinary incontinence in general practice: data from the Second Dutch National Survey. J Eval Clin Pract. 2009;15(2):341-345.

23. Paiva LL, Ferla L, Darski C, Catarino BM, Ramos JG. Pelvic floor muscle training in groups versus individual or home treatment of women with urinary incontinence: systematic review and meta-analysis. Int Urogynecol J. 2017;28(3):351-359.

24. CBS StatLine. Zorguitgaven. 2016; https://www.cbs.nl/nl-nl/nieuws/2017/20/ zorguitgaven-stijgen-in-2016-met-1-8-procent. Accessed October 24, 2017.

25. Lamb SE, Pepper J, Lall R, et al. Group treatments for sensitive health care problems: a randomised controlled trial of group versus individual physiotherapy sessions for female urinary incontinence. BMC Womens Health. 2009;9:26.

26. Dumoulin C, Alewijnse D, Bo K, et al. Pelvic-Floor-Muscle Training Adherence: Tools, Measurements and Strategies-2011 ICS State-of-the-Science Seminar Research Paper II of IV. Neurourol Urodyn. 2015;34(7):615-621.

27. Timmermans L, Falez F, Melot C, Wespes E. Validation of use of the International Consultation on Incontinence Questionnaire-Urinary Incontinence-Short Form (ICIQ-UISF) for impairment rating: a transversal retrospective study of 120 patients. Neurourol Urodyn. 2013;32(7):974-979.

28. Ministerie van Volksgezondheid Welzijn en Sport. Medisch-wetenschappelijk onderzoek; algemene informatie voor de proefpersoon. In:2014.

29. Slieker-ten Hove MC, Pool-Goudzwaard AL, Eijkemans MJ, Steegers-Theunissen RP, Burger CW, Vierhout ME. The prevalence of pelvic organ prolapse symptoms and signs and their relation with bladder and bowel disorders in a general female population. Int Urogynecol J Pelvic Floor Dysfunct. 2009;20(9):1037-1045.

30. Westerik-Verschuuren L, Moossdorff-Steinhauser H. Beroepsprofiel bekkenfysiotherapeut. KNGF; Augustus 20142014. 
31. Bo K, Talseth T, Holme I. Single blind, randomised controlled trial of pelvic floor exercises, electrical stimulation, vaginal cones, and no treatment in management of genuine stress incontinence in women. BMJ. 1999;318(7182):487-493.

32. Haskell $\mathrm{WL}$, Lee IM, Pate RR, et al. Physical activity and public health: updated recommendation for adults from the American College of Sports Medicine and the American Heart Association. Med Sci Sports Exerc. 2007;39(8):1423-1434.

33. Latorre GFS, de Fraga R, Seleme MR, Mueller CV, Berghmans B. An ideal e-health system for pelvic floor muscle training adherence: Systematic review. Neurourol Urodyn. 2018.

34. Avery K, Donovan J, Peters TJ, Shaw C, Gotoh M, Abrams P. ICIQ: a brief and robust measure for evaluating the symptoms and impact of urinary incontinence. Neurourol Urodyn. 2004;23(4):322-330.

35. Klovning A, Avery K, Sandvik H, Hunskaar S. Comparison of two questionnaires for assessing the severity of urinary incontinence: The ICIQ-UI SF versus the incontinence severity index. Neurourol Urodyn. 2009;28(5):411-415.

36. Grzybowska ME, Wydra D. 24/7 usage of continence pads and quality of life impairment in women with urinary incontinence. Int J Clinicall Pract. 2018.

37. Nystrom E, Sjostrom M, Stenlund H, Samuelsson E. ICIQ symptom and quality of life instruments measure clinically relevant improvements in women with stress urinary incontinence. Neurourol Urodyn. 2015;34(8):747-751.

38. Hudak PL, Wright JG. The characteristics of patient satisfaction measures. Spine (Phila Pa 1976). 2000;25(24):3167-3177.

39. Kamper SJ, Ostelo RW, Knol DL, Maher CG, de Vet HC, Hancock MJ. Global Perceived Effect scales provided reliable assessments of health transition in people with musculoskeletal disorders, but ratings are strongly influenced by current status. J Clin Epidemiol. 2010;63(7):760-766.e761.

40. Yalcin I, Bump RC. Validation of two global impression questionnaires for incontinence. Am J Obstet Gynecol. 2003;189(1):98-101.

41. Uebersax JS, Wyman JF, Shumaker SA, McClish DK, Fantl JA. Short forms to assess life quality and symptom distress for urinary incontinence in women: the Incontinence Impact Questionnaire and the Urogenital Distress Inventory. Continence Program for Women Research Group. Neurourol Urodyn. 1995;14(2):131-139.

42. van der Vaart $\mathrm{CH}$, de Leeuw JR, Roovers JP, Heintz AP. Measuring health-related quality of life in women with urogenital dysfunction: the urogenital distress inventory and incontinence impact questionnaire revisited. Neurourol Urodyn. 2003;22(2):97-104.

43. Garber CE, Blissmer B, Deschenes MR, et al. American College of Sports Medicine position stand. Quantity and quality of exercise for developing and maintaining cardiorespiratory, musculoskeletal, and neuromotor fitness in apparently healthy adults: guidance for prescribing exercise. Med Sci Sports Exerc. 2011;43(7):1334-1359.

44. Hay-Smith EJ, Herderschee R, Dumoulin C, Herbison GP. Comparisons of approaches to pelvic floor muscle training for urinary incontinence in women. Cochrane Database Syst Rev. 2011(12):Cd009508.

45. Nederland Z. Kostenhandleiding: Methodologie van kostenonderzoek en referentieprijzen voor economische evaluaties in de gezondheidszorg. In: Nederland Z, ed2015 (2). 
46. Zorginstituut Nederland. Richtlijn voor het uitvoeren van economische evaluaties in de gezondheidszorg. 2015 (1).

47. Versteegh M, Vermeulen K, Evers S, de Wit G, Prenger R, Stock E. Dutch tariff for the fivelevel version of EQ-5D. Value Health. 2016;19:343-352.

48. Sullivan SD, Mauskopf JA, Augustovski F, et al. Budget impact analysis-principles of good practice: report of the ISPOR 2012 Budget Impact Analysis Good Practice II Task Force. Value Health. 2014;17(1):5-14. 


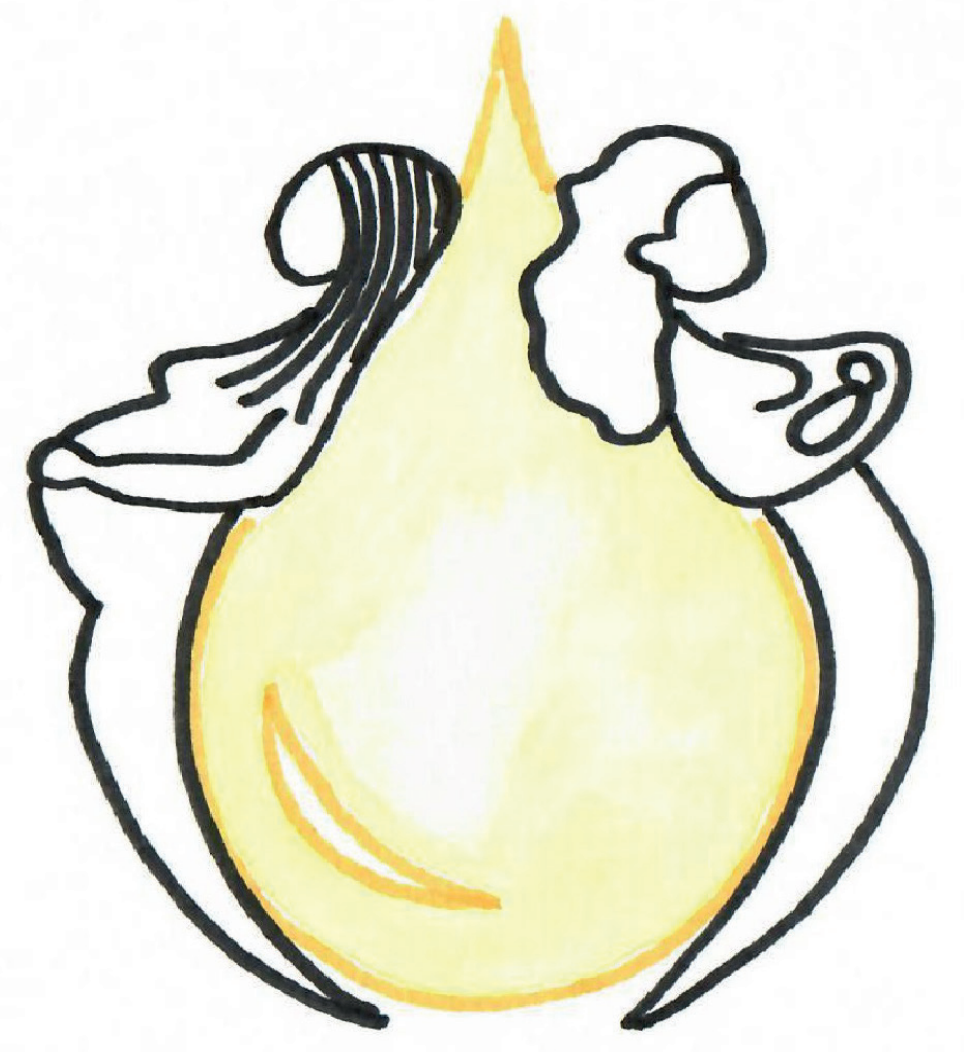




\title{
PELVIC FLOOR MUSCLE GROUP THERAPY FOR THE TREATMENT OF URINARY INCONTINENCE DURING PREGNANCY AND POST-PARTUM: A RANDOMIZED CONTROLLED TRIAL
}

Heidi F.A. Moossdorff-Steinhauser ${ }^{1}$ Bary C.M. Berghmans ${ }^{2}$ Marc E.A. Spaanderman ${ }^{3}$ Esther M.J. Bols ${ }^{1}$

\begin{abstract}
${ }^{1}$ Maastricht University, Faculty of Health, Medicine and Life Sciences, Dept. Epidemiology, CAPHRI Care and Public Health Research Institute, P.O. Box 616, 6200 MD Maastricht, The Netherlands; ${ }^{2}$ Pelvic care Center Maastricht, CAPHRI, Maastricht University Medical Centre (MUMC+), Maastricht, The Netherlands; ${ }^{3}$ Department of Obstetrics and Gynecology, MUMC+, The Netherlands
\end{abstract}




\section{ABSTRACT}

Objectives: Pelvic Floor Muscle Group Therapy (PFMGT) is an effective treatment option in the general population. However, the effect of therapy during pregnancy and shortly thereafter is unclear. Therefore, this study investigates the effect of PFMGT in peri-partum women with UI compared to care-as-usual.

Materials and Methods: Two randomized controlled trials: study 1: pregnant women and study 2: 6 weeks post-partum women, were performed. The primary outcome was UI severity based on the International Consultation on Incontinence Questionnaire-Urinary Incontinence Short form (ICIQ-UI SF). Secondary outcomes were the Global Impression of Severity (GPE) measuring patient's self-reported improvement and the Incontinence Impact Questionnaire-7 (IIQ-7), measuring UI impact. Descriptive and univariate analysis were reported and the non-parametric Mann-Whitney $U$ test was used to compare differences between groups.

Results: Inclusion numbers could not be met, and therefore all women received individual PFMT. Study 1 showed no significant results regarding the prevalence of UI (ICIQ-UI SF), GPE and IIQ-7 at any measurement moment. As compared to baseline, study 2 showed a significant improvement for prevalence of UI and impact of UI at 4 months post-partum, however there was no significant difference between groups at other measurement moments. Significant subjective improvement was seen at 4 and 9 months post-partum, in favor of the PFMT group $(p=.02)$.

Conclusion: PFMT, started after childbirth, demonstrated improved UI and quality of life with a lower number of complaints at the 4 months post-partum assessment. However, the full potential of effectiveness of PFMT could not be established due to insufficient inclusions. 


\section{INTRODUCTION}

Urinary incontinence (UI) is the complaint of involuntary loss of urine. ${ }^{1}$ The reported overall prevalence of UI varies between 25 and 46.4\%., 2,3 Stress urinary incontinence (SUI), the complaint of involuntary loss of urine on effort or physical exertion or on sneezing or coughing ${ }^{1}$, is the most prevalent type among peripartum women. ${ }^{2-4}$ During pregnancy prevalence of UI is reported between 9 and $75 \%$, and post-partum between 10 and 63\%.5-8 UI reduces quality of life (QoL) but nonetheless, many women tend to accept their problems because they are embarrassed, think it is normal and will diminish by itself. ${ }^{8-10}$

The development of UI peri-partum might be due to several reasons, including childbirth or physiological weight gain resulting in an increase of intra-abdominal pressure transmitted to the bladder and bladder neck, leading to urethral mobility and pelvic floor muscles (PFM) activity problems. ${ }^{11-13}$ The PFMs of women with UI during pregnancy are weaker and thinner. ${ }^{14}$ PFM training (PFMT) aims to improve the supportive system and is a first-line treatment option for UI. ${ }^{15,16}$ As the costs for healthcare are rising, it is important to provide cost-effective therapies. ${ }^{17}$ PFMT can be provided as individual, but also as group therapy (PFMGT). PFMGT appeared to be equally effective in the treatment of UI in women in the general or older population. ${ }^{18,19} \mathrm{~A}$ recent Cochrane systematic review concluded that it is uncertain whether PFMT is an effective treatment option for women with UI during pregnancy and post-partum. ${ }^{20}$ Also, information on cost-effectiveness of PFMT and long-term effects is lacking. ${ }^{20}$

Therefore, the primary aim of this study was to investigate whether a structured assessment and treatment program of intensive, supervised PFMGT, including a home maintenance program, reduces 18 months post-partum UI severity (frequency, amount, and impact) compared to care-as usual (CAU) in adult pregnant (study 1) and post-partum women with SUI (study 2). The secondary aim was to investigate whether PFMGT is cost-effective compared to CAU.

\section{MATERIALS AND METHODS}

\section{Study design}

In two randomized controlled multicenter trials, PFMGT (intervention group) was compared to CAU (control group). The two studies were registered as one trial in 
The Netherlands National Trial Register (NTR5971). The Medical Ethics Committee (METC) of the Maastricht University Medical Center (MUMC+) has approved study 1 (METC162038) and study 2 (METC162051). The ethics boards of the participating four hospitals, Zuyderland Medical Center (two locations), Laurentius hospital and Maxima Medical Center, approved the trial, indicating also coverage for 13 local midwifery practices. The study protocol was published previously ${ }^{21}$

\section{Participants}

The women were recruited in the southern part of The Netherlands between $1^{\text {st }}$ December 2017 and $1^{\text {st }}$ August 2019 by midwives and physicians (case managers). Women were included if they met amongst others the following criteria: (1) $\geq 18$ years, (2) UI (stress or mixed with predominant SUI factor, according to Haylen et al. ${ }^{22}$ ), and (3) a score of $>3$ on the International Consultation on Incontinence Questionnaire-Urinary Incontinence Short Form (ICIQ-UI SF). ${ }^{23}$ Exclusion criteria included: (1) UI prior to first pregnancy, still existing during pregnancy, (2) highrisk pregnancy, resulting in a contra-indication for performing intensive PFMT (e.g., placenta praevia, vaginal blood loss, preterm uterine contractions), (3) suffering from significant exercise limitations or co-morbidities (physical or psychological) that would restrain a woman from participation in the group therapy. A full description of in- and exclusion criteria is published elsewhere. ${ }^{21}$

\section{Randomization and blinding}

During a regular planned consultation with their case manager, women meeting the eligibility criteria and interested to participate, received a short vaginal examination to check the ability to contract the PFMs. The candidate participant received an email with a link to the electronic baseline questionnaire after signing the informed consent. Once the questionnaires were completed, blocked randomisation was done by a computer-generated sequence in a 1:1 ratio on patient and location level. Allocation in blocks of four was concealed and done using a central computer. Participants in the intervention group, who could not contract their PFMs correctly, were referred to a specialized (pelvic) physical therapist (PT) for individual instruction before joining PFMGT (Figure 1).

The participants, specialized PT and coordinating researcher could not be blinded. However, once the participant completed the questionnaires, they were 
blocked from making alterations. Before the statistical analyses all participants were appointed a new study number for which the coordinating researcher was blinded. Therefore, analyses were done blinded for treatment allocation.

\section{Intervention}

The intervention was provided by one specialized PT in every region. In The Netherlands, pelvic PT is a specialisation within the field of physical therapy and has its own registration in order to guarantee quality. ${ }^{24}$ The specialized PT's were instructed on the PFMGT protocol which consisted of eight once weekly PFMGT sessions of 60 minutes each. Pregnant and post-partum women could participate as soon as they were randomized in the same intervention group, with a maximum of four per group.

The intervention included instructions on pelvic floor anatomy and how to contract, relax and train the PFMs correctly in combination with general physical exercises with a strong focus on self-management. The PFMGT protocol has been published previously. ${ }^{21}$ The women in the intervention group received a mApp (iPelvis) 25 , which is an application with individualized pelvic PT exercises to reinforce adherence to and compliance with a home maintenance program.

\section{Care-as-usual}

Participants in the CAU group received regular advice from their case managers and were free to participate in any pregnancy-related course or visit a health care professional for their UI.

\section{Measurements}

Besides the measurement of the baseline characteristics in both studies the women were asked to fill in the questionnaires multiple times (Figure 1 and 2).

\section{Primary outcome measure}

The primary outcome is based on the ICIQ-UI SF. This is a validated brief (four questions) measure for evaluating the frequency, severity and impact on QoL of UI. ${ }^{26}$ The total score ranges from 0 (not affected) to 21 (severely affected). The questionnaire is translated in Dutch. ${ }^{27}$ Therapy success is defined as absence of 
UI or change from baseline of at least three points on the ICIQ-UI SF at 18 months post-partum. ${ }^{28}$

\section{Secondary outcome measures}

The Patient Global Impression of Severity (GPE) questionnaire was used to assess the patients' self-reported improvement. ${ }^{29}$ It is a reliable scale for incontinence, consisting of one question and seven response options ranging from very much improved to very much deterioration..$^{30,31}$

The validated Incontinence Impact Questionnaire-7 (IIQ-7) was used to determine the UI impact on four domains: mobility, physical functioning, emotional health and embarrassment. ${ }^{32}$ The total score ranges from 0 to 100,0 meaning no impact and 100 extreme impact.

\section{Sample size}

The total sample size estimate for study 1 was 150, and study 2 was 90. These numbers are based on a significance level of 0.05 , a power of $90 \%$, and a $20 \%$ drop-out rate. Further justification has been described elsewhere. ${ }^{21}$

\section{Statistical analysis}

The Consolidated Standards of Reporting Trials (CONSORT) statement ${ }^{33}$ was followed for reporting the trial. Data will be analyzed according to the intentionto-treat principle. Descriptive and univariate analysis were reported as means and standard deviations or $95 \%$ confidence intervals. The non-parametric MannWhitney $U$ test was performed to compare differences between the two groups. $A$ p-value $<0.05$ is considered to be statistically significant. Data analyses are carried out using IBM SPSS Statistics for Windows, version 25.0 (IBM Corp., Armonk, N.Y., USA).

\section{RESULTS}

Recruitment took place between 01.06.2017 and 01.08.2019. 


\section{Participants}

In study 1, 59 women were eligible for participation, of which 24 women were randomized (intervention group $=11$, control group=13) (Figure 1). Four participants completed the study (Figure 1). In study 2, 116 women were eligible of which 23 were randomized (intervention group=10, control group=13), 14 participants completed the study (Figure 2). Characteristics of the participants for study 1 and 2 are shown in Table 1.

\section{Outcomes}

The results are based on individual PFMT instead of PFMGT, as groups did not fill sufficiently (therefore, from this point on the term PFMT will be used). However, the original PFMGT protocol was followed. Study 1 showed no statistical significant differences between groups at any point regarding the ICIQ-UI SF total score, GPE and IIQ-7 (Table 2), although both groups showed improvements on all outcomes post-intervention.

In study 2, the intervention group improved significantly compared to the control group ( $p=0.012$ ) at four months post-partum with regard to the ICIQ-UI SF score of $(p=0.012)$ and IIQ-7 $(p=0.04)$.

Moreover, the GPE of the intervention group improved significantly at T1 and T2 $(p=0.02)$. T3 showed no statistical significant difference between groups (Table 2 ).

The mean number of days per week the participants performed PFM exercises during the eight week PFMGT was 5.9 (median 6.0) and 5.0 (median 5.3) in study 1 and 2 , respectively.

Cost-effectiveness outcomes have not been calculated because both studies were underpowered. 


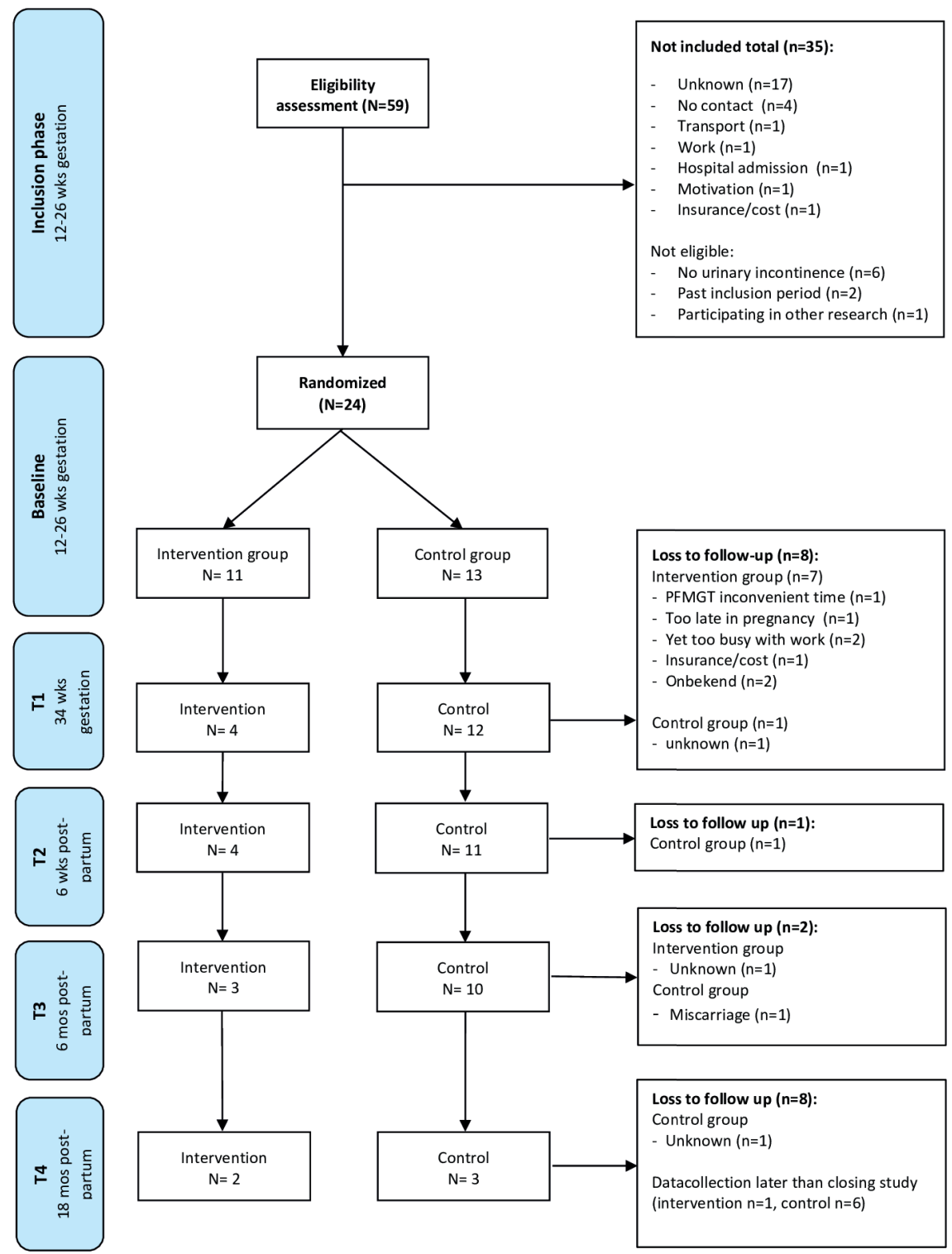

Figure 1: Flowchart study 1

T=measurement, wks=weeks, mos=months, $\mathrm{N}=$ =number, $\mathrm{PFMGT=pelvic}$ floor muscle group therapy 


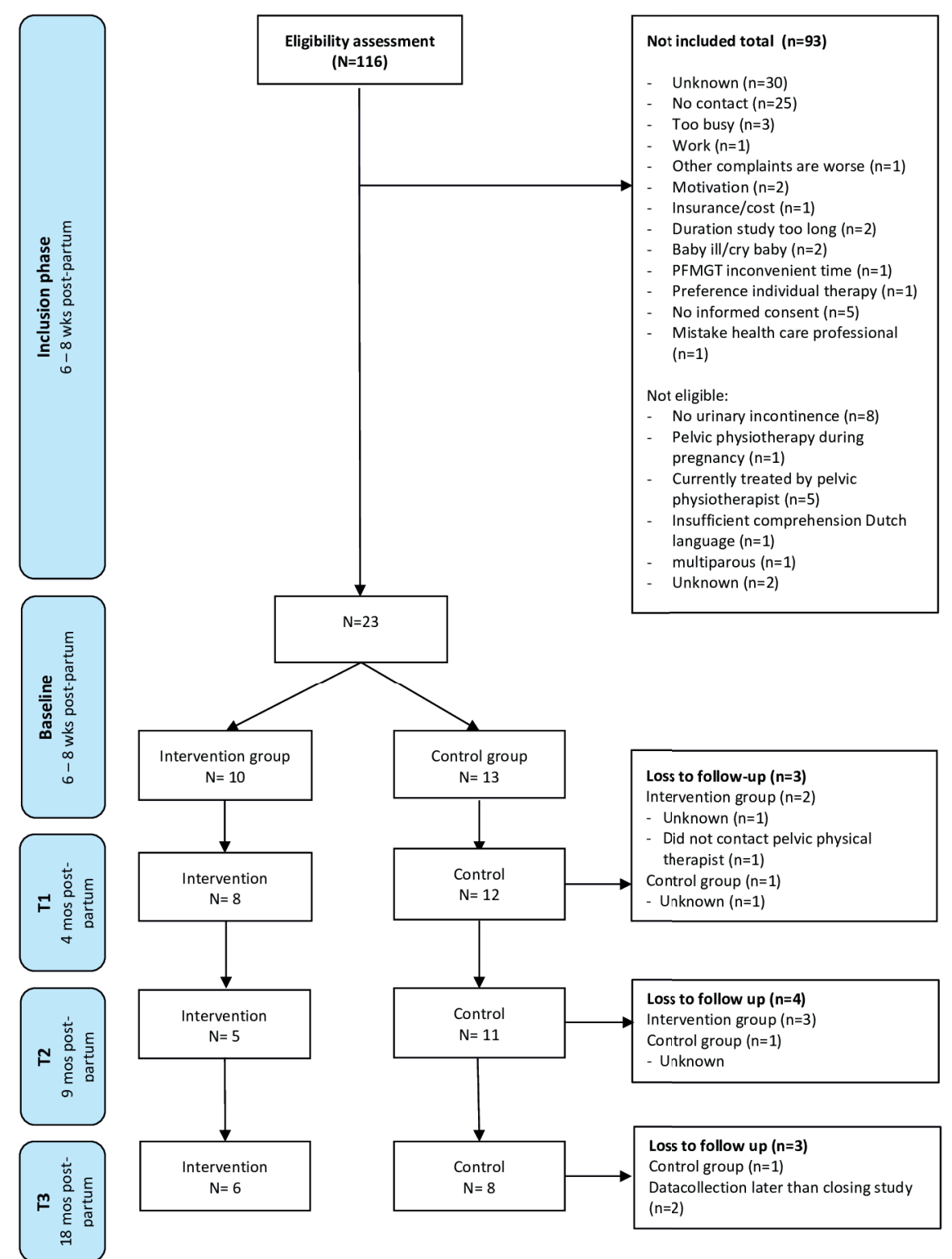

Figure 2: Flowchart study 2

$\mathrm{T}=$ measurement, wks=weeks, mos=months, $\mathrm{N}=$ =number, $\mathrm{PFMGT=pelvic}$ floor muscle group therapy 
Table 1 Participants' characteristics

\begin{tabular}{|c|c|c|c|c|c|c|c|}
\hline & & \multicolumn{3}{|l|}{$\begin{array}{l}\text { Study } 1 \\
\mathrm{~N}(\%)\end{array}$} & \multicolumn{3}{|l|}{$\begin{array}{l}\text { Study } 2 \\
\text { N (\%) }\end{array}$} \\
\hline & & $I(11)$ & C (13) & Total (24) & $I(10)$ & C (13) & Total (23) \\
\hline \multicolumn{2}{|c|}{ Age (mean, range) } & $\begin{array}{l}32.1 \\
(24-38)\end{array}$ & $\begin{array}{l}32.9 \\
(23-42)\end{array}$ & $\begin{array}{l}32.5 \\
(23-42)\end{array}$ & $\begin{array}{l}32.3 \\
(27-37)\end{array}$ & $\begin{array}{l}30.2 \\
(24-37)\end{array}$ & $\begin{array}{l}31.0 \\
(24-37)\end{array}$ \\
\hline \multirow[t]{2}{*}{ Education } & Secondary & $4(36.4)$ & $4(30.8)$ & $8(33.3)$ & $3(30.0)$ & $5(38.5)$ & $8(34.8)$ \\
\hline & Tertiary & $7(63.6)$ & $9(69.2)$ & $16(66.7)$ & $7(70.0)$ & $8(61.5)$ & $15(65.2)$ \\
\hline \multirow[t]{4}{*}{ Parity } & 0 & $4(36.4)$ & $4(30.8)$ & $8(33.3)$ & - & - & - \\
\hline & 1 & 7 (63.6) & $7(53.8)$ & $14(58.3)$ & $2(20.0)$ & $5(38.5)$ & 7 \\
\hline & $\geq 2$ & $0(0)$ & $2(15.4)$ & $2(4.2)$ & $1(10.0)$ & $1(7.7)$ & 2 \\
\hline & Missing & & & & 7 & 7 & 14 \\
\hline
\end{tabular}

$\mathrm{N}=$ number, $\mathrm{I}=$ intervention group, $\mathrm{C}=$ control group. 


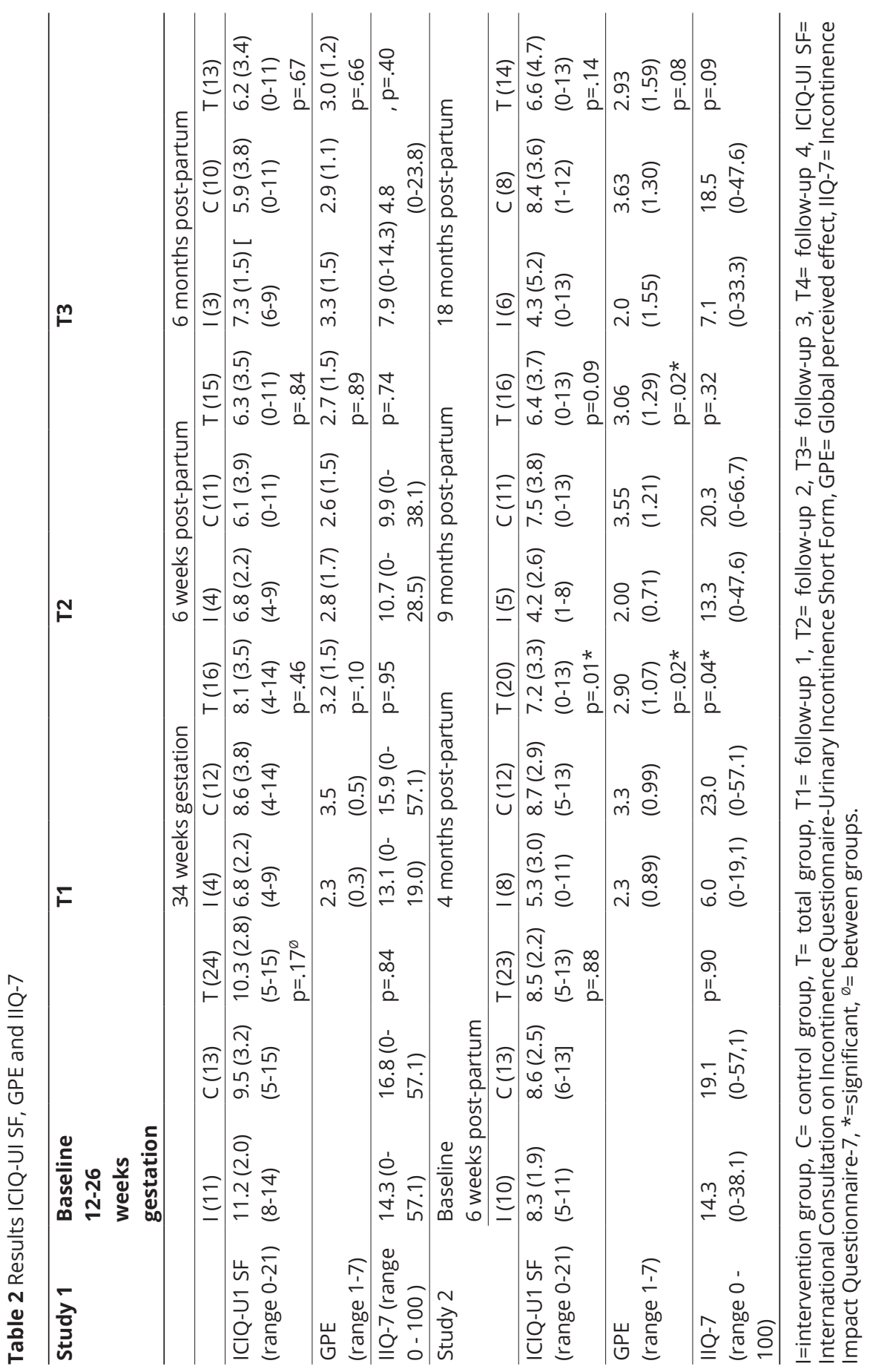




\section{DISCUSSION}

The (cost)-effectiveness of PFMT, for pregnant (study 1) and post-partum women (study 2) with SUI could not be established as planned, due to the small number of included women in both studies. As a consequence of the small numbers, all women in the intervention group received individual PFMT.

Therefore, the reported results should be interpreted with great caution and no conclusions regarding the original hypothesis can be made.

PFMT started during pregnancy showed no significant results regarding the effect on UI, impact, and self-perceived impression of severity of symptoms at any point. This is in line with a recent Cochrane systematic review, reporting no evidence of the treatment effect of PFMT on UI in late pregnancy. ${ }^{20}$ Most likely our findings must be explained by the fact the study is underpowered. In addition, during pregnancy the continence mechanism is challenged by a multitude of factors of which some are non-modifiable. Physiological weight gain ${ }^{2}$, and changes in the neuromuscular function of the urethral sphincter are considered examples of non-modifiable factors. ${ }^{34}$ However, PFMT in the general female population is a proven effective intervention. ${ }^{35}$

PFMT post-partum revealed a positive effect directly after PFMT regarding UI, impact and self-perceived impression of severity. However, this effect was not maintained at later follow-up, except for subjective improvement. Although this study focused on adherence strategies for PFMT, the effect did not last.

We anticipated no major problems in recruiting the necessary number of participants for both studies due to a number of reasons. Firstly, the recruitment was done by case managers covering the majority of maternal care (pre- and postpartum care) in the southern part of The Netherlands, in which over 8500 babies were born in 2019. ${ }^{17}$ Secondly, high prevalence rates of SUI during pregnancy and post-partum are reported in numerous studies ${ }^{6-8}$ and thirdly, other studies on PFMT peri-partum in northern Europe reported high inclusion and participation rates. ${ }^{36}$ Nonetheless, recruitment proved to be problematic.

In order to improve the number of inclusions several alterations to the eligibility criteria of the study were proposed and granted. The changes were: 1 . inclusion of all women regardless of parity instead of only primigravid and primiparous women. 
2. extending the inclusion period from 12 to 20 weeks up to 26 weeks of gestation. Other strategies to improve the inclusion rate were: regular presentations in the participating hospitals, visits to midwifery practices, attending clinics and regular phone conversations with midwifes and research assistants of the hospitals. Also, a monthly newsletter informing the healthcare professionals was send. Several factors might explain the disappointing inclusion numbers, which might also be useful for other researchers in the field to plan their studies or optimize their recruitment strategies. Firstly, our studies were so called 'efficiency studies' in which two different treatments are compared with regard to effect and financial costs, with the objective to discourage use of inefficient interventions. ${ }^{37}$ Due to this design, participants were only allowed to be included by a case manager like a midwife or obstetrician, which might have influenced the disappointing inclusion numbers. In the study of Mørkved et al. on the effect of PFMT to prevent UI during pregnancy, all women were asked to participate through a letter which they received in combination with the invitation for their standard appointment with their case manager. ${ }^{36}$ Secondly, a standard question on UI is lacking in electronic patient following systems in The Netherlands for case managers reporting peri-partum care. This digital reminder to ask for UI might have influenced the inclusion numbers. Thirdly, case managers involved in these studies mentioned their lack of attention as a major barrier to recruit participants together with lack of time and a difficult to implement protocol in usual clinical practice. These are well known barriers in clinical research. ${ }^{38,39}$ Moreover, the case managers also mentioned that the standard internal assessment of the PFM in the protocol was a barrier due to lack of time. The number of drop-outs in study 1 , once randomized, and in the initial inclusion phase in study 2, can be explained by known barriers for patient participation like inconvenience due to extra appointments, travel problems, costs and a preference for a specific study arm. Fourth, the sample size calculation for both studies was based on reported high UI prevalence numbers. However, the experienced bother was not taken into account. This might have resulted in an overestimation of the crude prevalence of $\mathrm{UI}$, because level of experienced bother is associated with help-seeking behavior. ${ }^{40}$

Our result regarding PFMT post-partum may justify and therefore support the recommendation of Woodley et al. ${ }^{20}$ for the development of a new RCT on this subject. However, it is advisable to recruit women through for instance (social) media because questions on UI are not standardly asked by health care professionals. ${ }^{41}$ 
Strengths of this study include that the intervention offered in both studies is protocol- and evidence based ${ }^{21}$ and the ability to contract the PFM is checked. Women who did not know how to contract the PFM received an individual session by a specialized PT in order to learn how to contract and relax, before joining PFMT; in addition the protocol has a strong emphasis on adherence with the use of a mApp. A mApp has shown to have a beneficial effect on adherence. ${ }^{42,43}$ The original design includes a long follow-up period and cost-effectiveness calculation.

In conclusion, PFMT, started post-partum, demonstrated statistically significant improvements in UI and QoL with a lower number of complaints at the 4 months post-partum assessment. However, the full potential of effectiveness of PFMGT could not be established due to insufficient inclusions, the latter most likely due to accepted bother from UI rather than the presence of UI itself. 


\section{REFERENCES:}

1. D'Ancona C, Haylen B, Oelke M, et al. The International Continence Society (ICS) report on the terminology for adult male lower urinary tract and pelvic floor symptoms and dysfunction. Neurourol Urodyn. 2019;38(2):433-477.

2. Schreiber Pedersen L, Lose G, Høybye MT, Elsner S, Waldmann A, Rudnicki M. Prevalence of urinary incontinence among women and analysis of potential risk factors in Germany and Denmark. Acta Obstet Gynecol Scand. 2017;96(8):939-948.

3. Hannestad YS, Rortveit G, Sandvik H, Hunskaar S. A community-based epidemiological survey of female urinary incontinence: the Norwegian EPINCONT study. Epidemiology of Incontinence in the County of Nord-Trøndelag. J Clin Epidemiol. 2000;53(11):11501157.

4. Botlero R, Davis SR, Urquhart DM, Shortreed S, Bell RJ. Age-specific prevalence of, and factors associated with, different types of urinary incontinence in community-dwelling Australian women assessed with a validated questionnaire. Maturitas. 2009;62(2):134139.

5. Hojberg KE, Salvig JD, Winslow NA, Lose G, Secher NJ. Urinary incontinence: prevalence and risk factors at 16 weeks of gestation. Br J Obstet Gynaecol. 1999;106(8):842-850.

6. Nigam A, Ahmad A, Gaur D, Elahi A, Batra S. Prevalence and risk factors for urinary incontinence in pregnant women in late third trimester. IJRCOG. 2016;5(7):2187-2191.

7. Rikard-Bell J, lyer J, Rane A. Perineal outcome and the risk of pelvic floor dysfunction: a cohort study of primiparous women. Aust N Z J Obstet Gynaecol. 2014;54(4):371-376.

8. Moossdorff-Steinhauser HFA, Berghmans BCM, Spaanderman MEA, Bols EMJ. Urinary incontinence during pregnancy: prevalence, experience of bother, beliefs, and helpseeking behavior. Int Urogynecol J. 2020.

9. Buurman MB, Lagro-Janssen AL. Women's perception of postpartum pelvic floor dysfunction and their help-seeking behaviour: a qualitative interview study. Scand J Caring Sci. 2013;27(2):406-413.

10. Mason L, Glenn S, Walton I, Hughes C. Women's reluctance to seek help for stress incontinence during pregnancy and following childbirth. Midwifery. 2001;17(3):212-221.

11. Swenson CW, Kolenic GE, Trowbridge ER, et al. Obesity and stress urinary incontinence in women: compromised continence mechanism or excess bladder pressure during cough? Int Urogynecol J. 2017;28(9):1377-1385.

12. DeLancey JO, Kearney R, Chou Q, Speights S, Binno S. The appearance of levator ani muscle abnormalities in magnetic resonance images after vaginal delivery. Obstet Gynecol. 2003;101(1):46-53.

13. MacLennan AH, Taylor AW, Wilson DH, Wilson D. The prevalence of pelvic floor disorders and their relationship to gender, age, parity and mode of delivery. BJOG. 2000;107(12):1460-1470.

14. Mørkved S, Salvesen KA, Bø K, Eik-Nes S. Pelvic floor muscle strength and thickness in continent and incontinent nulliparous pregnant women. Int Urogynecol J Pelvic Floor Dysfunct. 2004;15(6):384-389; discussion 390.

15. NICE. Urinary incontinence in women: management (cg 171). 2013; https://www.nhsggc. org.uk/media/251043/nice-guideline-urinary-incontinence-in-women-management. pdf. Accessed 2 May 2020. 
16. Kobashi K, Albo M, Dmochowski R, et al. Surgical Treatment of Female Stress Urinary Incontinence (SUI): AUA/SUFU Guideline (2017). 2017; https://www.auanet.org/ guidelines/stress-urinary-incontinence-(sui)-guideline. Accessed May 5th, 2020.

17. CBS Statline. Geboorte; kerncijfers vruchtbaarheid, leeftijd moeder, regio. 202029 June 2020: https://opendata.cbs.nl/statline/?themaNr=82388\#/CBS/nl/dataset/37201/ table?ts=1599385813955

18. Paiva LL, Ferla L, Darski C, Catarino BM, Ramos JG. Pelvic floor muscle training in groups versus individual or home treatment of women with urinary incontinence: systematic review and meta-analysis. Int Urogynecol J. 2017;28(3):351-359.

19. Dumoulin C, Morin M, Danieli C, et al. Group-Based vs Individual Pelvic Floor Muscle Training to Treat Urinary Incontinence in Older Women: A Randomized Clinical Trial. JAMA Intern Med. 2020.

20. Woodley SJ, Lawrenson P, Boyle R, et al. Pelvic floor muscle training for preventing and treating urinary and faecal incontinence in antenatal and postnatal women. Cochrane Database Syst Rev. 2020;5:Cd007471.

21. Moossdorff-Steinhauser HFA, Bols EMJ, Spaanderman MEA, et al. Long-term effects of motherfit group therapy in pre-(MOTHERFIT1) and post-partum women (MOTHERFIT2) with stress urinary incontinence compared to care-as-usual: study protocol of two multi-centred, randomised controlled trials. Trials. 2019;20(1):237.

22. Haylen BT, de Ridder D, Freeman RM, et al. An International Urogynecological Association (IUGA)/International Continence Society (ICS) joint report on the terminology for female pelvic floor dysfunction. Int Urogynecol J. 2010;21(1):5-26.

23. Timmermans L, Falez F, Melot C, Wespes E. Validation of use of the International Consultation on Incontinence Questionnaire-Urinary Incontinence-Short Form (ICIQ-UISF) for impairment rating: a transversal retrospective study of 120 patients. Neurourol Urodyn. 2013;32(7):974-979.

24. Westerik-Verschuuren L, Moossdorff-Steinhauser H. Beroepsprofiel bekkenfysiotherapeut. KNGF; Augustus 2014.

25. Latorre GFS, de Fraga R, Seleme MR, Mueller CV, Berghmans B. An ideal e-health system for pelvic floor muscle training adherence: Systematic review. Neurourol Urodyn. 2018.

26. Avery K, Donovan J, Peters TJ, Shaw C, Gotoh M, Abrams P. ICIQ: a brief and robust measure for evaluating the symptoms and impact of urinary incontinence. Neurourol Urodyn. 2004;23(4):322-330.

27. Grzybowska ME, Wydra D. 24/7 usage of continence pads and quality of life impairment in women with urinary incontinence. Int J Clin Pract. 2018.

28. Nyström E, Sjöström M, Stenlund H, Samuelsson E. ICIQ symptom and quality of life instruments measure clinically relevant improvements in women with stress urinary incontinence. Neurourol Urodyn. 2015;34(8):747-751.

29. Hudak PL, Wright JG. The characteristics of patient satisfaction measures. Spine (Phila Pa 1976). 2000;25(24):3167-3177.

30. Kamper SJ, Ostelo RW, Knol DL, Maher CG, de Vet HC, Hancock MJ. Global Perceived Effect scales provided reliable assessments of health transition in people with musculoskeletal disorders, but ratings are strongly influenced by current status. J Clin Epidemiol. 2010;63(7):760-766.e761. 
31. Yalcin I, Bump RC. Validation of two global impression questionnaires for incontinence. Am J Obstet Gynecol. 2003;189(1):98-101.

32. Utomo E, Korfage IJ, Wildhagen MF, Steensma AB, Bangma CH, Blok BF. Validation of the Urogenital Distress Inventory (UDI-6) and Incontinence Impact Questionnaire (IIQ-7) in a Dutch population. Neurourol Urodyn. 2015;34(1):24-31.

33. Boutron I, Altman DG, Moher D, Schulz KF, Ravaud P. CONSORT Statement for Randomized Trials of Nonpharmacologic Treatments: A 2017 Update and a CONSORT Extension for Nonpharmacologic Trial Abstracts. Ann Intern Med. 2017;167(1):40-47.

34. Weidner AC, South MM, Sanders DB, Stinnett SS. Change in urethral sphincter neuromuscular function during pregnancy persists after delivery. Am J Obstet Gynecol. 2009;201(5):529.e521-526.

35. Dumoulin C, Cacciari LP, Hay-Smith EJC. Pelvic floor muscle training versus no treatment, or inactive control treatments, for urinary incontinence in women. Cochrane Database Syst Rev. 2018;10(10):Cd005654.

36. Mørkved S, Bø K, Schei B, Salvesen KA. Pelvic floor muscle training during pregnancy to prevent urinary incontinence: a single-blind randomized controlled trial. Obstet Gynecol. 2003;101(2):313-319.

37. ZonMw. Research and results/efficiency studies. https://www.zonmw.nl/en/researchand-results/efficiency-studies/\#: :text=Efficiency\%20Studies\%20provide\%20the\%20 evidence, $\% 2$ C $\% 20$ researchers $\% 2$ C $\% 20$ practitioners $\% 20$ and $\% 20$ policymakers. Accessed 20 October, 2020.

38. Ross S, Grant A, Counsell C, Gillespie W, Russell I, Prescott R. Barriers to participation in randomised controlled trials: a systematic review. J Clin Epidemiol. 1999;52(12):11431156.

39. Isaksson E, Wester P, Laska AC, Näsman P, Lundström E. Identifying important barriers to recruitment of patients in randomised clinical studies using a questionnaire for study personnel. Trials. 2019;20(1):618.

40. Monz B, Chartier-Kastler E, Hampel C, et al. Patient characteristics associated with quality of life in European women seeking treatment for urinary incontinence: results from PURE. Eur Urol. 2007;51(4):1073-1081; discussion 1081-1072.

41. National Institute for health and care excellence (NICE). Antenatal care for uncomplicated pregnancies (CG62). 2008; https://www.nice.org.uk/guidance/cg62/resources/ antenatal-care-for-uncomplicated-pregnancies-pdf-975564597445. Accessed 8 February, 2021.

42. Bernard S, Boucher S, McLean L, Moffet H. Mobile technologies for the conservative self-management of urinary incontinence: a systematic scoping review. Int Urogynecol J. 2020;31(6):1163-1174.

43. Araujo CC, Marques AA, Juliato CRT. The Adherence of Home Pelvic Floor Muscles Training Using a Mobile Device Application for Women With Urinary Incontinence: A Randomized Controlled Trial. Femal Pelvic Med Reconstr Surg. 2020;26(11):697-703. 


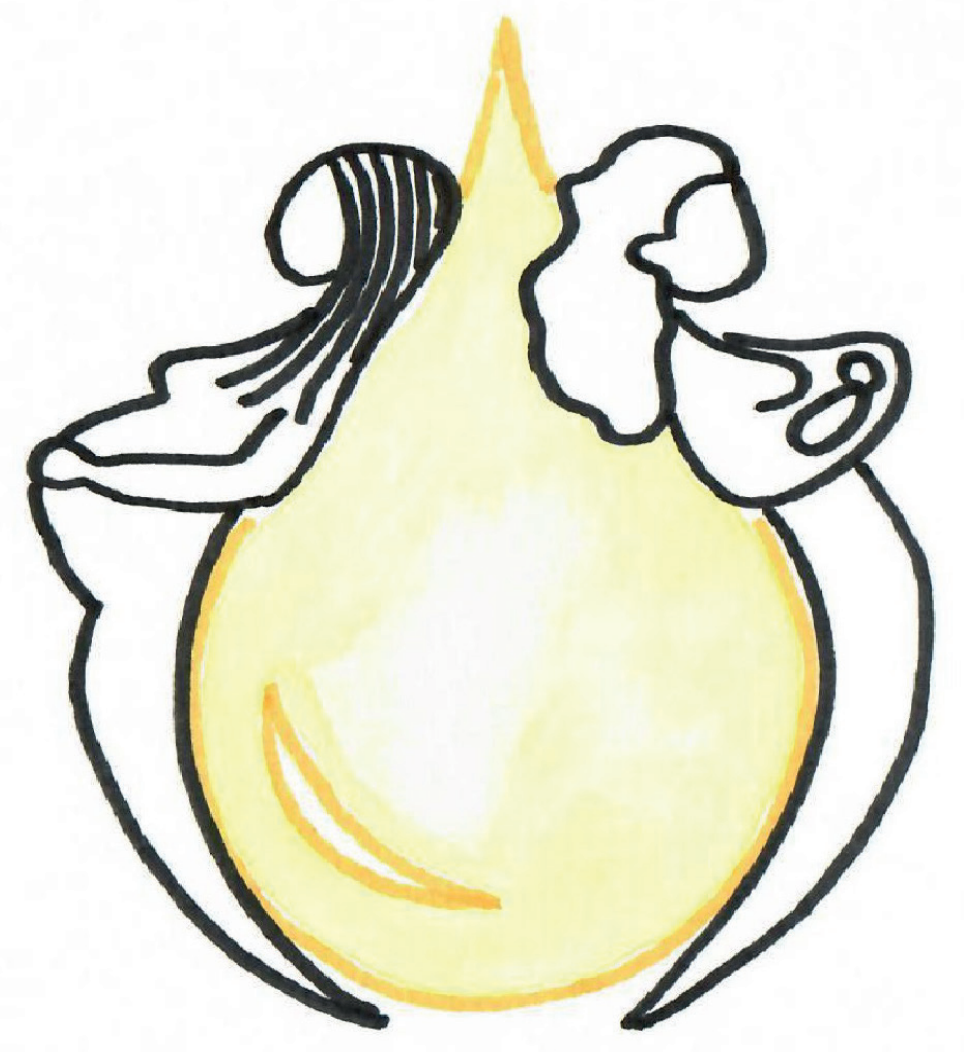




\section{URINARY INCONTINENCE DURING PREGNANCY: PREVALENCE, EXPERIENCE OF BOTHER, BELIEFS, AND HELP-SEEKING BEHAVIOR}

Heidi F.A. Moossdorff-Steinhauser ${ }^{1}$ Bary C.M. Berghmans ${ }^{2}$ Marc E.A. Spaanderman ${ }^{3}$ Esther M.J. Bols ${ }^{1}$

\footnotetext{
${ }^{1}$ Maastricht University, Faculty of Health, Medicine and Life Sciences, Dept. Epidemiology, CAPHRI Care and Public Health Research Institute, P.O. Box 616, 6200 MD Maastricht, The Netherlands; ${ }^{2}$ Pelvic care Center Maastricht, CAPHRI, Maastricht University Medical Centre (MUMC+), Maastricht, The Netherlands; ${ }^{3}$ Department of Obstetrics and Gynecology, MUMC+, The Netherlands
} 


\section{ABSTRACT}

Introduction and hypothesis: Pregnancy and delivery are thought to induce urinary incontinence (UI), but its clinical impact is less known. Therefore, we investigated the prevalence of self-reported UI, level of experience of bother and beliefs, to gain a greater understanding of help-seeking behavior in adult pregnant women.

Methods: A digital survey shared on social media was used for recruitment. The survey consists of: 1. demographic variables, 2. International Consultation on Incontinence Questionnaire-Urinary Incontinence Short Form (ICIQ-UI SF), 3. ICIQ Lower Urinary Tract Symptoms Quality of Life (ICIQ-LUTSqol), and 4. questions on beliefs and help-seeking behavior. For analysis, descriptive statistics and the independent samples t-test were used to determine differences between helpand non-help-seekers.

Results: 407 women were eligible for data analysis. The prevalence of UI rises from $55.1 \%$ in the first to $70.1 \%$ in the third trimester, with an overall prevalence of $66.8 \%$. Nearly $43.0 \%$ of the respondents reported UI occurring once a week or less. $92.5 \%$ of women lost a small amount. $90 \%$ reported slight to moderate impact on quality of life. Only $13.1 \%$ of the respondents sought help for their UI. The main reasons for not seeking help were: minimal bother and the idea that UI would resolve by itself. Help-seeking women showed significant higher scores than nonhelp-seeking women regarding ICIQ-UI SF ( $p<.001)$, ICIQ-LUTSqol $(p=<.001)$, and interference in daily life $(p<.001)$.

Conclusions: During pregnancy, UI affects two out of three women, but only one in eight women sought professional help. Non-help-seeking women experience less bother. 


\section{INTRODUCTION}

Urinary incontinence (UI) is the complaint of involuntary loss of urine. ${ }^{1}$ The selfreported prevalence of $\mathrm{UI}$ in the antenatal period is widely researched. These prevalence numbers vary greatly throughout published reports (9-63\%), depending on case definitions applied, recruited population and study methodology. Pregnant women seem to differ with regard to degree of experienced bother in relation to UI. ${ }^{2,3}$ Cautious interpretation of (high) prevalence rates is needed when case definitions used do not incorporate a measure of symptom bother as crude UI prevalence rate may overestimate the prevalence rate of significant or bothersome UI. Therefore, the International Consultation on Incontinence (ICI) recommends prevalence numbers to be accompanied by a measure of bother. ${ }^{4}$

For women with UI in the general population, it is known that bothersome UI, but also urgency UI (UUI), and UI severity (defined by the ICI as frequency of UI times volume of $\mathrm{UI}$ ) are associated with help-seeking behavior. ${ }^{4-6}$ Although pregnancy is known for its provoking effect on UI, knowledge on experience of UI bother and help-seeking behavior in this period is lacking. Furthermore, it is unclear which specific bothersome factors and beliefs are the main contributors to help-seeking behavior. Guidelines on UI in women in general recommend pelvic floor muscle training (PFMT) as a first-line treatment option.,8

To inform health care providers, researchers, and policy makers it is important to have accurate prevalence rates as well as knowledge on pregnant women's beliefs and help-seeking behavior. Therefore, we aim to investigate the prevalence of self-reported UI, level of experience of bother and beliefs, to explain help-seeking behavior in pregnant women in The Netherlands.

\section{MATERIAL AND METHODS}

\section{Study design}

A cross-sectional design was used to describe the prevalence, bother, beliefs, and help-seeking behavior of pregnant women. The Medical Ethics Committee of the Maastricht University Medical Centre (MUMC+) was consulted. It was stated that ethical approval was not necessary due to the non-invasive character of the study (MECC 019-1320). Pregnant women of 18 years and older, regardless of parity and weeks of gestation, and able to fill in a digital survey were eligible to participate. 
Based on an overall expected prevalence of UI of 41\%, a Z statistic of 1.96 and precision of 0.05 , a minimal sample size of 371 women was estimated to fill in the survey. ${ }^{9}$ Nationwide midwifery and pelvic physiotherapy practices were amongst others asked to share a social media message (using Facebook and LinkedIn), containing brief information on the study (goal, eligibility) and a link to the patient information letter and digital survey. Before proceeding to the anonymized digital survey, eligible women signed informed consent electronically, in agreement with ethical regulations. The survey took 10 to 15 minutes to complete.

\section{Outcome measures}

The survey consisted of four parts: 1. demographic variables like age, trimester of pregnancy, educational level and parity, 2. International Consultation on Incontinence Questionnaire-Urinary Incontinence Short Form (ICIQ-UI SF) ${ }^{10}, 3$. International Consultation on Incontinence Questionnaire Lower Urinary Tract Symptoms Quality of Life (ICIQ-LUTSqol) ${ }^{11}$, and 4. questions on beliefs and helpseeking behavior regarding UI.

The ICIQ-UI SF provides an indication of UI severity and consists of four questions. The first question assesses frequency of UI, with a score of 0 (never losing urine) to 5 (losing urine all the time). The second question describes the amount of urine loss, with four response categories ranging from 0 (no loss) to 6 (large amount). The third question assesses impact of $U I$ on daily life, ranging from 0 (not at all) to 10 (a great deal). The total score ranges from 0 (no impact of UI on quality of life) to 21 (very severe problem). The total score is divided into four severity categories: slight (1-5), moderate (6-12), severe (13-18), and very severe (19-21). ${ }^{12}$ A fourth question on the occurrence of symptoms of UI was used to indicate SUI or MUI. ${ }^{13}$ A respondent was considered to have SUI when leaking urine with a cough or a sneeze and/or when physically active/exercising, but not before getting to the toilet. UUI is considered when the respondent leaks, because of irresistible need to void, before getting to the toilet. A respondent with $\mathrm{MUI}$ experiences both SUI and UUI.

The ICIQ-LUTSqol is a condition-specific health-related quality of life questionnaire (20 questions) adapted for use within the ICIQ structure from the King's Health Questionnaire. ${ }^{11}$ It contains 19 questions that can be scored on life restrictions, 
emotional aspects and preventive measures. It is scored on a four-point Likert scale ranging from 1 (not at all) to 4 (a lot). Three questions on relationships, sex life, and family life included additionally 'not applicable'. 'Not applicable' was considered as not affecting daily life. ${ }^{14}$ The sum score ranges between 19 and 76. A higher score indicates a higher impact on quality of life. Every question is accompanied by a question regarding experienced bother (ranging from 0 (no bother) to 10 (extreme bother)). It is arbitrarily decided that a score of at least 5 indicates significant bother on a specific item. The $20^{\text {th }}$ question is on how much urinary symptoms interfere with daily life. This is scored between 0 to 10 (similar like experienced bother). Both the ICIQ-UI SF and ICIQ-LUTSqol are rated as 'high quality' questionnaires and are recommended by the ICI. ${ }^{4}$ The ICIQ-UI SF and the ICIQ-LUTSqol were provided in the Dutch language by the Bristol Urological Institute. ${ }^{15}$

All respondents at least filled in the demographic variables and ICIQ-UI SF. Answering 'never losing urine' at the frequency item of the ICIQ-UI SF indicated continence and consequently the survey was finished. When reporting $\mathrm{UI}$, women completed the remaining two parts on quality of life and help-seeking behavior.

The questions on beliefs and help-seeking behavior were self-constructed. Selection of question and answer options was based on models explaining help-seeking behavior, discussion with experts in the field (epidemiologists and obstetrician/gynecologist) and modified accordingly. ${ }^{16,17}$ Moreover, questions were reviewed by an expert for readability and comprehensiveness, followed by field testing. Ultimately, six questions were developed including four topics on health seeking behavior (actual help-seeking, reason(s) to (not) seek help, reason to seek help in the future and consulted health-care provider(s)) and two topics on beliefs (self-perceived prognosis and self-perceived best intervention to treat UI in general).

\section{Data analysis}

Data was analyzed using descriptive statistics presented as proportions (frequency and means (SD)). An independent sample t-test was conducted to compare helpseekers and non-help-seekers with regard to UI severity (ICIQ-UI-SF total score), bother (ICIQ-LUTSqol total score), and interference in daily life. A Chi-square 
test was used to test relationships between categorical variables. The effect size is estimated with Cohen's $d$. Cohen's $d$ presents the difference between groups (help-seekers and non-help-seekers) in standard deviation units. To interpret the strength of the effect size we follow the guidelines proposed by Cohen: .2=small, $.5=$ medium, .8=large. An alpha of 0.05 is considered significant. Analyses were done using IBM Statistical Package for Social Sciences (SPSS) version 26.0 (New York, NY, USA).

\section{RESULTS}

In March and April 2020, 415 women filled in the survey. Eight women did not complete the survey after giving consent and were excluded from analysis. This left 407 women eligible for data analysis. The mean age was 30.4 years (SD 3.9, range 18-49), of which 146 (35.9\%) were nulliparous (Table 1). The prevalence of UI rose from $55.1 \%(27 / 49)$ in the first trimester to $70.1 \%(162 / 231)$ in the third trimester.

The overall prevalence of UI was $66.8 \%$ (272/407, 95\% confidence interval (CI) (62.3 - 71.3)). SUI (76.8\% (209/272)) was the most frequently reported type of UI. Nulliparous women reported a significantly lower overall prevalence of $47.9 \%$ (70/146) compared with 77.4\% (202/261) for (multi)parous women $(p<.001)$.

Nearly 43.0\% (116/271) of the respondents reported UI frequency of once a week or lessandin91.1\%(247/271)ofcasesitwasasmallamountofurineperepisode(Table2). Ninety per cent of the women reported slight $(33.7 \%, 91 / 270)$ to moderate $(56.3 \%$, 152/270) impact of UI based on the ICIQ-UI SF score, whereas the mean ICIQLUTSqol total score was 28.2 (SD 7.2, range 19-57). The mean interference in daily life based on ICIQ-UI SF was 3.0 (SD 2.7, range 0-10), whereas 29.9\% (81/272) of women indicated a significant interference of $\geq 5$. The ICIQ-UI SF and ICIQ-LUTSqol total scores and interference in daily life did not increase by trimester. Pregnant women experienced significant bother in relation to having UI on only 2 out of 19 questions on the ICIQ-LUTSqol, namely 'changing of wet underclothes' and 'worry because of smell'.

In total, 13.1\% (35/267) of the respondents with UI sought help (Table 3). The majority of women seeking help (91\%, 32/35) visited a (specialized) physiotherapist. Seven women (21.9\%) reported that they initially visited the 
pelvic physiotherapist for another health problem, like pelvic girdle pain. The reasons provided for not seeking help were: minimal bother (53\%, 123/232), the idea that UI would improve by itself (38\%, 89/232), and wanting to postpone until after the delivery (32\%, 75/232). The most important reasons for seeking help in the future were: the constant use of pads (47\%, 110/232), the feeling that others can smell the urine loss (33\%, 77/232), and leaking/getting wet clothes (30\%, 70/232). 56\% (130/232) of women who did not seek help in contrast to $5.8 \%(2 / 35)$ of the women who did seek help for their UI, thought that their UI would completely resolve or improve a great deal in the future. Figure 1 shows the beliefs about prognosis of UI among non-help-seeking and help-seeking women as relative percentages of 100\%. Of all women with UI, 71.5\% (191/267), thought that the best way to treat their UI would be pelvic floor muscle exercises. Help-seeking women showed significant higher scores than non-help-seeking women regarding ICIQ-UI SF $(p<.001)$, ICIQ-LUTSqol $(p<.001)$, and interference in daily life $(p<.001)$, with corresponding large effect sizes (ICIQ-UI SF total score: Cohen's $d=.80$, ICIQ-LUTSqol total score: Cohen's $d=.74$, and interference in daily life Cohen's $d=.76)$. 
Table 1 Background variables and urinary incontinence prevalence

\begin{tabular}{|c|c|c|c|}
\hline \multicolumn{3}{|c|}{ Background variables $(\mathrm{N}=407)$} & \multirow[t]{2}{*}{ N (\%) } \\
\hline Age (mean, SD, range) & \multicolumn{2}{|c|}{$30.4(3.9,18-49)$} & \\
\hline \multirow[t]{3}{*}{ Education } & \multicolumn{2}{|c|}{ Primary education } & $2(0.5)$ \\
\hline & \multicolumn{2}{|c|}{ Secondary education } & $185(45.5)$ \\
\hline & \multicolumn{2}{|c|}{ Tertiary education } & $220(54.1)$ \\
\hline \multirow[t]{2}{*}{ Parity } & \multicolumn{2}{|c|}{ Nulliparous } & $146(35.9)$ \\
\hline & \multicolumn{2}{|c|}{ Multiparous } & $261(64.1)$ \\
\hline \multirow[t]{3}{*}{ Pre-partum period } & \multicolumn{2}{|c|}{ Trimester 1 (1-13 weeks) } & $49(12.0)$ \\
\hline & \multicolumn{2}{|c|}{ Trimester 2 (14-26 weeks) } & $127(31.2)$ \\
\hline & \multicolumn{2}{|c|}{ Trimester 3 (27-42 weeks) } & $231(56.8)$ \\
\hline \multirow[t]{11}{*}{ UI prevalence (by) } & \multirow{2}{*}{\multicolumn{2}{|c|}{ Overall }} & $272(66.8)$ \\
\hline & & & $95 \% \mathrm{Cl}(62.3-71.3)$ \\
\hline & \multirow[t]{4}{*}{ Type } & SUI & $209(76.8)$ \\
\hline & & UUI & $11(4.0)$ \\
\hline & & MUI & $34(12.5)$ \\
\hline & & $\begin{array}{l}\text { Other (such as: UI during } \\
\text { sleep or UI for no obvious } \\
\text { reason) }\end{array}$ & $18(6.6)$ \\
\hline & \multirow[t]{3}{*}{ Trimester } & 1st (1-13 weeks) & $\begin{array}{l}27 / 49 \text { (55.1) } \\
95 \% \mathrm{Cl}(41.2-69.0)\end{array}$ \\
\hline & & 2nd (14-26 weeks) & $\begin{array}{l}\text { 83/127 (65.4) } \\
95 \% \mathrm{Cl}(57.1-73.7)\end{array}$ \\
\hline & & $3 r d$ (27-42 weeks) & $\begin{array}{l}\text { 162/231 (70.1) } \\
95 \% \mathrm{Cl}(64.2-76.0)\end{array}$ \\
\hline & \multirow[t]{2}{*}{ Parity } & Nulliparous & $70 / 146(47.9)$ \\
\hline & & Primi-/multiparous & $202 / 261(77.4)$ \\
\hline
\end{tabular}

$\mathrm{N}=$ number $\%$ =percentage, $\mathrm{SD}=$ standard deviation, $\mathrm{Cl}=$ confidence interval, $\mathrm{UI}=$ urinary incontinence, SUI=stress urinary incontinence, UUI=urgency urinary incontinence, $\mathrm{MUI}=$ mixed urinary incontinence 
Table 2 ICIQ-UI SF questionnaire results

\begin{tabular}{|c|c|c|}
\hline ICIQ-UI SF & & $\mathbf{N}(\%)$ \\
\hline \multirow[t]{5}{*}{ ICIQ Frequency } & About once a week or less often & $116(42.6)$ \\
\hline & Two or three times a week & $53(19.6)$ \\
\hline & About once a day & $36(13.3)$ \\
\hline & Several times a day & $63(23.3)$ \\
\hline & All the time & $3(1.1)$ \\
\hline \multirow[t]{4}{*}{ ICIQ Amount } & None & $4(1.5)$ \\
\hline & A small amount & $247(92.5)$ \\
\hline & A moderate amount & $20(7.5)$ \\
\hline & A large amount & $0(0.0)$ \\
\hline $\begin{array}{l}\text { ICIQ-UI SF overall } \\
\text { interference (range 0-10) }\end{array}$ & $\geq 5$ & $81(29.9)$ \\
\hline $\begin{array}{l}\text { ICIQ-UI SF total score } \\
\text { mean (SD, range) }\end{array}$ & $0-21$ & $7.5(3.6,0-19)$ \\
\hline \multirow{4}{*}{$\begin{array}{l}\text { Categories ICIQ-UI SF } \\
2 \text { missing }\end{array}$} & Slight (1-5) & $91(33.7)$ \\
\hline & Moderate (6-12) & $152(56.3)$ \\
\hline & Severe (13-18) & $26(9.6)$ \\
\hline & Very severe (19-21) & $1(0.4)$ \\
\hline
\end{tabular}

ICIQ-UI SF= International Consultation on Incontinence Questionnaire Urinary Incontinence Short Form, $\mathrm{N}=$ number, $\%=$ percentage, $\mathrm{SD}=$ standard deviation 
Table 3 Beliefs and help-seeking behavior in relation to urinary incontinence

\begin{tabular}{|c|c|c|}
\hline \multicolumn{3}{|l|}{ BELIEFS } \\
\hline $\begin{array}{l}\text { Prognosis UI without seeking } \\
\text { help }\end{array}$ & Help-seekers $(\mathrm{N}=35)$ & Non-help-seekers $(\mathrm{N}=\mathbf{2 3 2})$ \\
\hline Complete recovery & $1(2.9)$ & $71(30.6)$ \\
\hline Good improvement & $1(2.9)$ & $59(25.4)$ \\
\hline Some improvement & $3(8.6)$ & $36(15.5)$ \\
\hline About the same & $13(37.1)$ & $44(19.0)$ \\
\hline Some deterioration & $7(20.0)$ & $13(5.6)$ \\
\hline Great deterioration & $8(22.9)$ & $8(3.4)$ \\
\hline Worse than ever & $2(5.7)$ & $1(0.4)$ \\
\hline \multicolumn{3}{|l|}{ Best way to solve UI } \\
\hline Surgery & $3(8.6)$ & $3(1.3)$ \\
\hline Medication & $0(0)$ & $0(0)$ \\
\hline Pelvic floor muscle exercises & $24(68.6)$ & $167(72.0)$ \\
\hline It will resolve by itself & $0(0)$ & $30(12.9)$ \\
\hline There is no solution & $0(0)$ & $3(1.3)$ \\
\hline I don't know & $5(14.3)$ & $22(9.5)$ \\
\hline Other & $3(8.6)$ & $7(3.0)$ \\
\hline HELP-SEEKING & Help-seekers & Non-help-seekers \\
\hline Reason to seek help & I sought help because* & $\begin{array}{l}\text { I will seek help in the } \\
\text { future if }\end{array}$ \\
\hline $\begin{array}{l}\text { Getting wet clothes/leaking } \\
\text { through }\end{array}$ & $6(17.1)$ & $70(30.2)$ \\
\hline Need to use pad all the time & $7(20.0)$ & $110(47.4)$ \\
\hline Others can smell me & $0(0)$ & $77(33.2)$ \\
\hline Hindrance during sports & $5(14.3)$ & $29(12.5)$ \\
\hline Hindrance during work & $3(8.6)$ & $56(24.1)$ \\
\hline Hindrance playing with children & $0(0)$ & $41(17.7)$ \\
\hline $\begin{array}{l}\text { Hindrance during household } \\
\text { tasks/activities }\end{array}$ & $1(2.9)$ & $27(11.6)$ \\
\hline I don't know & $0(0)$ & $28(12.1)$ \\
\hline Other reason(s) & $13(37.1)$ & $30(12.9)$ \\
\hline Reason not to seek help & & Non-help-seekers $(\mathrm{N}=\mathbf{2 3 2})$ \\
\hline Minimal bother & & $123(53.0)$ \\
\hline It will improve by itself & & $89(38.4)$ \\
\hline Postpone until after delivery & & $75(32.3)$ \\
\hline Lack of time & & $8(3.4)$ \\
\hline No childcare & & $5(2.2)$ \\
\hline Costs & & $2(0.9)$ \\
\hline No transport & & $0(0.0)$ \\
\hline Other & & $22(9.5)$ \\
\hline
\end{tabular}

$\mathrm{N}=$ number, $\mathrm{UI}=$ urinary incontinence, ${ }^{*}=$ one answer possible, ${ }^{*}=$ multiple answers possible 


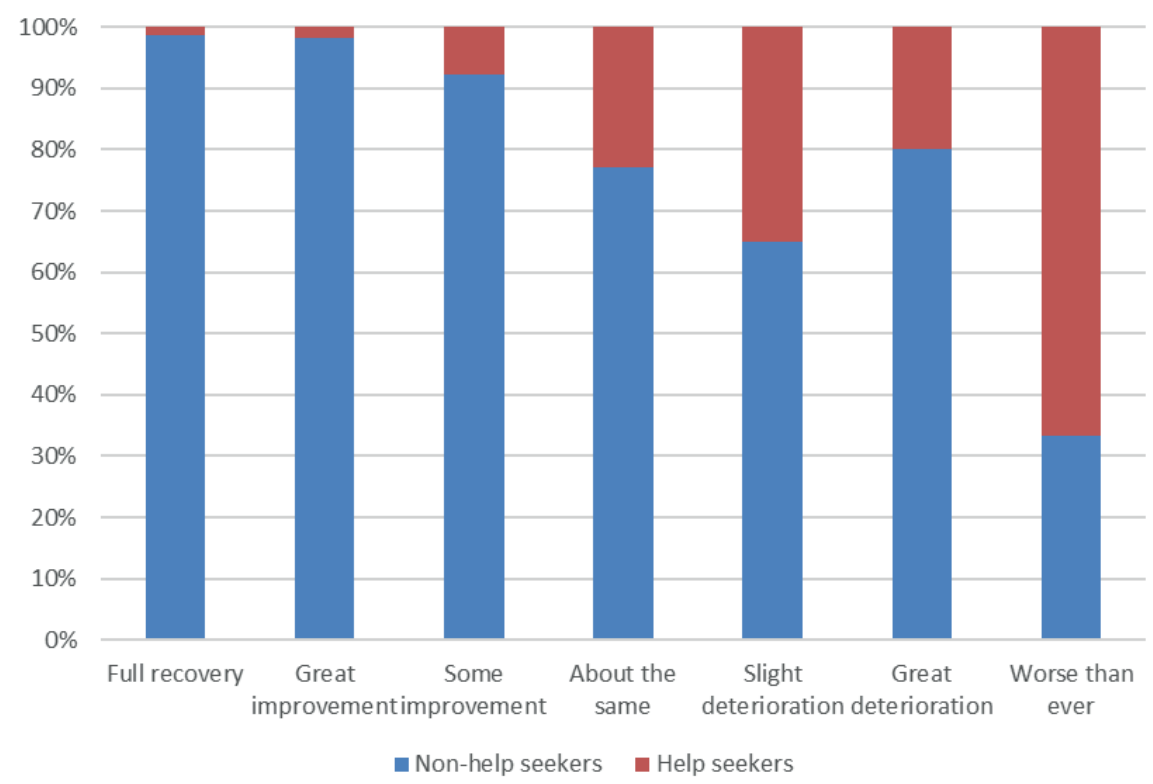

Figure 1 Beliefs about prognosis of urinary incontinence if help is not sought among nonhelp-seekers and help-seekers.

\section{DISCUSSION}

\section{Principal Findings}

This study showed that the crude prevalence of self-reported UI during pregnancy is high (66.8\%) and rises by trimester. SUI is the most frequently reported type of UI (76.8\%) with a notable difference between nulliparous (47.9\%) and parous women (77.4\%) in overall UI prevalence. The severity of $\mathrm{UI}$ is slight (33.7\%) to moderate (56.3\%), total bother is experienced as low and only less than one third of women indicate a significant impact in daily life. Only the presence of the factors 'changing of wet underclothes' and 'worry because of smell' were considered as a significant bother. Only $13 \%$ of respondents sought help for UI. The responders who sought help were often already seeing a (specialized) physiotherapist for other pregnancyrelated problems, like pelvic girdle pain. The pelvic floor muscles are reported to play an important role in trunk stability. ${ }^{18}$ Therefore, it is common practice for (specialized) physiotherapists to discuss any incontinence with pregnant women presenting with pelvic girdle pain. This encourages the women to mention their $\mathrm{UI}$ and seek help. ${ }^{19}$ To our knowledge this is the first study reporting on the 
percentage of women who actually seek help for their UI during pregnancy. However, the numbers on help-seeking might have been influenced by the fact that social media messages were sent by both midwifery and pelvic physiotherapy practices. The respondents who did not seek help stated that their UI didn't bother them a lot (53\%).

Several factors might explain why pregnant women with UI do not seek help. Firstly, nearly $40 \%$ of the respondents thought that UI would improve spontaneously after delivery. However, pregnant women might be insufficiently aware that women with UI during pregnancy have a 2 to 6 fold risk of UI post-partum, depending on severity of UI in pregnancy and period post-partum. ${ }^{20}$ Secondly, the reported overall bother was low and impact on quality of life due to UI was not greatly affected. A higher level of bother is associated with help-seeking. ${ }^{19,21}$ Thirdly, only $4 \%$ of the respondents had UUI and especially women with UUI are reported to have lower quality of life than women with SUI and seek more help ${ }^{5}$. Fourthly, 32\% of the respondents wanted to wait until after the delivery to seek help. In contrast to the non-help-seekers (28.4\%), most of the help-seekers $(85.7 \%)$ thought that without help their UI would remain the same or deteriorate post-partum. This is consistent with Schreiber et al. who reported that women who are afraid that their UI would get worse are triggered to seek help. ${ }^{22}$

Over $70 \%$ of all respondents reported that they think that pelvic floor exercises are the best treatment option for UI. This does not mean that these women actually exercise. Burgio et al. found that although $84.6 \%$ of women had heard of pelvic floor muscle exercises, only $46.7 \%$ of the women really did exercise during pregnancy. ${ }^{20}$ Women want to be informed about pelvic floor dysfunctions preferably during pregnancy. ${ }^{19,21}$ Antenatal classes may be a perfect opportunity to discuss pelvic floor related issues and misconceptions like the fact that UI would resolve by itself. If the importance and positive effect of PFMT are explained, women may be more willing to do their exercises. ${ }^{23}$ Women who attend or have attended antenatal classes are more likely to practice pelvic floor muscle exercises than women who have not. ${ }^{24}$ Another option to inform women might be with a mobile app (mApp). However, at the moment the only existing evidence-based mApp is not specifically developed for pregnant women and focusses on selftreatment and adherence of $\mathrm{UI}$ and not on providing information on pelvic floor dysfunctions in pregnancy. ${ }^{25}$ Although PFMT is an effective and well-established treatment option for women with UI, the treatment effect for UI during pregnancy 
is still uncertain. ${ }^{26}$ Heterogeneity in studies due to differences in characteristics as parity, PFMT programs and control interventions may underlie the absence of robust evidence of effectiveness. Therefore, studies compensating for this heterogeneity are still needed to investigate the direct or remote effect of PFMT on UI during pregnancy.

Screening for the presence of $\mathrm{UI}$ and the degree of bother it causes in daily life (e.g. on activity and participation level) by health care professionals who see pregnant women is relevant to check for misconceptions and to have proper indications for subsequent interventions. However, health care professionals report not having enough time and knowledge to discuss UI. ${ }^{27}$

\section{Clinical and research implications}

The difference between the crude prevalence of $\mathrm{UI}$ and bothersome prevalence of UI during pregnancy demonstrates clearly the importance of reporting both prevalence numbers and the experience of bother in relation to UI. ${ }^{4}$ This study reveals large effect sizes between help- and non-help-seekers regarding ICIQ-UI SF total, ICIQ-LUTSqol total scores and interference in daily life. This indicates that non-help-seeking pregnant women experience little bother, just like women in the general population. ${ }^{21}$ This is an important factor to take into account in care planning and research as less bothered women will be not known to the healthcare system.

\section{Strengths and limitations}

Strength of this study is the large nationwide sample. Another strength is the use of high quality and recommended questionnaires to measure the prevalence and bother of UI, and impact on quality of life. To our knowledge this is the first study to use the ICIQ-LUTSqol to study bother extensively in pregnant women.

This survey has several limitations. Firstly, women in The Netherlands who do not speak Dutch could not fill in the survey. This might have influenced the outcome regarding the knowledge on the best treatment option for UI. Non-native speakers are less likely to be familiar with possible treatments e.g. pelvic floor muscle exercises. ${ }^{24}$ Secondly, we did not ask if UI occurred before the first pregnancy or in previous pregnancies. Therefore, we do not know at what stage in their 
obstetric history pregnant women experienced new onset UI. The third limitation comprises the possible risk of bias due to the accessibility of social media for recruitment. Finally, the non-response rate is not known. However, we do know that the average age and education level are comparable with another large study performed in pregnant women in The Netherlands. ${ }^{28}$

\section{CONCLUSION:}

$\mathrm{UI}$ is highly prevalent throughout pregnancy with prevalence increasing by trimester. However, the majority of women were only slightly bothered by their UI and relatively few women sought help. 


\section{REFERENCES:}

1. Haylen BT, de Ridder D, Freeman RM, et al. An International Urogynecological Association (IUGA)/International Continence Society (ICS) joint report on the terminology for female pelvic floor dysfunction. Int Urogynecol J. 2010;21(1):5-26.

2. Oliveira C, Seleme M, Cansi PF, et al. Urinary incontinence in pregnant women and its relation with socio-demographic variables and quality of life. Rev Assoc Med Bras (1992). 2013;59(5):460-466.

3. Dolan LM, Walsh D, Hamilton S, Marshall K, Thompson K, Ashe RG. A study of quality of life in primigravidae with urinary incontinence. Int Urogynecol J Pelvic Floor Dysfunct. 2004;15(3):160-164.

4. Abrams A, Cardozo L, Wagg A, Wein A, eds. Incontinence 6th edition. Bristol, UK: ICI-ICS. International Continence Society; 2017.

5. Hägglund D, Walker-Engström ML, Larsson G, Leppert J. Quality of life and seeking help in women with urinary incontinence. Acta Obstet Gynecol Scand. 2001;80(11):1051-1055.

6. Monz B, Chartier-Kastler E, Hampel C, et al. Patient characteristics associated with quality of life in European women seeking treatment for urinary incontinence: results from PURE. Eur Urol. 2007;51(4):1073-1081; discussion 1081-1072.

7. Kobashi K, Albo M, Dmochowski R, et al. Surgical Treatment of Female Stress Urinary Incontinence (SUI): AUA/SUFU Guideline (2017). 2017; https://www.auanet.org/ guidelines/stress-urinary-incontinence-(sui)-guideline. Accessed May 5th, 2020.

8. NICE. Urinary incontinence in women: management (cg 171). 2013; https://www.nhsggc. org.uk/media/251043/nice-guideline-urinary-incontinence-in-women-management. pdf. Accessed 2 May 2020.

9. Taherdoost H. Determining Sample Size; How to Calculate Survey Sample Size. In J Econ Manag Systems 2017:237-239.

10. Avery K, Donovan J, Peters TJ, Shaw C, Gotoh M, Abrams P. ICIQ: a brief and robust measure for evaluating the symptoms and impact of urinary incontinence. Neurourol Urodyn. 2004;23(4):322-330.

11. Kelleher CJ, Cardozo LD, Khullar V, Salvatore S. A new questionnaire to assess the quality of life of urinary incontinent women. Br J Obstet Gynaecol. 1997;104(12):1374-1379.

12. Klovning A, Avery $K$, Sandvik H, Hunskaar S. Comparison of two questionnaires for assessing the severity of urinary incontinence: The ICIQ-UI SF versus the incontinence severity index. Neurourol Urodyn. 2009;28(5):411-415.

13. Espuna-Pons M, Dilla T, Castro D, Carbonell C, Casariego J, Puig-Clota M. Analysis of the value of the ICIQ-UI SF questionnaire and stress test in the differential diagnosis of the type of urinary incontinence. Neurourol Urodyn. 2007;26(6):836-841.

14. Nystrom E, Sjostrom M, Stenlund H, Samuelsson E. ICIQ symptom and quality of life instruments measure clinically relevant improvements in women with stress urinary incontinence. Neurourol Urodyn. 2015;34(8):747-751.

15. Bristol Urological Institute. International Consultation on Incontinence Modular Questionnaire (ICIQ). ICIQ structure Short form. 2014.

16. Kraaimaat F. Symptoomperceptie en klachtenbeleving. In: Lechner L, Mesters I, Bolman 
C, eds. Gezondheidspsychologie bij patienten Assen, The Netherlands Koninklijke van Gorcum BV; 2010:151-169.

17. Nijkamp M. Naar hulpvraag en diagnose. In: Lechner L, Mesters I, Bolman C, eds. Gezondheidspsychologie bij patienten. Assen, The Netherlands: Koninklijke Van Gorcum BV; 2010:169-190.

18. Sapsford R. Rehabilitation of pelvic floor muscles utilizing trunk stabilization. Man Ther. 2004;9(1):3-12.

19. Mason L, Glenn S, Walton I, Hughes C. Women's reluctance to seek help for stress incontinence during pregnancy and following childbirth. Midwifery. 2001;17(3):212-221.

20. Burgio KL, Zyczynski H, Locher JL, Richter HE, Redden DT, Wright KC. Urinary incontinence in the 12-month postpartum period. Obstet Gynecol. 2003;102(6):1291-1298.

21. Kinchen KS, Burgio K, Diokno AC, Fultz NH, Bump R, Obenchain R. Factors associated with women's decisions to seek treatment for urinary incontinence. J Womens Health (2002). 2003;12(7):687-698.

22. Schreiber Pedersen L, Lose G, Hoybye MT, Jurgensen M, Waldmann A, Rudnicki $M$. Predictors and reasons for help-seeking behavior among women with urinary incontinence. Int Urogynecol J. 2018;29(4):521-530.

23. Whitford HM, Jones M. An exploration of the motivation of pregnant women to perform pelvic floor exercises using the revised theory of planned behaviour. Br J Health Psychol. 2011;16(4):761-778.

24. Hill AM, McPhail SM, Wilson JM, Berlach RG. Pregnant women's awareness, knowledge and beliefs about pelvic floor muscles: a cross-sectional survey. Int Urogynecol J. 2017;28(10):1557-1565.

25. Asklund I, Nyström E, Sjöström M, Umefjord G, Stenlund H, Samuelsson E. Mobile app for treatment of stress urinary incontinence: A randomized controlled trial. Neurourol Urodyn. 2017;36(5):1369-1376.

26. Woodley SJ, Lawrenson P, Boyle R, et al. Pelvic floor muscle training for preventing and treating urinary and faecal incontinence in antenatal and postnatal women. Cochrane Database Syst Rev. 2020;5:Cd007471.

27. Wagg AR, Kendall S, Bunn F. Women's experiences, beliefs and knowledge of urinary symptoms in the postpartum period and the perceptions of health professionals: a grounded theory study. Prim Health Care Res Dev. 2017;18(5):448-462.

28. van Brummen HJ, Bruinse HW, van de Pol G, Heintz AP, van der Vaart CH. Bothersome lower urinary tract symptoms 1 year after first delivery: prevalence and the effect of childbirth. BJU Int. 2006;98(1):89-95. 


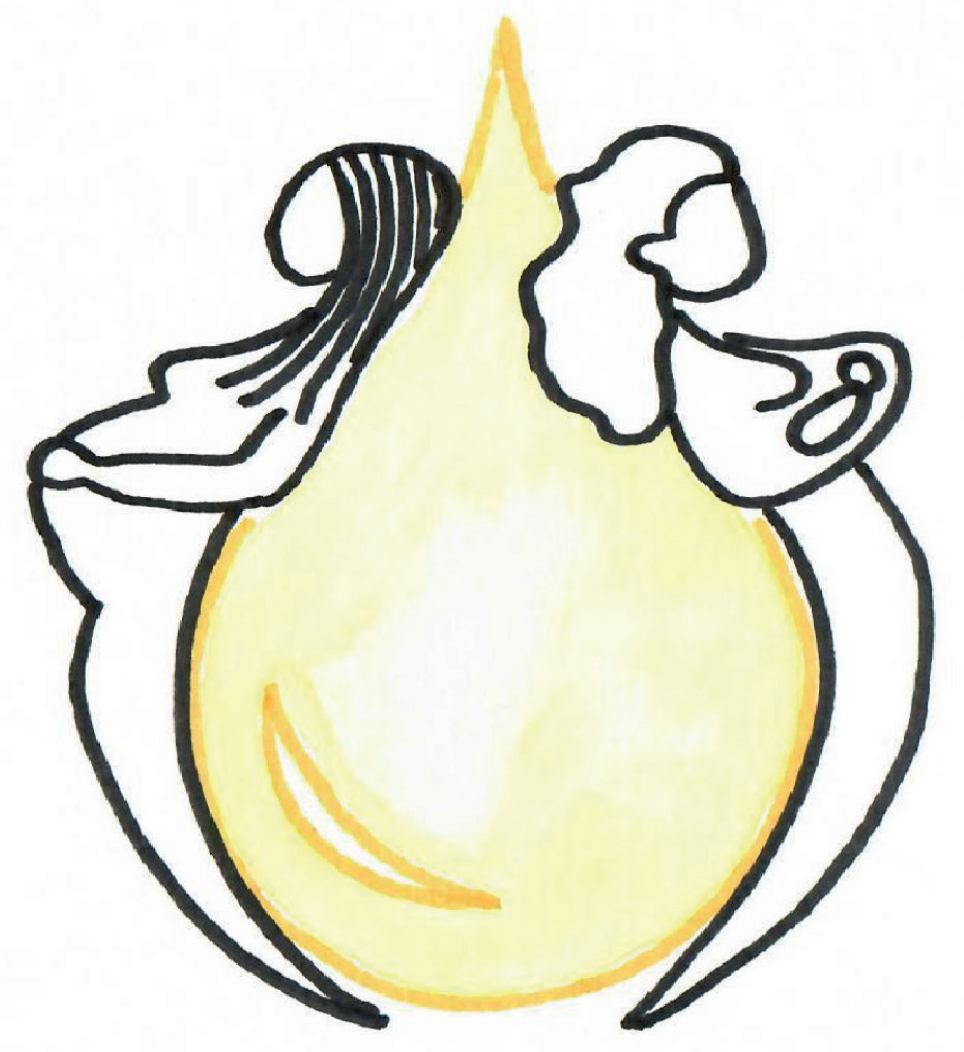




\section{URINARY INCONTINENCE 6 WEEKS TO} 1 YEAR POST-PARTUM: PREVALENCE, EXPERIENCE OF BOTHER, BELIEFS, AND HELP-SEEKING BEHAVIOR

Heidi F.A. Moossdorff-Steinhauser ${ }^{1}$ Bary C.M. Berghmans ${ }^{2}$ Marc E.A. Spaanderman ${ }^{3}$ Esther M.J. Bols ${ }^{1}$

${ }^{1}$ Maastricht University, Faculty of Health, Medicine and Life Sciences, Dept. Epidemiology, CAPHRI Care and Public Health Research Institute, P.O. Box 616, 6200 MD Maastricht, The Netherlands; ${ }^{2}$ Pelvic care Center Maastricht, CAPHRI, Maastricht University Medical Centre (MUMC+), Maastricht, The Netherlands; ${ }^{3}$ Department of Obstetrics and Gynecology, MUMC+, The Netherlands 


\section{ABSTRACT}

Introduction and hypothesis: Post-partum, women often experience urinary incontinence $(\mathrm{UI})$. However, the association between experienced $\mathrm{UI}$ bother and $\mathrm{UI}$ beliefs and help-seeking behavior is less known. Therefore, we aim to investigate the prevalence of self-reported UI, the level of experienced bother and beliefs, to explain help-seeking behavior for $\mathrm{UI}$ in women in the Netherlands from 6 weeks to one year post-partum.

Methods: A digital survey among post-partum women, shared on social media, was used for recruitment. The survey consists of: 1. demographic variables, 2. International Consultation on Incontinence Questionnaire-Urinary Incontinence Short Form (ICIQ-UI SF), 3. ICIQ Lower Urinary Tract Symptoms Quality of Life (ICIQLUTSqol), and 4. questions on beliefs and help-seeking behavior. For analysis, descriptive statistics and the independent samples t-test were used to determine differences between help- and non-help-seekers.

Results: 415 women filled in the survey. The mean age was 30.6 years (SD 4.0, range $21-40$ ) of which $48.2 \%$ was primiparous. The overall prevalence of UI was $57.1 \%$ (95\% confidence interval (CI) (52.3 - 61.8)). Primiparous women reported a statistically significantly lower overall prevalence than multiparous women, $52.0 \%$ and $61.9 \%$ respectively $(p=.043)$. UI was reported as bothersome in $38 \%$ of women, $25 \%$ of all women sought help. Help-seeking women showed significantly higher scores for bother, measured by the ICIQ-UI SF, than non-help seekers $(p=.001)$.

Conclusions: More than half of all post-partum women in the Netherlands from 6 weeks to one year post childbirth experience UI (57.1\%), 38\% classified their UI as bothersome. In total $25 \%$ of UI women sought professional help. 


\section{INTRODUCTION}

Urinary incontinence (UI) as a symptom is defined by the International Continence Society as the 'complaint of involuntary loss of urine'.1 Prevalence numbers of UI from six weeks to one year post-partum range from 10.5 to $63.0 \%$.,3 The wide range in reported prevalence might be explained by the use of different case definitions, post-partum period and study methodology. On the one hand, the International Consultation on Incontinence (ICI) has recommended to accompany prevalence numbers with experienced symptom bother, and on the other hand to measure this construct with high quality measurement instruments preferably within the International Consultation on Incontinence Questionnaire (ICIQ) structure. ${ }^{4}$ Despite the $\mathrm{ICl}$ recommendations, symptom bother is often not included in prevalence studies. Moreover, a variety of measurement instruments are used for symptom bother, ranging from high quality to non-validated self-constructed questionnaires. ${ }^{2,3}$ These factors influence reliable prevalence numbers for (bothersome) UI, which are of relevance for health care providers, policy makers, and researchers. ${ }^{5}$ To date, knowledge on crude prevalence numbers (categorized by type of UI, post-partum period, or parity) and symptom bother measured with measurement instruments within the ICIQ structure in the post-partum period are largely lacking.

The level of bother, type and severity of UI are associated factors in help-seeking behavior in the general female population. ${ }^{6}$ After delivery, women often believe that their UI will improve by itself. ${ }^{7}$ Pelvic floor muscle training (PFMT) is an effective treatment option for post-partum women with $\mathrm{UI}$ and recommended as first treatment option in guidelines on UI. ${ }^{8}$ However, to our knowledge it is unknown if and what kind of experiences and daily activities contribute to help-seeking and why post-partum women do not seek help. Therefore, the aim is to investigate the prevalence of self-reported UI, the level of experienced bother and beliefs, to explain help-seeking behavior in women in the Netherlands from 6 weeks to one year post-partum.

\section{MATERIAL AND METHODS}

\section{Study design}

A cross-sectional design was used to describe the prevalence, bother, believes, and help-seeking behavior of post-partum women. The Medical Ethics Committee of the Maastricht University Medical Centre (MUMC+) approved this study (number 
2019-1320). All women of 18 years and older, regardless of parity and between 6 weeks and one year post-partum, who were able to fill in a digital questionnaire in the Dutch language were eligible to participate. Based on an overall prevalence of $\mathrm{UI}$ in women of 33\%, a Z statistic of 1.96 and precision of 0.05 , a minimal sample size of 340 women was estimated to fill out the survey. ${ }^{9}$ Nationwide midwifery and physical therapy practices were amongst others asked to share a social media message (using Facebook and LinkedIn), containing brief information on the study (goal, eligibility) and a link to the patient information letter and digital survey. In this context a physical therapist is defined as a physical therapist, educated and specialized in health problems related to the pelvic floor and organs in the pelvis minor.

Before proceeding to the anonymized digital survey, eligible women signed informed consent electronically, in agreement with ethical regulations. The survey took 10 to 15 minutes to complete.

\section{Outcome measures}

The survey consists of four parts: 1. demographic variables like age, educational level and parity, 2. International Consultation on Incontinence Questionnaire Short Form (ICIQ-UI SF) ${ }^{10}$, 3. International Consultation on Incontinence Questionnaire Lower Urinary Tract Symptoms Quality of Life (ICIQ-LUTSqol)11 and 4. questions on beliefs and help-seeking behavior regarding UI.

The ICIQ-UI SF consists of four questions and provides an indication of UI severity. The first question is with regard to the frequency of UI, with a score of 0 (never losing urine) to 5 (losing urine all the time). The second question asks for amount of urine loss, with four response categories ranging from 0 (no loss) to 6 (large amount). The third question evaluates impact of UI on daily life, ranging from 0 (not at all) and 10 (a great deal). The total score ranges from 0 (no UI) to 21 (very severe problem). The total score is divided into four categories: slight (1-5), moderate (612), severe (13-18), and very severe (19-21). ${ }^{12} \mathrm{~A}$ fourth question on the occurrence of symptoms of UI was used to indicate SUI, UUI and MUI. ${ }^{13}$ A participant was considered to have SUI when leaking urine with a cough or a sneeze and/or when physically active/exercising, but not before getting to the toilet. UUI is considered when the respondent leaks before getting to the toilet. A respondent with MUI experiences both SUI and UUI. 
The ICIQ-LUTSqol is a condition-specific health-related quality of life questionnaire (20 questions), adapted for use within the ICIQ structure from the King's Health Questionnaire. ${ }^{11}$ It contains 19 questions that can be scored on life restrictions, emotional aspects and preventive measures. It is scored on a four-point Likert scale ranging from 1 (not at all) to 4 (a lot). Three questions on relationships, sex life, and family life include additionally 'not applicable'. 'Not applicable' was considered as not affecting daily life. The sum score ranges between 19 and 76. A higher score indicates a higher impact on quality of life. Every question is accompanied by a question regarding experienced bother (ranging from 0 (no bother) to 10 (extreme bother)). It is arbitrarily decided that a score of at least 5 indicates significant bother on a specific item. The $20^{\text {th }}$ question is on how much urinary symptoms interfere with daily life, scored between 0 to 10 (like bother). Both the ICIQ-UI SF and ICIQ-LUTSqol are rated as 'high quality' questionnaires and are recommended by the $\mathrm{ICI}^{4}$

All respondents at least filled in the demographic variables and ICIQ-UI SF. Answering 'never losing urine' at the frequency item of the ICQ-UI SF indicated continence and consequently the survey was finished. When reporting UI, women completed the remaining two parts on quality of life and help-seeking behavior.

The questions on beliefs and help-seeking behavior were self-constructed. Selection of question and answer options was based on models explaining help-seeking behavior, discussion with experts in the field (epidemiologists and obstetrician/gynecologist) and modified accordingly. ${ }^{14}$ Moreover, questions were reviewed by an expert for readability and comprehensiveness, followed by field testing. Ultimately, six questions were developed including four topics on health seeking behavior (actual help-seeking, reason(s) to (not) seek help, reason to seek help in the future and consulted health-care provider(s)) and two topics on beliefs (self-perceived prognosis and self-perceived best intervention to treat UI in general).

\section{Data analysis}

Data was analyzed using descriptive statistics presented as proportions (frequency and means (SD)) and correlation was performed by Pearson's correlation coefficient. Post-partum women were categorized into three groups: 6 weeks to 3 months, 3 to 6 months and 6 to 12 months post-partum. Independent sample 
t-tests were conducted to compare help-seekers and non-help seekers with regard to UI severity (ICIQ-UI SF total score), bother (ICIQ-LUTSqol total score), and interference in daily life. Chi-square tests were used to test relationships between categorical variables. One-way analysis of variance (ANOVA) was used to explore differences in experienced bother, measured with the ICIQ-UI SF scores, across the three post-partum periods. The effect size was estimated with Cohen's $d$. Cohen's $d$ presents the difference between groups (help-seekers and non-helpseekers) in standard deviation units. To interpret the strength of the effect size we followed the guidelines proposed by Cohen: .2=small, .5=medium, .8=large. An alpha of 0.05 is considered statistically significant. Analyses were done using IBM Statistical Package for Social Sciences (SPSS) version 26.0 (New York, NY, USA).

\section{RESULTS}

In March 2020, 415 women filled in the survey. The mean age was 30.6years (SD 4.0, range $21-40$ ) of which $48.2 \%$ (200/415) was primiparous (Table 1). A total of $37.7 \%$ (157/415) followed secondary and $61.4 \%$ (255/415) tertiary education. The overall prevalence of UI was 57.1\% (95\% confidence interval (CI) 52.3 - 61.8). Primiparous women reported a lower overall prevalence of UI compared to multiparous women (52\%, 104/200) and 61.9\%, 133/215 respectively) which was statistically significant $(p=.043)$. The prevalence of UI does not change significantly across the three post-partum periods $(p=.15)$. However, the pattern over time shows the highest prevalence between 6 weeks and 3 months with 66.7\% (50/75), almost statistically significant decreasing to 52.6\% (61/116) between 3 and 6 months after which there is no significant change thereafter $(56.3 \%(126 / 224)$, between 6 and 12 months. SUI $(62.9 \%, 149 / 237)$ was the most frequently reported type of UI.

UI frequency of once a week or less was reported in 43.9\% (104/237) and in 89.5\% $(212 / 237)$ of the cases it was a small amount of urine (Table 1$)$. The impact of UI based on the ICIQ-UI SF score was reported by $29.7 \%$ (70/236) of the women as slight and by $57.6 \%(136 / 236)$ as moderate. There were no statistically significant differences for the ICIQ-UI SF score across the three post-partum periods $(p=.06)$. The mean interference in daily life based on ICIQ-UI SF was 3.8 (SD 2.4, range 0-9), whereas 38\% (90/237) of the respondents reported an overall interference in daily life of $\geq 5$. The mean ICIQ-LUTSqol was 29.8 (SD 7.9, range 20-58). Respondents reported that they experienced a significant bother on three daily activities based 
on the ICIQ-LUTSqol. The first is on 'physical activities', like going for a walk, run or sports. The second is regarding the 'need to change wet underclothes' and the third is about 'worrying because of smell'. Respondents with UI were least affected and bothered by the items on maintaining friendships, the effect on sleep and feeling tired. The correlation between the total score of the ICIQ-UI SF and the ICIQ-LUTSqol was high $\left(0.74, p=.001, R^{2}=0.54\right)$.

In total, $25.7 \%(61 / 237)$ of the respondents sought help for their UI post-partum (Table 2). The majority of women seeking help (92\%) visited a physical therapist. The reasons provided for not seeking help were: minimal bother $(52.9 \%, 91 / 172)$ and the idea that their UI would improve in time by itself $(54.1 \%, 93 / 172)$. The most important reasons for seeking help in the future were: the constant use of pads (45.9\%, 79/172), leaking/getting wet clothes (35.5\%, 61/172), the feeling that others can smell the urine loss $(27.9 \%, 48 / 172)$ or hindrance at work $(27.9 \%, 48 / 172)$. With regard to seeking help in the future, 32\% (55/172) of women reported one and $68 \%(117 / 172)$ reported two or three reasons why they would seek help in the future. 


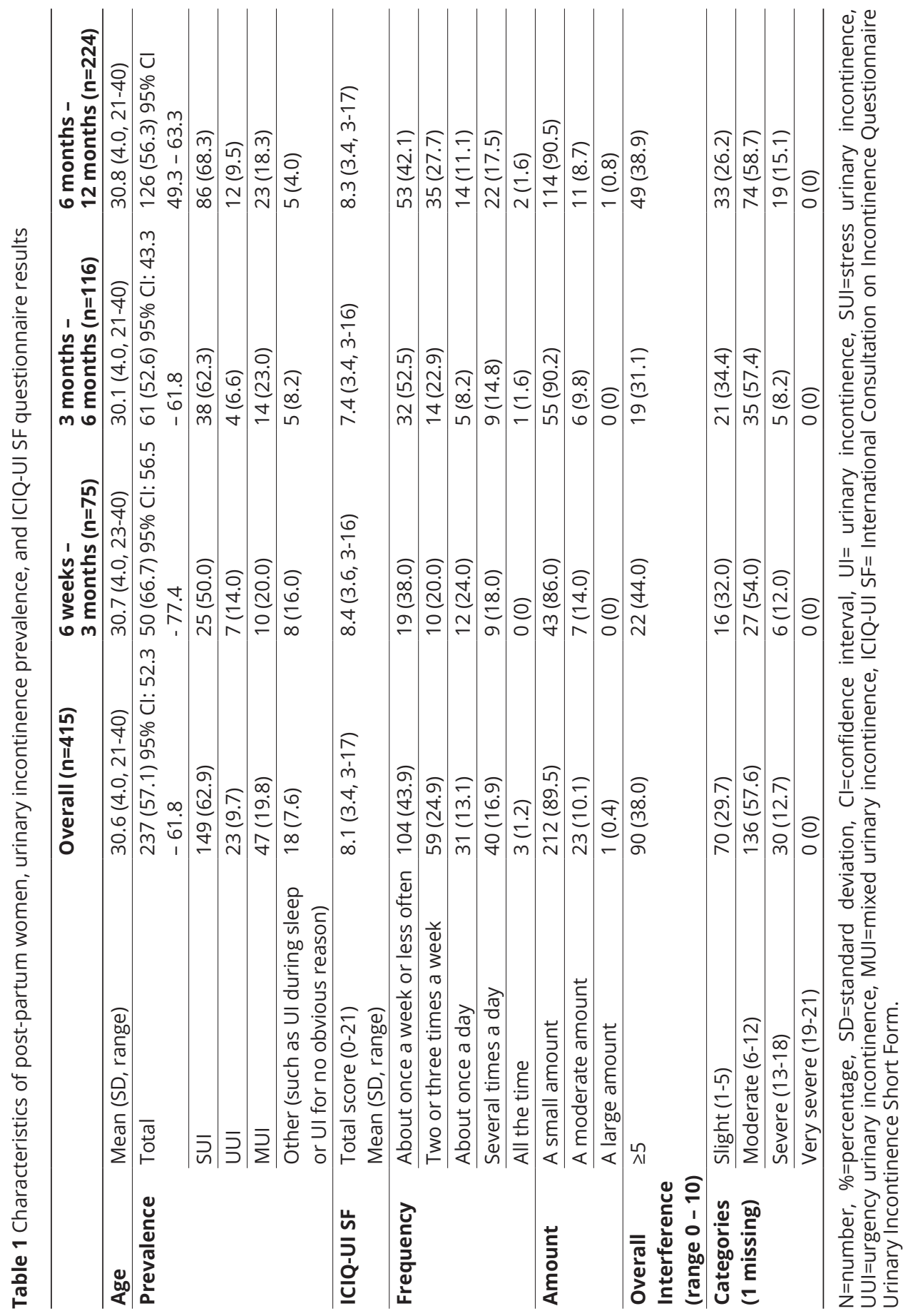


Table 2 Beliefs and help-seeking behavior in relation to urinary incontinence

\begin{tabular}{|c|c|c|}
\hline \multicolumn{3}{|l|}{ BELIEFS } \\
\hline Prognosis UI without seeking help & $\begin{array}{l}\text { Help-seekers } \\
(\mathrm{N}=61)\end{array}$ & $\begin{array}{l}\text { Non-help-seekers } \\
(\mathrm{N}=172)\end{array}$ \\
\hline Complete recovery & $2(3.2)$ & $38(22.1)$ \\
\hline Good improvement & $2(3.2)$ & $47(27.3)$ \\
\hline Some improvement & $12(19.7)$ & $34(19.8)$ \\
\hline About the same & $17(27.9)$ & $41(23.8)$ \\
\hline Some deterioration & $15(24.6)$ & $11(6.4)$ \\
\hline Great deterioration & $9(14.8)$ & $1(0.6)$ \\
\hline Worse than ever & $4(6.6)$ & $0(0)$ \\
\hline \multicolumn{3}{|l|}{ Best way to solve UI } \\
\hline Surgery & $3(4.9)$ & $3(1.7)$ \\
\hline Medication & $2(3.3)$ & $0(0)$ \\
\hline Pelvic floor muscle exercises & $46(75.4)$ & $143(83.1)$ \\
\hline It will resolve by itself & $1(1.6)$ & $6(3.5)$ \\
\hline There is no solution & $1(1.6)$ & $4(2.3)$ \\
\hline I don't know & $6(9.8)$ & $13(7.6)$ \\
\hline Other & $2(3.3)$ & $3(1.7)$ \\
\hline HELP-SEEKING & Help-seekers & Non-help-seekers \\
\hline Reason to seek help & I sought help because* & $\begin{array}{l}\text { I will seek help in the } \\
\text { future if }\end{array}$ \\
\hline Getting wet clothes/leaking through & $2(3.3)$ & $61(35.5)$ \\
\hline Need to use pad all the time & $11(18.0)$ & $79(45.9)$ \\
\hline Others can smell me & $1(1.6)$ & $48(27.9)$ \\
\hline Hindrance during sports & $12(19.7)$ & $27(15.7)$ \\
\hline Hindrance during work & $4(6.6)$ & $48(27.9)$ \\
\hline Hindrance playing with children & $5(8.2)$ & $32(18.6)$ \\
\hline $\begin{array}{l}\text { Hindrance during household tasks/ } \\
\text { activities }\end{array}$ & $0(0)$ & $14(8.1)$ \\
\hline I don't know & $24(39.3)$ & $25(14.5)$ \\
\hline Other reason(s) & $0(0)$ & $10(5.8)$ \\
\hline Reason not to seek help & & $\begin{array}{l}\text { Non-help-seekers } \\
(\mathrm{N}=172)\end{array}$ \\
\hline Minimal bother & & $91(52.9)$ \\
\hline It will improve by itself & & $93(54.1)$ \\
\hline Lack of time & & $25(15.5)$ \\
\hline No childcare & & $13(7.6)$ \\
\hline Costs & & $7(4.1)$ \\
\hline No transport & & $3(1.7)$ \\
\hline Other & & $28(16.3)$ \\
\hline
\end{tabular}

$\mathrm{N}=$ number,${ }^{*}=$ only one response option, ${ }^{\#=}$ multiple response options possible. 
More women, 49.4\% (85/172) who did not seek help in contrast to 6.4\% (4/61) of the women who did seek help for their UI, thought that their UI would completely resolve or improve a great deal in the future $(p<.001)$. Figure 1 shows the beliefs about self-perceived prognosis of UI among non-help-seeking and help-seeking women as relative percentages of $100 \%$. Of all women with UI, 79.7\% (189/237) thought that the best way to treat their UI would be pelvic floor muscle exercises.

Help-seeking women showed significant higher scores than non-help-seeking women regarding ICIQ-UI SF ( $p=.001)$, ICIQ-LUTSqoI $(p<.001)$, and interference in daily life $(p=.002)$, with corresponding medium effect sizes (ICIQ-UI SF total score: Cohen's $d=0.52$, ICIQ-LUTSqol total score: Cohen's $d=0.57$, and interference in daily life: Cohen's d=0.48). Parity, level of education, age, type of UI, ICIQ-UI SF Amount, and ICIQ-UI SF Frequency showed only weak correlations with help-seeking (ranging between $0.1-0.24$ ).

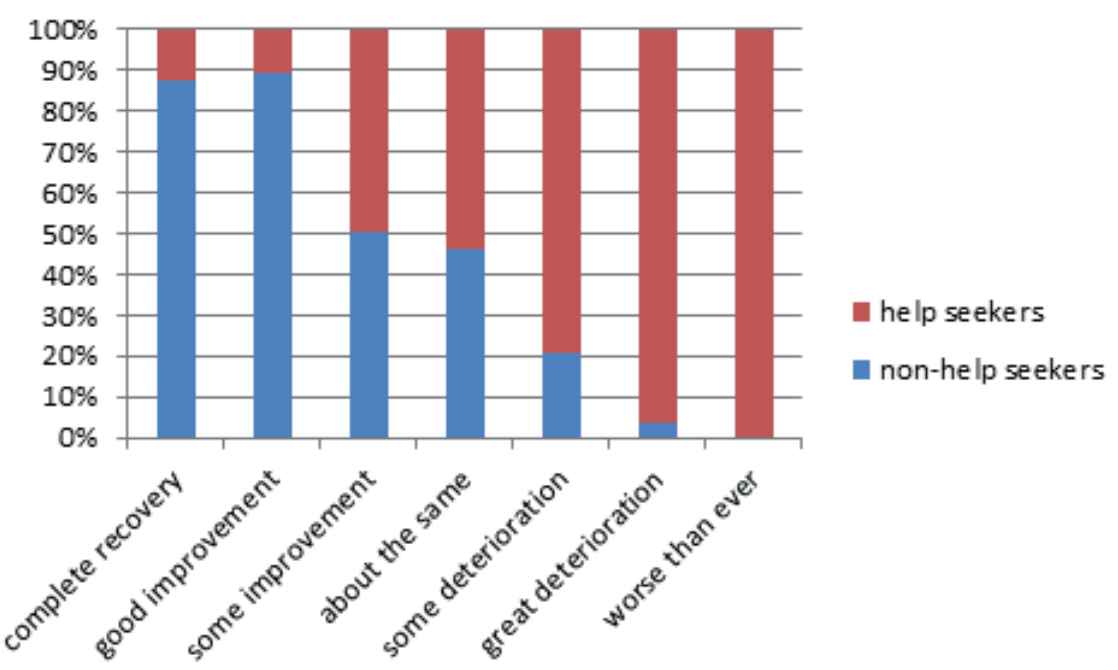

Figure 1 Beliefs about prognosis of urinary incontinence if help is not sought among nonhelp seekers and help seekers. 


\section{DISCUSSION}

\section{Principal findings}

This study showed that the overall crude prevalence of self-reported UI postpartum is high (57.1\%), with $38 \%$ experienced as bothersome UI. SUI is the most prevalent type (62.9\%), followed by MUI (19.8\%) and UUI (8.9\%).

The high overall crude prevalence in this study is not uncommon compared to other studies. ${ }^{2}$ The prevalence of UI in primiparous women was $52.0 \%$ rising to $61.9 \%$ in multiparous women. This is in line with other research, indicating that the first delivery is a major risk factor for UI. ${ }^{15}$ The prevalence of UI post-partum did not change significantly in the course of the first year post-partum. Although the initial prevalence between 6 weeks and 3 months almost statistically significantly decreased at 3 to 6 months post-partum, the difference between this initial period and the second half of the year after childbirth was not statistically significant. Both Gartland et al. and Brown et al. reported a decrease of UI prevalence and thereafter an increase throughout the first year after childbirth. ${ }^{16,17}$ The decreasing prevalence at three to six months post-partum might be explained by physiological recovery and the rise thereafter because of an increase in return to activities provoking UI, such as physical activity or work. ${ }^{18}$

This is one of the first studies to report the number and reasons of post-partum women to seek help for their UI. ${ }^{19}$ In total $25.7 \%$ of post-partum women sought help for their UI, in $92 \%$ of cases they visited a physical therapist. This reflects the recommendations in the guidelines on $\mathrm{UI}$ for the general practitioners in The Netherlands proposing physical therapy as a first treatment option. ${ }^{20}$ The fact that participants were recruited through social media from both midwifery and physical therapy practices this number might have been influenced. The helpseeking women reported a greater interference in daily life compared to not-helpseeking women. $46 \%$ of help-seeking women think that their UI would deteriorate when they would not seek help in contrast to $7 \%$ of non-help-seeking women $(p<.001)$.This is in line with other studies in which women mentioned that they did not seek help because they were not greatly bothered by their UI and thought that it would diminish by itself in time. ${ }^{7}$ However, up to $91 \%$ of women with SUI after their first delivery still report SUI 12 years later. ${ }^{21}$ Although UI is not life threatening, women in the general population with UI report lower health-related quality of life 
and mental well-being and $45 \%$ of women report a moderately to totally limiting effect on exercise. ${ }^{22}$ Women with $\mathrm{UI}$ in this study reported significant bother of $\mathrm{UI}$ regarding physical activities like in the study of Monz et al..22 Women with UI during physical activities adapt by e.g. reducing the intensity and avoiding specific UI provoking activities that may impact physical fitness and mental health. ${ }^{23}$

\section{Clinical and research implications}

Generally, women in the Western world have a final check at six to eight weeks post-partum by a midwife or gynecologist. This recovery period might be short to judge actual pelvic floor dysfunctions. ${ }^{24}$ On the one hand, the contractility of the pelvic floor muscles are considered to need at least 12 weeks to recuperate and at four to six months post-partum the distensibility of the hiatal area is still significantly increased during Valsalva compared to early pregnancy which can limit the physical resilience of the pelvic floor. ${ }^{25}$ On the other hand women are in the early post-partum period also busy finding a new balance in their life and their own health may be considered less important to them at that moment. ${ }^{7}$ With this in mind it might be more appropriate to check the mother's health regarding pelvic floor dysfunctions like UI at a later stage (three to six months post-partum). At the moment there is no validated easy assessment tool that evaluates women's well-being in a broader, more general perspective. Therefore, an evidence-based selection tool investigating and mapping women's health in general and the pelvic floor specifically, aiming to record whether and to what extent an intervention is warrant. For this purpose, a physical therapist, as an expert on both women's health and in conservative management of pelvic floor dysfunctions, may use the tool of the physical therapeutic diagnostic consultation that, given the medical diagnosis of $\mathrm{UI}$, looks at the consequences of this health problem on three different levels, being the local level (impairments), personal level (disabilities) and the sociocultural level (restriction in participation. ${ }^{26}$ Our results show that $75.4 \%$ of help seeking and $83.1 \%$ of non-help seeking women think PFMT is the best way to solve UI. This suggests that PFMT is a well-known treatment option in The Netherlands. However, this number might not reflect the knowledge of PFMT in other parts of the world as Asia and Africa. For example, 55.5\% and 58\% of pregnant women in Thailand and Malaysia, respectively, possessed knowledge of PFMT. ${ }^{27,28}$ 


\section{Strengths and Limitations}

The strength of this study is the large nationwide sample on post-partum women in The Netherlands. Another strength is the use of high quality, recommended questionnaires to measure the prevalence and bother of UI, and impact on quality of life. To our knowledge this is the first study to use the ICIQ-LUTSqol to study quality of life and therefor to evaluate bother extensively in post-partum women from 6 weeks to 1 year post-delivery, next to their relations with help-seeking behavior.

This survey has several limitations. Firstly, women in The Netherlands who do not speak Dutch could not fill in the survey. This might have influenced the outcome regarding the knowledge on the best treatment option for UI. Nevertheless, nonnative speakers are less likely to be familiar with possible treatments e.g. PFMT. ${ }^{29}$ Secondly, we did not ask if UI occurred before the first pregnancy or during the pregnancies. Therefore, we do not know at what stage in their obstetric history women experienced new onset UI. The third limitation comprises the possible risk of bias due to the accessibility of social media for recruitment. Though, in 2020, $75 \%$ of The Dutch population use Facebook and 38\% Linkedln..$^{30}$ Finally, the nonresponse rate is not known.

\section{CONCLUSION}

More than half of all post-partum women in the Netherlands from 6 weeks to one-year post childbirth experience UI (57.1\%), of whom, 38\% classified their UI as bothersome.. In women with UI, $25 \%$ sought help and in $92 \%$ of cases this was with a specialized (pelvic) physical therapist. Help-seeking women experience higher impact on bother than non-help seekers. 


\section{REFERENCES:}

1. Haylen BT, de Ridder D, Freeman RM, et al. An International Urogynecological Association (IUGA)/International Continence Society (ICS) joint report on the terminology for female pelvic floor dysfunction. Int Urogynecol J. 2010;21(1):5-26.

2. Durnea CM, Khashan AS, Kenny LC, Tabirca SS, O'Reilly BA. The role of prepregnancy pelvic floor dysfunction in postnatal pelvic morbidity in primiparous women. Int Urogynecol J. 2014;25(10):1363-1374.

3. Burgio KL, Zyczynski H, Locher JL, Richter HE, Redden DT, Wright KC. Urinary incontinence in the 12-month postpartum period. Obstet Gynecol. 2003;102(6):1291-1298.

4. Abrams A, Cardozo L, Wagg A, Wein A, eds. Incontinence 6th edition. Bristol, UK: ICI-ICS. International Continence Society; 2017.

5. Williams R, Wright J. Epidemiological issues in health needs assessment. BMJ (Clinical research ed). 1998;316(7141):1379-1382.

6. Kinchen KS, Burgio K, Diokno AC, Fultz NH, Bump R, Obenchain R. Factors associated with women's decisions to seek treatment for urinary incontinence. J Womens Health (2002). 2003;12(7):687-698.

7. Buurman MB, Lagro-Janssen AL. Women's perception of postpartum pelvic floor dysfunction and their help-seeking behaviour: a qualitative interview study. Scand J Caring Scie. 2013;27(2):406-413.

8. NICE. Urinary incontinence in women: management (cg 171). 2013; https://www.nhsggc. org.uk/media/251043/nice-guideline-urinary-incontinence-in-women-management. pdf. Accessed 2 May 2020.

9. Taherdoost H. Determining Sample Size; How to Calculate Survey Sample Size. In J Econ Manag Systems 2017:237-239.

10. Avery K, Donovan J, Peters TJ, Shaw C, Gotoh M, Abrams P. ICIQ: a brief and robust measure for evaluating the symptoms and impact of urinary incontinence. Neurourol Urodyn. 2004;23(4):322-330.

11. Kelleher CJ, Cardozo LD, Khullar V, Salvatore S. A new questionnaire to assess the quality of life of urinary incontinent women. Br J Obstet Gynaecol. 1997;104(12):1374-1379.

12. Klovning A, Avery K, Sandvik H, Hunskaar S. Comparison of two questionnaires for assessing the severity of urinary incontinence: The ICIQ-UI SF versus the incontinence severity index. Neurourol Urodyn. 2009;28(5):411-415.

13. Espuña-Pons M, Dilla T, Castro D, Carbonell C, Casariego J, Puig-Clota M. Analysis of the value of the ICIQ-UI SF questionnaire and stress test in the differential diagnosis of the type of urinary incontinence. Neurourol Urodyn. 2007;26(6):836-841.

14. Kraaimaat F. Symptoomperceptie en klachtenbeleving. In: Lechner L, Mesters I, Bolman C, eds. Gezondheidspsychologie bij patienten Assen, The Netherlands Koninklijke van Gorcum BV; 2010:151-169.

15. MacArthur $C$, Wilson $D$, Herbison $P$, et al. Urinary incontinence persisting after childbirth: extent, delivery history, and effects in a 12-year longitudinal cohort study. BJOG. 2016;123(6):1022-1029. 
16. Gartland D, MacArthur C, Woolhouse H, McDonald E, Brown SJ. Frequency, severity and risk factors for urinary and faecal incontinence at 4 years postpartum: a prospective cohort. BJOG. 2016;123(7):1203-1211.

17. Brown S, Gartland D, Perlen S, McDonald E, MacArthur C. Consultation about urinary and faecal incontinence in the year after childbirth: a cohort study. BJOG. 2015;122(7):954962.

18. Tunn R, DeLancey JO, Howard D, Thorp JM, Ashton-Miller JA, Quint LE. MR imaging of levator ani muscle recovery following vaginal delivery. Int Urogynecol J Pelvic Floor Dysfunct. 1999;10(5):300-307.

19. Ruiz de Viñaspre Hernández R, Tomás Aznar C, Rubio Aranda E. Factors associated with treatment-seeking behavior for postpartum urinary incontinence. J Nurs Scholarsh. 2014;46(6):391-397.

20. NHG-STANDAARD. Incontinentie voor urine bij vrouwen (M46). NHG-STANDAARD 2015; https://richtlijnen.nhg.org/standaarden/incontinentie-voor-urine-bij-vrouwen. Accessed 27 September, 2020.

21. Diez-Itza I, Zubikarai M, Galan C, Ginto L, Saro J, Arrue M. Factors involved in the persistence of stress urinary incontinence from postpartum to 12 years after first delivery. Neurourol Urodyn. 2020.

22. Monz B, Pons ME, Hampel C, et al. Patient-reported impact of urinary incontinence-results from treatment seeking women in 14 European countries. Maturitas. 2005;52 Suppl 2:S24-34.

23. Nygaard I, Girts T, Fultz NH, Kinchen K, Pohl G, Sternfeld B. Is urinary incontinence a barrier to exercise in women? Obstetrics and gynecology. 2005;106(2):307-314.

24. Mason L, Glenn S, Walton I, Hughes C. Women's reluctance to seek help for stress incontinence during pregnancy and following childbirth. Midwifery. 2001;17(3):212-221.

25. Van de Waarsenburg MK, Verberne EA, van der Vaart $\mathrm{CH}$, Withagen MIJ. Recovery of puborectalis muscle after vaginal delivery: an ultrasound study. Ultrasound Obstet Gynecol. 2018;52(3):390-395.

26. WHO. International Classification of Functioning, Disability and Health (ICF). 2001. Accessed 9 October, 2020.

27. Jaffar A, Mohd-Sidik S, Nien FC, Fu GQ, Talib NH. Urinary incontinence and its association with pelvic floor muscle exercise among pregnant women attending a primary care clinic in Selangor, Malaysia. PloS one. 2020;15(7):e0236140.

28. Temtanakitpaisan T, Bunyavejchevin S, Buppasiri P, Chongsomchai C. Knowledge, Attitude, and Practices (KAP) Survey Towards Pelvic Floor Muscle Training (PFMT) Among Pregnant Women. Int J Womens Health. 2020;12:295-299.

29. Boutron I, Altman DG, Moher D, Schulz KF, Ravaud P. CONSORT Statement for Randomized Trials of Nonpharmacologic Treatments: A 2017 Update and a CONSORT Extension for Nonpharmacologic Trial Abstracts. Ann intern Med. 2017;167(1):40-47.

30. Newcom. Nationale Social Media Onderzoek. 2020; https://www.newcom.nl/ socialmedia2020. Accessed 5 October, 2020. 


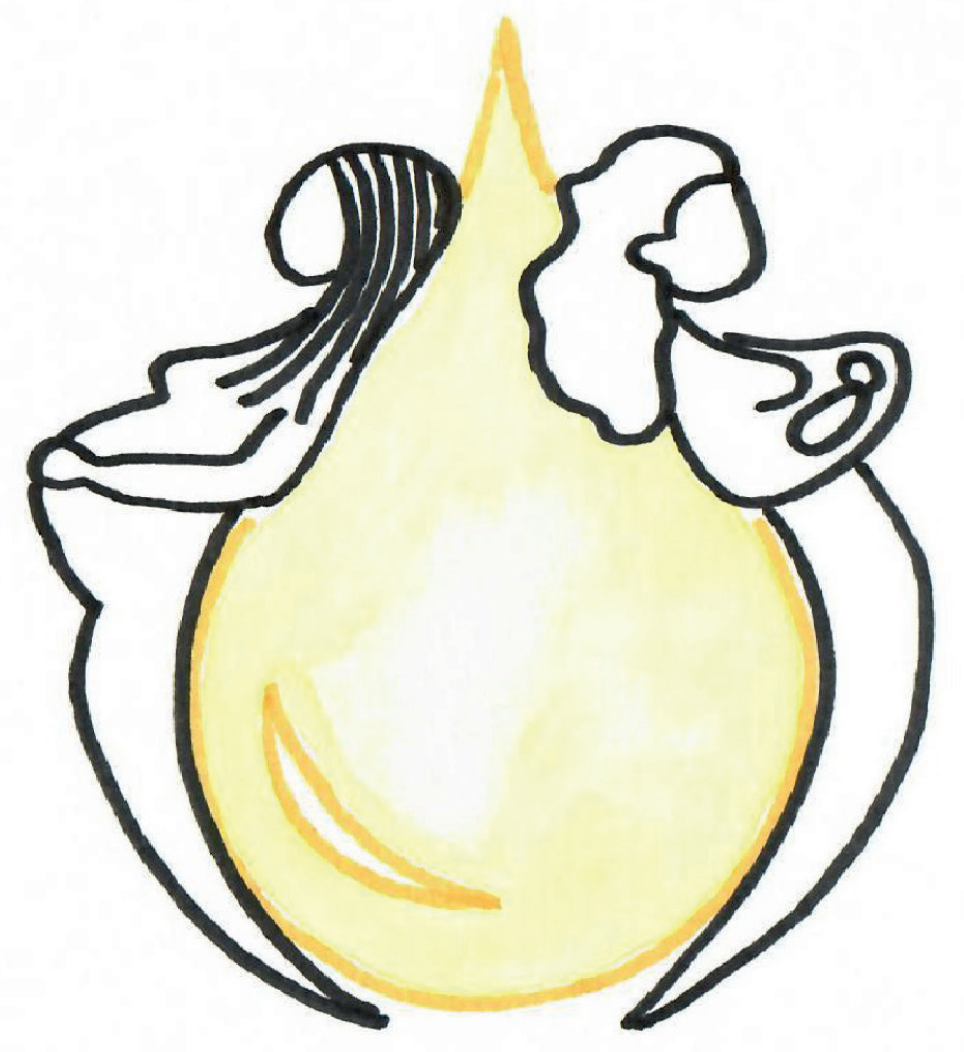




\section{CHAPTER 8}

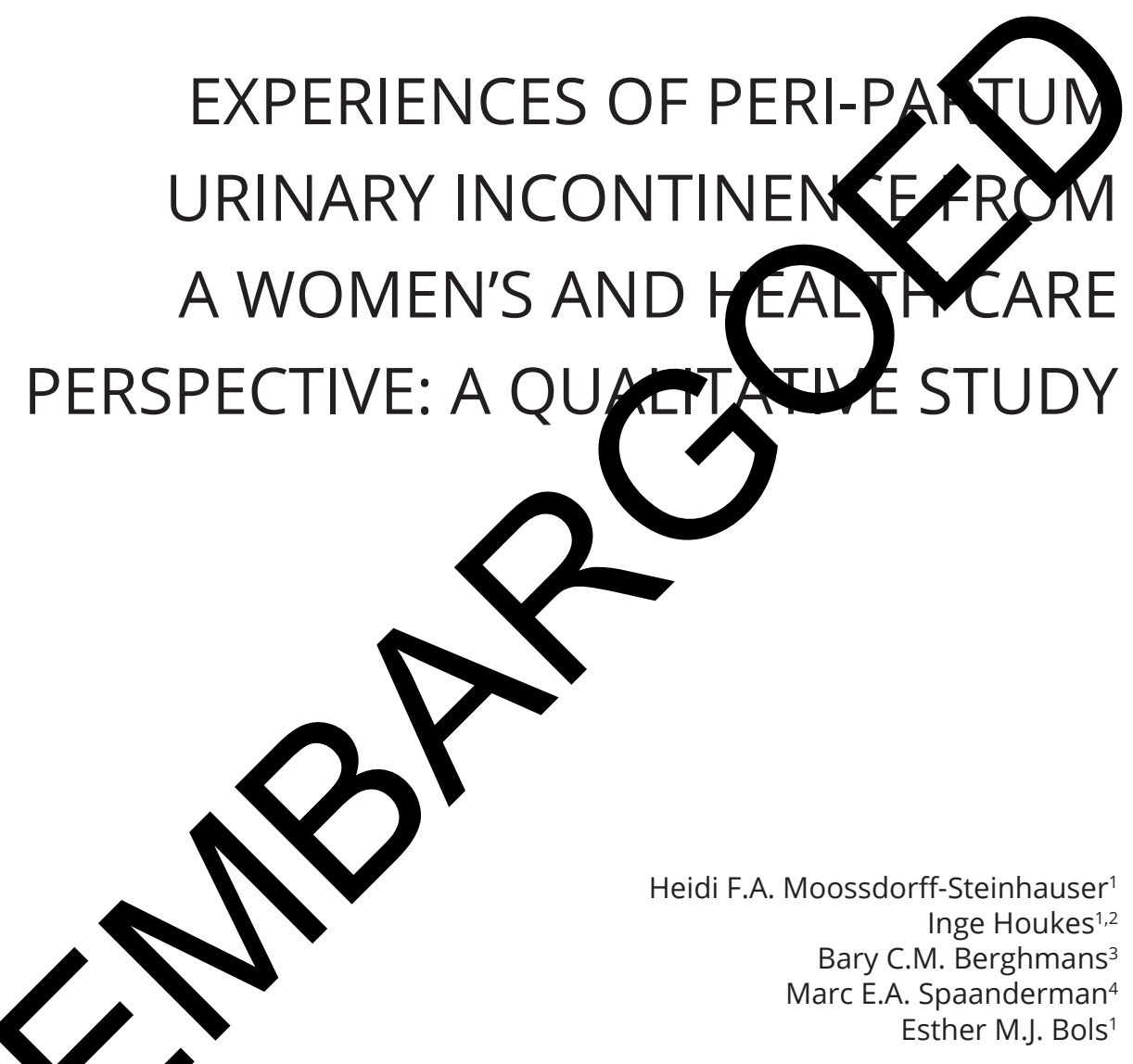

aastricht University, Faculty of Health, Medicine and Life Sciences, Dept. pidemiology, CAPHRI Care and Public Health Research Institute, P.O. Box 616, 6200 MD Maastricht, The Netherlands; ${ }^{2}$ Department of Social Medicine, Maastricht University, The Netherlands; ${ }^{3}$ Pelvic care Center Maastricht, CAPHRI, Maastricht University Medical Centre (MUMC+), Maastricht, The Netherlands; ${ }^{4}$ Department of Obstetrics and Gynaecology, MUMC+, Maastricht, The Netherlands 
CHAPTER 9

GENERAL DISCUSSION 


\section{MAIN FINDINGS}

Urinary incontinence (UI) is a highly prevalent condition amongst women and often develops during pregnancy and childbirth. Despite the high reported numbers, there seems to be a mismatch between prevalence and help-seeking behavior. The main objective of this thesis was to investigate several aspects of pregnancyrelated UI, including prevalence, experienced bother, anticipated course, therapeutic effect of physical therapy, and help-seeking behavior. In addition, the (cost-) effectiveness of conservative treatment of UI during pregnancy and in the post-partum period, and experiences of peri-partum UI of women and health care professionals (HCP) were of interest.

We evaluated the prevalence, incidence, and bothersomeness of UI in pregnancy (chapter 2) and between 6 weeks to 1 year post-partum (chapter 3) in two systematic reviews and meta-analyses. Based on 44 studies, with a total of 88.305 women, the mean prevalence of $\mathrm{UI}$ in pregnancy is $41 \%$. The mean prevalence between 6 weeks and 1 year post-partum is 31\%, based on 20 studies and 35.064 women. Stress (S) UI is the most prevalent type of UI, accounting for $63 \%$ of the cases in pregnancy and $54 \%$ of the cases post-partum. Both chapters show that the majority of studies did not combine prevalence numbers with a measure of symptom bother, as recommended by the International Consultation on Incontinence $(\mathrm{ICI}){ }^{1}$ The overall reported bother during pregnancy and between 6 weeks and 1 year post-partum was mild to moderate. The next chapter (chapter 4) shows the design of two randomized controlled trials (RCT) on the long-term effects of pelvic floor muscle group therapy (PFMGT) compared to care-as-usual (CAU) for the treatment of $U I$ in pregnancy and post-partum. The results of the RCTs (chapter $\mathbf{5}$ ) show no difference between groups during pregnancy regarding the prevalence and severity of UI, global perceived effect, and the impact of UI at any follow-up moment. Due to low inclusion numbers, groups did not reach the size indicated by the power calculation. As a consequence, results are based on individual pelvic floor muscle therapy (PFMT) instead of PFMGT. The results of PFMT commenced post-partum revealed a significant improvement of the prevalence and impact of UI at 4 months post-partum compared to CAU. However, at 9 and 18 months post-partum this effect was seen to decrease. Two surveys on the prevalence of UI, experienced bother and help-seeking behavior in pregnancy (chapter 6) and between 6 weeks and 1 year post-partum (chapter 7) revealed 
that despite high prevalence of $\mathrm{UI}$ in both groups, women experienced only mild to moderate bother of UI. Amongst pregnant and post-partum women, only $16 \%$ and $25 \%$, respectively, sought help for their UI. Women in both studies who sought help scored higher regarding bother compared to non-help-seeking women. The majority of women who did not seek help thought that their UI would resolve by itself. Moreover, a qualitative study on the experiences of peri-partum UI from a woman's and HCP perspective showed that, although women were surprised because they were unaware that UI could be a problem peri-partum, they accept their $\mathrm{UI}$ as a result of pregnancy and/or delivery (chapter 8). Moreover, none of HCPs routinely asked about the presence of UI during pregnancy. Although midwifes tend to pay attention to $U I$ at the 6 week post-natal check, the presence of $\mathrm{UI}$ is not routinely asked by the majority of the gynecologists and registrars.

\section{METHODOLOGICAL CONSIDERATIONS}

$\mathrm{UI}$ in the peri-partum period is highly prevalent. Therefore, the aim was to perform two studies evaluating the effect of PFMGT compared to CAU for the treatment of UI in pregnancy and post-partum. The PFMGT program had a strong emphasis on promoting a healthy lifestyle ('motherfit') including pelvic floor muscle (PFM) exercises as part of it. In both studies the inclusion of participants was very slow, resulting in two underpowered studies. Therefore, the presented results need to be interpreted with caution. Due to insufficient inclusion numbers, groups did not fill and results are, as a consequence based on individual PFMT instead of PFMGT and we were unable to establish the long-term effects and cost effectiveness in our two RCTs comparing PFMGT to CAU.

\section{Recruitment of participants}

One of the most common challenges of randomized controlled trials (RCTs) is related to optimize patient recruitment. ${ }^{2}$ The recruitment rate is influenced by both patient and investigator factors. Eligible patients may not want to participate (in general) as they may have a preference for a certain therapy and/or do not want to be randomized, they perceive the trial (information) as too complex or have difficulties completing the follow-up requirements. Investigator-related factors may be difficulties following the protocol or obtaining informed consent. ${ }^{2}$ 
As experiencing $\mathrm{UI}$ is a delicate subject and being in the peri-partum period is demanding, more specific reasons for recruitment problems or higher drop-out may be considered in our trials, such as: having insufficient bother in relation to UI, feeling embarrassed (in a group), strong preference for individual therapy, unfamiliarity with specialized (pelvic) physical therapy and/or group therapy (e.g. wrong idea that women need to undress), not convinced of a positive outcome, experiencing mental health issues, inconvenient time of therapy, need to arrange a babysitter, fear of losing urine during group therapy, belief that UI will resolve by itself, planning to be pregnant again soon, too many effort or impersonal contact with the investigator. Hypothetically, several reasons based on the timing of the start of PFMGT might also play a part: women being too busy finding a new balance in life, taking care of the baby and organizing going back to work as maternity leave ends standardly between 10 and 12 weeks post-partum in The Netherlands. Another factor that might be an issue is that women start with sporting activities after their post-partum check at 6 weeks and therefore might not have been aware that they have SUI, because their continence system has not been challenged yet.

The decision to participate will probably be a complex interplay between the before-mentioned factors, of which some will be modifiable and others not. ${ }^{3,4}$

We initially intended to include 150 primigravid and 90 primipara women. These figures were based on several sources, i.e. prevalence numbers of $\mathrm{UI}$ in both groups ${ }^{5}$, number of babies born in the study area each year ${ }^{6}$, number of participating HCPs, and previous studies with similar population characteristics and an acceptable drop-out rate. ${ }^{7,8}$ Woldringh et al. studied the effect of PFMT for the treatment of $\mathrm{UI}$ in pregnancy in The Netherlands. ${ }^{7}$ The women received three individual therapy sessions during pregnancy between 22 and 30 weeks of gestation, and one session at 6 weeks post-partum. During the three PFMT sessions in pregnancy, they lost $17 \%$ of the participants. Inclusion was unproblematic and the drop-out rate was within the range that was accounted for. Similarly, in the Swedish study of Ahlund et $a l^{8}{ }^{8}$ on the effect of PFMT in post-partum women with $\mathrm{UI}$, there was no account on inclusion problems and the drop-out rate during the trial was $18 \%$.

To stimulate the inclusion of participants during the course of our studies, inclusion criteria were changed. First, the criterion of primigravidity and primiparity was broadened to all women regardless of parity. In the original design only primigravid 
or primiparae were included because there are strong indications that the first pregnancy and vaginal delivery are the greatest risk factor for the development of pelvic floor dysfunctions like UI. ${ }^{9}$ Kamisan Atan et al. more recently showed that there is no significant difference in levator ani muscle (LAM) avulsions between primi- and multipara. ${ }^{10}$ This confirmation that consecutive vaginal deliveries do not add to the prevalence of LAM avulsion together with Altman et al. who reported that the number of vaginal deliveries did not affect the risk of $\mathrm{UI}$, allowed the adaptation from only primigravid/para to all pregnant and post-partum women. ${ }^{11}$ Second, the inclusion period of pregnant women was widened from up and until 20 weeks to 26 weeks of gestation as the prevalence of SUI rises substantially with gestation. ${ }^{12,13}$

We were unable to fully explain our disappointing inclusion numbers, because in the majority of cases the reasons for non-participation were unknown. On the one hand we do not know how many women were actually asked by their HCP to participate and how many declined at that point. On the other hand in the majority of cases considered eligible by the HCP and who consented in being approached by the researcher, it was impossible to get in contact with the women (after multiple attempts).

To get more insight into the high non-response (unlike high UI prevalence) and low inclusion rate, the research team discussed what the reasons could be as to why the studies did not run as expected in relation to reported UI prevalence.

Firstly, the way of organizing the inclusion could have played a role. In our study, the including HCPs checked eligibility of women and had to perform an internal assessment of the woman's ability to contract the pelvic floor muscles. In both Woldringhs and Ahlunds study, midwives filled in a screening list for all pregnant and post-partum women with UI, who were sent to the research institute. ${ }^{7,8}$ Then, the researcher checked eligibility and finished the inclusion process. The fact that the midwives routinely used a screening form for all women helped in making it a habit. In our study, the workload for the HCPs was a lot higher because they were fully responsible for the inclusion process, checking eligibility, and filling in an online form. Therefore, it seems advisable to minimize responsibility or workload for the inclusion process for HCPs or integrate the eligibility check as much as possible in their regular practice. However, because our studies were efficiency studies it was not possible to make any changes in the inclusion process of the HCPs. 
Secondly, with regard to intervention-related factors it is notable that there was larger number of drop-out $(64 \%, 7 / 12)$ of pregnant women once randomized in the PFMGT group compared to the CAU group (8\%, 1/13). The women dropped out for a variety of reasons like: inconvenient time of PFMGT $(n=1)$, too busy with work $(n=2)$, costs $(n=1)$, and without given reason(s) $(n=2)$. One woman was too late in her pregnancy to start PFMGT, once the informed consent procedure had been taken care off. In the post-partum study, some eligible women who decided not to participate provided the reasons during the telephone conversation with the researcher, which were: experiencing mental health issues, issues concerning the baby's health, and not being bothered enough by UI. This (limited) information tells us that the nature of reasons for non-participation in both studies are in line with known barriers for participating in RCTs which seem to be the same in pregnant and non-pregnant women..$^{4,8}$ Most of the expressed reasons are difficult to modify.

The mentioned reasons also tell us that organizational reasons prevail in the prepartum study (above reasons related to the added value or content of PFM(G) $\mathrm{T})$, and reasons for non-participation in the post-partum study are more patientrelated. When reasons for non-participation differ between pre- and post-partum period, emphasis on providing information on misconceptions with regard to these issues need to be tackled.

Thirdly, the reported prevalence of UI is probably lower than expected and found in the literature.5,14 Women experiencing UI are often unknown to the HCPs and/ or underreport their UI. 15,16 This could be related to a misconception on the course of UI, acceptance of UI as a fact of life or little knowledge on the possibility to seek for effective interventions.

Fourthly, the preference for individual instead of group therapy may explain nonparticipation to a small extent. It appears that only a small amount of women seem to have a strong preference for individual therapy. Demain et $a . .^{17}$ reported in a pilot study on group versus individual therapy for UI in women that $15 \%$ of women declined because they prefer individual therapy. However, in the Dutch study of Janssen et al. ${ }^{18}$ only $7 \%$ of women declined because of preference for individual therapy. Another study on group versus individual therapy for the treatment of UI asked participants before randomization if they could choose whether they preferred the group therapy, individual therapy or if they had no preference. 
This study showed that although $36 \%$ of women expressed a preference for individual therapy before randomization, this did not influence the attendance in both treatment groups, which was similar. ${ }^{19}$ Next, Griffiths et al. ${ }^{20}$ interviewed the women in their study who were randomized to group therapy, although they had a preference for individual therapy. These women mentioned the benefit of a group with women of the same age group or problem, like post-partum UI. ${ }^{20} \mathrm{Next}$ to this these women would recommend group therapy in the future. ${ }^{19,20}$

PFMT has proven benefit on improving UI during and after pregnancy. Apart from PFMGT being a potential (cost-) effective strategy, as it has been reported as equally effective compared to individual PFMT in women ${ }^{18,19,21}$, another benefit is that in group therapy, women can motivate each other to do their exercises and discuss experiences and coping strategies on how to implement PFMT in daily life. ${ }^{20,22,23}$ HCPs should therefore tailor peri-partum care. For those women who have a strong preference for individual therapy, which seems to be a minority ${ }^{19}$, individual specialized (pelvic) physical therapy is available. Based on the evidence, group therapy seems to be accepted and feasible in the majority of peri-partum women. Studies evaluating PFMGT differ in offered group size, namely 8, 4-12, and 8-10 participants respectively. ${ }^{17,18,21}$ The studies don't mention the reasons for the choice of the group size.

Fifthly, we hypothesized that even though timing of pregnancy-related interventions always interferes with creating balance in a period of a major life event, only when experienced bother in relation to UI is high, women are willing to do something about it. ${ }^{24,25}$ The fact that not only the presence of UI, but especially the experienced bother in relation to UI, could be responsible (and could be underestimated as a factor) for explaining the tendency to participate, seemed very relevant to us and worthwhile to investigate.

Based on those reasons, the main focus of this thesis changed from the (cost-) effectiveness of PFMGT to learning more about other aspects of UI in pregnancy and post-partum, such as UI prevalence, experienced bother and help-seeking behavior in relation to UI. 


\section{Prevalence and incidence}

We performed two systematic reviews and meta-analyses on the prevalence of UI during pregnancy and between 6 weeks and 1 year post-partum (chapters 2 and 3). To our knowledge no such study exists regarding pregnant women and for post-partum women it can only be compared with the study of Thom et al. ${ }^{26}$ However, Thom et al. does not report incidence and experienced bother. Because reported prevalence numbers of UI during pregnancy ${ }^{27,28}$ and between 6 weeks and 1 year post-partum ${ }^{29,30}$ vary greatly throughout published reports, the objective was to provide more accurate prevalence numbers, by calculating the weighted prevalence based on a large number of studies..$^{15,31,32}$

A more detailed assessment of the results of the systematic reviews reveals some remarkable observations. To begin with, the difference between the overall prevalence of $41 \%$ of $\mathrm{UI}$ in pregnancy and the prevalence by gestational period, which is maximal $34 \%$ in the third trimester. We hypothesize that the reported prevalence numbers might be influenced by differences in used methodology (such as used case definitions).

Next, we evaluated the wide reported range in UI between studies in relation to the calculated risk of bias. Studies with high risk of bias report higher prevalence numbers. Risk of bias was assessed with the critical appraisal checklist for systematic reviews of prevalence studies, designed by the Joanna Briggs Institute $(\mathrm{JI}) .{ }^{33} \mathrm{JBI}$ is an Australian-based international research organization, which develops evidence based practice tools and resources. We have decided not to exclude studies based on risk of bias after contacting the JBI to ask their advice regarding how to report the risk of bias. ${ }^{33}$ Although systematic reviewers can, if explained well, decide to use predetermined cut-off points, the JBI recommends presenting the results of critical appraisal for all questions via a table rather than summarizing with a score. Based on the above the authors have arbitrarily chosen cut-off points to provide an indication of the risk of bias of each study, next to presenting the critical appraisal in Table 1 of both studies. Finally, the heterogeneity in both systematic reviews was very high. Nonetheless, Borges Migliavaca et al. ${ }^{34}$ showed that an $\mathrm{I}^{2}>90 \%$ in systematic reviews, including meta-analysis of prevalence studies, is very common and inevitable. Especially when there are many studies in a meta-analysis, the chi-squared test for heterogeneity has high power to detect a small amount of heterogeneity that may be clinically unimportant. ${ }^{35}$ 
In order to gain more insight into the Dutch population with regard to prevalence, experience of bother, beliefs, and help-seeking behavior we performed two digital surveys shared by midwifery and pelvic physical (PT) practices on their Facebook pages. The results of the surveys (chapter 6 and 7) report both relatively high prevalence numbers compared to the systematic reviews and meta-analyses (chapters 2 and 3). This is in line with the study of Pandya et al. who have recently shown that prevalence of UI reported using an online platform like Facebook is on the higher end of reported prevalence numbers. ${ }^{36}$ This study also revealed that participating women reported a low level of experienced bother in relation to $\mathrm{UI}$ which is in line with our findings. ${ }^{36}$

To gain more knowledge on the number of women becoming incontinent, incidence is an important frequency measure. ${ }^{37}$ Incidence rates (when possible among subgroups) provide value information on the etiology of UI with pregnancy or delivery as a (multifactorial) exposure. ${ }^{38}$ Unfortunately, it was impossible to pool incidence numbers (that are both reliable and generalizable) in both systematic reviews due to the low number of studies reporting incidence numbers and, if reported, the wide range of case definitions used (such as any UI, UI at least once a month, type of UI (like only SUI and mixed (M) UI) and type of reporting (selfreported UI or with a cough stress test).

\section{Experienced bother}

Women with a higher level of experienced bother of UI may seek and embrace more help. ${ }^{15,31,32}$ We have shown that prevalence numbers of UI are often not accompanied by measures of symptom bother (chapter 2 and 3 ) as recommended by ICI. ${ }^{1}$. If prevalence numbers of UI are reported with the experienced bother, this can facilitate clinical reasoning, patient selection, improve research planning and aid policy makers. On that account, we have described the experienced bother (in our systematic reviews and meta-analyses) and assessment methods as reported in the prevalence studies. We showed that it is not common practice yet to report bother in prevalence studies and that bother is heterogeneously assessed (chapter 2 and 3). Amongst measurement instruments used were the International Consultation on Incontinence Questionnaire Urinary Incontinence Short Form $\left(\right.$ ICIQ-UI SF) ${ }^{39}$, Incontinence Impact Questionnaire (IIQ) ${ }^{40}$, and Incontinence Quality of Life (I-QoL). ${ }^{41}$ These questionnaires measure bother differently. As our objective 
was to report prevalence numbers with experienced bother, we encountered the issue that results of the different measurement instruments for bother could not be compared because they use different scoring options. Therefore, the total scores of the different measurement instruments for bother were converted to a (standardized) 0 to 100 scale, with 0 indicating no bother and 100 indicating extremely bothered. ${ }^{42}$ The conversion enabled us to combine studies and thus provide the more precise results of experienced bother in relation to $\mathrm{UI}$ based on more women.

Most frequently used questionnaires for measuring bother (chapters 2 and 3) consist of multiple questions, which require more effort to be put in by both participants as well as HCPs. The numeric rating scale (NRS) is a valid and reliable, unidimensional, measurement instrument, widely used in pain research. ${ }^{43,44}$ Therefore, we wanted to assess whether a single question using a NRS $(0=$ no bother; $10=$ extreme bother) can be used as an alternative 'quick but complete' question to indicate bother of UI. Thus, we calculated the correlation between two questions regarding bother (chapter 6 and 7). Question 3 of the ICIQ-UI SF, i.e. 'how much does leaking urine interfere with your everyday life' (NRS 0-10) correlated with the total ICIQ-Lower Urinary Tract (LUTS)qol score. The correlation in pregnant and post-partum women was moderate to large, $0.67(p<0.001)$ and $0.73(p<0.001)$, respectively. This is an interesting indication that separate reporting of the result of the NRS might be sufficient to report experienced bother.

The optimal cut-off point for clinically relevant burden of symptoms differs per symptom and varies mostly between a score of 4 and 6 on a scale from 0 to $10 .{ }^{45} \mathrm{As}$ the cut-off point for clinically relevant bother of $\mathrm{UI}$ is unknown, we have decided to consider a score of $\geq 5$, being in the middle of the NRS score, as the cut-off point for clinically relevant bother in our two surveys (chapter 6 and 7). To our knowledge, the NRS has not been studied with regard to validity, reliability and responsiveness in women with UI. Therefore, these clinimetric properties of the NRS for use as a measure of symptom bother of $\mathrm{UI}$ in studies needs to be assessed, in addition to establishing the cut-off point for clinically relevant bother of UI.

Differences in case definitions for presence of UI hamper interpretation of UI in prevalence studies. The same issue applies for definitions used for 'bother', being effect on daily activities/everyday life, interference on daily life, health-related 
quality of life, severity, lifestyle changes, (perceived) impact on quality of life, distress, experienced discomfort and amount of bother (chapter 2 and 3). ${ }^{46}$ The Dutch participants in the qualitative study (not included in manuscript, chapter 8) were asked what word they would use to described the experience of their UI. Women described their bother of UI in the Dutch language as: 'vervelend' (wearing), 'hinderlijk' (annoying) or 'ongemak' (inconvenience). These results are not published in chapter 8 because the question specifically concerned 'the Dutch' language. A more clearly defined concept of bother and the most appropriate word for it 1) needs to be addressed country-specific, because of differences in culture and language, 2) helps HCPs in their (standardized) communication with patients, 3) assists in clinical reasoning and multidisciplinary communication among HCPs, 4) facilitates interpretability and comparison of research results, and 5) facilitates reporting of research results.

Moreover, The International Continence Society (ICS) has multi-disciplinary working groups developing standardisation of terminology. ${ }^{47}$ It is advisable to include the concept of bother for further clarification.

\section{METHODOLOGICAL QUALITY}

Our studies have been developed following the appropriate reporting guidelines. Moreover, the research protocol of the systematic reviews and meta-analyses was registered in the PROSPERO database (registration number CRD42018111991) and the MOOSE statement for reporting systematic reviews and meta-analyses was followed. ${ }^{48}$ The design of the randomised controlled trials was published ${ }^{49}$ and the Consolidated Standards of Reporting Trials (CONSORT) statement ${ }^{50}$ was followed for reporting the trial. The intervention offered in both RCTs was protocoland evidence based ${ }^{49}$ and the ability to contract the PFM - as a pre-requisite for the intervention under study - was checked. Women who did not know how to contract the PFM received an individual session by a specialized physical therapist in order to learn how to contract and relax, before joining PFMGT. The surveys (chapters 6 and 7) consisted of high quality measurement instruments to study the prevalence and quality of life. The questions on beliefs and help-seeking behavior were self-constructed. Selection of question and answer options was based on models explaining help-seeking behavior and discussion with experts in the field (epidemiologists and obstetrician/gynecologist). ${ }^{51,52}$ Moreover, questions were 
reviewed by an expert for readability and comprehensiveness, followed by field testing. In our qualitative study, the Standards for Reporting Qualitative Research (SRQR) were followed. ${ }^{53}$

\section{PERI-PARTUM URINARY INCONTINENCE}

\section{Knowledge and beliefs regarding peri-partum urinary incontinence}

We observed that although $\mathrm{UI}$ is highly prevalent during pregnancy and up to one year post-partum, women are unaware prior to becoming pregnant that this symptom can arise and accept UI as part of being pregnant. Only few women actually seek help for their UI. This might be explained by the finding that $38 \%$ of the non-help-seeking pregnant and $54 \%$ of post-partum women believe that their UI will improve by itself (chapters 6 and 7) and that it is a normal consequence of pregnancy and delivery (chapter 8). ${ }^{54-56}$ However, pregnant women are not or insufficiently aware that having UI in pregnancy means a 2 to 6 fold the risk of post-partum UI. ${ }^{30}$ An average of $31 \%$ of post-partum women have UI up to one year with only small fluctuations throughout the first year after childbirth (chapter 6). ${ }^{57,58}$ Studies have shown that 6 and 12 years post-delivery, a large number of women with post-partum UI haven't recovered (73\% and 91\%, respectively). ${ }^{59,60}$ The difference between beliefs regarding the cause and recovery of UI might be due to gaps in knowledge. ${ }^{61-63}$

The majority of peri-partum women report that they experience mild to moderate bother by their UI (chapters 2, 3, 6 and 7). ${ }^{46,54,55}$ Women indicated that they would seek help if there was an increase in the amount and frequency of urine loss, occurrence at unexpected moments or an increase in negative feelings regarding their UI (chapters 6 and 7). As expected, women who experience higher symptom severity and/or who are more bothered by their UI are also more likely to seek help. 31,54,55,64-66 This accounts for peri-partum women as well as older women in the general population. It is known that SUI is the dominant subtype of UI until a woman is in her 50's and mixed (M)UI gradually takes over this position. ${ }^{67,68} \mathrm{MUI}$ is the complaint of involuntary leakage associated with urgency(UI) and SUI. ${ }^{47}$ Women with MUI, which occurs more unexpected than SUI, experience more bother than women with SUI alone. ${ }^{69}$ This might explain one of the reasons that younger women seek less help for their UI than older women. ${ }^{70}$ In addition, helpseeking also depends on beliefs, perceptions, and knowledge regarding UI and 
effect of treatment options. ${ }^{31,70,71}$ Therefore, it is important to provide peri-partum women with trustworthy information and thus increase the level of knowledge. Women need to be given Information on causes, effective solutions and where they can get help. This is essential in order to improve the quality of life of women bothered by UI.

\section{Peri-partum care}

Pre- and post-partum care is organized differently throughout the world. In The Netherlands, care for uncomplicated pregnancy and delivery is provided by a midwife in primary care. High risk pregnancies and deliveries are taken care of in secondary and third line of health care by a clinical midwife or gynecologist. The National Institute for Health and Care Excellence (NICE) guideline on prepartum care (CG62) recommends to, ideally at the 10-week appointment, discuss PFM exercises. ${ }^{72}$ The Dutch (multidisciplinary) standard of integral perinatal care ${ }^{73}$, covers the period from preconception until the 6-weeks post-partum check. However, the Dutch standard of integral perinatal care, in contrast to the NICE guidelines $^{72}$, does not discuss UI and PFMT pre-partum. The Dutch standard of perinatal care describes that, post-partum, the pelvic floor is one of the topics that need to be addressed. ${ }^{73}$ The guidelines of the Royal Dutch Organisation for Midwives (KNOV) more specifically recommends that UI, the pelvic floor, and PFM exercises as a treatment for post-partum UI are discussed post-partum. ${ }^{74}$ If UI does not improve or gets worse, a referral to a specialized (pelvic) physical therapist is recommended. ${ }^{74}$ However, counselling for pelvic floor dysfunctions, like UI peri-partum, is not routinely done by all HCPS. One of the main barriers is a lack of time (chapter 8)..$^{75,76}$ Women wish the HCP to start the conversation and to be provided with information on UI. ${ }^{61,62,77,78}$ Women use different strategies to get information. Some women search the internet and/or discuss their UI with friends or relatives. ${ }^{15,71}$ This informal information usually leads to normalization and with it acceptance of UI.25,31 Informing and educating women on UI, how women should perceive this involuntary and abnormal loss of urine, and the potential benefits of PFMT, will help to empower and motivate them to seek treatment rather than just accept it. ${ }^{75}$ Therefore, we recommend 1) that HCPs involved in women's healthcare discuss the occurrence of UI pre- and post-partum and the beneficial effects of PFMT, 2) to add this topic to peri-partum guidelines, like the standard of 
integral perinatal care, and 3) to add questions on $\mathrm{UI}$ and experienced bother in the electronic patient file as a reminder for the HCP.

\section{Pelvic floor muscle therapy}

Although peri-partum women are aware that PFM exercises can help to treat UI (chapters 6 and 7), this does not mean that they are actually doing them, nor that they are able to perform them effectively. ${ }^{61} \mathrm{~A}$ barrier women expressed to start with PFM exercises was that they did not know whether or not they were contracting the PFM correctly (chapter 8). Less than $25 \%$ of women know how to contract their PFM properly, even if they think they know how to contract. ${ }^{79,80}$ Instructing women verbally how to contract the PFM has been shown not to be effective ${ }^{79}$, in contrast to giving digital feedback during a vaginal examination. ${ }^{81} \mathrm{~A}$ one-time vaginal examination and instruction has been shown to be a quick and effective way to instruct a correct PFM contraction. ${ }^{81}$ However, some peri-partum women might prefer not to have a vaginal examination. Those women should be offered other strategies to learn a proper PFM contraction like for instance; with (self) palpation on the perineum or with ultrasound.

PFMT is a proven effective treatment option for $\mathrm{UI}$ in the general female population. ${ }^{82}$ In studies where peri-partum women are selected properly, wellestablished risk factors have been identified, UI has been diagnosed and/or women have been motivated to seek help for their health problem, PFMT studies have shown likewise positive effects. Unfortunately, many studies on PFMT for the treatment of UI during pregnancy and post-partum show varying results regarding the effect. PFMT protocols differ considerably between studies and are often not properly described..$^{83}$ The studies are also small and of low to very low quality. ${ }^{83}$ Our study showed a positive effect of PFMT started post-partum (chapter 5). However, this effect seems to diminish in the longer term. Because of the sample size of our study, the results can only be interpreted as an indication.

There is still uncertainty as to why PFMT during pregnancy or post-partum does not show the positive effect as in the general female population. During pregnancy the continence mechanism is challenged by factors like physiological weight gain $^{32}$ and the neuromuscular function of the urethral sphincter. ${ }^{84}$ Therefore, the $^{2}$ question remains if PFMT would be effective for a specific group of women with UI during pregnancy, for example, primigravid women with no UI prior to pregnancy. 
This was an initial inclusion criterion of our RCTs. Starting PFMT between 6 weeks and 3 months post-partum might be too early in effectiveness studies as there are indications that recovery of urethral support takes up to 6 months. ${ }^{85}$

\section{Post-partum consultation}

Currently, women get their final obstetric check at 6 weeks post-partum. At that time, the majority of women have not yet started with sports or their job, and as a consequence, have not yet challenged the PFM like they would in those circumstances. Thus, when a HCP at the post-partum check asks a woman if she experiences UI, this question might be answered negatively, because the symptom threshold has not yet been reached. With regard to pelvic floor dysfunctions like UI the post-partum check might be too soon and based on natural recovery of the urethral support, 6 months post-partum would be more appropriate. ${ }^{85}$ With all this in mind it is perhaps time to reconsider peri-partum care. Women with or at risk of pelvic floor dysfunctions like $\mathrm{UI}$ should be given the opportunity to have a consultation with a HCP, specialized in assessing the mother's health with regard to pelvic floor dysfunctions, at approximately 6 months post-partum. A specialized (pelvic) PT would be very well suited for this task as this is an expert in pelvic health and exercise. ${ }^{86}$ Therefore, they have the knowledge to empower women in self-management by providing information, instruction in how to perform a correct PFM contraction with a vaginal assessment and provide a PFMT program. Currently, the Dutch Society for Pelvic Physical Therapy is pilot testing a 'postpartum consultation'. Based on the results of a questionnaire on the domains of pelvic (floor) dysfunctions it is established if women need to be advised to visit a specialized PT for a post-partum consultation. Information with regard to UI can be provided through a leaflet, a website, a mobile app, and in-person. A mobile app has several advantages, like accessibility at time of preference and the option to build in interactive features. It can provide information, support PFM exercises and support adherence. Nearly all women in The Netherlands use mobile internet on their smartphone. ${ }^{87}$ Several studies have shown the (long-term) effect of the use of a mobile app in the treatment of $\mathrm{UI}$ and improving adherence. ${ }^{88-91}$ The combination of the assurance of a proper PFM contraction, information and advices of a specialized PT together with a mobile app, like the iPelvis mobile app used in our studies, might be an effective new path to improve PFM fit mothers in a post-partum consultation. 


\section{How to improve peri-partum care regarding UI}

There are still a lot of women that are on the one hand unaware that UI can occur in the peri-partum period and on the other hand think this is normal and will resolve by itself. Next to this, HCPs do not standardly ask for UI during pregnancy and post-partum and therefore women might not be informed on this highly prevalent issue. In order to address these issues and improve peri-partum care regarding UI a multi-faceted approach is necessary. Several suggestions to raise awareness and educate women have been made in previous paragraphs based on the research of this thesis. In addition, other strategies on how peri-partum care can be improved further will be discussed.

First, all Dutch guidelines regarding peri-partum care should add UI as a topic to be discussed by HCPs. As a result, electronic patient files should standardly have questions on $\mathrm{UI}$ and experienced bother, which will remind HCPs to discuss this symptom. Second, women should be provided with or know where to find trustworthy information or help on UI. This can be facilitated by for instance their HCP (midwife, gynecologist, general practitioner, physical therapist) or a patient organization. Women prefer to be informed during pregnancy about UI. ${ }^{92}$ Peripartum women also like to be informed through a leaflet and/or website. ${ }^{92} \mathrm{~A}$ leaflet regarding $\mathrm{UI}$ in the general public has shown that it encourages women to discuss UI, to change health behavior regarding UI, and to seek help. ${ }^{93}$ However, peri-partum women receive a lot of information on a large number of topics and a leaflet might get lost or overseen, and therefore a trustworthy website that can be accessed where and whenever a woman wants, would be of great benefit. An example would be the website of the 'continence foundation of Australia' providing a lot of information (in multiple languages) on UI like: causes, solutions, where to get help etc. In the Netherlands the website of the patient organization 'bekkenbodem4all' provides (some) information. With the proper funding this could evolve in an attractive website where HCPs can direct their patients to and where women can find information. Third way to reach women and create awareness could be for instance during the annual continence awareness week. During this special week, a joint effort of different HCPs (midwife, gynecologist, urologist, continence nurse, and specialized physical therapist), the patient organization and women could participate in a multitude of different actions to reach the public and create awareness. One can think of: discussing UI on television and radio, but also 
of editorials in magazines, newspapers etc. Fourth, if studies on the 6 month postpartum consultation by a specialized (pelvic) physical therapist show a beneficial effect, this should be offered to women with pregnancy-related UI.

Although all these suggestions will add to the improvement of peri-partum care separately, it is advisable to investigate first which strategies are necessary at different patient, HCP, and policy maker levels. Next, a planned implementation strategy for the different target groups should be developed and used as this is a key factor for success. ${ }^{94}$

\section{RECOMMENDATIONS FOR FUTURE RESEARCH}

As PFMGT is a potentially (cost-) effective intervention for women with pregnancyrelated UI, it is still an important intervention to study. However, the RCTs described in this thesis dealt with major inclusion problems resulting in two underpowered studies. Beforehand we anticipated to have no inclusion problems based on: high prevalence numbers ${ }^{5}$, inclusion rates in Scandinavian and Dutch studies on this topic ${ }^{14,18}$, and the large number of HCPs involved in including participants. Therefore, before designing a future study on this topic it is important to gain more knowledge regarding acceptability, barriers and facilitators and therefore viability of PFMGT in peri-partum women. ${ }^{20}$

Another issue that needs to be addressed is the uncertainty as to why PFMT during pregnancy or post-partum for women with UI does not show the positive effect as in the general female population. During pregnancy new onset UI might well be explained by non-modifiable factors like anatomical and hormonal changes ${ }^{95}$ as well as physiological weight gain. ${ }^{96}$ However, PFMT in early pregnancy for the prevention of antenatal and post-partum UI shows a positive effect. ${ }^{83}$ Therefore, a preventative strategy might be more appropriate and effective for pregnant women. If we could identify women at risk of becoming incontinent during pregnancy then PFMT could be offered as a preventive strategy. Post-partum, the initially positive effect of PFMT disappears which might be due to a lack of adherence. Adherence in the first year post-partum might be extra challenging because new mothers are often sleep deprived and thus fatigued. ${ }^{97,98} \mathrm{New}$ mothers and in particular those working experience a lack of time to get all things done. ${ }^{98}$

Women have expressed that a mobile app can support motivation with for instance 
reminders and the first results regarding adherence are promising. ${ }^{99-101}$ Therefore, an evidence-based mobile app, like the iPelvis mobile app we used in our studies, specifically designed for pregnant and post-partum women, can help providing information and empower women to exercise their PFM or seek help. The iPelvis app needs further validation and field testing regarding (Dutch) language, user friendliness and (cost-) effectiveness.

To accurately report the prevalence of UI based on the experienced bother we need to define the construct of 'bother' and the best way to assess bother in prevalence studies. In addition, cut-off points regarding clinical significant bother need to be established.

Peri-partum women have misconceptions regarding their $\mathrm{UI}$ and the natural course. This knowledge gap can influence beliefs and help-seeking behavior. It can be of interest to study whether the level of bother and help-seeking behavior changes in women who have been provided more information on UI. Women express the wish to be informed about pelvic floor dysfunctions like UI during and after pregnancy. This is not standardly described in all guidelines (midwifery and gynecology) in The Netherlands and not common practice yet. Therefore we recommend reviewing peri-partum guidelines on this topic.

To further optimize information provision regarding UI, a deeper understanding of the wishes and needs of peri-partum women is necessary. Therefore, we need to acquire more knowledge about 1) what information peri-partum women need at 2) which peri-partum period and 3) the best strategy to provide this.

The 6-weeks post-partum check might be too soon for a check on pelvic floor dysfunctions. Therefore, care for peri-partum women regarding pelvic floor dysfunctions like UI should be reviewed. A post-partum pelvic floor check at approximately 6 months might be more appropriate. A concept based on this idea (post-partum consultation) is currently being pilot tested in The Netherlands. The post-partum consultation needs to be refined based on the pilot, tested with appropriate numbers of participants conjoint with a cost-analysis.

In order to improve peri-partum care regarding UI, it is advisable to study which strategies are necessary at different levels: patient, HCP, and policy makers. Next, an implementation strategy should be developed and used as this is a key factor for success. ${ }^{94}$ 
But probably most important is to better understand what moves women to decide on starting therapy for UI or not. We hypothesize that the following issues might contribute to the decision to seek treatment in the peri-partum period. First, is the impact of the symptom indicating the underlying problem considered lifethreatening or not. Second, thought is given to the consequence of watchful waiting or active treatment; does waiting make things worse? Third, does the problem raise a lot of bother? Fourth, knowledge regarding PFMT and the effectiveness of treatment. The fifth and the final consideration regards the costs in time, effort and finance for accepting and undergoing treatment. It follows that the willingness and motivation to do something about peri-partum UI and as a consequence seek help is limited, because UI is considered as not life threatening (issue 1), a large proportion (chapters 6 and 7) of non-help seeking women think their UI will resolve by itself over time (issue 2), bother of $\mathrm{UI}$ (issue 3 ) is experienced as mild to moderate (chapters 2,3,6, and 7), and although women have heard about pelvic floor muscle exercises (chapters 6 and 7) we wonder whether peri-partum women are fully aware of the benefit (issue 4) of PFMT, as UI is not standardly discussed by HCPs peri-partum (chapter 8). Finally, it is a very busy period in the life of women adapting to pregnancy, looking after a baby and returning to work (issue 5). From the perspective of UI treatment, women's decision for treatment can only improve by increasing the knowledge of the natural course of UI, as most anticipate on spontaneous recovery while this is not the case; increase knowledge about PFMT and by reducing the costs, so making the therapy as easy accessible as possible. Only when these factors are sufficiently addressed, then PFM(G)T could be studied in a novel RCT. Moreover, implementation should be facilitated in general care. Not women, but their HCPs should be aware of possible misjudgments regarding UI (in both women and professionals). They should actively transfer knowledge, but also equalize the path towards preventive PFM(G)T by reducing women's costs (and increasing the gains). This care trajectory for women should be developed multidisciplinary, including midwife, gynecologist, urologist, physical therapist, and general practitioner, all with facilitating women in mind. 


\section{CONCLUDING COMMENTS}

This thesis has shown that $\mathrm{UI}$ is highly prevalent during pregnancy and up to one year post-partum. Women experience UI as mild to moderate bother. Only a minority of peri-partum women seek help for their UI. A substantial part of nonhelp seeking women think that $\mathrm{UI}$ is a consequence of pregnancy and delivery and will resolve by itself. Reasons women express for help-seeking in the future are an increase in the level of bother and if UI occurs when it is not expected. It is not common practice for HCPs to standardly ask for UI in the peri-partum period. Women should be better informed on UI (consequences) and management, which may promote help-seeking behavior. The long term (cost-) effectiveness of PFMGT for the treatment of UI during pregnancy and post-partum could not be established due to low inclusion numbers. As PFMGT is a potentially (cost-) effective intervention it is important to increase the knowledge regarding acceptability, barriers and facilitators and therefore viability of PFMGT in peri-partum women before designing a new study. It might be time for a change in peri-partum care by adding a 6 month post-partum consultation for women with UI. Therefore, the added value of a post-partum consultation needs to be studied because new mothers deserve to be 'motherfit'. 


\section{REFERENCES}

1. Abrams P, Cardozo L, Wein A, eds. Incontinence 6th Edition. ICI-ICS. International Continence Society, Bristol, UK; 2017.

2. Thoma A, Farrokhyar F, McKnight L, Bhandari M. Practical tips for surgical research: how to optimize patient recruitment. Can J Surg. 2010;53(3):205-210.

3. Oude Rengerink K, Logtenberg S, Hooft L, Bossuyt PM, Mol BW. Pregnant womens' concerns when invited to a randomized trial: a qualitative case control study. $B M C$ Pregnancy Childbirth. 2015;15:207.

4. van der Zande ISE, van der Graaf R, Hooft L, van Delden JJM. Facilitators and barriers to pregnant women's participation in research: A systematic review. Women Birth. 2018;31(5):350-361.

5. Morkved S, Bo K. Prevalence of urinary incontinence during pregnancy and postpartum. Int Urogynecol J. 1999;10(6):394-398.

6. (CBS). CBvdS. Leeftijd moeder bij eerste kind stijgt naar 29,9 jaar. 2019; https:// www.cbs.nl/nl-nl/nieuws/2019/19/leeftijd-moeder-bij-eerste-kind-stijgt-naar29-9-jaar\#: :text=Minder\%20jonge\%20vrouwen\%20voor\%20het\%20eerst\%20 moeder\&text $=$ In\%202018\%20werden\%2035\%20duizend,geboorten\%20van\%20 eerste\%20kinderen\%20gedaald.accessed. Accessed 15 January, 2021.

7. Woldringh $\mathrm{C}$, van den Wijngaart $\mathrm{M}$, Albers-Heitner $\mathrm{P}$, Lycklama à Nijeholt $\mathrm{AA}$, LagroJanssen T. Pelvic floor muscle training is not effective in women with UI in pregnancy: a randomised controlled trial. Int Urogynecol J Pelvic Floor Dysfunct. 2007;18(4):383-390.

8. Ahlund S, Nordgren B, Wilander EL, Wiklund I, Fridén C. Is home-based pelvic floor muscle training effective in treatment of urinary incontinence after birth in primiparous women? A randomized controlled trial. Acta Obstet Gynecol Scand. 2013;92(8):909-915.

9. DeLancey JO, Kearney R, Chou Q, Speights S, Binno S. The appearance of levator ani muscle abnormalities in magnetic resonance images after vaginal delivery. Obstet Gynecol. 2003;101(1):46-53.

10. Kamisan Atan I, Lin S, Dietz HP, Herbison P, Wilson PD. It is the first birth that does the damage: a cross-sectional study 20 years after delivery. Int UrogynecolJ. 2018;29(11):16371643.

11. Altman D, Ekström A, Gustafsson C, López A, Falconer C, Zetterström J. Risk of urinary incontinence after childbirth: a 10-year prospective cohort study. Obstet Gynecol. 2006;108(4):873-878.

12. Bekele $A$, Adefris $M$, Demeke $S$. Urinary incontinence among pregnant women, following antenatal care at University of Gondar Hospital, North West Ethiopia. BMC Pregnancy Childbirth. 2016;16 (1) (no pagination)(333).

13. Dinc A. Prevalence of Urinary Incontinence During Pregnancy and Associated Risk Factors. Low Urin Tract Symptoms. 2018;10(3):303-307.

14. Mørkved S, Bø K, Schei B, Salvesen KA. Pelvic floor muscle training during pregnancy to prevent urinary incontinence: a single-blind randomized controlled trial. Obstet Gynecol. 2003;101(2):313-319.

15. Mason L, Glenn S, Walton I, Hughes C. Women's reluctance to seek help for stress incontinence during pregnancy and following childbirth. Midwifery. 2001;17(3):212-221. 
16. Hannestad YS, Rortveit G, Hunskaar S. Help-seeking and associated factors in female urinary incontinence. The Norwegian EPINCONT Study. Epidemiology of Incontinence in the County of Nord-Trøndelag. Scand J Prim Health Care. 2002;20(2):102-107.

17. Demain S, Fereday-Smith J, Hiller L, Dziedzic K. Comparison of Group and Individual Physiotherapy for Female Urinary Incontinence in Primary Care. Physiotherapy. 2001;87(5).

18. Janssen CC, Lagro-Janssen AL, Felling AJ. The effects of physiotherapy for female urinary incontinence: individual compared with group treatment. BJU Int. 2001;87(3):201-206.

19. Lamb SE, Pepper J, Lall R, et al. Group treatments for sensitive health care problems: a randomised controlled trial of group versus individual physiotherapy sessions for female urinary incontinence. BMC Womens Health. 2009;9:26.

20. Griffiths F, Pepper J, Jørstad-Stein EC, Smith JF, Hill L, Lamb SS. Group versus individual sessions delivered by a physiotherapist for female urinary incontinence: an interview study with women attending group sessions nested within a randomised controlled trial. BMC Womens Health. 2009;9:25.

21. Dumoulin C, Morin M, Danieli C, et al. Group-Based vs Individual Pelvic Floor Muscle Training to Treat Urinary Incontinence in Older Women: A Randomized Clinical Trial. JAMA Intern Med. 2020;180(10):1284-1293.

22. Paiva LL, Ferla L, Darski C, Catarino BM, Ramos JG. Pelvic floor muscle training in groups versus individual or home treatment of women with urinary incontinence: systematic review and meta-analysis. Int Urogynecol J. 2017;28(3):351-359.

23. Poget F, Blackburn T, Descloux F, Fiddler H. Participating in an exercise group after anterior cruciate ligament reconstruction (ACLR) is perceived to influence psychosocial factors and successful recovery: a focus group qualitative study. Physiotherapy. 2019;105(4):492-500.

24. Hägglund D, Walker-Engström ML, Larsson G, Leppert J. Quality of life and seeking help in women with urinary incontinence. Acta Obstet Gynecol Scand. 2001;80(11):1051-1055.

25. Monz B, Chartier-Kastler E, Hampel C, et al. Patient characteristics associated with quality of life in European women seeking treatment for urinary incontinence: results from PURE. Eur Urol. 2007;51(4):1073-1081; discussion 1081-1072.

26. Thom DH, Rortveit G. Prevalence of Postpartum Urinary Incontinence: A Systematic Review. J Wound Ostomy Continence Nurs. 2011;38:S25-26.

27. Oliveira C, Seleme M, Cansi PF, et al. Urinary incontinence in pregnant women and its relation with socio-demographic variables and quality of life. Rev Assoc Med Bras (1992). 2013;59(5):460-466.

28. Dolan LM, Walsh D, Hamilton S, Marshall K, Thompson K, Ashe RG. A study of quality of life in primigravidae with urinary incontinence. Int Urogynecol J Pelvic Floor Dysfunct. 2004;15(3):160-164.

29. Durnea CM, Khashan AS, Kenny LC, Tabirca SS, O'Reilly BA. The role of prepregnancy pelvic floor dysfunction in postnatal pelvic morbidity in primiparous women. Int Urogynecol J. 2014;25(10):1363-1374.

30. Burgio KL, Zyczynski H, LocherJL, Richter HE, Redden DT, Wright KC. Urinary incontinence in the 12-month postpartum period. Obstet Gynecol. 2003;102(6):1291-1298. 
31. Kinchen KS, Burgio K, Diokno AC, Fultz NH, Bump R, Obenchain R. Factors associated with women's decisions to seek treatment for urinary incontinence. J Women's Health (2002). 2003;12(7):687-698.

32. Schreiber Pedersen L, Lose G, Høybye MT, Elsner S, Waldmann A, Rudnicki M. Prevalence of urinary incontinence among women and analysis of potential risk factors in Germany and Denmark. Acta Obstet Gynecol Scand. 2017;96(8):939-948.

33. Munn Z, Moola S, Lisy K, Riitano D, Tufanaru C. Methodological guidance for systematic reviews of observational epidemiological studies reporting prevalence and cumulative incidence data. Int J Evid Based Healthc. 2015;13(3):147-153.

34. Borges Migliavaca C, Stein C, Colpani V, et al. How are systematic reviews of prevalence conducted? A methodological study. BMC Med Res Meth. 2020;20(1):96.

35. Higgins J, Thomas J, Chandler J, et al. Types of synthesis. In: Cochrane Handbook for Systemtic Revies of Interventions.. 6.2 (updated February 2021) ed.2021.

36. Pandya LK, Hundley AF, Hudson CO, Nekkanti S, Escobar Smith P, Lynch CD. Engaging Women in Pelvic Floor Disorders Research Using the Internet. Female Pelvic Med Reconstr Surg. 2021;27(1):e22-e27.

37. Noordzij M, Dekker FW, Zoccali C, Jager KJ. Measures of disease frequency: prevalence and incidence. Nephron Clin Pract. 2010;115(1):c17-20.

38. Ward MM. Estimating disease prevalence and incidence using administrative data: some assembly required. J Rheumatol. 2013;40(8):1241-1243.

39. Avery K, Donovan J, Peters TJ, Shaw C, Gotoh M, Abrams P. ICIQ: a brief and robust measure for evaluating the symptoms and impact of urinary incontinence. Neurourol Urodyn. 2004;23(4):322-330.

40. Uebersax JS, Wyman JF, Shumaker SA, McClish DK, Fantl JA. Short forms to assess life quality and symptom distress for urinary incontinence in women: the Incontinence Impact Questionnaire and the Urogenital Distress Inventory. Continence Program for Women Research Group. Neurourol Urodyn. 1995;14(2):131-139.

41. Wagner TH, Patrick DL, Bavendam TG, Martin ML, Buesching DP. Quality of life of persons with urinary incontinence: development of a new measure. Urology. 1996;47(1):67-71; discussion 71-62.

42. Utomo E, Korfage IJ, Wildhagen MF, Steensma AB, Bangma CH, Blok BF. Validation of the Urogenital Distress Inventory (UDI-6) and Incontinence Impact Questionnaire (IIQ-7) in a Dutch population. Neurourol Urodyn. 2015;34(1):24-31.

43. Hjermstad MJ, Fayers PM, Haugen DF, et al. Studies comparing Numerical Rating Scales, Verbal Rating Scales, and Visual Analogue Scales for assessment of pain intensity in adults: a systematic literature review. J Pain Symptom Manage. 2011;41(6):1073-1093.

44. Williamson A, Hoggart B. Pain: a review of three commonly used pain rating scales.J Clin Nurs. 2005;14(7):798-804.

45. Oldenmenger $\mathrm{WH}$, de Raaf PJ, de Klerk C, van der Rijt CC. Cut points on 0-10 numeric rating scales for symptoms included in the Edmonton Symptom Assessment Scale in cancer patients: a systematic review. J Pain Symptom Manage. 2013;45(6):1083-1093.

46. Moossdorff-Steinhauser HFA, Berghmans BCM, Spaanderman MEA, Bols EMJ. Prevalence, incidence and bothersomeness of urinary incontinence in pregnancy: a systematic review and meta-analysis. Int Urogynecol J. 2021. 
47. (ICS) ICS. ICS Glossary of Terminology https://www.ics. or g / g I os s a ry ? g c I i d = C j 0 KC Q i A - a G C B h C w A R I s A H DI 5 x_ Mp81EyuUcYQ4Ter8ZweGevTXZHwgiS_91k7WYbAbvCfhlcxYUSIMaAo7cEALw_wcB\#S. Accessed 10 March, 2021.

48. Stroup DF, Berlin JA, Morton SC, et al. Meta-analysis of observational studies in epidemiology: a proposal for reporting. Meta-analysis Of Observational Studies in Epidemiology (MOOSE) group. JAMA. 2000;283(15):2008-2012.

49. Moossdorff-Steinhauser HFA, Bols EMJ, Spaanderman MEA, et al. Long-term effects of motherfit group therapy in pre-(MOTHERFIT1) and post-partum women (MOTHERFIT2) with stress urinary incontinence compared to care-as-usual: study protocol of two multi-centred, randomised controlled trials. Trials. 2019;20(1):237.

50. Boutron I, Altman DG, Moher D, Schulz KF, Ravaud P. CONSORT Statement for Randomized Trials of Nonpharmacologic Treatments: A 2017 Update and a CONSORT Extension for Nonpharmacologic Trial Abstracts. Ann Intern Med. 2017;167(1):40-47.

51. Kraaimaat F. Symptoomperceptie en klachtenbeleving. In: Lechner L, Mesters I, Bolman C, eds. Gezondheidspsychologie bij patienten Assen, The Netherlands Koninklijke van Gorcum BV; 2010:151-169.

52. Nijkamp M. Naar hulpvraag en diagnose. In: Lechner L, Mesters I, Bolman C, eds. Gezondheidspsychologie bij patienten. Assen, The Netherlands: Koninklijke Van Gorcum BV; 2010:169-190.

53. O'Brien BC, Harris IB, Beckman TJ, Reed DA, Cook DA. Standards for reporting qualitative research: a synthesis of recommendations. Acad Med. 2014;89(9):1245-1251.

54. Moossdorff-Steinhauser HFA, Berghmans BCM, Spaanderman MEA, Bols EMJ. Urinary incontinence during pregnancy: prevalence, experience of bother, beliefs, and helpseeking behavior. Int Urogynecol J. 2020.

55. Moossdorff-Steinhauser HFA, Berghmans BCM, Spaanderman MEA, Bols EMJ. Urinary incontinence 6 weeks to 1 year post-partum: prevalence, experience of bother, beliefs, and help-seeking behavior. Int Urogynecol J. 2021.

56. Hill AM, McPhail SM, Wilson JM, Berlach RG. Pregnant women's awareness, knowledge and beliefs about pelvic floor muscles: a cross-sectional survey. Int Urogynecol J. 2017;28(10):1557-1565.

57. Gartland D, MacArthur C, Woolhouse H, McDonald E, Brown SJ. Frequency, severity and risk factors for urinary and faecal incontinence at 4 years postpartum: a prospective cohort. BJOG. 2016;123(7):1203-1211.

58. Brown S, Gartland D, Perlen S, McDonald E, MacArthur C. Consultation about urinary and faecal incontinence in the year after childbirth: A cohort study. BJOG. 2015;122(7):954962.

59. MacArthur C, Wilson D, Herbison $P$, et al. Urinary incontinence persisting after childbirth: extent, delivery history, and effects in a 12-year longitudinal cohort study. BJOG. 2016;123(6):1022-1029.

60. Diez-Itza I, Zubikarai M, Galan C, Ginto L, Saro J, Arrue M. Factors involved in the persistence of stress urinary incontinence from postpartum to 12 years after first delivery. Neurourol Urodyn. 2020. 
61. Daly D, Cusack C, Begley C. Learning about pelvic floor muscle exercises before and during pregnancy: a cross-sectional study. Int Urogynecol J. 2019;30(6):965-975.

62. Neels H, Tjalma WA, Wyndaele JJ, De Wachter S, Wyndaele M, Vermandel A. Knowledge of the pelvic floor in menopausal women and in peripartum women. J Phys Ther Sci. 2016;28(11):3020-3029.

63. Charrié M, Billecocq S. [Knowledge of pelvic floor disorders in peripartum women: A systematic review]. Progres Urologie. 2020.

64. Margalith I, Gillon G, Gordon D. Urinary incontinence in women under 65: quality of life, stress related to incontinence and patterns of seeking health care. Qual Life Res. 2004;13(8):1381-1390.

65. Schreiber Pedersen L, Lose G, Høybye MT, Jürgensen M, Waldmann A, Rudnicki $M$. Predictors and reasons for help-seeking behavior among women with urinary incontinence. Int Urogynecol J. 2018;29(4):521-530.

66. Biyik I, Kucuk B, Arpaci HF, Demirci H. Factors affecting doctor visits of postmenopausal women with urinary incontinence. Low Urin Tract Symptoms. 2019;11(4):200-205.

67. Fitzgerald J, Pierce C, Nugent J, Blomquist J, Handa VL. Care-Seeking for Stress Incontinence and Overactive Bladder Among Parous Women in the First Two Decades After Delivery. Fem Pelvic Med Reconstruct Surg. 2016;22(4):199-204.

68. Hunskaar S, Burgio K, Diokno A, Herzog AR, Hjälmås K, Lapitan MC. Epidemiology and natural history of urinary incontinence in women. Urology. 2003;62(4 Suppl 1):16-23.

69. Coyne KS, Zhou Z, Thompson C, Versi E. The impact on health-related quality of life of stress, urge and mixed urinary incontinence. BJU Int. 2003;92(7):731-735.

70. Koch LH. Help-seeking behaviors of women with urinary incontinence: an integrative literature review. J Midwifery Women's Health. 2006;51(6):e39-44.

71. Melville JL, Wagner LE, Fan MY, Katon WJ, Newton KM. Women's perceptions about the etiology of urinary incontinence. J Women's Health (2002). 2008;17(7):1093-1098.

72. National Institute for health and care excellence (NICE). Antenatal care for uncomplicated pregnancies (CG62). 2008; https://www.nice.org.uk/guidance/cg62/resources/ antenatal-care-for-uncomplicated-pregnancies-pdf-975564597445. Accessed 8 February, 2021.

73. (CPZ). CPZ. Zorgstandaard intergrale geboortezorg. 2020; 1.2:https://www. kennisnetgeboortezorg.nl/wp-content/uploads/2020/11/zorgstandaard-integralegeboortezorg-1.2.pdf. Accessed 2 March, 2021.

74. Koninklijke Nederlandse Organisatie van Verloskundigen (KNOV). Multidisciplinaire richtlijn postnatale zorg 2018; https://www.knov.nl/serve/file/knov.nl/knov_ downloads/2882/file/Postnatale_zorg_opgemaakte_versie_door_IB_md_10_aug_2018. pdf. Accessed 8 February 2021.

75. Dessie SG, Hacker MR, Dodge LE, Elkadry EA. Do Obstetrical Providers, Counsel Women About Postpartum Pelvic Floor Dysfunction?J Reprod Med. 2015;60(5-6):205-210.

76. Cooke CM, O'Sullivan OE, O'Reilly BA. Urogynaecology providers' attitudes towards postnatal pelvic floor dysfunction. Int Urogynecol J. 2018;29(5):751-766.

77. Wagg AR, Kendall S, Bunn F. Women's experiences, beliefs and knowledge of urinary symptoms in the postpartum period and the perceptions of health professionals: a grounded theory study. Prim Health Care Res Dev. 2017;18(5):448-462. 
78. Buurman MB, Lagro-Janssen AL. Women's perception of postpartum pelvic floor dysfunction and their help-seeking behaviour: a qualitative interview study. Scand J Caring Sci. 2013;27(2):406-413.

79. Moen MD, Noone MB, Vassallo BJ, Elser DM. Pelvic floor muscle function in women presenting with pelvic floor disorders. Int UrogynecolJ Pelvic Floor Dysfunct. 2009;20(7):843846.

80. Kandadai $P$, O'Dell K, Saini J. Correct performance of pelvic muscle exercises in women reporting prior knowledge. Female Pelvic Med Reconstruct Surg. 2015;21(3):135-140.

81. Nguyen MT, Armstrong AA, Wieslander CK, Tarnay CM. Now Anyone Can Kegel: OneTime Office Teaching of Pelvic Floor Muscle Exercises. Female Pelvic Med Reconstruct Surg. 2019;25(2):149-153.

82. Dumoulin C, Cacciari LP, Hay-Smith EJC. Pelvic floor muscle training versus no treatment, or inactive control treatments, for urinary incontinence in women. Cochrane Database Syst Rev. 2018;10(10):Cd005654.

83. Woodley SJ, Lawrenson P, Boyle R, et al. Pelvic floor muscle training for preventing and treating urinary and faecal incontinence in antenatal and postnatal women. Cochrane Database Syst Rev. 2020;5(5):Cd007471.

84. Weidner AC, South MM, Sanders DB, Stinnett SS. Change in urethral sphincter neuromuscular function during pregnancy persists after delivery. Am J Obstet Gynecol. 2009;201(5):529.e521-526.

85. Wijma J, Weis Potters AE, van der Mark TW, Tinga DJ, Aarnoudse JG. Displacement and recovery of the vesical neck position during pregnancy and after childbirth. Neurourol Urodyn. 2007;26(3):372-376.

86. Westerik-Verschuuren L, Moossdorff-Steinhauser HFA. Beroepsprofiel Bekkenfysiotherapeut. 2014; https://nvfb.kngf2.nl/Vakgebied/kwaliteit/beroepsprofiel. html. Accessed 14 March, 2021.

87. Statistiek. CBvd. ICT- gebruik van huishoudens en personen. 2019; https:// longreads.cbs.nl/ict-kennis-en-economie-2019/ict-gebruik-van-huishoudensen-personen/\#: : text $=\ln \% 202018 \% 20$ gebruikte $\% 2094 \% 20$ procent, tot $\% 20$ 45\%E2\%80\%91jarigen\%20mobiel\%20internet.\&text=2\%20Van\%20de\%2045\%2D\%20 tot,smartphones\%20het\%20meest\%20in\%20trek. Accessed 3 March, 2021.

88. Rygh P, Asklund I, Samuelsson E. Real-world effectiveness of app-based treatment for urinary incontinence: a cohort study. BMJ open. 2021;11(1):e040819.

89. Latorre GFS, de Fraga R, Seleme MR, Mueller CV, Berghmans B. An ideal e-health system for pelvic floor muscle training adherence: Systematic review. Neurourol Urodyn. 2019;38(1):63-80.

90. Asklund I, Nyström E, Sjöström M, Umefjord G, Stenlund H, Samuelsson E. Mobile app for treatment of stress urinary incontinence: A randomized controlled trial. Neurourol Urodyn. 2017;36(5):1369-1376.

91. Hoffman V, Söderström L, Samuelsson E. Self-management of stress urinary incontinence via a mobile app: two-year follow-up of a randomized controlled trial. Acta Obstet Gynecol Scand. 2017;96(10):1180-1187.

92. Moossdorff-Steinhauser HF, Albers-Heitner P, Weemhoff M, Spaanderman ME, Nieman $\mathrm{FH}$, Berghmans B. Factors influencing postpartum women's willingness to participate in a preventive pelvic floor muscle training program: a web-based survey. Eur J Obstet 
Gynecol Reprod Biol. 2015;195:182-187.

93. O'Connell B, Wellman D, Baker L, Day K. Does a continence educational brochure promote health-seeking behavior? J Wound Ostomy Continence Nurs. 2006;33(4):389-395.

94. Wensing $\mathrm{M}$, Grol R. Knowledge translation in health: how implementation science could contribute more. BMC medicine. 2019;17(1):88.

95. Hvidman L, Hvidman L, Foldspang A, Mommsen S, Bugge Nielsen J. Correlates of urinary incontinence in pregnancy. Int Urogynecol J Pelvic Floor Dysfunct. 2002;13(5):278-283.

96. Wesnes SL, Hunskaar S, Bo K, Rortveit G. Urinary incontinence and weight change during pregnancy and postpartum: A cohort study. Am J Epidemiol. 2010;172(9):10341044.

97. Henderson J, Alderdice F, Redshaw M. Factors associated with maternal postpartum fatigue: an observationalstudy. BMJ open. 2019;9(7):e025927.

98. Albanese AM, Geller PA, Steinkamp JM, Barkin JL. In Their Own Words: A Qualitative Investigation of the Factors Influencing Maternal Postpartum Functioning in the United States. Int J Environment Res Public Health. 2020;17(17).

99. Asklund I, Samuelsson E, Hamberg K, Umefjord G, Sjöström M. User Experience of an App-Based Treatment for Stress Urinary Incontinence: Qualitative Interview Study. J Med Internet Res. 2019;21(3):e11296.

100. Kinouchi K, Ohashi K. Smartphone-based reminder system to promote pelvic floor muscle training for the management of postnatal urinary incontinence: historical control study with propensity score-matched analysis. PeerJ. 2018;6:e4372.

101. Bernard S, Boucher S, McLean L, Moffet H. Mobile technologies for the conservative self-management of urinary incontinence: a systematic scoping review. Int Urogynecol J. 2020;31(6):1163-1174. 


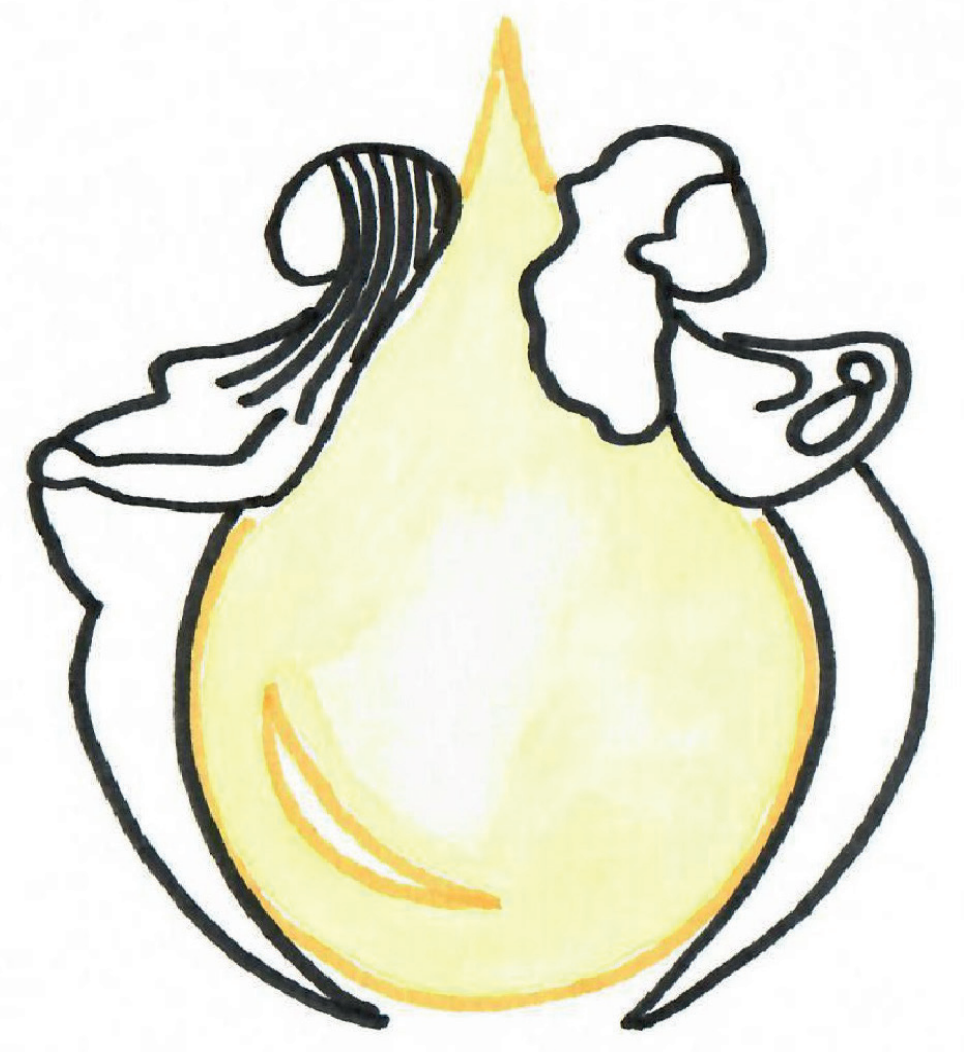


CHAPTER 10

\section{SCIENTIFIC AND SOCIETAL IMPACT}


Pregnancy and delivery are the most prominent risk factors for the development of urinary incontinence (UI) in women. The results of this thesis will shed light on various aspects regarding pregnancy-related UI like prevalence, experienced bother, anticipated course, therapeutic effect of physical therapy, and helpseeking behavior as well as the experiences of peri-partum UI of women and health care professionals (HCP). The findings presented in this thesis will add to the body of knowledge of HCPs and researchers as well as policy makers. It can help researchers in for instance research planning, HCPS in their UI management and communication with peri-partum women, and provide policy makers with more details on the prevalence and incidence of peri-partum UI and their experienced bother. This chapter will highlight how the results have been and will be further disseminated, and elaborate on what the findings mean for a broad audience.

\section{DISSEMINATION OF RESULTS DURING PHD TRAJECTORY AND PLANS FOR THE FUTURE}

During the PhD trajectory the results of our studies were firstly shared in peerreviewed scientific journals as described at the beginning of each chapter. Secondly, results were shared at multiple international conferences of the International Continence Society (ICS). The ICS members attending the meetings consist of urologists, urogynecologists, physical therapists (PT), nurses and researchers with a focus on continence and pelvic floor disorders. At ICS 2019 and 2020 the results of chapter 2 and 7 were presented. In The Netherlands the results of chapter 2 were presented at the 2019 conference of the Royal Dutch Society for Physical Therapy (KNGF).

At ICS 2021, the results of this dissertation in general, the problems we encountered with the inclusion of participants in the randomized controlled trials (RCT), and the actions taken to improve this, will be presented. In addition, I will also write a blog post and make a YouTube video on this dissertation for my social media channels. They will be posted on https://www.pelvicnewschannel.com and on YouTube (https://www.youtube.com/channel/UCZIOBILVAuESzlu0OdXjJlw). The blog will also be translated into Spanish, Portuguese and Japanese. The objective of the blog and YouTube channel is to share scientific research with colleagues with an interest in the pelvic region, especially pelvic physical therapists. By providing easily accessible short versions of studies with the implications for clinical practice 
in multiple languages, colleagues who otherwise might not be aware of these studies or for whom the English language is a barrier, also have access.

\section{SCIENTIFIC AND SOCIETAL IMPACT OF THE GENERATED KNOWLEDGE}

The initial primary aim of this dissertation was to study the long-term (cost-) effect of pelvic floor muscle group therapy (PFMGT) compared to care as usual (CAU) during pregnancy and post-partum in two RCTs. However, the inclusion rate in both studies was very low, even after several facilitating changes were made to the inclusion process. The low inclusion rate in comparison to the high prevalence of UI was thoroughly discussed by all who (the research team and the HCPs) were involved in the studies. The fact that not only the presence of UI, but especially the experienced bother in relation to UI, could be responsible for explaining the tendency to participate, seemed very relevant to us and worthwhile to investigate. Therefore, the main focus of the thesis changed from the (cost-) effect of PFMGT, to learning more about other aspects of UI in pregnancy and post-partum, such as UI prevalence, experienced bother and help-seeking behavior in relation to UI. Sharing our inclusion strategies and encountered problems and subsequent actions taken with researchers will help planning future research in this field.

\section{Prevalence and bother}

As reported prevalence numbers of pregnancy related UI vary greatly between studies, one of our aims was to provide more accurate prevalence numbers. The International Consultation on Incontinence $(\mathrm{ICI})$ recommends reporting prevalence numbers of UI with the experienced bother. ${ }^{1}$ Therefore we also studied the experienced bother of UI. This is important information for research planning and policy makers because women with a higher level of experienced bother of UI seek more help. ${ }^{2-4}$ Our systematic reviews on the prevalence, incidence and experienced bother of UI during pregnancy and between 6 weeks and 1 year post-partum are to our knowledge the first ones in this field. No such study exists regarding pregnant women and for post-partum women it can only be compared with the study of Thom et al. ${ }^{5}$ However, Thom et al. only reports for women up to 3 months post-partum and does not report incidence and bother. 
We showed that although the overall prevalence of UI during pregnancy and post-partum is high, $41 \%$ and $31 \%$ respectively, the experienced bother is low to moderate. It was also obvious that it is not common practice yet to report bother in prevalence studies and that bother is heterogeneously assessed (chapter 2 and 3).

Our results showed that the numeric rating scale (NRS, $0=$ no bother- $10=$ extreme bother) might be an appropriate measurement instrument to quantify experienced bother of UI. The NRS is a valid and reliable, unidimensional, measurement instrument, widely used in pain research. However, to our knowledge the NRS for bother of UI has not been studied with regard to validity, reliability and responsiveness in women. A cut-off point for clinically relevant bother of UI also needs to be established. The NRS is quick to administer, easy to interpret, and very well suited to add to an electronic patient file. Therefore, the NRS has the potential to help HCPs in communicating with patients and in clinical decision making.

We observed a great variety of words used to describe 'bother' of UI in our studies (chapter 2 and 3). A more clearly defined concept of bother could help in the assessment, standardisation of communication and reporting of study results. The International Continence Society (ICS) has multi-disciplinary working groups developing standardisation of terminology. ${ }^{6}$ We advise to include the concept of bother for further clarification. When we asked Dutch women with pregnancyrelated UI what word they would use for their experience of UI, several words were suggested and none of them was the word the research team thought beforehand was the most appropriate. This shows the importance of studying the 'best' word to discuss bother, country-specific because of differences in language and culture. Knowing the word that resonates the best with women regarding bother of UI can help HCPs in their communication with patients and with other HCPs (multidisciplinary). In addition, it can facilitate the interpretability and comparison of research results. Moreover, it is useful when information is developed regarding $\mathrm{UI}$ in women

\section{Help-seeking behavior}

Women in our studies indicated that they would seek help if there was an increase in the amount and frequency of urine loss, occurrence at unexpected moments or an increase in negative feelings regarding their UI (chapter 6 and 7). Only a small number of peri-partum women actually sought help for their UI. Reasons for not 
seeking help were often based on the belief that UI would resolve by itself and that it is a normal consequence of pregnancy and delivery. This misconception is important knowledge for HCPs, as they can provide peri-partum women with trustworthy information. Information on causes, solutions and where they can get help when they need it. To further optimize information provision regarding Ul, a deeper understanding of the wishes and needs of peri-partum women is necessary. Therefore, we need to acquire more knowledge about 1) what information peri-partum women need at 2) which peri-partum period and 3) the best strategy to provide this.

Good information sites are available. Examples are 'the pelvic floor' by HCPs of the University of Antwerp, Belgium at https://www.thepelvicfloor.be/ (in Dutch), and 'pelvic floor first' from the Continence Foundation of Australia at (http://www. pelvicfloorfirst.org.au/ (English).

\section{Pelvic floor muscle therapy}

Based on the promising effects of pelvic floor muscle therapy (PFMT), described in the first version of the Cochrane systematic review on 'pelvic floor muscle training for prevention and treatment of $\mathrm{UI}$ and fecal incontinence in antenatal and postnatal women', we planned our two RCTs. ${ }^{7}$ They were designed following the recommendations of the CONSORT statement to ensure high quality. The latest update of this Cochrane review reports that there is still uncertainty regarding the treatment effect of PFMT provided in the pre- or post-partum period. ${ }^{8}$ However, we have to keep in mind that these results are based on a small number of studies of (very) low quality. Current peri-partum multi-disciplinary guidelines recommend PFMT for post-partum UI. ${ }^{9-11}$

Unfortunately, our studies on the long-term effect of PFMT compared to careas-usual were underpowered and results therefore need to be interpreted with caution. Our study showed a positive effect of PFMT started post-partum (chapter 5). However, this effect seems to diminish longer term. There is still uncertainty as to why PFMT during pregnancy or post-partum does not show the positive effect as in the general female population. The question remains if PFMT would be effective for a specific group of women with UI during pregnancy, for example, primigravid women with no UI prior to pregnancy. Starting PFMT between 6 weeks and 3 months post-partum might be too early in effectiveness studies. Based on 
the current evidence we recommend offering women with UI after delivery PFMT as a treatment option. Therefore, we suggest changes in the current peri-partum care as will be discussed next.

\section{Peri-partum care}

Dutch guidelines regarding pre-partum care incorporate no discussion of or recommendations for pelvic floor dysfunctions like UI and for the post-partum period recommendations vary. ${ }^{10,12}$ There may be a difference between the need of peri-partum women and the HCP regarding this topic. Therefore, more attention and uniformity regarding this topic in peri-partum guidelines is warranted.

We suggest it is time for a change in post-partum care. Currently, women get their final obstetric check at 6 weeks post-partum. But at that time, women have not yet (fully) started with sports and/or their job and as a consequence the symptom threshold, for pelvic floor dysfunctions like UI, might not have been reached yet. A check at 6 months after delivery for women at risk for pelvic floor dysfunctions might be more appropriate. A specialized (pelvic) PT would be very well suited for this task as this is an expert in pelvic health and exercise. ${ }^{13}$ They have the knowledge to empower women in self-management by providing information, instruct a proper pelvic floor muscle contraction with a vaginal assessment and give a pelvic floor muscle training program. In The Netherlands, the Dutch Society for Pelvic Physical therapy has developed and pilot tested a concept called the 'post-partum consultation'. Based on the pilot study the concept needs further refinement and needs to be studied with appropriate numbers of participants conjoint with a cost-analysis. A post-partum consultation has the potential to be a valuable extension of current peri-partum care, for women with or at risk of UI, and empower women to seek help and become 'motherfit'.

\section{Education}

The pelvic floor muscles and pelvic floor dysfunctions are hardly discussed in the curricula of physical therapists in The Netherlands, although pelvic floor dysfunctions are very prevalent. Basic knowledge of the pelvic floor, dysfunctions and the relation with the moving body should therefore be part of the curriculum. This also raises interest and awareness for the specialization of pelvic physical 
therapist. In the curricula for HCPs involved in peri-partum care like the gynecologist, midwife or specialized pelvic physical therapist it is important to emphasize the importance of asking a woman specifically about UI together with the experienced bother. In addition, HCPs should learn how to assess experienced bother and know where women can find trustworthy information and get good quality care to remain or become 'motherfit'.

HCPs in training can contribute to the body of knowledge regarding research questions on peri-partum UI. If existing research questions are specifically adapted for students, taking into account the amount of time students have for a (graduation) project (sub-questions), this could be a win-win situation on all accounts. For this purpose, good contacts between (or within departments of) research institutions, educational institutions, HCP courses, but also with professional associations is a prerequisite. At the moment, contacts exist between various stakeholders with regard to research questions for specialized pelvic physical therapy in training, though informally. Collaboration could be more effective if this would be formalized.

\section{CONCLUSION}

The initial primary aim of this dissertation to study the long-term (cost-) effect of pelvic floor muscle group therapy (PFMGT) compared to care as usual (CAU) during pregnancy and post-partum did not succeed due to very low inclusion rates. However by sharing our inclusion strategies and encountered problems and subsequent actions taken with researchers will help planning future research in this field. To reveal possible reasons of the disappointing inclusion numbers other aspects of UI in pregnancy and post-partum such as UI prevalence, experienced bother and help-seeking behavior in relation to UI were studied. We showed that although the overall prevalence of UI during pregnancy and post-partum is high, the experienced bother is low to moderate and few women seek help. It was also evident that prevalence studies do not report the accompanying bother standardly and that bother is heterogeneously assessed. UI is not a standard question for the majority of HCPs in peri-partum care. More attention and uniformity regarding UI in peri-partum guidelines is warranted.

As a consequence of the hurdles we had to take, the key factors in medical decision 
making for patients with UI had to be reviewed. That lead to profound insight in the most important variables that are almost unnoticedly weighed by those offered care or execute RCTs. From our experiences and observations we learned that we should better understand and systematically weigh what factors women drive to decide on starting therapy. We hypothesized on five issues that might contribute to deciding to seek help: 1) the impact of the symptom indicating the underlying problem is considered life-threatening or not, 2) the consequence of expectant management as compared to active treatment, 3) experienced bother, 4) knowledge regarding PFM(G)T, and 5) the costs in time, effort and finance for accepting and undergoing treatment. Holding a clear view on all these factors might be incredibly helpful on designing future studies and care trajectories and weighing the necessity to implement them upfront.

The results have been and will be shared in various ways to reach as many researchers, HCPs and the general public. Our results can help researchers with research planning, HCPs regarding communication with patients, and policy makers can use our results in calculating future health care cost. 


\section{REFERENCES}

1. Abrams P, Cardozo L, Wein A, eds. Incontinence 6th Edition. ICI-ICS. International Continence Society, Bristol, UK; 2017.

2. Mason L, Glenn S, Walton I, Hughes C. Women's reluctance to seek help for stress incontinence during pregnancy and following childbirth. Midwifery. 2001;17(3):212-221.

3. Kinchen KS, Burgio K, Diokno AC, Fultz NH, Bump R, Obenchain R. Factors associated with women's decisions to seek treatment for urinary incontinence. J Womens Health (2002). 2003;12(7):687-698.

4. Schreiber Pedersen L, Lose G, Høybye MT, Elsner S, Waldmann A, Rudnicki M. Prevalence of urinary incontinence among women and analysis of potential risk factors in Germany and Denmark. Acta Obstet Gynecol Scand. 2017;96(8):939-948.

5. Thom DH, Rortveit G. Prevalence of Postpartum Urinary Incontinence: A Systematic Review. J Wound Ostomy Continence Nurs. 2011;38:S25-26.

6. (ICS) ICS. ICS Glossary of Terminology https://www.ics.org/glossary?gclid=Cj0KCQiA-aGCBhCwARIsAHDI5x_ Mp81EyuUcYQ4Ter8ZweGevTXZHwgiS_91k7WYbAbvCfhlcxYUSIMaAo7cEALw_wcB\#S. Accessed 10 March, 2021.

7. Hay-Smith J, Mørkved S, Fairbrother KA, Herbison GP. Pelvic floor muscle training for prevention and treatment of urinary and faecal incontinence in antenatal and postnatal women. Cochrane Database Syst Rev. 2008(4):Cd007471.

8. Woodley SJ, Lawrenson P, Boyle R, et al. Pelvic floor muscle training for preventing and treating urinary and faecal incontinence in antenatal and postnatal women. Cochrane Database Syst Rev. 2020;5(5):Cd007471.

9. Nederlands Huisartsen Genootschap (NHG). Standaard Zwangerschap en kraamperiode (M78) (tweede herziening). . https://www.knov.nl/uploads/knov.nl/knov_ downloads/150/file/Zwangerschap\%20en\%20kraambed.pdf. Accessed 8 February, 2021.

10. Koninklijke Nederlandse Organisatie van Verloskundigen (KNOV). Multidisciplinaire richtlijn postnatale zorg 2018; https://www.knov.nl/serve/file/knov.nl/knov_ downloads/2882/file/Postnatale_zorg_opgemaakte_versie_door_IB_md_10_aug_2018. pdf. Accessed 8 February 2021.

11. National Institute for Health and Care Excellence (NICE). Postnatal care up to 8 weeks after birth (CG 37). 2006; https://www.nice.org.uk/guidance/cg37/resources/postnatalcare-up-to-8-weeks-after-birth-pdf-975391596997. Accessed 2 March, 2021.

12. (CPZ). CPZ. Zorgstandaard intergrale geboortezorg. 2020; 1.2:https://www. kennisnetgeboortezorg.nl/wp-content/uploads/2020/11/zorgstandaard-integralegeboortezorg-1.2.pdf. Accessed 2 March, 2021.

13. Westerik-Verschuuren L, Moossdorff-Steinhauser HFA. Beroepsprofiel Bekkenfysiotherapeut. 2014; https://nvfb.kngf2.nl/Vakgebied/kwaliteit/beroepsprofiel. html. Accessed 14 March, 2021. 


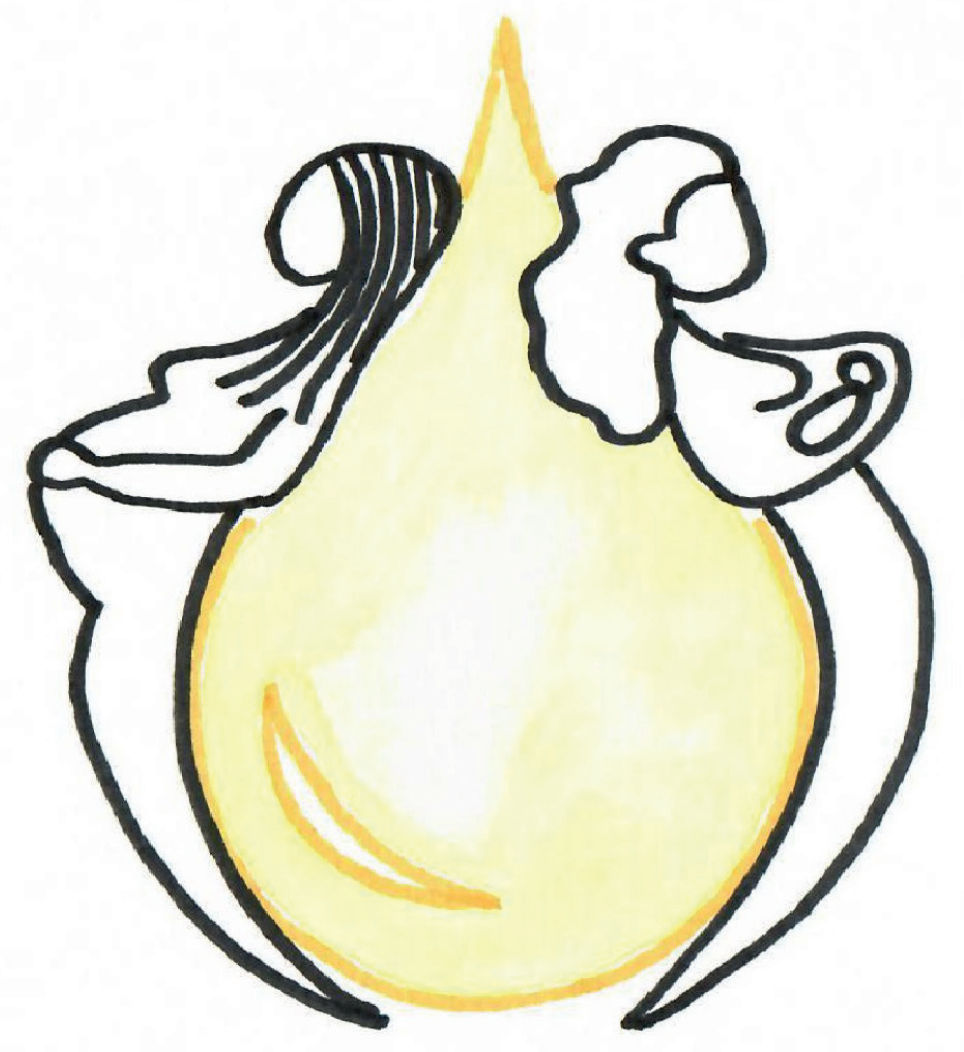


Summary

Samenvatting Dankwoord

Curriculum vitae List of publications (peer-reviewed) 


\section{SUMMARY}

The main objective of this thesis was to gain more knowledge on pregnancy-related urinary incontinence (UI) including prevalence, experienced bother, anticipated course, therapeutic effect of physical therapy and help-seeking behavior. In addition, the (cost-)effectiveness of conservative treatment of UI during pregnancy and in the post-partum period, and experiences of peri-partum UI of women and health care professionals (HCPs) were of interest.

Chapter 1 discusses the background and subsequent research questions of this thesis. UI is a very common symptom in women. Pregnancy and delivery are well known risk factors for developing UI, of which stress (S) UI is the most common type of pregnancy-related UI. UI often has a negative impact on quality of life and reduces participation in sports and other activities. Pelvic floor muscle therapy (PFMT) is an accepted and effective treatment option for women with UI. PFMT may be provided individually or in a group. Group PFM(G)T seems to be equally effective as individual PFMT. The latter is of particular interest as group therapy is less expensive when compared to individual therapy, and might therefore be a costeffective strategy. Reported prevalence and incidence figures of UI in pregnancy and post-partum show a wide range and it is advised to report prevalence figures with a measure of symptom bother. There are indications that the level of perceived bother influences help-seeking behavior for UI. The lifetime risk of surgery for SUI is high and therefore (cost-)effective strategies are warranted. The reported studies in this thesis contribute to the body of knowledge of (HCPs) concerning the beliefs of peri-partum women regarding UI. This may support the development and dissemination of adequate information (strategies). Moreover, accurate prevalence numbers, knowledge about experienced bother in relation to peri-partum UI and help-seeking behavior, provide relevant information on the extent and impact of $\mathrm{UI}$ in this population, which may help HCPs optimizing their clinical reasoning and guide researchers and policy makers in policy making.

Chapter $\mathbf{2}$ and $\mathbf{3}$ discusses the findings of two systematic reviews and metaanalyses on the prevalence, incidence, and bothersomeness of UI during pregnancy (chapter 2) and between 6 weeks and 1 year post-partum (chapter 3). Based on 44 studies (chapter 2), involving a total of 88.305 women, the weighted average of UI prevalence among pregnant women was $41.0 \%$. SUI was the most 
common type of UI, accounting for $63 \%$ of cases. The overall prevalence for UI rises by trimester, $9 \%, 19 \%$, and 34\%, respectively. Of those experiencing UI, $40 \%$ of women have monthly UI, 33\% have weekly UI, and $26 \%$ have daily UI. Bother was heterogeneously assessed. The overall bother of UI during pregnancy, on a 0 to 100 scale, ranges between 9.5 and 34.1, consistent with mild to moderate bother, whereas the experienced bother is higher in the $3^{\text {rd }}$ trimester. Few studies have examined incidence of UI during pregnancy.

The mean weighted prevalence of UI between 6 weeks and 1 year post-partum (chapter 3 ) is 31.0\%, based on 24 studies with a total of 35.064 women. At 6 weeks post-partum, $24 \%$ of women have UI, at 3 months $21 \%$, and then gradually rising to $32 \%$ at 1 year post-partum. Primi- and multiparous women did not differ with regard to prevalence of UI. The most common type of UI was SUI with 54\% of cases. Bother was heterogeneously assessed. The overall bother of UI post-partum, on a 0 to 100 scale, ranges between 24.3 and 47.6, consistent with mild to moderate bother. The incidence of $\mathrm{UI}$ in primiparous and multiparous women up and until three months was $9.0-21.9 \%$ and $4.4-30.0 \%$, respectively. Incidence up to 1 year was $4.3-34.1 \%$ in primiparous women.

Chapter 4 describes the design of two multi-centre randomized controlled trials (RCTs). The RCTs aimed to study the long-term effect of PFMGT (Motherfit) compared to care-as-usual in pre- (study 1) and post-partum (study 2) women with SUI. Eligible women were amongst others $\geq 18$ years of age, had SUI or mixed (M)UI (SUI dominant). Women were recruited by their midwife or gynaecologist during their routine check-up. Inclusion period during pregnancy was between 12 and 26 weeks of gestation (study 1) and at the final 6-week post-partum checkup (study 2). Motherfit group therapy consisted of eight group sessions of 60 minutes each, instructed and supervised by a registered pelvic physical therapist. Motherfit group therapy included instructions on pelvic floor anatomy and how to contract, relax and train the pelvic floor muscles correctly and was combined with general physical exercises. Adherence during and after motherfit was stimulated with reinforcement techniques and a m(obile)App. The primary outcome measure was the absence of self-reported UI based on the severity sum score of the International Consultation on Incontinence Questionnaire Short Form (ICIQ-UI SF) at 18 months post-partum. Secondary outcomes evaluated quality of life, subjective improvement and health care costs. 
Chapter 5 presents the results of the two RCTs. In both RCTs, inclusion numbers could not be met, and therefore all women received individual PFMT instead of PFMGT. Study 1 showed no significant results regarding the prevalence of UI (based on the ICIQ-UI SF), subjective improvement and quality of life at any measurement moment. As compared to baseline, study 2 showed a significant improvement for prevalence of UI and impact of UI at 4 months post-partum, however no significant difference existed between groups at other follow-up moments. Significant subjective improvement was seen at 4 and 9 months post-partum, in favor of the PFMT group $(p=.02)$. The full potential of (cost-) effectiveness of PFMT could not be established due to insufficient inclusions. To increase our knowledge on experienced bother in relation toUI and help-seeking behavior, as well as which specific bothersome factors and beliefs are the main contributors to help-seeking behavior in the peripartum period, two digital surveys were performed in The Netherlands.

Chapter 6 describes the results regarding prevalence, experience of bother, beliefs, and help-seeking behavior of pregnant women. The prevalence of UI rises from $55.1 \%$ in the first to $70.1 \%$ in the third trimester, with an overall prevalence of $66.8 \%$. SUI was the most frequently reported type of UI. Nearly $43.0 \%$ of the respondents reported UI occurring once a week or less. $92.5 \%$ of women lost a small amount. 90\% reported slight to moderate impact on quality of life. Only $13.1 \%$ of the respondents sought help for their UI. The main reasons for not seeking help were minimal bother and the idea that UI would resolve by itself. The most important reasons for seeking help in the future were: the constant use of pads, the feeling that others would smell the urine loss, and leaking/getting wet clothes. Help-seeking women showed significant higher scores than non-helpseeking women regarding bother and interference in daily life.

Chapter 7 describes the results regarding prevalence, experience of bother, beliefs, and help-seeking behavior of women between 6 weeks and 1 year postpartum. The overall prevalence of UI was $57.1 \%$ and did not change significantly across the post-partum period. SUI was the most frequently reported type of UI (62.9\%). Primiparous women reported a statistically significantly lower overall prevalence than multiparous women, $52.0 \%$ and $61.9 \%$ respectively $(p=.043)$. UI frequency of once a week or less was reported in $43.9 \%$ whereas in $89.5 \%$ of the cases it was a small amount of urine. UI was reported as bothersome in 38\% of women, $25 \%$ of all women with UI sought help. Help-seeking women showed significantly higher scores for experienced bother, than non-help seekers $(p=.001)$. 
The most important reasons for seeking help in the future were: the constant use of pads, leaking/getting wet clothes, the feeling that others would smell the urine loss or hindrance at work. In order to gain more understanding regarding the gap between the prevalence of UI and actual help-seeking behavior for UI of peripartum women, it is important to understand the health beliefs of these women and their HCPs regarding UI, how peri-partum women experience their UI, and to acquire knowledge on subsequent health care management.

Chapter $\mathbf{8}$ discusses the results of a qualitative study on this topic. Adult pregnant and up to one year post-partum women were interviewed and a focus group with HCPs involved in the care of pregnant and post-partum women was performed. Nearly all women expressed to be not, or only slightly bothered by their UI and accept it as a result of pregnancy and/or delivery. Women were surprised because they were unaware that UI could be a problem peri-partum. None of the HCPS routinely asked about the presence of $\mathrm{UI}$ during pregnancy. At the post-natal check at 6 weeks post-partum, UI is still not a standard question for the majority of the gynecologists and registrars in contrast to the midwives.

Chapter 9, the general discussion, presents an overview of the main findings of the studies presented in this thesis. Methodological strengths and weaknesses are discussed as well as implications for clinical practice and future research. Overall, we can conclude that peri-partum UI is a common symptom, which is underestimated by women and HCPs. To be motherfit, presence and burden of UI should receive more attention from relevant HCPs; women should be better informed on UI (consequences) and management, which may promote helpseeking behavior.

Finally, in chapter 10, the scientific and societal impact of this thesis is discussed. The results of our studies, have been and will be in the future, disseminated in peer-reviewed journals and presented at various conferences and on social media in order to reach as many researchers, HCPs, and the general public as possible. Our results can help researchers with research planning, HCPs regarding management of UI and communication with patients, and policy makers can use our results in estimating disease burden and future health care cost for UI. Last but not least, if HCPs adapt their management and communication regarding UI, based on the results of our studies, it will help and empower peri-partum women to become 'motherfit'. 


\section{SAMENVATTING}

Het hoofddoel van dit proefschrift was het verkrijgen van meer kennis over zwangerschapsgerelateerde incontinentie voor urine (UI) waaronder de prevalentie, ervaren hinder, verwachtte beloop, therapeutisch effect van fysiotherapie en hulpzoekgedrag. Daarnaast waren ook de (kosten)effectiviteit van conservatieve behandeling van UI tijdens de zwangerschap en in de postpartum periode en de ervaringen van vrouwen en zorgprofessionals van belang.

Hoofdstuk 1 bespreekt de achtergrond en vervolgens de onderzoeksvragen van dit proefschrift. UI is een veelvoorkomend symptoom bij vrouwen. De zwangerschap en bevalling zijn bekende risicofactoren voor het ontstaan van UI. Stress (S)UI is het meest voorkomende type van zwangerschapsgerelateerd UI. UI heeft vaak een negatieve impact op de kwaliteit van leven en belemmerd de deelname aan sport en andere activiteiten. Bekkenbodemoefeningen (PFMT) zijn een geaccepteerde en effectieve behandeloptie voor vrouwen met UI. PFMT kan zowel individueel als in een groep worden gegeven. Groep PFM(G)T lijkt even effectief te zijn als individuele PFMT. Dat laatste is in het bijzonder interessant omdat de kosten voor groepstherapie lager zijn in vergelijking met individuele therapie en het daarom mogelijk een kosteneffectieve strategie is. De gerapporteerde prevalentie en incidentie cijfers van UI in de zwangerschap en post-partum laten een grote spreiding zien en het wordt geadviseerd om prevalentie cijfers te rapporteren met de mate van ervaren hinder van UI. Er zijn aanwijzingen dat de mate van ervaren hinder hulpzoekgedrag voor UI beïnvloedt. De kans op een operatie voor SUI is groot en daarom zijn (kosten)effectieve strategieën belangrijk. De studies in dit proefschrift dragen bij aan de bbody of knowledge $\mathrm{van}$ zorgprofessionals (HCP) met betrekking tot de overtuigingen die peri-partum vrouwen hebben met betrekking tot UI. Dit kan de ontwikkeling en verspreiding van goede informatie (strategieën) ondersteunen. Bovendien kunnen accurate prevalentie cijfers, kennis over ervaren hinder met betrekking tot peri-partum UI en hulpzoekgedrag relevante informatie verschaffen over de mate en impact van UI in deze populatie. Dit kan HCPs helpen hun klinisch redeneren te optimaliseren en onderzoekers en beleidsmakers hun toekomstige plannen op te baseren.

Hoofdstuk 2 en 3 bespreken de resultaten van twee systematische reviews en meta-analyses over de prevalentie, incidentie en ervaren hinder van UI tijdens de 
zwangerschap (hoofdstuk 2) en tussen 6 weken en 1 jaar post-partum (hoofdstuk 3). Gebaseerd op 44 studies (hoofdstuk 2) en in totaal 88.305 vrouwen, is de gewogen gemiddelde prevalentie van UI onder zwangere vrouwen $41.0 \%$. SUI was het meest voorkomende type UI, verantwoordelijk voor $63 \%$ van de gevallen. De totale prevalentie voor UI stijgt per trimester respectievelijk 9\%, 19\% en 34\%. Van degene die UI ervaren, heeft 40\% van de vrouwen maandelijks UI, 33\% wekelijks UI en $26 \%$ dagelijks UI. De ervaren hinder werd heterogeen gemeten. De totaal ervaren hinder van UI tijdens de zwangerschap gemeten op een 0 tot 100 schaal, varieert tussen de 9.5 en 34.1 wat overeenkomt met een mild tot matige ervaren hinder. De ervaren hinder van UI in het derde trimester is hoger. Weinig studies hebben de incidentie van UI tijdens de zwangerschap onderzocht. De gemiddelde gewogen prevalentie van UI tussen 6 weken en 1 jaar post-partum (hoofdstuk 3 ) is $31 \%$, gebaseerd op 24 studies met in totaal 35.064 vrouwen. Op 6 weken post-partum hebben $24 \%$ van de vrouwen UI, op 3 maanden $21 \%$ om vervolgens geleidelijk te stijgen tot 32\%, 1 jaar post-partum. Er was geen verschil in prevalentie van UI tussen primi- en multipara. Het meest voorkomende type UI was SUI in $54 \%$ van de gevallen. Ervaren hinder werd heterogeen gemeten. De totale ervaren hinder van UI post-partum, op een schaal van 0 tot 100 varieert tussen de 24.3 en 47.6 overeenkomstig met een mild tot matig ervaren hinder. De incidentie van UI in primi en multipara tot en met 3 maanden post-partum was respectievelijk 9.0 21.9\% en 4.4 - 30\%. De incidentie tot 1 jaar was $4.3-34.1 \%$ in primipara.

Hoofdstuk 4 beschrijft het design van twee multicenter gerandomiseerde gecontroleerde studies (RCTs). De RCTs hadden tot doel om het lange termijn effect van PFMGT (Motherfit) te vergelijken met standaard zorg in pre- (studie 1) en post-partum (studie 2) vrouwen met SUI. Om deel te mogen nemen moest vrouwen onder andere $\geq 18$ jaar zijn, SUI of gemengd (M)UI (dominant SUI) hebben. Vrouwen werden geworven door hun verloskundige of gynaecoloog gedurende de standaard controle. In studie 1 werden vrouwen tussen de 12 en 26 weken zwangerschap en in studie 2 tijdens de nacontrole, 6 weken postpartum, geïncludeerd. De motherfit groepstherapie bestond uit 8 groepstherapie behandelingen van ieder 60 minuten die werden gegeven door een geregistreerd bekkenfysiotherapeut. De motherfit groepstherapie bestond uit uitleg over de anatomie van de bekkenbodem en hoe de bekkenbodem moet worden aan- en ontspannen en correct moet worden getraind in combinatie met oefeningen voor 
de algemene fitheid. Therapietrouw tijdens en na motherfit werd gestimuleerd door therapietrouw versterkende technieken en een app. De primaire uitkomstmaat was de afwezigheid van subjectief ervaren UI gebaseerd op de ernst gebaseerd op de International Consultation on Incontinence Questionnaire Short Form (ICIQUI SF) op 18 maanden post-partum. De secondaire uitkomstmaten onderzochten de kwaliteit van leven, de subjectief ervaren verbetering en de kosten voor de gezondheidszorg.

Hoofdstuk 5 rapporteert de resultaten van twee RCTs. In beide RCTs werden de inclusie aantallen niet gehaald en daarom hebben alle vrouwen individuele PFMT in plaats van PFMGT gekregen. Studie 1 toonde geen significant resultaat aan betreffende de prevalentie van UI (gebaseerd op de ICIQ-UI SF), de subjectieve verbetering en de kwaliteit van leven op enig meetmoment. Studie 2 toonde een significante verbetering aan voor de prevalentie en impact van UI op 4 maanden post-partum in vergelijking met de nulmeting Er was echter geen significant verschil tussen de groepen op andere meetmomenten. Op 4 en 9 maanden postpartum was een significante subjectieve verbetering te zien in voordeel van de PFMT groep ( $p=.02$ ). De mogelijke (kosten)effectiviteit van PFMT kon niet worden vastgesteld als gevolg van onvoldoende inclusies. Om onze kennis te vergroten over de ervaren hinder van UI, hulpzoekgedrag en welke specifieke factoren en overtuigingen het meeste bijdragen aan hulpzoekgedrag in de peri-partum periode werden twee digitale vragenlijstonderzoeken gedaan in Nederland.

Hoofdstuk 6 beschrijft de resultaten betreffende de zwangere vrouwen. De prevalentie van UI stijgt van $55.1 \%$ in het eerste tot $70.1 \%$ in het derde trimester met een gemiddelde prevalentie van $66.8 \%$. SUI was de meest gerapporteerde vorm van UI. Bijna $43 \%$ van de respondenten ervaarden eens per week of minder UI. 92.5\% van de vrouwen verloren een kleine hoeveelheid urine. 90\% gaf een lichte tot matige invloed aan op de kwaliteit van leven. Slechts $13.1 \%$ van de respondenten heeft hulp gezocht voor hun UI. De hoofdredenen om geen hulp te zoeken waren het ervaren van minimale hinder en het idee dat het UI vanzelf over zou gaan. De belangrijkste redenen om in de toekomst hulp te zoeken waren het continue gebruik van opvangmateriaal, het gevoel dat anderen urine kunnen ruiken en het doorlekken en krijgen van natte kleding. Vrouwen die hulp gezocht hadden scoorden significant hoger dan niet hulp zoekende vrouwen met betrekking tot ervaren hinder en inbreuk op het dagelijks leven. 
Hoofdstuk 7 beschrijft de resultaten met betrekking tot de prevalentie, ervaren hinder, overtuigingen en hulpzoekgedrag van vrouwen tussen de 6 weken en 1 jaar post-partum. De gemiddelde prevalentie van UI was $57.1 \%$ en dit veranderde niet significant gedurende de post-partum periode. SUI was met $62.9 \%$ het meest gerapporteerde type UI. Vrouwen die voor het eerst waren bevallen gaven in vergelijking met vrouwen die meerdere keren bevallen waren een lagere prevalentie aan, respectievelijk $52.0 \%$ en $61.9 \%(p=.43)$. In $43.9 \%$ van de gevallen hadden vrouwen eens per week of minder vaak UI en in $89.5 \%$ van de gevallen was dit een kleine hoeveelheid. UI werd door 38\% van de vrouwen als hinderlijk ervaren en $25 \%$ van alle vrouwen heeft hulp gezocht. Vrouwen die hulp gezocht hebben scoorden significant hoger op ervaren hinder dan de vrouwen die geen hulp gezocht hebben $(p=.001)$. De belangrijkste redenen om in de toekomst hulp te zoeken waren het continue gebruik van opvangmateriaal, doorlekken en krijgen van natte kleding, het gevoel dat anderen urine kunnen ruiken en hinder tijdens het werk. Om meer inzicht te krijgen in het verschil tussenprevalentie van UI en het daadwerkelijke hulpzoekgedrag voor UI van peri-partum vrouwen. is het belangrijk om de overtuigingen met betrekking tot gezondheid van deze vrouwen en hun zorgprofessionals te begrijpen met betrekking tot UI. Kennis over hoe peripartum vrouwen hun UI ervaren en om inzicht te krijgen in het hierop volgend gezondheidsmanagement.

Hoofdstuk 8 beschrijft de resultaten van een kwalitatieve studie over dit onderwerp. Volwassen zwangere en tot 1 jaar post-partum vrouwen werden geïnterviewd en een focusgroep werd gehouden met zorgprofessionals die betrokken zijn bij de zorg van zwangere en post-partum vrouwen. Bijna alle vrouwen gaven aan niet of slechts een klein beetje hinder te ervaren van hun UI en zij accepteren het als gevolg van de zwangerschap en/of bevalling. Vrouwen waren verbaasd omdat ze zich niet bewust waren dat UI een probleem kon zijn in de peri-partum periode. Geen van de zorgprofessionals vroeg standaard naar UI tijdens de zwangerschap. Bij de 6 weken post-partum nacontrole was een vraag over UI nog steeds niet een standaard vraag voor de meerderheid van gynaecologen en arts-assistenten in tegenstelling tot de verloskundigen.

Hoofstuk 9, de algemene discussie, laat een overzicht zien van de belangrijkste resultaten van de studies die in dit proefschrift worden beschreven. De methodologische sterke en zwakke punten worden besproken net als de 
gevolgen voor de klinische praktijk en toekomstig onderzoek. In het algemeen kunnen we concluderen dat peri-partum UI een veel voorkomend symptoom is, dat wordt onderschat door vrouwen en zorgprofessionals. Om motherfit te zijn moet de aanwezigheid en de ervaren hinder van UI meer aandacht krijgen van de betrokken zorgprofessionals, moeten vrouwen beter geïnformeerd worden over (de consequenties) UI en wat er aan gedaan kan worden. Dit kan mogelijk hulpzoekgedrag bevorderen.

Tot slot wordt in hoofdstuk 10 de wetenschappelijke en maatschappelijke impact van dit proefschrift besproken. De resultaten van onze studies zijn en zullen in de toekomst worden gedeeld in peer-reviewed journals en worden gepresenteerd op verschillende congressen en via sociale media met als doel om zoveel mogelijk onderzoekers, zorgprofessionals en de bevolking te bereiken. Onze resultaten kunnen onderzoekers helpen bij het plannen van onderzoeken, zorgprofessionals helpen in hun aandacht voor $\mathrm{UI}$ en de communicatie met patiënten en beleidsmakers kunnen onze resultaten gebruiken bij het schatten van de ziektelast en toekomstig zorgkosten met betrekking tot UI. Tot slot, als zorgprofessionals hun management en communicatie met betrekking tot UI, gebaseerd op de resultaten van onze studies aanpassen zal dit peri-partum vrouwen helpen en in staat stellen om 'motherfit' te worden. 


\section{DANKWOORD}

\section{"It is not the mountain we conquer but ourselves" \\ (Sir Edmund Hillary)}

Promoveren wil ik vergelijken met de beklimming van een berg, een hele hoge berg. De weg naar de top is lang, zowel fysiek als mentaal zwaar en vol met uitdagingen die overwonnen moeten worden. Een goed team ter ondersteuning van de bergbeklimmer is daarbij onontbeerlijk en van onschatbare waarde. Voor het proefschrift dat voor $u$ ligt (mijn beklimming) had ik een fantastisch team. Graag wil ik hen hier persoonlijk bedanken.

Als eerste wil ik natuurlijk graag mijn promotieteam bedanken. Beste Marc (promotor). Wij kenden elkaar nog niet echt toen ik dit avontuur aanging. Niet echt betekend wel een klein beetje, want jij bent coauteur van een van de eerste artikelen die ik in het verleden gepubliceerd heb. Jouw aardige berichtje toen het artikel eenmaal was gepubliceerd staat mij nog goed bij en dit gaf mij dan ook een goed gevoel om jou als promotor te hebben. Inmiddels heb ik je beter leren kennen en kan ik zeggen dat mijn gevoel me niet in de steek gelaten heeft. Opeens een telefoontje om een en ander door te spreken op belangrijke momenten was soms net wat ik nodig had en daarvoor wil ik je heel erg bedanken.

Beste Bary (promotor), 'you made my dream come true'. Dank je wel voor de kans die je mij hebt gegeven om als onderzoeker te kunnen werken bij het Maastricht Universitair Medisch Centrum (MUMC+) en daarna door te stromen als promovendus bij de Universiteit Maastricht. Onze eerste samenwerking gaat terug naar de tijd van mijn afstuderen als fysiotherapie wetenschapper. Bij de bull uitreiking zei jij destijds al: wij gaan samen verder onderzoek doen. Dat het motherfit onderzoek is gehonoreerd met een subsidie door ZonMw is mede te danken aan jouw doorzettingsvermogen en rotsvaste vertrouwen in dit project. Jouw uitspraak, 'een nee is een uitgesteld ja tot het tegendeel bewezen is' zal ik niet snel vergeten. Dank je wel voor het vertrouwen en de kansen die je mij hebt gegeven.

Beste Esther (copromotor). Hartstikke bedankt voor jouw intensieve hulp en ondersteuning de afgelopen jaren. Jij stond altijd voor mij klaar als ik vragen had. Bijna niets was je te veel en jouw reactiesnelheid op e-mails is fenomenaal. 
Jaren geleden heb ik als bekkenfysiotherapeut nog meegewerkt aan jouw promotieonderzoek. Ik kan me nog goed de informatie bijeenkomst herinneren voor een volle zaal enthousiaste geïnteresseerde bekkenfysiotherapeuten. Jouw onderzoek heeft bij mij het vuurtje voor de wetenschap verder aangewakkerd. Dat jij ooit mijn copromotor zou worden had ik nooit kunnen bedenken, zo fijn en wat heb ik geboft.

Beste Carmen. Bedankt voor de tijd die je in het motherfit onderzoek hebt gestopt. Jij was met name in de beginfase betrokken als copromotor. Toen echter de focus van het promotietraject veranderde heb je heel collegiaal aangegeven dat jij jouw rol als copromotor af wilde staan aan Esther.

Voor de verschillende studies wil ik de lokale projectleiders: Martin Bergmans (Laurentius ziekenhuis), Mirjam Weemhoff (Zuyderland ziekenhuis) en Joggem Veen (Maxima Medisch Centrum) bedanken voor de deelname aan het motherfit onderzoek en voor het faciliteren en organiseren van bijeenkomsten. In het bijzonder wil ik ook Mireille Vencken (Laurentius Ziekenhuis), Jolanda Willems (Zuyderland Ziekenhuis), Ingrid van Hooff (MMC) en Tanne van Dooren (MUMC+) bedanken voor jullie hulp. Jullie inzet is van groot belang geweest.

In de loop van de jaren heb ik ook met veel verloskundigen contact gehad, dank je wel voor jullie tijd en aandacht. Een aantal verloskundigen heb ik bovengemiddeld vaak gesproken en daarom wil ik Esther Schoffelen, Chantal Triebels, Malou van Gool, Ellen Brakke en Hilde Coolen in het bijzonder bedanken. Ik zal nooit vergeten hoe Esther, die ondanks de net verloren portemonnee en de vakantie naar Bali de volgende dag, toch aan het einde van haar werkdag nog naar het ziekenhuis kwam om deel te nemen aan de focusgroep. Je bent een kanjer.

Nog een mooi voorbeeld van hoe veel verloskundigen mij geholpen hebben blijkt uit het volgende. Precies in de tijd dat de eerste coronagolf enorm in omvang toenam, er steeds meer beperkingen kwamen en de ernst van de situatie duidelijk werd, kreeg ik groen licht voor de twee vragenlijst onderzoeken. Ondanks de hectiek van dat moment hebben vele verloskundigenpraktijken in heel Nederland toch de tijd en moeite genomen om mijn bericht op hun Facebook pagina te delen. Dit heeft er voor gezorgd dat ik in korte tijd ruim voldoende inclusies had voor beide studies. Verloskundigen in heel Nederland die mijn bericht gedeeld; hebben heel erg bedankt! 
Verder wil ik graag de bekkenfysiotherapeuten, Netty aan de Meulen-Dijkstra , Vera Heessen, Ellen de Jong, Maura Seleme, Marianne Bleijenberg, Joyce Schevers en Barbara Senft bedanken voor hun bereidheid om de motherfit groepstherapie te geven.

Natuurlijk wil ik ook alle vrouwen bedanken die meegedaan hebben aan de verschillende studies. Zonder hen was dit proefschrift niet mogelijk geweest.

De leden van de beoordelingscommissie, prof. dr. G.A. van Koeveringe, prof. dr. R.F.P.M. Kruitwagen, prof. dr. M.Y. Bonger, prof. dr. J.P.W.R. Roovers wil ik danken voor hun bereidheid mijn proefschrift te beoordelen. Prof. dr. S. Mørkved, thank you for your willingness to assess my dissertation.

Dear Julia, thank you so much for checking the English language of my manuscripts. I hope we can meet again at a future ICS meeting, enjoy a bit of sight seeing and have lots of fun.

Lieve Lilian, bedankt voor al de gezellige persoonlijke maar ook vakinhoudelijke gesprekken die we hebben gehad tijdens de lunch. Ik keek altijd uit naar de lunch en heb dit als een moment van rust ervaren tussen alle hectiek door.

Lieve Jean en Jolanta, ik promoveer in Maastricht maar woon in Dordrecht. Jarenlang waren jullie mijn tweede thuis. Naast gezelligheid zorgden jullie altijd voor een heerlijk ontbijt en slaapthee als ik uit mijn werk kwam. Bedankt voor al jullie goede zorgen.

Zo langzamerhand zijn we bij het basiskamp aangekomen te weten het thuisfront.

Lieve familie bedankt voor jullie interesse de afgelopen jaren. Lieve papa en mama, jullie hulp als oppas gaf mij jaren geleden de kans om weer te gaan studeren. Dank je wel, want zonder jullie hulp was dit alles niet mogelijk geweest.

Als laatste natuurlijk mijn gezin.

Lieve Dennis en Emma, wat ben ik enorm trots dat jullie hier naast mij staan als paranimf, dat is voor mij echt de kers op de taart. Samen met papa hebben jullie zeker de laatste maanden van mijn promotietraject gezorgd dat ik bijna niet na hoefde te denken over de boodschappen, koken, de was en al dat soort zaken. Jullie hebben mij daarmee de ruimte gegeven om me helemaal te kunnen focussen op het afronden van mijn proefschrift. 
Allerliefste Ton, jij bent mijn rots die stormen kan doorstaan. Jouw rust, geduld en begrip maar ook de ruimte die je me geeft, maakt dat ik kan zijn wie ik ben. Dank je wel. 


\section{CURRICULUM VITAE}

Heidi Moossdorff-Steinhauser was born on November $5^{\text {th }}, 1968$ in Dordrecht, The Netherlands. After completing secondary education (Scholengemeenschap Noordendijk, Dordrecht) she went to Australia for a year. Once back in The Netherlands she studied physical therapy at Hogeschool West-Brabant and graduated in 1994. From 1999 onwards she specialized in pelvic physical therapy. Once the specialized register for pelvic physical therapists was initiated in 2005 she obtained her registration. Because of her interest in scientific research, she studied clinical health sciences (part-time) at Utrecht University and graduated in 2011.

In 2015, she started as a researcher at the urology department of Maastricht University Medical Center (MUMC+) in combination with first line patient care. In December 2016, she commenced as a PhD student at the Department of Epidemiology of the Faculty of Health, Medicine and Life Sciences (FHML) of Maastricht University, on the research project that led to this thesis: pregnancyrelated urinary incontinence, does it bother. At the moment, Heidi is a senior lecturer at Avans+ for the pelvic physical therapy education.

From 2011 to 2016, Heidi was a board member of the Dutch Society for Pelvic Physical therapy (science and education). Besides this, she was a Faculty board member as a representative of the scientific staff of FHML (Faculty of Health, Medicine and Life sciences), of Maastricht University, between 2017 and 2019 and from 2015 to date she is a member of the ethics committee of the International Continence Society (ICS). In October of 2021 Heidi will join the physiotherapy committee of ICS.

Heidi has co-authored the Dutch proficiency profile of the pelvic physical therapist. In order to raise awareness for pelvic floor dysfunctions, she published many nonpeer reviewed articles for colleagues and the general public. In addition she has a blog and YouTube channel for professionals with an interest in the pelvic region since 2019 (https://www.pelvicnewschannel.com) in which she discusses recently published studies on a variety of topics on the pelvic region. 


\section{LIST OF PUBLICATIONS}

Moossdorff-Steinhauser HFA, Berghmans LCM, Spaanderman MEA, Bols EMJ. Urinary incontinence 6 weeks to 1 year post-partum: prevalence, experience of bother, beliefs, and help-seeking behavior. Int Urogynecol J. 2021 Jul; 32(7):18171824.

Moossdorff-Steinhauser HFA, Berghmans LCM, Spaanderman MEA, Bols EMJ. Prevalence, incidence and bothersomeness of urinary incontinence between 6 weeks and 1 year post-partum: a systematic review and meta-analysis. Int Urogynecol J. 2021 Jul; 32(7):1675-1693.

Moossdorff-Steinhauser HFA, Berghmans LCM, Spaanderman MEA, Bols EMJ. Prevalence, incidence and bothersomeness of urinary incontinence in pregnancy: a systematic review and meta-analysis. Int Urogynecol J. 2021 Jul; 32(7):1633-1652.

Moossdorff-Steinhauser HFA, Berghmans LCM, Spaanderman MEA, Bols EMJ. Urinary incontinence during pregnancy: prevalence, experience of bother, beliefs, and help-seeking behavior. Int Urogynecol J. 2021 Mar; 32(3):695-701.

Moossdorff-Steinhauser HFA, Berghmans LCM, Spaanderman MEA, Bols EMJ. Pelvic floor muscle group therapy for the treatment of urinary incontinence during pregnancy and post-partum: a randomized controlled trial. Pelviperineology 2021; 40(2):67-75.

Moossdorff-Steinhauser HFA, Bols EMJ, Spaanderman MEA, Dirksen CD, Weemhoff M, Nieman FHM, Berghmans B. Long-term effects of motherfit group therapy in pre-(MOTHERFIT1) and post-partum women (MOTHERFIT2) with stress urinary incontinence compared to care-as-usual: study protocol of two multicentred, randomised controlled trials. Trials. 2019 Apr 25;20(1):237.

Moossdorff-Steinhauser $\mathbf{H}$, Rademakers KLJ, Nieman F, van Koeveringe GA, Berghmans B. A Survey on Voiding Complaints in Women Presenting at a Pelvic Care Center. Curr Urol. 2019 Sep; 13(1):31-36.

Albers-Heitner P, Bekkers L, Moossdorff-Steinhauser H, Berghmans B, Verdonk $P$. Is Urinary Incontinence during and after pregnancy related to family history? A web-based survey among post-partum women. CEOG 43(2). March 2016 
Moossdorff-Steinhauser HF, Albers-Heitner P, Weemhoff M, Spaanderman ME, Nieman FH, Berghmans B. Factors influencing postpartum women's willingness to participate in a preventive pelvic floor muscle training program: a web-based survey. Eur J Obstet Gynecol Reprod Biol. 2015 Dec; 195:182-7.

Moossdorff-Steinhauser HF, Berghmans B. Effects of percutaneous tibial nerve stimulation on adult patients with overactive bladder syndrome: a systematic review. Neurourol Urodyn. 2013 Mar; 32(3):206-14. 

